ELOI RUFATO JUNIOR

\title{
VIABILIDADE TÉCNICA E ECONÔMICA DA MODERNIZAÇÃO DO SISTEMA DE PROTEÇÃO DA DISTRIBUIÇÃO
}

Dissertação apresentada à Escola Politécnica da Universidade de São Paulo para obtenção do Título de Mestre em Engenharia.

São Paulo 
ELOI RUFATO JUNIOR

\title{
VIABILIDADE TÉCNICA E ECONÔMICA DA MODERNIZAÇÃO DO SISTEMA DE PROTEÇÃO DA DISTRIBUIÇÃO
}

\author{
Dissertação apresentada à Escola \\ Politécnica da Universidade de São \\ Paulo para obtenção do título de \\ Mestre em Engenharia. \\ Área de Concentração: \\ Sistemas de Potência \\ Orientador: \\ Professor Doutor Carlos César Barioni \\ de Oliveira.
}

São Paulo 
Este exemplar foi revisado e alterado em relação à versão original, sob responsabilidade única do autor e com a anuência de seu orientador.

São Paulo, 16 de outubro de 2006.

Assinatura do autor

Assinatura do orientador

\section{FICHA CATALOGRÁFICA}

Rufato Junior, Eloi

Viabilidade técnica e econômica da modernização do sistema

de proteção da distribuição / E. Rufato Junior. - ed.rev. -- São Paulo, 2006.

202 p.

Dissertação (Mestrado) - Escola Politécnica da Universidade de São Paulo. Departamento de Engenharia de Energia e Automação Elétricas.

1.Proteção de sistemas elétricos 2.Relés 3.Sistemas elétricos de potência 4.Distribuição de energia elétrica I.Universidade de São Paulo. Escola Politécnica. Departamento de Engenharia de Energia e Automação Elétricas II.t. 
Dedico este trabalho a quem sempre me incentivou, meus Pais, Eloi e Eunice. $E$ principalmente a Marli, minha amada esposa e nossos filhos Leonardo e Fernando, pela compreensão pelas longas horas que passamos distantes. 


\section{AGRADECIMENTOS}

Agradeço ao nosso Pai Eterno.

Agradeço ao Eng. José Molinari Pinto, pelo incentivo e principalmente pelas idéias e sugestões para melhoria deste trabalho.

Ao Eng. Roberto Cambuí, o qual acreditou e incentivou a realização do curso.

Ao Professor Dr. Carlos César Barioni de Oliveira pelas suas orientações para tornar este trabalho concluído e no desenvolvimento de outros trabalhos relativos ao assunto.

Ao Professor Dr. Eduardo César Senger pelo auxílio, durante suas aulas e esclarecimentos sobre o tema desenvolvido.

Ao Professor Dr. Ernesto João Robba pelas suas orientações e esclarecimentos de dúvidas.

A todos os Professores da Universidade de São Paulo, da Escola Politécnica, das áreas Elétrica, Civil, Mecânica e Química nas quais foram cursadas as disciplinas para realização deste trabalho. 
"Um trabalho bem feito é o mais alto testemunho que podemos dar de nosso caráter" Orison Sweet Marden 


\section{RESUMO}

O objetivo do desenvolvimento deste trabalho é tecer uma análise da viabilidade técnica - econômica da modernização do sistema de Proteção da Distribuição, comparando a utilização dos relés digitais aos quais foram incorporadas novas funções, em relação aos relés eletromecânicos e estáticos. As informações apresentadas nesse trabalho mostram que os relés digitais oferecem uma significante economia quanto ao custo de aquisição e implantação, no desenvolvimento dos projetos de aplicação e na manutenção destes equipamentos após instalados em campo. Os relés eletromecânicos tem sido largamente utilizados nos esquemas de proteção de consumidores industriais e residencias de grande porte e nos sistemas de proteção das companhias de eletricidade. Devido a quantidade de peças móveis e freqüentes re-ajustes que estes tipos de equipamentos necessitam, os mesmos demandam muitas horas dispendidas pelo pessoal de calibração e manutenção das empresas de eletricidade. A realização de Estudos de Proteção, com a parametrização destes relés muitas vezes torna-se inviável, sob o ponto de vista de sensibilidade e da coordenação das proteções, devido ao fato de que estes equipamentos possuem ajustes limitados tanto de valores de corrente de partida como na seleção de curvas tempo x corrente utilizadas para temporização das proteções, no caso de relés eletromecânicos de sobrecorrente. Durante os últimos anos, com o advento da evolução da indústria, da micro eletrônica e do desenvolvimento de softwares, os relés digitais veêm substituíndo os relés eletromecânicos e estáticos, tanto em instalações novas como também nas remodelações das instalações mais antigas, nos sistemas elétricos de proteção industrial e de empresas de eletricidade. Realizou-se uma análise quanto ao histórico dos relés de proteção, mostrando o seu desenvolvimento desde os relés mais antigos, tipos eletromecânicos, após os relés estáticos, que foram a evolução dos anteriores e finalmente estudando os relés digitais. Os relés digitais oferecem muitas vantagens se comparados com os relés eletromecânicos e estáticos, as quais serão abordandos em items específicos da revisão de literatura neste trabalho. 0 trabalho é finalizado com uma análise de casos, onde foram computados e analisados casos, como índices de fornecimento, custos de instalação de relés digitais em substituição à relés e sistemas eletromecânicos e estáticos, utilizados 
convencionalmente para a proteção em alimentadores de Subestações da Copel Companhia Paranaense de Energia, com o objetivo de coletar-se e analisar-se, ao longo de 12 meses as reais vantagens e desvantagens da utilização destes equipamentos nos sistemas elétricos de proteção dos circuitos de distribuição de energia. 


\begin{abstract}
The purpose of this study is to carry out a technical and economic feasibility assessment of the updating of the Distribution Protection system, comparing the use of digital relays, to which new functions have been integrated, with electromechanical and static relays. Information hereby presented shows that digital relays are significantly cost-effective in terms of acquisition and implementation for developing application projects and in maintaining that equipment after it has been set up in the field. Electromechanical relays have been largely used in protection schemes for large-scale industrial and residential consumers, as well as in security schemes for power plant companies. Because of the large number of moving parts and frequent readjustments required by that type of equipment, many manhours must be put in by calibration and maintenance staff employed by power plant companies. Carrying out a Protection Study that establishes parameters for those relays is often unfeasible given the sensitivity and coordination of the protections, in that the equipment in question has limited adjustments, both in terms of pick-up currents values and of the selection of time curve vs. current used in the protection timer, in the case of overcurrent electromechanical relays. During the last years, with the rise of industrial evolution, microelectronics and software development, digital relays are replacing electromechanical and static relays in electrical security systems used by industrial and power plant company protection, both in new facilities and in refurbished facilities. A study was carried out on the history of protection relays showing how they developed from the older, electromechanical type after the static relays, which evolved form the former, and was concluded with the study of digital relay models. Digital relays provide significant advantages compared to electromechanical and static relays, which will be covered under specific revision items of the references provided herein. The study is concluded by assessing case studies that were accounted for and assessed, such as supply rates, installation costs of digital relays to replace electromechanical and static systems used traditionally to provide protection for COPEL's (Power Company of the State of Paraná) Substations. The purpose was to collect and analyze, over a 12-month period, the actual advantages and disadvantages of using that type of equipment in electrical systems that provide circuit protection for power distribution
\end{abstract}




\section{SUMÁRIO}

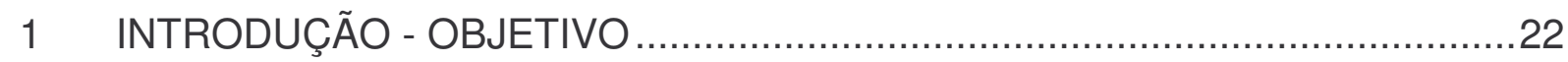

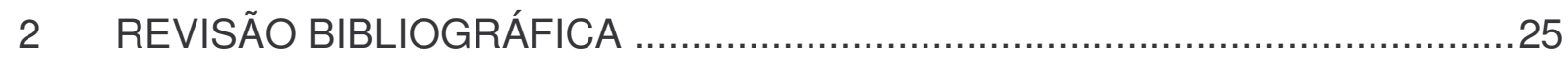

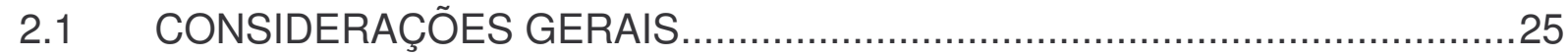

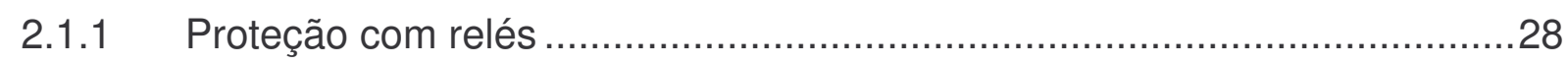

2.1.2 Composição Probabilística das Faltas no Sistema de Distribuição...............30

2.1.3 Causas das Falhas no Sistema de Distribuição .........................................30

2.1.4 Relatório de Defeitos em Sistemas de Proteção.........................................31

2.1.5 Sistema de Distribuição da Copel Estudado ..................................................33

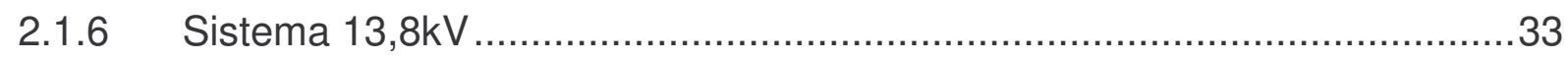

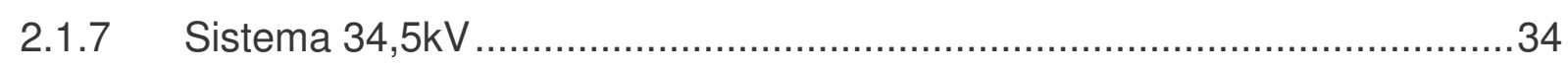

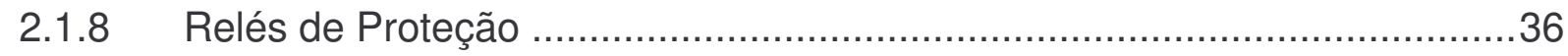

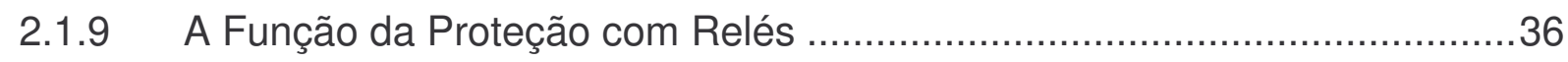

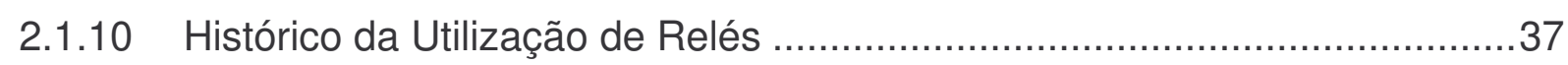

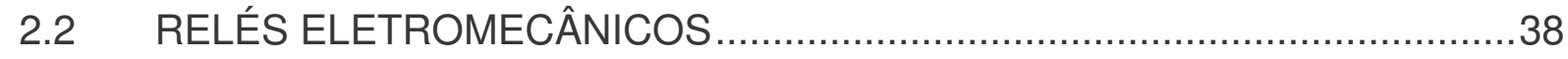

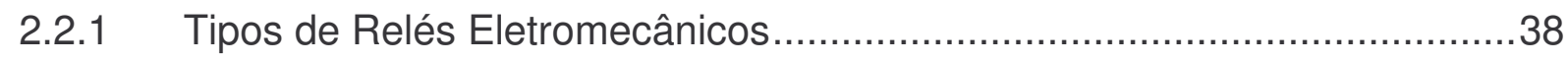

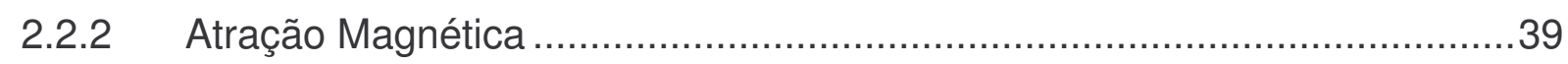

2.2.2.1 Mecanismo tipo Bobina Móvel...........................................................39

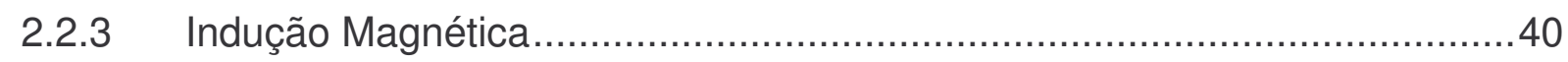

2.2.3.1 Mecanismo de Disco de Indução.........................................................40

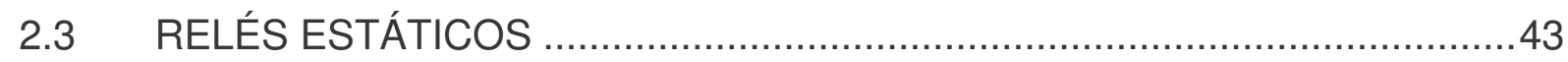

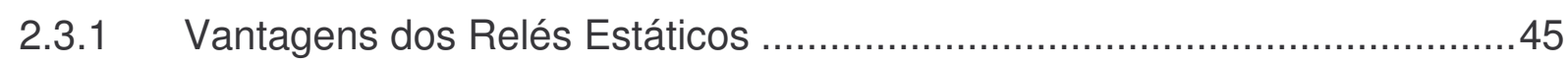

2.3.2 Forma Construtiva dos Relés Estáticos ……….....................................

2.3.3 Diferenças entre os Relés Eletromecânicos e Estáticos de Sobrecorrente.48

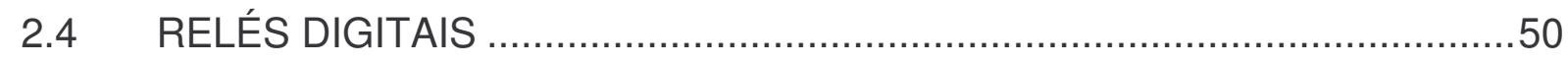

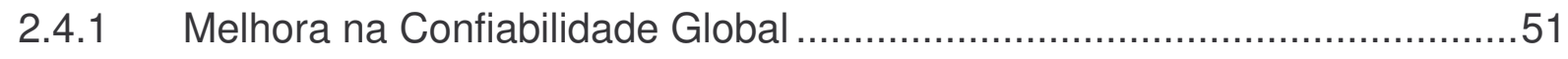

2.4.2 Recurso de Comunicação ...................................................................52 


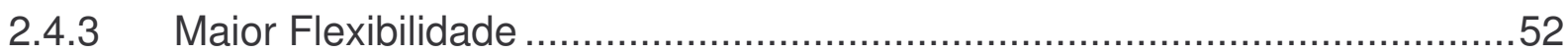

2.4.4 Facilidade de Integração com Novas Tecnologias...................................52

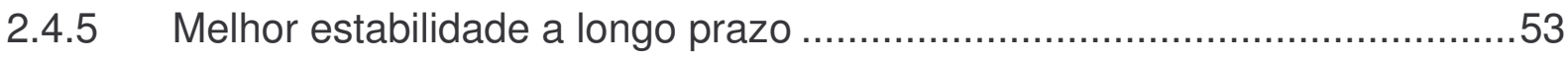

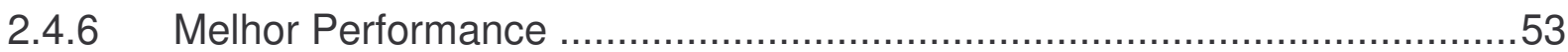

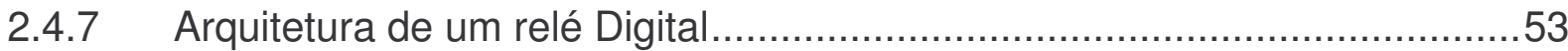

2.4.8 Componentes Básicos de um Relé Digital ..............................................54

2.4.9 Autotestes em Relés Microprocessados ................................................56

2.4.10 Porque testar os relés de Proteção ? ...................................................56

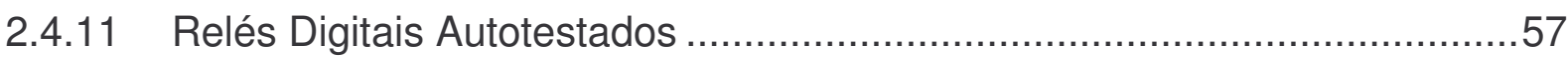

2.5 DESENVOLVIMENTO DE MICROPROCESSADORES E O USO DE

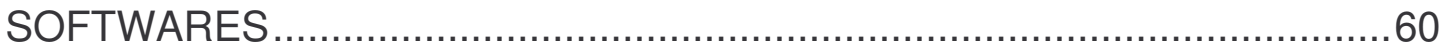

2.6 EXPERIÊNCIA DE CONFIABILIDADE DE SOFTWARE EM OUTRAS INDÚSTRIAS 63

2.7 CARACTERÍSTICAS DO HARDWARE DE RELÉS DIGITAIS ......................65

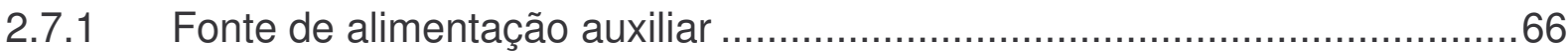

2.7.2 Fonte de alimentação de retaguarda .....................................................67

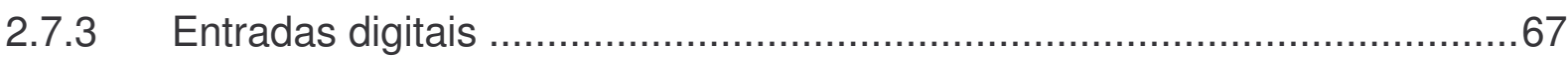

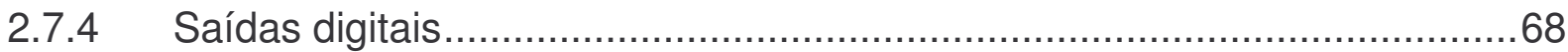

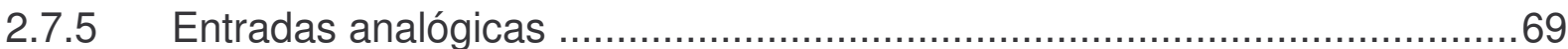

2.8 COMPARANDO PROTEÇÕES ELETROMECÂNICAS E

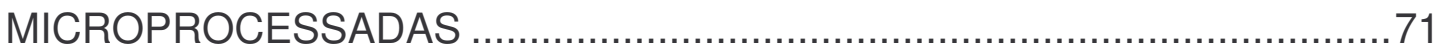

2.8.1 Requisitos quanto ao espaço e ao hardware ..........................................71

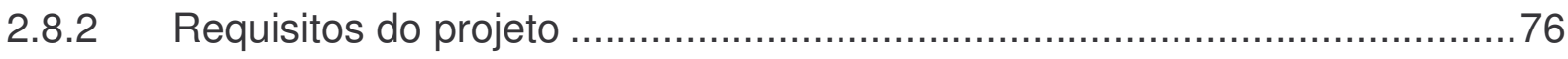

2.8.3 Padronização de curvas de atuação e adaptação a sistemas existentes ...79

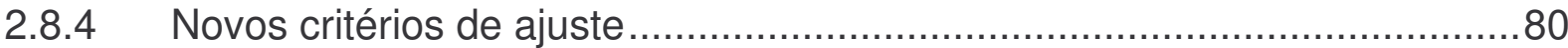

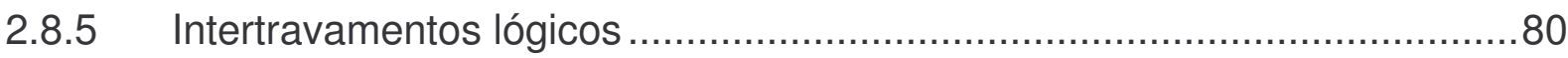

2.8.6 Automonitoramento dos equipamentos e circuitos ................................82

2.8.7 Medição, comando e comunicação integrados à proteção …………….....83

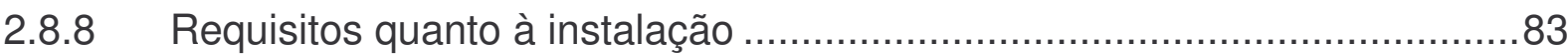




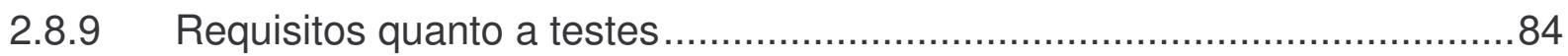

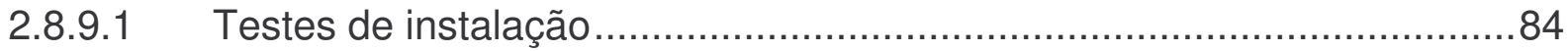

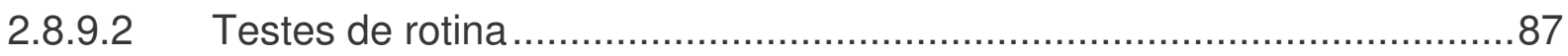

2.8.9.3 Redução significativa da manutenção ...........................................88

2.9 APLICAÇÕES DOS RELÉS MICROPROCESSADOS ............................90

2.9.1 Modernização dos esquemas de Proteção com relés mais antigos ...........90

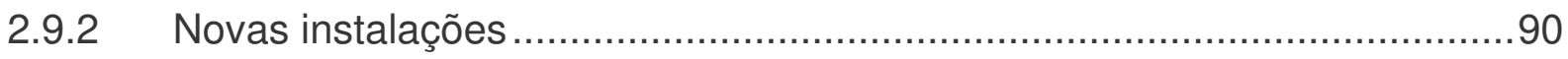

3 NOVAS FUNÇÕES INCORPORADAS NOS RELÉS DIGITAIS ......................91

3.1.1 Esquemas com auxílio da comunicação ........................................91

3.1.2 Múltiplos Grupos de Ajuste ...........................................................

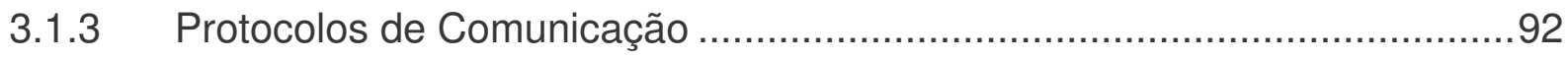

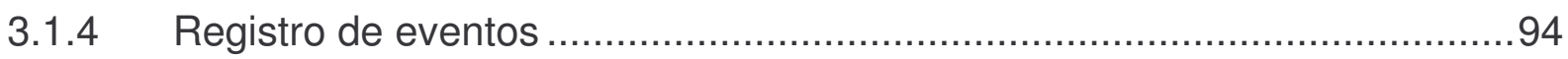

3.1.5 Geração e Análise de Oscilografia...................................................97

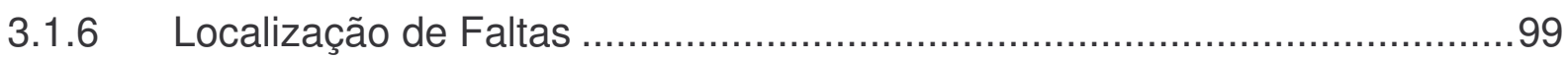

3.1.7 Alteração dos Parâmetros de Proteção em função do horário do sistema101

4 AVALIAÇÃO DE DESEMPENHO E ANÁLISE ECONÔMICA........................102

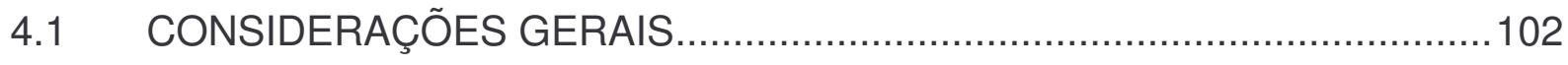

4.2 RELÉS MICROPROCESSADOS TIPO PANACEA, AMAZON E FORM 6.. 103

4.2.1 Tempo Mínimo de Resposta .......................................................... 105

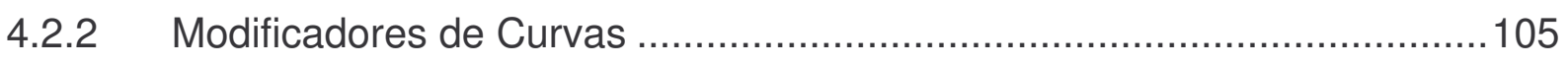

4.2.3 Análise de Eventos e Oscilografias.............................................. 108

4.3 ANÁLISE DA MELHORIA DE ÍNDICES DE FORNECIMENTO PROPORCIONADOS APÓS A SUBSTITUIÇÃO DOS EQUIPAMENTOS DE

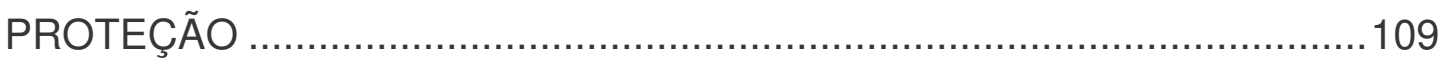

4.3.1 Testes de Filtragem de Componentes Harmônicos em Laboratório ..........116

4.3.2 Substituição dos Relés Estáticos por Microprocessados .......................119

4.3.3 Análise dos Índices de Interrupção dos Alimentadores ............................124

4.3.4 Análise Econômica pelo método de Priorização de Obras - Payoff ..........134

4.4 ANÁLISE ECONÔMICA DA SUBSTITUIÇÃO EQUIPAMENTOS ...............139 
4.4.1 Vantagens Econômicas dos Controladores de Subestação - Dispositivos Eletrônicos Inteligentes - IEDs 139

4.4.2 Análise Econômica da Substituição de Religadores com relés Estáticos por Religadores com Relés Microprocessados - Automatizados 141

4.4.3 Comparação dos Casos por Investimento Inicial e Fluxo de Caixa 143

4.4.4 Comparação dos Casos pelo método de Valor Presente Líquido (VPL) e Taxa Interna de Retorno (TIR) 147

5 CONCLUSÕES 153

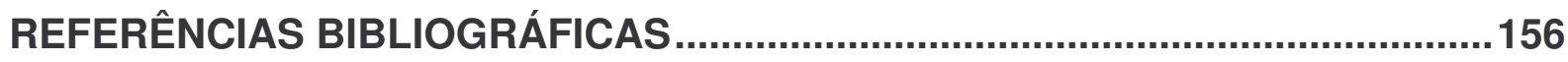

APÊNDICE A - RELÉS DE PROTEÇÃO

APÊNDICE B - CARACTERÍSTICAS FUNCIONAIS DOS RELÉS ........................164

APÊNDICE C - RELÉS ELETROMECÂNICOS...............................................176

APÊNDICE D - RELÉS ESTÁTICOS............................................................. 181

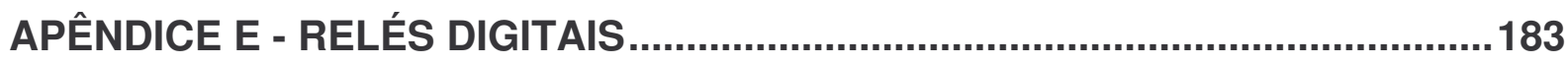

APÊNDICE F - NORMAS TÉCNICAS E ENSAIOS APLICADOS EM RELÉS ...... 194 


\section{LISTA DE FIGURAS}

Figura 1 - Mapa Abrangência da Copel - Paraná - Fonte Copel.

Figura 2 - Sistema de Distribuição da Copel - 13,8 kV 34

Figura 3 - Sistema de Distribuição da Copel - 34,5 kV 35

Figura 4 - Mecanismo de Bobina Móvel [ referência 24] 40

Figura 5 - Mecanismo do tipo Disco de Indução [ referência 24 ].

Figura 6 - Relé Eletromecânico de Sobrecorrente - Disco de Indução [referência 8] 42

Figura 7 - Diagrama de Blocos de Relé Estático [ referência 26].... 47

Figura 8 - Placa principal de um relé Estático [ referência 11] .48

Figura 9 - Arquitetura do Relé Digital [ referência 16] 55

Figura 10 - Testes de Recebimento em relés Digitais [Referência ZIV]. 57

Figura 11 - Expectativa de Vida de Relés de Proteção [6] 61

Figura 12 - Evolução do desenvolvimento dos Relés - USA [6] .62

Figura 13 - Relé Multifunção Team-Arteche 65

Figura 14 - Relé Digital de Proteção de Alimentador 351 S - SEL 65

Figura 15 - Exemplo de Fonte de alimentação auxiliar (Team-Arteche) .66

Figura 16 - Exemplo de Cartão de Entradas Digitais (Team-Arteche) 67

Figura 17 - Exemplo de Cartão de Saídas Digitais (Team-Arteche) .68 
Figura 18 - Saídas Digitais Programáveis do relé F6 - Cooper Power Systems [52]

Figura 19 - Exemplo de Cartão de Entradas Analógicas (Team-Arteche). 69

Figura 20 - Painel Traseiro do relé Digital F6 - Cooper Power Systems [referência 52]. 70

Figura 21 - Layout de Painel com relés Eletromecânicos[5] 72

Figura 22 - Layout de Painel utilizando relés microprocessados [5]. 73

Figura 23 - Comparação entre tecnologia eletromecânica e digital de relés [referência 11]..... 74

Figura 24 - Painéis de Proteção Eletromecânica e Digital para Geradores [42]..75 Figura 25 - Painel de Proteção Eletromecânica de Subestação [referência Copel] .76

Figura 26 - Diagramas esquemáticos AC e DC de relés eletromecânicos[referência 5$\}$

Figura 27 - Diagramas Esquemáticos de AC e DC de relés microprocessados [referência 5].....

Figura 28 - Curvas de atuação Tempo x Corrente de relés Digitais. 79

Figura 29 - Exemplo de Esquema Lógico - relé F6 Cooper Power Systems[52] 81

Figura 30 - Lógica Interna de Sub e Sobre Tensão relé IRV [ZIV Espanha] ..... 81

Figura 31 - Automonitoramento de relé IDP-210 [Cooper Power System] ...... 82

Figura 32 - Testes de Calibração e Recebimento em relés Eletromecânicos [referência Copel] 85

Figura 33 - Realização de Testes em Relés Digitais [referência Copel]..... 86 
Figura 34 - Testes Automatizados em relés Digitais

Figura 35 - Diagrama em Blocos de um relé Digital [ referência 48] 88

Figura 36 - Tela de Grupos de Ajuste - relé F6 [ referência Cooper Power Systems] .92

Figura 37 - Relatório de Eventos de um relé digital 351P - Whipp\&Bourne .94

Figura 38 - Registro de Seqüência de Eventos relé 351P Whipp\&Bourne. .96

Figura 39 - Oscilografia de um relé digital - falta no neutro - referência[43] ......98

Figura 40 - Oscilografia de Tensões, Correntes e Sinais Digitais - relé SEL......98

Figura 41 - Oscilografia de uma falta entre fases - referência [43] 99

Figura 42 - Curvas características de relés digitais [ZIV - Espanha] 104

Figura 43 - Tempo Mínimo de Resposta Modificado. 105

Figura 44 - Curvas Tempo x Corrente Modificada. 106

Figura 45 - Painel Frontal do Relé Digital F6 - Cooper Power Systems [52] ....107

Figura 46 - Diagrama Unifilar da EC Cândido de Abreu - referência Copel......110

Figura 47 - Analisador de Qualidade de Energia [Reason] 112

Figura 48 - Religador com Relé Estático - Monitoração das Grandezas ..... 113

Figura 49 - Oscilografia das correntes distorcidas no relé estático 113

Figura 50 - Fasores de Corrente no relé estático do alimentador monitorado...114

Figura 51 - Espectro de Freqüência da Corrente durante a abertura do religador com relé Estático. 
Figura 52 - Teste de distorção harmônica de corrente - distorção combinada de freqüências baixas em relé microprocessado.

Figura 53- Teste de distorção harmônica de corrente - distorção de freqüências altas em relé microprocessado.

Figura 54 - Valores dos componentes harmônicos de corrente filtrados pelo relé microprocessado testado. 118

Figura 55 - Tela de Programação relé Siemens 7SJ600 - Valores com Harmônicos ou sem Harmônicos. 120

Figura 56 - Coordenograma com curvas sem modificadores - SE Cândido de Abreu - Relés Descoordenados. 122

Figura 57 - Coordenograma com os modificadores de curvas e funções Implantados na SE Cândido de Abreu - Relés Coordenados. 123

Figura 58 - Perfil de Evolução do DEC anual dos alimentadores da SE CDA...127 Figura 59 - Perfil de Evolução do FEC anual dos alimentadores da SE CDA....128 Figura 60 - Evolução do DEC devido a Causa Não Identificada - SE CDA .......132 Figura 61 - Evolução do FEC devido a Causa Não Identificada - SE CDA .......133

Figura 62 - Perfil de Valor Presente Líquido para substituição de relés estáticos por microprocessados. 150

Figura 63 - Composição de um sistema de proteção. [17] .................................164

Figura 64 - Zonas de Proteção do Sistema Elétrico ………………………....166

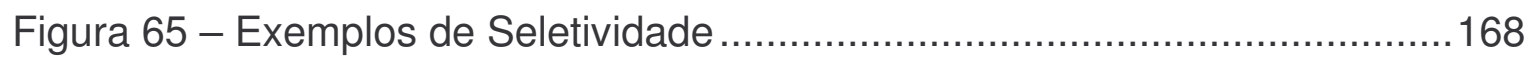

Figura 66 - Exemplos de Sensibilidade de dispositivos de proteção ..................170

Figura 67 - Mecanismo de Armadura em Charneira [ referência 24].................177 
Figura 68 - Mecanismo tipo Ferro Móvel [ referência 24 ]

Figura 69 - Mecanismo do Tipo Cilindro de Indução [referência 24] 179

Figura 70 - Mecanismo do Tipo D’Arsoval [referência 24] 180

Figura 71 - Diagrama de um Relé Estático de Sobrecorrente. [referência 46] ..181

Figura 72 - Formas de Onda do relé estático [ referência 46] 182

Figura 73 - Características de Filtros [referência 46]..... 185

Figura 74 - Amostragem do Sinal [referência 46] 187

Figura 75 - Amostragem de Sinais Incorreta e Correta [referência 46] 188

Figura 76 - Multiplexador - [referência 46] 189

Figura 77 - Sistema de Entrada de Dados Analógicos e conversão digital [16] 190

Figura 78 - Diagrama em Blocos de um relé Digital [ referência 11] 191 


\section{LISTA DE TABELAS}

Tabela 1 - Distribuição de Faltas no Sistema de Distribuição .30

Tabela 2 - Percentagem de Faltas no Sistema de Distribuição 31

Tabela 3 - Valores de DEC e FEC dos Alimentadores da SE Cândido de Abreu 125

Tabela 4 - Causas de Interrupções nos Alimentadores da SE CDA 130

Tabela 5 - Custo Inicial Substituição de 4 religadores com relé microprocessado 138

Tabela 6 - Comparação entre Scada Tradicional e Controlador de Subestação[20] 139

Tabela 7 - Fluxo de Entrada de Caixa Operacional de Subestação com Relés Microprocessados 144

Tabela 8 - Fluxo de Entrada de Caixa Operacional de Subestação com Relés Estáticos e Remota Convencional. 145

Tabela 9 - Análise pelo VPL e TIR para substituição de Quatro Religadores ... 148

Tabela 10 - Normas de Imunidade 196

Tabela 11 - Nível de Severidade de Descarga Eletrostática 197

Tabela 12 - Nível de Severidade 197

Tabela 13 - Nível de Severidade de Pulso Burst. 198

Tabela 14 - Nível de Severidade de Pulso Surge 199

Tabela 15 - Nível de Severidade de Injeção de Corrente e Rádio Freqüência..200

Tabela 16 - Nível de Severidade para Campos Magnéticos 200 
Tabela 17 - Nível de Severidade para Pulsos Magnéticos ................................201

Tabela 18 - Nível de Severidade para Variação de Tensão ...............................202 


\section{LISTA DE ABREVIATURAS, SIGLAS E UNIDADES}
A
- Ampéres
$\mathrm{A} / \mathrm{D}$
- Analógico - Digital
$\mathrm{A} / \mathrm{m}$
- Ampéres/metro
ABNT
- Associação Brasileira de Normas Técnicas
ANEEL
- Agência Nacional de Energia Elétrica
ANSI
- American National Standards Institute
$\mathrm{BCl}$
- Injeção de Corrente de Rádio Freqüência
BS
- British Standard
CA
- Corrente Alternada
CC
- Corrente Contínua
CLP
- Controlador Lógico Programável
CPU
- Unidade Central de Processamento
DEC
- Duração Equivalente por Consumidor
DFR
- Registrador Digital de Sinais
DLP
- Proteção Digital de Linha
DNP
- Distribute Network Protocol
DSP
- Processador de Sinal Digital
EC
- Estação de Chaves
EFT
- Transiente Elétrico Rápido
EMC
- Compatibilidade Eletro Magnética
$\mathrm{f}$
- Freqüência
FEC
- Freqüência Equivalente por Consumidor
GE
- General Electric
GVR
- Modelo de religador da Whipp\&Bourne
IA, IB, IC, IN - Correntes de Fase e de Neutro
ICC
- Corrente de Curto Circuito
IEC
- International Eletrotechnical Commission
IED
- Dispositivo Eletrônico Inteligente
IEEE
- Institute of Electrical and Electronic Engineers
IRV
- Modelo de relé de Sobrecorrente - ZIV
ISO
- International Organization for Standardization
MTBF
- Mínimo Tempo entre Falhas 


$\begin{array}{ll}\text { PCH } & \text { - Pequena Central Hidroelétrica } \\ \text { PCT } & \text { - Pequena Central Térmica } \\ \text { RMS } & \text { - Root Mean Square } \\ \text { RQE } & \text { - Registrador de Qualidade de Energia } \\ \text { RTU } & \text { - Remote Terminal Unit } \\ \text { S } & \text { - Segundos } \\ \text { SCADA } & \text { - Supervisory Control And Data Acquisition } \\ \text { SE } & \text { - Subestação } \\ \text { SEF } & \text { - Sensitive Earth Fault } \\ \text { SEL } & \text { - Schweitzer Engineering Laboratories } \\ \text { SEP } & \text { - Sistema Elétrico de Potência } \\ \text { SF6 } & \text { - Hexafluoreto de Enxofre } \\ \text { SFC } & \text { - Sequential Function Chart } \\ \text { TC } & \text { - Transformador de Corrente } \\ \text { TFD } & \text { - Transformada Discreta de Fourier } \\ \text { THD } & \text {-Total Harmonic Distortion } \\ \text { TIR } & \text { - Taxa Interna de Retorno } \\ \text { TP } & \text { - Transformador de Potencial } \\ \text { UAC } & \text { - Unidade de Aquisição e Controle } \\ \text { UCC } & \text { - Unidade Central de Controle } \\ \text { UTR } & \text { - Unidade Terminal Remota } \\ \text { V } & \text { - Volts } \\ \text { VA, VB,VC } & \text { - Tensões de Fase A, B e C } \\ \text { VN } & \text { - Tensão de Neutro } \\ \text { VF } & \text { - Tensão de Fase } \\ \text { VPL } & \text { - Valor Presente Líquido } \\ & \end{array}$




\section{INTRODUÇÃO - OBJETIVO}

O objetivo do desenvolvimento deste trabalho é tecer uma análise da viabilidade técnica - econômica, comparando a utilização dos relés digitais aos quais foram incorporadas novas funções, em relação aos relés eletromecânicos e estáticos. As informações apresentadas nesse trabalho mostram que os relés digitais oferecem uma significante economia quanto ao custo de aquisição e implantação, no desenvolvimento dos projetos de aplicação e na manutenção utilizada para 0 mantenimento destes equipamentos após instalados em campo.

Os relés eletromecânicos tem sido largamente utilizados nos esquemas de proteção de consumidores industriais e residenciais de grande porte e nos sistemas de proteção das companhias de eletricidade. Devido a quantidade de peças móveis e frequêntes re-ajustes que estes tipos de equipamentos necessitam, os mesmos demandam muitas horas dispendidas pelo pessoal de calibração e manutenção das empresas de eletricidade.

A realização de Estudos de Proteção, com a parametrização destes relés muitas vezes torna-se inviável, sob o ponto de vista de sensibilidade e da coordenação das proteções, devido ao fato de que estes equipamentos possuem ajustes limitados tanto de valores de corrente de partida como na seleção de curvas tempo x corrente utilizadas para temporização das proteções, no caso de relés eletromecânicos de sobrecorrente.

Durante os últimos anos, com o advento da evolução da indústria, da micro eletrônica e do desenvolvimento de softwares, os relés digitais veêm substituíndo os relés eletromecânicos, tanto em instalações novas como também nas remodelações das instalações mais antigas, nos sistemas elétricos de proteção industrial e de empresas de eletricidade. 
No capítulo 2, foi realizada uma revisão na bibliografia analisando o histórico dos relés de proteção, mostrando o seu desenvolvimento desde os relés mais antigos, tipos eletromecânicos, após os relés estáticos, que foram a evolução dos anteriores e finalmente estudando os relés digitais.

Após, no capítulo 3 foram abordadas especificamente as novas funções incorporadas nos relés digitais, mostrando que os relés digitais oferecem muitas vantagens se comparados com os relés eletromecânicos e estáticos, neste capítulo, a título de exemplos, mostra-se os ajustes possíveis de serem implementados nestes relés, no passado, e quais os novos ajustes e funções que se podem implementar e utilizar nos relés digitais atuais.

O trabalho é finalizado com uma análise de casos, no capítulo 4 , onde avalia-se o desempenho dos relés digitais, que foram instalados em alimentadores de Subestações da Copel - Companhia Paranaense de Energia, com o objetivo de computar-se ao longo de 12 meses após a instalação, comparando-se com período igual anterior, onde os alimentadores estavam protegidos com relés eletromecânicos e estáticos, as reais vantagens e desvantagens da utilização destes equipamentos nos sistemas elétricos de proteção dos circuitos de distribuição de energia.

Os relés de proteção são designados para atuar quando condições anormais ocorrem no sistema elétrico de potência. Essas condições anormais podem ser curtos circuitos, condições de sobrecarga ou perda de sincronismo do sistema.

Devido ao número de componentes que constituem os esquemas de proteção, testes detalhados de instalação e programas para a manutenção de rotina devem ser executados, para assegurar que os esquemas estejam funcionando corretamente.

Os relés digitais oferecem muitas vantagens sobre os esquemas que utilizam componentes distintos. O esquema total, com equipamentos digitais, ocupa um menor espaço nos painéis e casas de relés. O número de 
componentes é enormemente reduzido. Os relés microprocessados também oferecem muitas características e funções além das básicas de proteção, as quais serão abordadas durante a pesquisa bibliográfica realizada sobre o assunto, nos items seguintes deste trabalho.

Os relés digitais podem ser utilizados substituíndo a maioria das aplicações de relés eletromecânicos. Os benefícios adicionados por um esquema simples e pela confiabilidade melhorada fazem deles uma opção muito atrativa.

Os relés digitais também tornam acessíveis novas aplicações e filosofias de proteção.

Os esquemas de proteção estão sob constantes modificações e aperfeiçoamentos. As mudanças dos tradicionais esquemas de proteção muitas vezes requerem a aquisição e instalação de equipamentos adicionais. Se houver a necessidade de implememtar novos ajustes nos equipamentos convencionais de proteção, os mesmos tem que ser realizados pelo pessoal de manutenção e parametrização, manualmente, em cada relé. Esta operação é demorada e muitas vezes pode ser realizada com a introdução de erros de equipamentos ou humanos. 


\section{REVISÃo BIBLIOGRÁFICA}

Neste capítulo são analisados e discutidos trabalhos relevantes referentes ao assunto "relés de proteção", onde realizou-se uma pesquisa referente aos equipamentos mais antigos, eletromêcanicos, mostrando suas características principais, assim como mecanismos de atuação, até os equipamentos mais recentes do tipo microprocessados, mostrando suas características, sua arquitetura e também uma comparação entre as famílias destes equipamentos.

\subsection{CONSIDERAÇÕES GERAIS}

Com tamanho e características que permitem considerá-lo único em âmbito mundial, o sistema elétrico brasileiro se caracteriza por ser um sistema hidrotérmico de grande porte com forte predominância de usinas hidroelétricas, ou seja, a energia elétrica pode ser gerada através de fontes renováveis de energia, como por exemplo, a força das águas, ou através de fontes não renováveis, como por exemplo, combustíveis fósseis, carvão etc.

No Brasil, a opção hidráulica é a mais utilizada e apenas uma pequena parte da energia consumida é gerada a partir de fontes não renováveis, em usinas térmicas [14].

Em períodos de condições hidrológicas desfavoráveis, as usinas térmicas contribuem para o atendimento ao mercado como um todo. A exploração coordenada dos recursos hidroelétricos e termoelétricos permite que se maximize a disponibilidade e a confiabilidade do suprimento de energia com redução dos custos para os consumidores.

Assim, a participação complementar das usinas térmicas no mercado consumidor exige interconexão e interligação.

A opção pela intensa utilização do potencial hidroelétrico do país determinou 
as características singulares do sistema. As usinas desse tipo são construídas onde melhor se podem aproveitar as afluências e os desníveis dos rios, muitas vezes em locais distantes dos centros consumidores. Conseqüentemente, para atender ao mercado, foi necessário desenvolver um extenso sistema de transmissão, em que as linhas de transmissão criam uma complexa rede de caminhos alternativos para escoar, com segurança, toda a energia produzida nas usinas até os centros de consumo, passando pelas subestações de distribuição e destas chegando até os consumidores finais através de alimentadores em classes de tensão de distribuição que no caso específico da Copel são de 13,8 kV e 34,5 kV. A área de abrangência atendida pela Copel é mostrada na Figura 1.

O sistema de distribuição é operado de forma coordenada, visando obter ganhos a partir do perfeito funcionamento do sistema elétrico. A operação coordenada visa minimizar os custos globais de produção de energia elétrica e aumenta a confiabilidade do fornecimento de energia ao mercado consumidor final. 


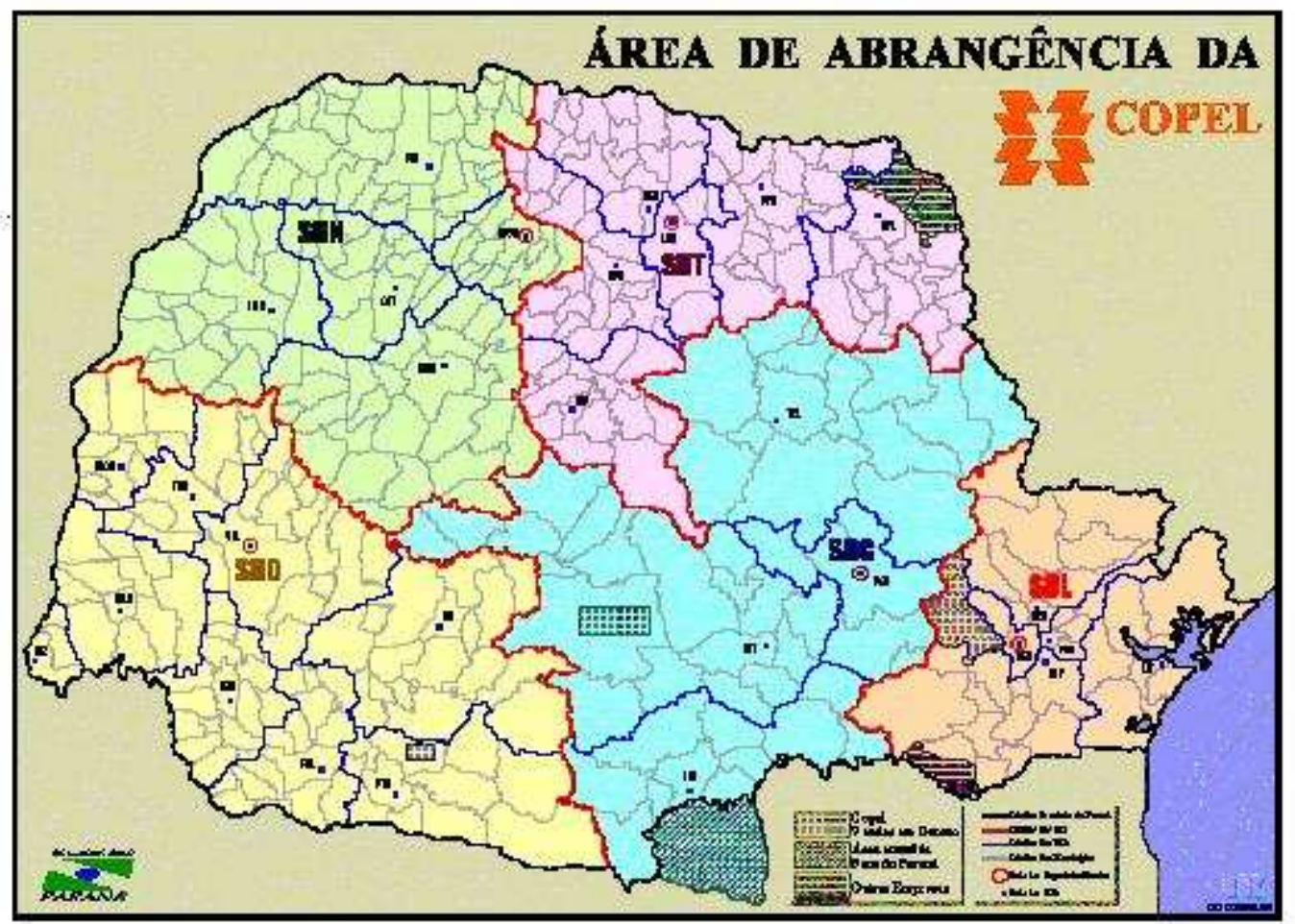

Figura 1 - Mapa Abrangência da Copel - Paraná - Fonte Copel 


\subsubsection{Proteção com relés}

Conforme a referência [31], o autor escreve que normalmente pensa-se em um sistema de energia elétrica em termos de suas partes mais impressionantes as grandes estações geradoras, transformadores, linhas de alta tensão, etc. Enquanto estes são alguns dos elementos básicos, há muitos outros componentes necessários e fascinantes. Proteção com relés é um destes.

O papel da proteção com relés em um sistema elétrico é explicado por um exame breve em cima do sistema. Há três aspectos de um sistema de potência que servirão aos propósitos deste exame. Estes aspectos são:

-Operação normal;

-Prevenção de falhas elétricas;

-Evolução dos efeitos das falhas elétricas

O termo operação normal assume que não há falhas de equipamento, nenhum erro de pessoal, ou "acasos fortuitos".Isto envolve as exigências mínimas para alimentar a carga existente e uma certa quantia de carga futura antecipada. Algumas das considerações são:

-Escolha entre hidroelétrica, vapor, ou outras fontes de potência;

-Localização das estações geradoras;

-Transmissão de potência para a carga;

-Estudo das características das cargas e planejamento do seu crescimento futuro;

-Medição;

-Tensão e regulação de freqüência;

-Operação do sistema.

-Manutenção normal.

As providências para operação normal envolvem a despesa com equipamentos e operação. 
Devem haver providências adicionais para minimizar danos a equipamentos e interrupções do serviço quando falhas acontecerem.

Dois fatores são considerados: (1) incorporar características de projeto para prevenir falhas, e (2) incluir providências para diminuir os efeitos de falhas quando elas ocorrerem. Modernos sistemas de potência empregam graus variados destes recursos, como ditado pelas economias de qualquer situação. Avanços notáveis continuam sendo feitos para maior confiança. Mas também, crescentemente maior confiança está sendo colocada no sistema de potência.[31]

Por conseguinte, embora a probabilidade de falha seja diminuída, a tolerância do possível dano para o serviço também é diminuída. Mas é fútil ou pelo menos não economicamente justificável tentar prevenir falhas completamente. É muito mais lucrativo, então, deixar algumas falhas acontecerem e providenciar para diminuir os seus efeitos.[31] 
2.1.2 Composição Probabilística das Faltas no Sistema de Distribuição

Abaixo são apresentadas as distribuições percentuais das faltas que ocorrem nos sistemas de distribuição, onde se pode ver que a maioria dos defeitos que ocorrem nos sistemas aéreos de distribuição são do tipo que envolve a terra (fase-terra) e defeitos transitórios.

Tabela 1 - Distribuição de Faltas no Sistema de Distribuição

$\begin{array}{lccc} & \text { Total } & \text { Permanentes } & \text { Transitórias } \\ \text { Trifásicos } & 2 \% & 95 \% & 5 \% \\ \text { Bifásicos } & 11 \% & 70 \% & 30 \% \\ \text { Fase/terra } & 79 \% & 20 \% & 80 \% \\ \text { Outros } & 8 \% & & \end{array}$

Os dados da tabela acima foram retirados de relatórios estatísticos da Copel.

\subsubsection{Causas das Falhas no Sistema de Distribuição}

$\mathrm{Na}$ Tabela 2 é apresentada a distribuição percentual dos fatores que originam as faltas nos sistemas de distribuição, onde se pode verificar que a maioria dos defeitos são originários de fenômenos naturais (ventos e descargas atmosféricas), para o caso de sistemas aéreos de distribuição. 
Tabela 2 - Percentagem de Faltas no Sistema de Distribuição

$\begin{array}{lc}\text { Árvores e ventos } & 46 \% \\ \text { Descargas atmosféricas } & 19 \% \\ \text { Falhas de equipamentos } & 11 \% \\ \text { Erro humano } & 9 \% \\ \text { Falhas de isoladores } & 6 \% \\ \text { Objetos estranhos } & 2 \% \\ \text { Outras causas } & 6 \%\end{array}$

Os valores da Tabela 2 foram retirados dos relatórios estatísticos gerados na Copel e do Livro: Curto Circuito de Geraldo Kindermann.[18]

\subsubsection{Relatório de Defeitos em Sistemas de Proteção}

Quando ocorrerem à operação indevida ou falha de coordenação nas proteções, para que se possa executar um estudo da ocorrência, a mesma deve ser relatada e informada ao corpo técnico das empresas de energia responsáveis pela elaboração dos estudos de causas de ocorrências, com os seguintes dados: [19]

Número de série e marca do religador/relé

Data de instalação do religador/relé

Croqui com o local de instalação no circuito

Valores de correntes de curto-circuito no ponto de instalação

Tensão e corrente nominal dos equipamentos

Corrente de carga no ponto de instalação

Quantidade de operações até a data de ocorrência do defeito

Condições do tempo na ocasião

Eventuais rompimentos de jumpers ou queda de condutores à montante e à jusante do equipamento 
Número de tentativas manuais quando da ocorrência

Outras informações consideradas relevantes para análise da ocorrência 


\subsubsection{Sistema de Distribuição da Copel Estudado}

\subsubsection{Sistema 13,8kV}

O sistema de $13,8 \mathrm{kV}$, com ligação em triângulo e aterrado por reatância (transformador de aterramento) na subestação admite um único caminho de retorno no caso de defeitos fase-terra, que é o neutro do transformador de aterramento ligado em zig-zag. Neste caso a corrente de curto-circuito calculada em um determinado ponto do sistema é a mesma que flui em todo o sistema, facilitando a análise da coordenação. Para ser considerado um sistema aterrado por reatância deve obedecer a relação $X 0 / X 1>3$, e o da COPEL está $3<\mathrm{X} 0 / \mathrm{X} 1<10$. O transformador de aterramento serve para limitar a sobretensão nas fases sãs e tornar possível à circulação de corrente originária de seqüência fase-terra.[21] 
Onde $: V p=$ Tensão Primária $\quad V s=$ Tensão Secundária

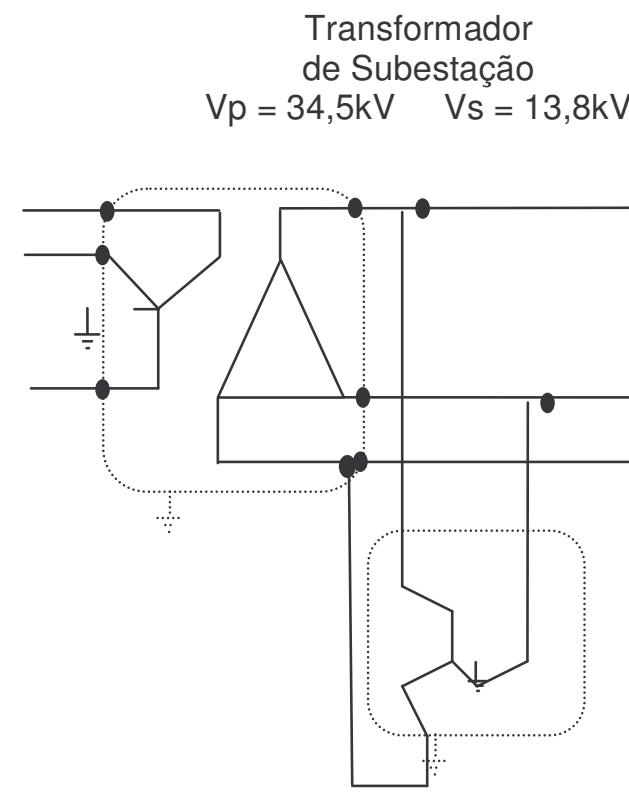

Transformador de Aterramento
Transformador de Distribuição Trifásico

$\mathrm{Vp}=13,8 \mathrm{kV} \quad \mathrm{Vs}=220 / 127 \mathrm{~V}$

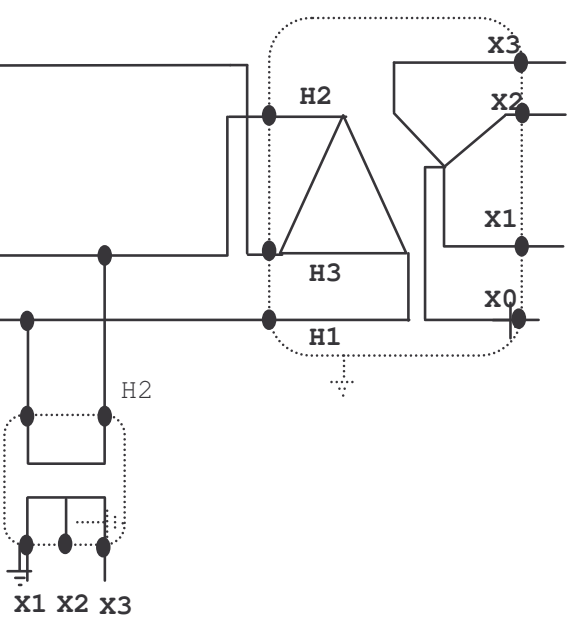

Transformador de Distribuição Monofásico

Figura 2 - Sistema de Distribuição da Copel - 13,8 kV

\subsubsection{Sistema $34,5 \mathrm{kV}$}

O sistema de $34,5 \mathrm{kV}$ é ligado em estrela aterrado é considerado efetivamente aterrado, pois mantém a relação de $\mathrm{X} 0 / \mathrm{X} 1<=3$ e $\mathrm{R} 0 / \mathrm{X} 1<=1$, o que, em caso de defeito fase-terra, provoca contribuições de correntes (seqüência zero) pelos neutros de todos os transformadores do sistema. Neste caso a parcela de corrente que irá fluir pelo neutro de um transformador de uma Subestação pode ser muito inferior ao valor calculado em um determinado ponto do sistema, tornando a análise da proteção mais complexa.[21] 
Sistema de Neutro Aterrado conforme configuração abaixo, sendo os transformadores de distribuição monofásicos ligados entre fase e terra e os trifásicos em estrela aterrada.

Onde: $V p=$ Tensão Primária

$$
\text { Vs = Tensão Secundária }
$$

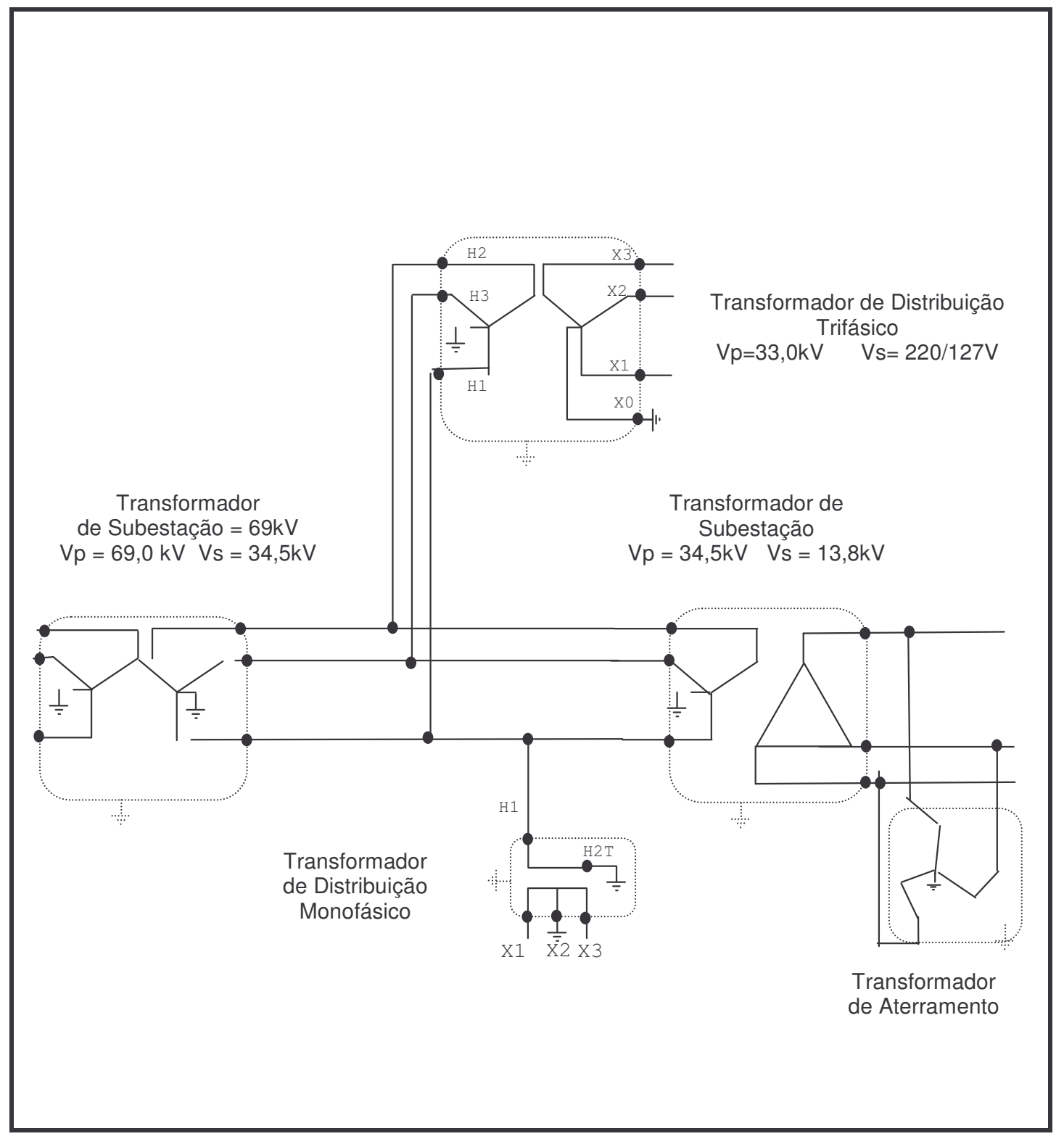

Figura 3 - Sistema de Distribuição da Copel - 34,5 kV 


\subsubsection{Relés de Proteção}

Conforme a referência [05] o relé de proteção é um dispositivo destinado a detectar anormalidades no sistema elétrico, atuando diretamente sobre um equipamento ou sistema, retirando de operação os equipamentos / componentes envolvidos com a anormalidade, acionando circuitos de alarme quando necessário. Por outro lado, também pode ser o elemento que satisfeitas certas condições de normalidade, irá dar a permissão para a energização de um equipamento ou de um sistema.

\subsubsection{A Função da Proteção com Relés}

Conforme a referência [31], a função de proteção com relés é causar a remoção imediata de serviço de qualquer elemento de um sistema de potência quando ocorrer um curto circuito, ou quando começa a operar de qualquer forma anormal que possa causar dano ou caso contrário poderia interferir com a operação efetiva do resto do sistema.

O equipamento relé é ajudado nesta tarefa e através de disjuntores e religadores são capazes de desconectar o elemento defeituoso quando eles são chamados para fazer a abertura através dos relés de proteção.

Disjuntores ficam geralmente situados de forma que cada gerador, transformador, barra, linha de transmissão, etc., podem ser desconectados completamente do resto do sistema. Os disjuntores têm que ter capacidade suficiente de forma que eles possam suportar o valor máximo momentaneamente de corrente de curto circuito corrente que pode fluir por eles, e então interrompa esta corrente.[31] 
2.1.10 Histórico da Utilização de Relés

Conforme a referência [01], as primeiras pesquisas em aplicação de computadores digitais em sistemas elétricos de potência (SEPs) remontam ao final dos anos 60 , onde se vislumbrava a possibilidade de concentrar todas as operações e proteções de uma subestação em um único computador de grande porte.

Os avanços na tecnologia de sistemas digitais e na teoria de tratamento digital de sinais permitiram realizar a primeira instalação piloto de proteção de linha logo em 1972 pela Westinghouse e Pacific Gas \& Electric.

A tecnologia eletromecânica estava bem estabelecida e sempre teve uma reputação de durabilidade e confiabilidade (desde que bem mantidos), porém vislumbraram-se com a aplicação de sistemas digitais uma maior flexibilidade de aplicação, maior compactação dos equipamentos, uma melhor performance dos sistemas e a exploração de um novo nicho pelos fabricantes destes sistemas.

O grande desafio da tecnologia digital tem sido se igualar à tecnologia eletromecânica em termos de durabilidade e obsolescência dos equipamentos uma vez que para os sistemas digitais estima-se uma vida útil média de 10 anos, enquanto que os sistemas eletromecânicos têm uma vida útil média verificada de 30 anos. Para tal, investimentos maciços vêm sendo realizados para o aperfeiçoamento destes sistemas, de modo que hoje a tecnologia digital já conquistou definitivamente o seu espaço nos SEPs e é aplicada em larga escala. 


\subsection{RELÉS ELETROMECÂNICOS}

Estes relés utilizam propriedades magnéticas dos circuitos de entrada para atuar um mecanismo, tal como uma armadura ou um disco de indução. São normalmente fornecidos em um compartimento retangular que é permantemente encaixado em um conjunto de contatos. Este tipo de relé inclui uma bandeirola mecânica que indica a operação do relé, ajudando na solução de problemas. O corpo do relé é encaixado dentro de compartimento metálico ou plástico e pode ser retirado quando for conveniente, para testes de rotina e manutenção.

Os relés eletromecânicos geralmente apresentam apenas uma função. Alguns podem apresentar duas funções que estão relacionadas, como as funções de sobrecorrente instantânea e temporizada (50/51), ou então sub e sobretensão (27/59).

Aplicações próprias dos relés eletromecânicos mais avançados requerem informações do sistema, como ângulo de fase, direção de atuação, polaridades das tensões e correntes, polaridade do relé e diagramas de fasores. Tais informações variam de acordo com a aplicação.

\subsubsection{Tipos de Relés Eletromecânicos}

São classificados em quatro tipos, quanto ao princípio de atuação:

- atração magnética;

- indução magnética;

- D'Arsonval;

- Térmicos.

Cada um deles será visto a seguir. 


\subsubsection{Atração Magnética}

Três tipos construtivos de atração magnética são comumente usados:

- bobina móvel (solenóide);

- armadura em charneira;

- ferro móvel (polarizado).

\subsubsection{Mecanismo tipo Bobina Móvel}

Este tipo de unidade possui bobinas cilíndricas com uma estrutura magnética externa e um atuador central. Quando a corrente ou a tensão aplicada à bobina excede o valor de disparo, o atuador se move para cima para operar um jogo de contatos. A força requerida para mover o atuador é proporcional ao quadrado da corrente na bobina. Pode ser do tipo rotatório, que é mais barato, ou do tipo axial, que possui maior sensibilidade.

As características de operação do modelo de bobina móvel são determinadas pelo modelo do atuador, pelo núcleo interno, pela estrutura magnética, pelo projeto da bobina e pelo shunt magnético. Estas unidades são instantâneas e nenhum atraso é propositadamente introduzido. Tempos típicos de operação vão de $5 \mathrm{~ms}$ a $50 \mathrm{~ms}$, com os tempos mais longos ocorrendo próximos do limiar dos valores de disparo.

O mecanismo da Figura 4 é utilizado em um relés de sobrecorrente instantâneo. O atuador de aço repousa em uma lacuna provida por um anel não magnético no centro do núcleo magnético. Quando a bobina é energizada, o conjunto do atuador se move para cima, carregando um disco que conecta três contatos estacionários. A mola helicoidal absorve as vibrações do atuador, proporcionando uma boa ação de contato. A lacuna de ar fornece uma relação retorno do disco para atuação de 90 por cento [24]. 


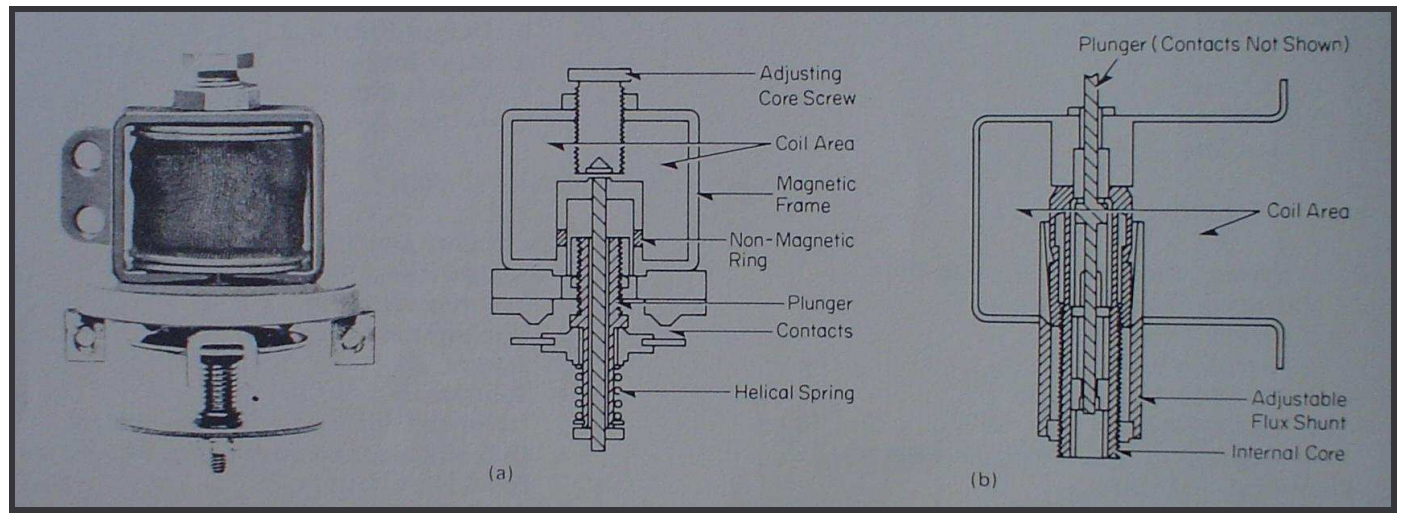

Figura 4 - Mecanismo de Bobina Móvel [ referência 24]

Os demais tipos de mecanismos de atração magnética se encontram no Apêndice deste trabalho.

\subsubsection{Indução Magnética}

Existem dois tipos gerais de mecanismos de indução magnética, que são:

- disco de indução;

- cilindro de indução.

\subsubsection{Mecanismo de Disco de Indução}

Originalmente, os modelos com disco de indução eram baseados nos projetos de medidores de energia do tipo wattimétricos. Entretanto, os modelos mais modernos, apesar de usarem o mesmo princípio operacional, são um pouco diferentes. Todos operam por um torque derivado da interação dos fluxos produzidos por um eletromagnético com aqueles das correntes induzidas no plano do disco girante de alumínio.[24] 
A unidade tipo "E" da Figura 5 tem três pólos em um lado do disco e um membro magnético comum ou segurador no lado oposto. A bobina principal está na perna central. Circulando corrente nesta bobina, produz-se fluxo magnético, o qual passa através da abertura e do disco para o segurador (uma pequena porção do fluxo se dispersa). O fluxo então retorna dividido entre as pernas esquerda e direita. Uma bobina curto circuitada, chamada de espira de sombra, na perna esquerda gera um fluxo contrário que retarda os outros dois fluxos, produzindo uma ação motorizada no disco. O fluxo na perna esquerda induz uma tensão e uma corrente na bobina curto circuitada. O fluxo resultante de todo este processo induz correntes no disco, e da interação dos fluxos é produzido um torque que faz com que o disco entre em movimento se ultrapassados os valores de resistência dos elementos antagônicos que existem neste tipo de mecanismo.

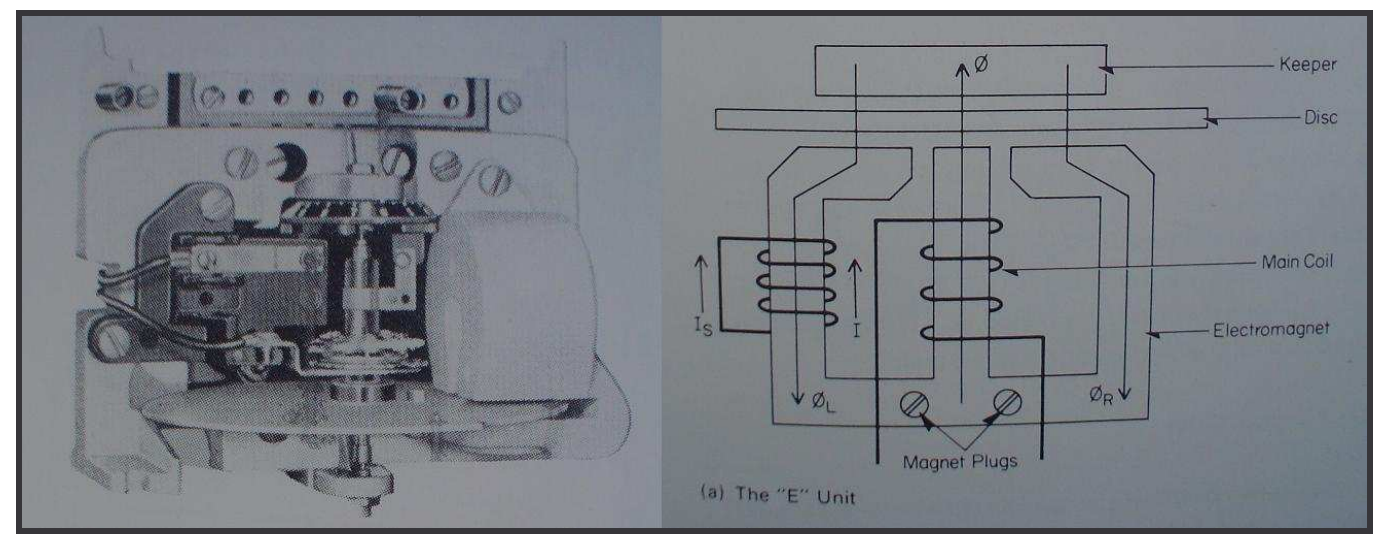

Figura 5 - Mecanismo do tipo Disco de Indução [ referência 24 ] 
Na Figura 6 é apresentada a estrutura de um relé eletromecânico de sobrecorrente, onde pode-se ver as suas partes principais.

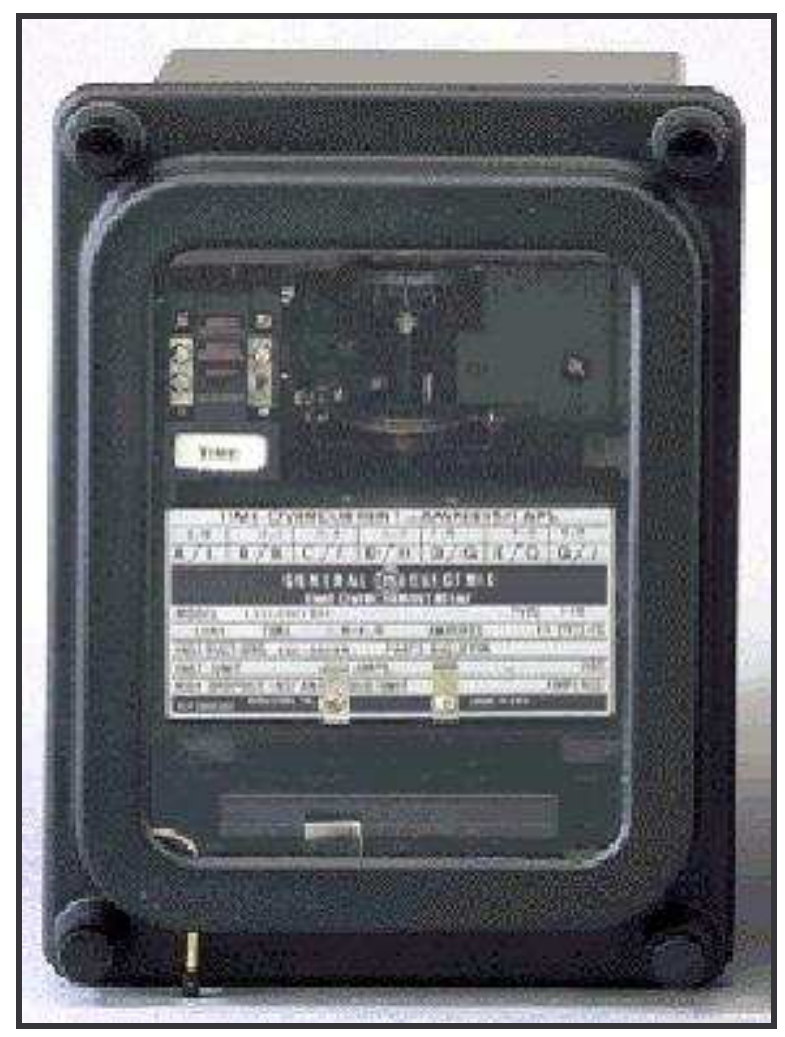

Figura 6 - Relé Eletromecânico de Sobrecorrente - Disco de Indução [referência 8]

Os demais tipos de mecanismos de indução magnética e D'Arsoval se encontram no Apêndice deste trabalho. 


\subsection{RELÉS ESTÁTICOS}

Os relés do tipo estático que sucederam os relés do tipo eletromecânicos operam com base no funcionamento de circuitos lógicos eletrônicos de estado sólido.

O desenvolvimento dos relés estáticos é aplicado de maneira idêntica aos relés eletromecânicos, entretanto, apresentam-se como equipamento de maior operacionalidade, permitindo não só melhorar a atuação dos esquemas de proteção tradicionais, mas também desenvolver esquemas de proteção mais avançados.

Conforme a referência [26], o termo "relé estático" geralmente se refere a um relé que incorpora componentes de estado sólido como transistores, diodos, resistores, capacitores, etc. Neste tipo de relé, as funções de comparação e medição são realizadas por circuitos estáticos nos quais não há partes móveis. Contém características que simulam aquelas dos relés eletromecânicos correspondentes. Estes relés podem ter tanto uma como múltiplas funções, com mostradores e configurações pré-definidas para serem selecionadas diretamente no relé. $O$ circuito analógico também permite combinações de funções de proteção para múltiplas fases no mesmo encapsulamento do relé. De acordo com uma decisão recente da International Eletrotechnical Comission (IEC) os termos relacionados a relés estáticos são os seguintes:[26]

Relé estático: É um relé no qual a resposta projetada é desenvolvida por componentes eletrônicos, magnéticos ou outros, sem movimento mecânico. 
Relé estático com contatos de saída: Um relé estático que possui um contato em uma ou mais de suas saídas. Inicialmente era chamado de relé semi-estático.

Relé estático sem contatos de saída: Um relé estático que não tem contato em seus circuitos de saída. O termo anteriormente aplicado era relé completamente estático.

Com o crescimento dos sistemas de potência em complexidade e níveis de falta, a necessidade de maior sensibilidade e rapidez, esquemas de proteção mais confiáveis vieram. $O$ advento dos semicondutores superou os problemas associados às válvulas. O uso de amplificadores transistorizados, etc. derivando sua alimentação de uma fonte externa, ou em alguns casos auto alimentados a partir de transformadores de corrente e potencial, tornaram possível alcançar grande sensibilidade e ao mesmo tempo obter excelente estabilidade mecânica..

Deve ficar claro que, geralmente, não é econômico substituir os relés eletromecânicos existentes por relés estáticos correspondentes apenas para reduzir a manutenção; o ganho no desempenho técnico deve também ser obtido.

Os relés estáticos foram inicialmente comercializados somente em casos como relés de distância e diferenciais, enquanto que casos muito mais simples, como os relés de sobrecorrente, não tinham muita saída. A razão disto se dá ao fato de que os esquemas diferenciais e de distância são mais fáceis de serem analisados matematicamente enquanto que as características dos de sobrecorrente, como aquelas dadas pelos relés com disco de indução, são mais empíricas e menos matemáticas. Assim, um relé estático não pode competir com o padrão eletromecânico de sobrecorrente de tempo inverso, já que esta característica é atingida pelas características de saturação do eletromagnético. Por outro lado, o relé de tempo inverso exigido pela proteção de sobrecarga em retificadores tem a característica da 
forma $l^{2} t=K$ que pode ser alcançada com circuitos estáticos, mas será extremamente difícil alcançá-la com um disco de indução.

Quando os relés estáticos foram desenvolvidos inicialmente, a disponibilidade de componentes e sua confiabilidade eram baixas. Agora este componente tem alcançado um nível de confiabilidade muito maior que os componentes convencionais. Milhares de relés estáticos já foram fabricados e utilizados.

\subsubsection{Vantagens dos Relés Estáticos}

Os relés estáticos em geral possuem as seguintes vantagens:

- Representam uma carga baixa para transformadores de corrente e de potencial, já que a potência de operação é, em muitos casos, de uma fonte externa;

- Ausência de inércia mecânica, alta resistência ao choque e vibração;

- Operação rápida e vida longa;

- Baixa manutenção devido à ausência de partes móveis e de atrito.

- Rápido reinicio da ação e ausência de overshoot;

- A facilidade de fornecer amplificação permite maior sensibilidade;

- Possibilidade de criar características pouco convencionais - os blocos de construção básicos de circuitos semicondutores permitem um elevado grau de sofisticação no modelamento de características operacionais, habilitando a utilização prática dos relés mais próximas dos requisitos ideais;

- O baixo nível de energia requerido nos circuitos de medição permite a miniaturização dos módulos do relé;

- Os relés estáticos podem ser dispositivos de uma, duas ou múltiplas entradas; 
- Temporizações são muito mais precisas quando feitas por relés estáticos com circuitos de estado sólido que com elementos eletromagnéticos.

Apesar das vantagens listadas, os relés estáticos com componentes de estado sólido possuem certas limitações, mas que podem ser superadas como indicado em cada caso:

- Sensibilidade à temperatura - circuitos de compensação de temperatura foram desenvolvidos (ex.: uso de termistores)

- Envelhecimento - isto é eliminado pela exposição de componentes por várias horas sob uma temperatura relativamente alta.

- Sensibilidade a picos de tensão - isto pode ser eliminado por filtros de proteção.

- Danos devido à sobrecarga - pode ser eliminado por cuidadosos projetos de circuitos.

\subsubsection{Forma Construtiva dos Relés Estáticos}

Basicamente, estes relés são conversores analógico-binários com funções de medição. As variáveis como corrente, tensão, ângulo de fase ou freqüência e valores derivados obtidos por diferenciação, integração ou outras operações matemáticas, aparecem sempre como sinais analógicos à entrada da unidade de medição. A saída será sempre um sinal binário, isto é, um comando para abertura ou fechamento, dependendo da função do relé. Estes sinais de saída podem no entanto facilmente ser avaliados por elementos de controle subseqüentes requerendo muito pouco esforço técnico. 
Cada relé de proteção é constituído de elementos individuais de acordo com o diagrama de blocos mostrado na Figura 7.

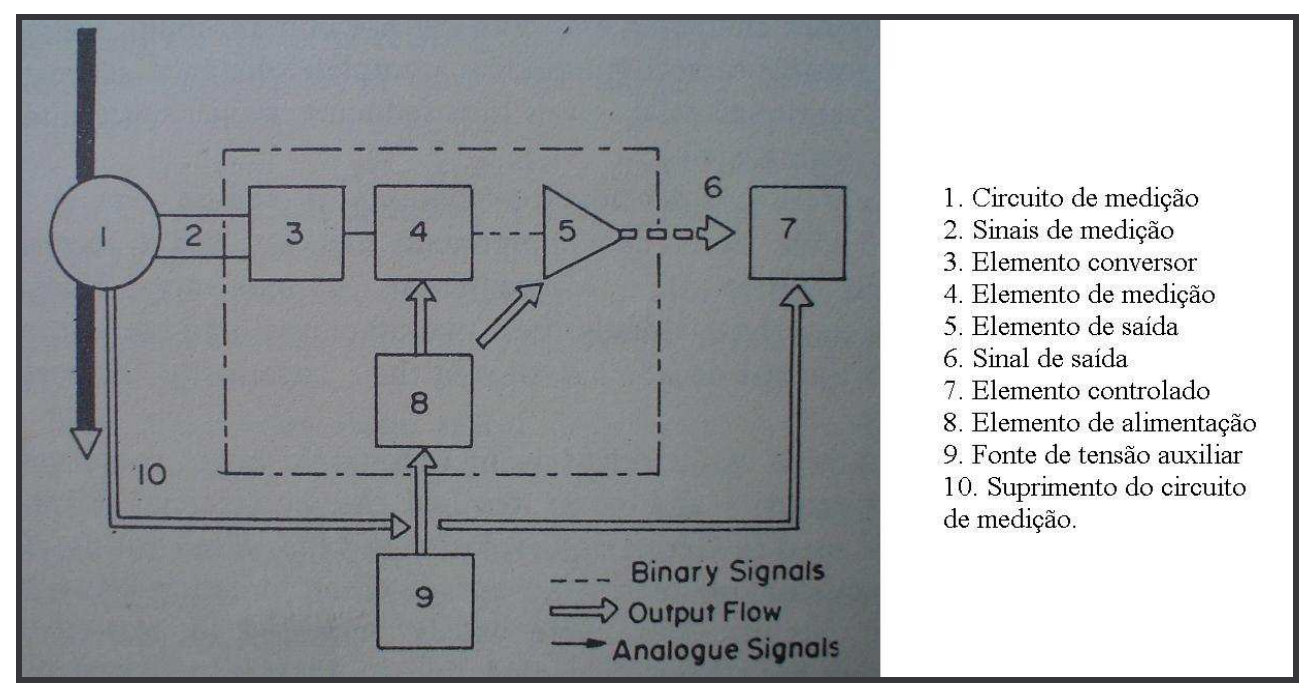

Figura 7 - Diagrama de Blocos de Relé Estático [ referência 26]

Os sinais, que ocorrem na forma de variáveis contínuas dos circuitos de medição são primeiro enviados à unidade conversora do relé protetor. Esta unidade converte os sinais medidos de forma que possam ser facilmente processados pela unidade de medição que se segue. Este elemento de medição será operado quando do sinal de entrada alcança um certo valor fornecendo um sinal de fechamento na sua saída. O elemento de saída amplifica este sinal fraco e o transfere para um ou mais elementos controlados. Os elementos controlados carregam as funções de operação finais, como por exemplo abrindo um disjuntor. Os elementos de medição ou de saída são supridos por um elemento de alimentação. Esta potência de alimentação é obtida tanto de uma fonte de tensão auxiliar ou do próprio circuito de medição.[26] 
Na Figura 8 é mostrado um exemplo real da arquitetura de um relé estático, conforme referência 11, onde são mostrados todos os principais equipamentos que fazem parte da placa mãe, como: elementos de medição, elemento conversor, elementos de saída, e controlado.

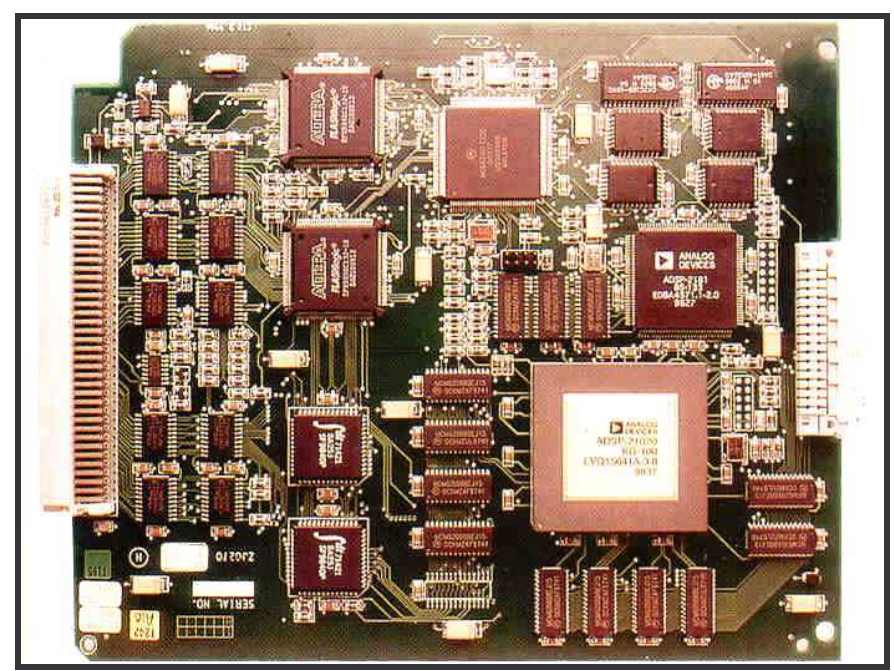

Figura 8 - Placa principal de um relé Estático [ referência 11]

\subsubsection{Diferenças entre os Relés Eletromecânicos e Estáticos de Sobrecorrente.}

Conforme a referência [8], existem duas áreas específicas onde os relés eletromecânicos tipos (IAC e IFC) e estático tipo (SFC) diferem, que são o tempo de sobre viagem e o tempo de zeramento.

O tempo de sobre viagem em relés eletromecânicos é uma função do desenho do relé, sua corrente de partida e ajustes do tempo, e a magnitude de corrente de falta. Não é um número fácil para determinar uma estimativa de 0.1 segundos precisamente e tradicionalmente tem provado ser suficientemente longo. O tempo de sobre viagem nos relés estáticos de sobrecorrente tipo SFC é de 0.01 segundos ou menos. 
Baseados nestes números, as margens de coordenação mínimas seguintes podem ser determinadas:

Tipo do Relé

IAC IFC SFC

Tempo de disjuntor

$0.0833 \quad 0.0833 \quad 0.0833(\mathrm{~s})$

Overtravel

0.1000

$0.1000 \quad 0.0100(\mathrm{~s})$

Fator de segurança

0.1933

0.1933

$0.1933(\mathrm{~s})$

Tempo Total

$\begin{array}{lll}0.3766 & 0.3766 & 0.2866(\mathrm{~s})\end{array}$

Para propósitos práticos, estes números podem ser dados como 0.3 segundos para os relés eletromecânicos do tipo IAC e IFC e de 0.2 segundos para os relés estáticos do tipo SFC.

O tempo de zeramento é o tempo requerido para o relé voltar a sua posição completamente depois que o religador ou disjuntor interrompesse o curto circuito.

Para relés eletromecânicos convencionais, o tempo de zeramento é muito longo. $O$ relé eletromecânico da GE tipo IAC 77 necessita um minuto completo para voltar à posição de zeramento da posição contato-fechado quando se ajusta a curva de atuação número 10.

Porém, o relé estático tipo SFC zera em 0.1 segundos ou menos independentemente da característica ou do dial de tempo utilizado, que é mais rápido que o tempo de religamento de qualquer religador de distribuição ou disjuntor disponível. 


\subsection{RELÉS DIGITAIS}

Conforme a referência [02], os relés digitais surgiram como sucessores dos relés do tipo estático. Os primeiros trabalhos na área digital surgiram nos anos 60 , quando os computadores começaram a substituir ferramentas tradicionais na análise dos sistemas de potência. Resolvidos os problemas de cálculo de curto-circuito, fluxo de potência e estabilidade, as atenções voltaram-se para os relés de proteção que prometiam ser um excitante campo. Mas logo ficou claro que o desenvolvimento tecnológico dos computadores desta época, ainda não podia atender às necessidades das funções de proteção, nem era economicamente atraente. $O$ interesse sobre o assunto ficou então restrito à área acadêmica onde os pesquisadores mantiveram o desenvolvimento dos algoritmos de proteção, até que a oportunidade surgisse.

Com a evolução rápida dos computadores, a sofisticada demanda dos programas de proteção pode ser atendida com velocidade e economia pelos atuais computadores. A tecnologia digital tem se tornado a base da maioria dos sistemas de uma subestação, atuando nas funções de medição, comunicação, proteção e controle. Desta forma, além das funções de proteção, o relé digital pode ser programado para desempenhar outras tarefas, como, por exemplo, medir correntes e tensões dos circuitos.

Outra importante função deste tipo de relé é o autodiagnóstico (autoteste). Esta função faz com que o relé realize uma supervisão contínua de seu hardware e software, detectando qualquer anormalidade que surja e que possa ser reparada antes que o relé opere incorretamente ou deixe de fazêlo na ocasião certa.

Observação: Os relés digitais também são chamados de relés microprocessados, nos textos abordados neste trabalho. 
Os relés digitais apresentam ainda as seguintes vantagens:

-Oscilografia e análise de seqüência de eventos - a habilidade dos sistemas de proteção em armazenar amostras de quantidades analógicas e o status de contatos em um intervalo de tempo possibilita a análise de perturbações. -Localização de defeitos - o principal benefício obtido é a redução do número de faltas permanentes, através da manutenção corretiva em pontos indicados pela reincidência de faltas transitórias, tais como as causadas por queimadas, descargas atmosféricas ou isoladores danificados.

-Detecção de defeitos incipientes em transformadores - a maioria dos defeitos internos em transformadores começa com descargas parciais que podem ser detectados através da monitoração de espectro de freqüência de TC's ligados nestes transformadores.

-Monitoração de disjuntores - o tempo de abertura e fechamento de um disjuntor também pode ser monitorado através dos relés usados para disparo e religamento.

Conforme a referência [27], as vantagens da Proteção Digital são:

\subsubsection{Melhora na Confiabilidade Global}

Os relé digitais possuem:

-Maior número de componentes, logo poderão ter maios taxa de falhas; -Recursos de auto -teste altamente desenvolvidos.

Apesar da maior taxa de falhas, a confiabilidade global do sistema de proteção é maior para os relés digitais. 


\subsubsection{Recurso de Comunicação}

Através de um canal de comunicação, o relé pode transmitir/receber qualquer informação relativa à tarefa de proteção ( ocorrência de eventos, ajustes, etc)

\subsubsection{Maior Flexibilidade}

Toda a inteligência se encontra no software ( ajustes, curvas e funções de proteção são facilmente alteráveis).

Flexibilidade mais Comunicação - representa em novas filosofias de proteção ( proteção adaptativa).

Funções secundárias implementadas ao lado da função de proteção principal( oscilografia, registro de eventos, religamento, falha de disjuntor, etc).

Hardware padronizado - Maior facilidade de manutenção.

2.4.4 Facilidade de Integração com Novas Tecnologias

Os relés digitais possuem portas de comunicação assim como entradas e saídas de sinais que permitem a sua conexão com:

-Fibras óticas para transmissão e recebimento de sinais;

-TPs e TCs óticos;

-Integração com sistema de Supervisão e Controle da Subestação ( automação). 


\subsubsection{Melhor estabilidade a longo prazo}

-Poucos pontos de ajuste dentro do equipamento;

-Performance pouco influenciada pelo envelhecimento dos componentes. Este era um dos problemas principais que existiam nos relés de proteção estáticos, onde o envelhecimento dos componentes discretos (resistores, capacitores, indutores, etc), provocavam a alteração da atuação destes equipamentos assim como reduziam a sua vida útil.

-Possibilidade de calibração e ajustes automáticos.

\subsubsection{Melhor Performance}

-Permite um processamento de sinal sofisticado e complexo.

\subsubsection{Arquitetura de um relé Digital}

Na referência [16], é apresentado o diagrama esquemático do hardware de um relé digital para a proteção de linhas de transmissão, e o fluxo de informações entre as unidades em termos do processamento digital de sinais.

A relação entre os sinais de tensão e corrente provenientes do sistema analisado independe de qualquer consideração digital $\mathrm{O}$ sinal é convertido para a forma digital em intervalos de tempo constantes denominados intervalos de tempo entre amostras.

Como primeira etapa do esquema, tem-se a entrada de dados, que são os sinais de tensão e corrente contínuos no tempo, provenientes do sistema de potência. A seguir, os sinais são transformados na forma digital e interpretados pelo algoritmo. Infelizmente o processo de discretização introduz alguns erros nos sinais de entrada que precisam ser considerados causados pelos transdutores, saturação dos TC's, etc. 
2.4.8 Componentes Básicos de um Relé Digital

Conforme a referência [16], o relé digital é constituído de submódulos com funções bem definidas, as quais mostram os estágios de condicionamento a que os sinais de entrada do relé são submetidos desde a entrada até o processamento, e são classificados e compostos por três subsistemas fundamentais conforme mostra a Figura 9:

- $\quad$ subsistema de condicionamento de sinais;

- $\quad$ subsistema de conversão de sinais;

- $\quad$ subsistema de processamento digital de sinais. 


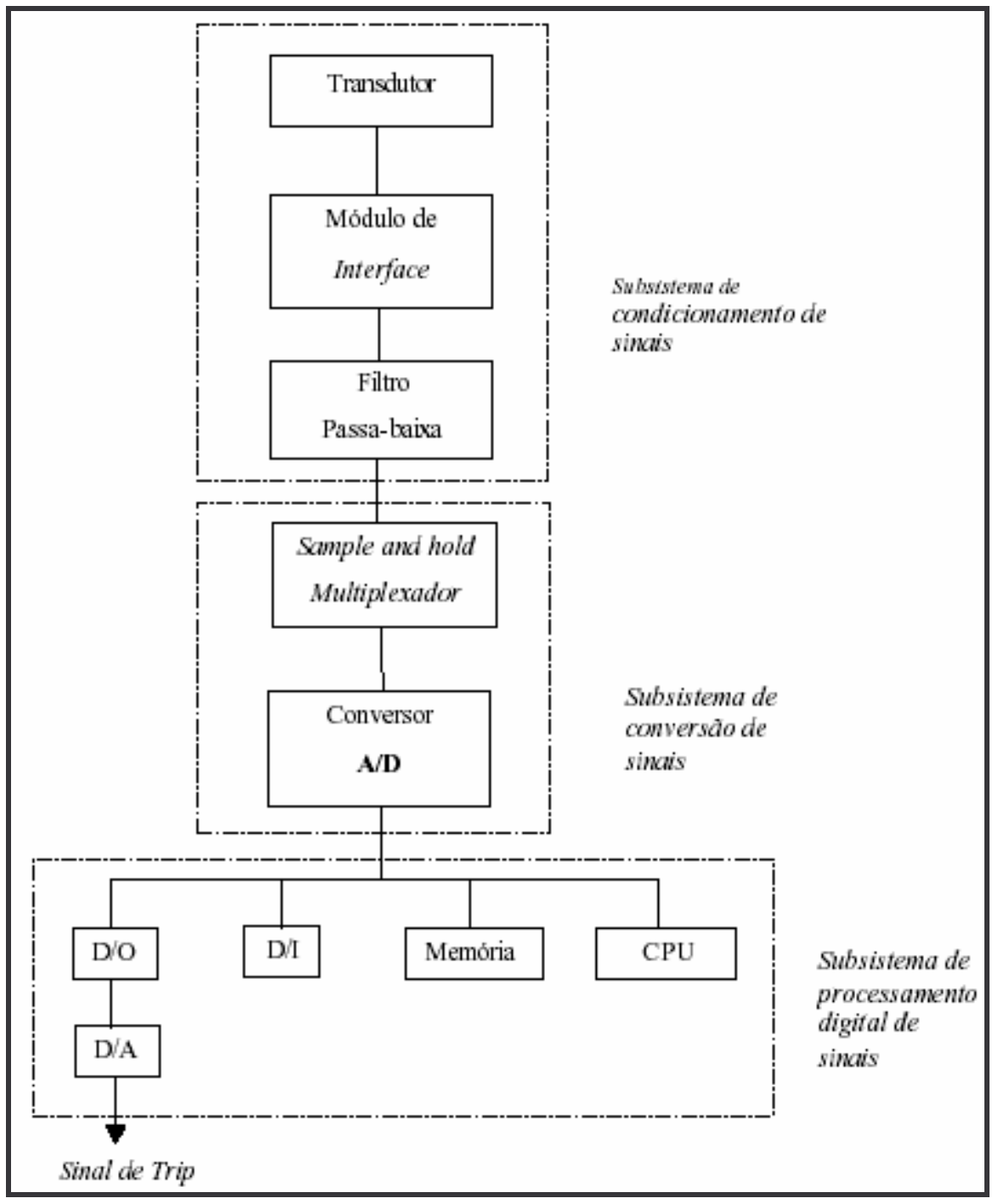

Figura 9 - Arquitetura do Relé Digital [ referência 16]

D/O = saída de dados

$\mathbf{D} / \mathbf{A}$ = Conversor digital - analógico

D/I = entrada de dados

$\mathbf{A} / \mathbf{D}=$ Conversor analógico - digital

$\mathbf{C P U}=$ Unidade Central de Processamento 
Os subsistemas de condicionamento e de conversão de sinais são comuns em quase todos os tipos de relé digital $O$ terceiro subsistema varia de acordo com a aplicação para a qual o relé foi projetado.

Cada um dos três subsistemas é formado por um número de componentes e circuitos que estão detalhados no Apêndice deste trabalho.

\subsubsection{Autotestes em Relés Microprocessados}

Na referência [28] são realizadas algumas análises referentes aos autotestes nos relé microprocessados.

Conforme a referência [28], os relés de proteção microprocessados efetuam autotestes para determinar que os subsistemas do relé estejam funcionando corretamente. Em um artigo mais recente destes autores é mostrado que a confiança no autoteste do relé, seguramente permite sua utilização para aumentar o intervalo da tradicional rotina de manutenção para estes relés.

\subsubsection{Porque testar os relés de Proteção?}

O objetivo do teste em relés de proteção é para maximizar a disponibilidade da proteção e minimizar os riscos de operações erradas do relé. Pensando nisso, tem que se definir testes adequados e monitoramentos práticos para os relés digitais de proteção.[28]. 


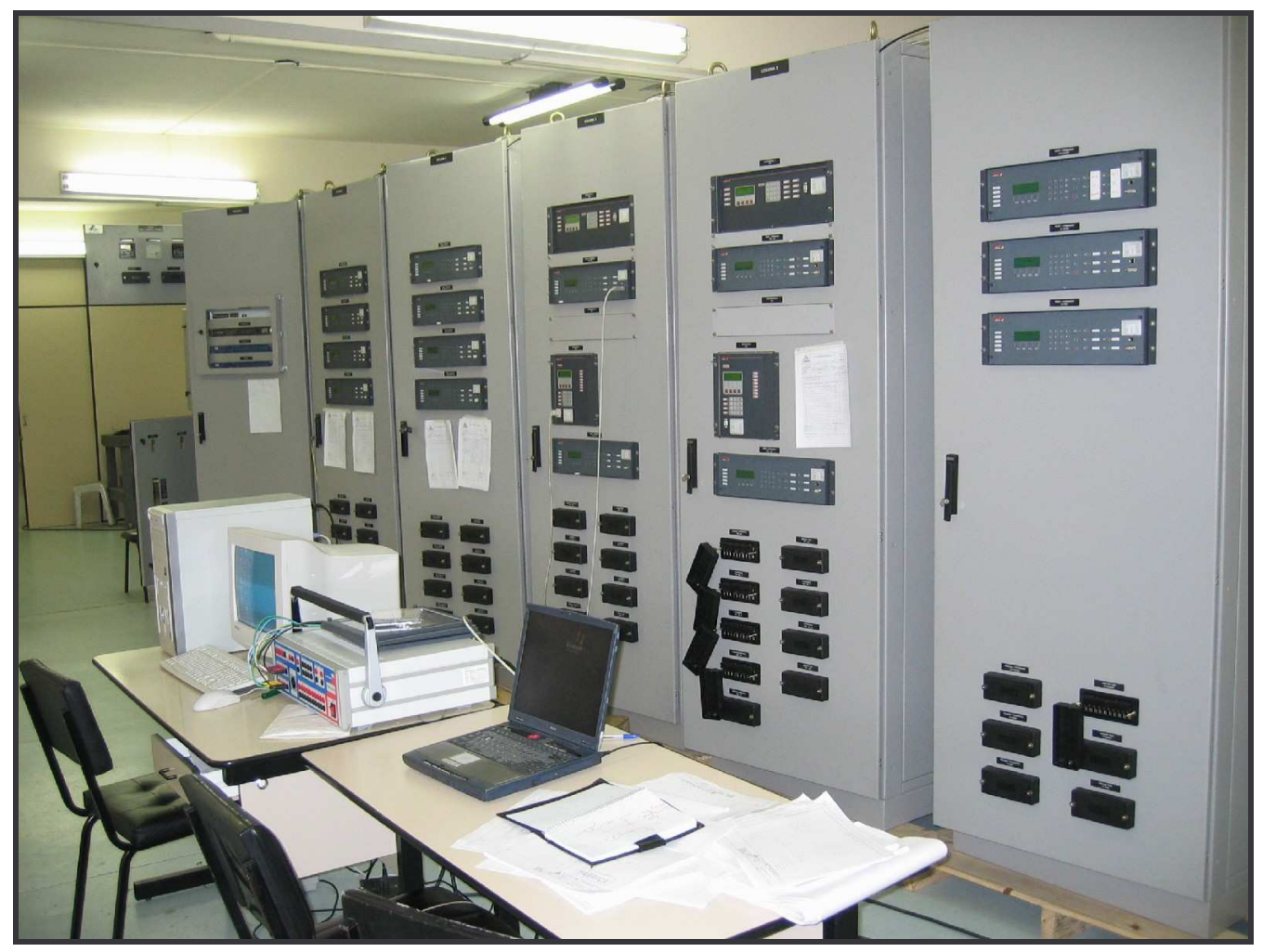

Figura 10 - Testes de Recebimento em relés Digitais [Referência ZIV]

\subsubsection{Relés Digitais Autotestados}

Relés digitais usam um microprocessador, uma aquisição de dados de sinais AC, componentes de memória contendo os algoritmos do relé, contatos de entrada para controle do relé e contatos de saída para controle de outros equipamentos. $\mathrm{O}$ algoritmo e ajustes contidos na memória do relé definem a característica da proteção.

Relés digitais usualmente incluem funções de autoteste automático. Estes autotestes verificam a correta operação de componentes críticos do relé. Se o autoteste detecta uma condição anormal, o relé pode fechar um contato de saída, enviar a mensagem , ou providenciar alguma outra indicação de falha. O relé desabilita as funções de disparo e controle com a detecção de certas falhas no autoteste.

Desde que autotestes em relés digitais são executados freqüentemente, eles detectam falhas em componente logo após eles ocorrerem. No mínimo, 
esses autotestes incluem testes nos chips de memória, conversor análogo/digital, fonte de alimentação e microprocessador.[28].

$\mathrm{Na}$ referência [28] os autores consideram os relés digitais divididos em três seções onde se deve realizar o autoteste:

1. Seção de entradas analógicas

2. Circuitos dos contatos de entrada/saída

3. Seção de processamento

A seção de entradas analógicas, consiste na conexão dos sinais, transformadores isoladores, filtros passa-baixo um ou mais multiplexadores e o conversor análogo-digital.

O autoteste automático monitora parcialmente a seção de entradas analógicas. Desde que a parcela de entradas analógicas não seja totalmente testada, as praticas de manutenções deveriam verificar os componentes de entrada analógica.[28]

Os circuitos dos contatos de entrada/saída são outra parte do relé digital que permitem somente um autoteste automático parcial. É possível projetar este hardware para uma redundância completa e verificável através do autoteste. Entretanto, o hardware existente é confiável, e o custo adicional par um hardware mais complexo não é justificável. A verificação de rotina nos contatos de saída e entradas ópticas isoladas é apropriada quando os equipamentos não operam regularmente em resposta à falhas.

A seção de processamento digital, tipicamente um microprocessador, é a interface entre a seção de entrada analógica e a seção dos contatos de entrada/saída. Autotestes monitoram o processador e componentes de memória associadas. Desde que as seções de contatos de entrada e saída e analógica não podem funcionar sem a seção de processamento, o uso normal também verifica a seção de processamento do relé.[28].

Segundo o artigo [28], dados de campo mostram que um valor prático de eficiência do autoteste é de $80 \%$. Seria possível projetar o hardware e o software do relé para descobrir quase todos os defeitos, mas isto tornaria o 
relé muito caro. Entretanto, é importante para fabricantes de relés projetar um hardware confiável, e incorporar testes simples para detectar as muitas possibilidades de falhas. Para beneficiar a operação de autoteste do relé, deveriam ser monitoradas as saídas de contatos de alarme de todos relés digitais.

Os autores enfocam como conclusões sobre o autoteste em relés digitais:

A característica dos relés digital reduz a rotina de testes para uma lista muito pequena:

- Verificação de medidas e testes de entrada/saída. Característica do relé e verificação de temporizações não são partes necessárias da rotina dos testes de manutenção para relés digitais.

-Monitorar o contato de alarme no autoteste do relé. Mesmo que a eficiência do autoteste seja baixa, há melhoria significativa no relé e disponibilidade do sistema de potência quando as falhas no relé são detectadas e reparadas rapidamente.

- Verificar a operação dos contatos de entrada/saída pelo exame no relatório de eventos do relé, ou através de testes executados quando a linha estiver fora de serviço.

-Utilizar as funções de relatório do relé digital como ferramenta de manutenção. A analise do relatório de eventos irá complementar ou substituir a rotina de manutenção de relés com autoteste. A analise do relatório de eventos aumenta o entendimento do testador de relés digitais e do sistema de potência. 


\subsection{DESENVOLVIMENTO DE MICROPROCESSADORES E O USO DE SOFTWARES}

Conforme a referência [6], o desenvolvimento de microprocessadores e memórias de alta velocidade conduziu ao crescimento rápido de computadores pessoais durante a década dos anos 1980. Também foram utilizados microprocessadores e memórias de alta velocidade para desenvolver relés digitais de proteção para aplicação na indústria de energia elétrica. Um exemplo disto é o relé General Electric - Proteção de Linha Digital (DLP) [4], relé que emprega alta resolução direta de amostragem da forma de onda da entrada de corrente e tensão, processamento digital e hardware de microprocessador múltiplo.

Conforme os autores [6], a rápida evolução em relés eletrônicos leva dois assuntos novos importantes para o engenheiro de proteção.

Primeiro, a vida do projeto efetiva para obsolescência técnica está dramaticamente reduzida.

Na Figura 11 é mostrado que a expectativa de vida do projeto encolheu de mais de 30 anos com a tradicional tecnologia eletromecânica para aproximadamente 5 anos com a presente mudança rápida da tecnologia eletrônica. 


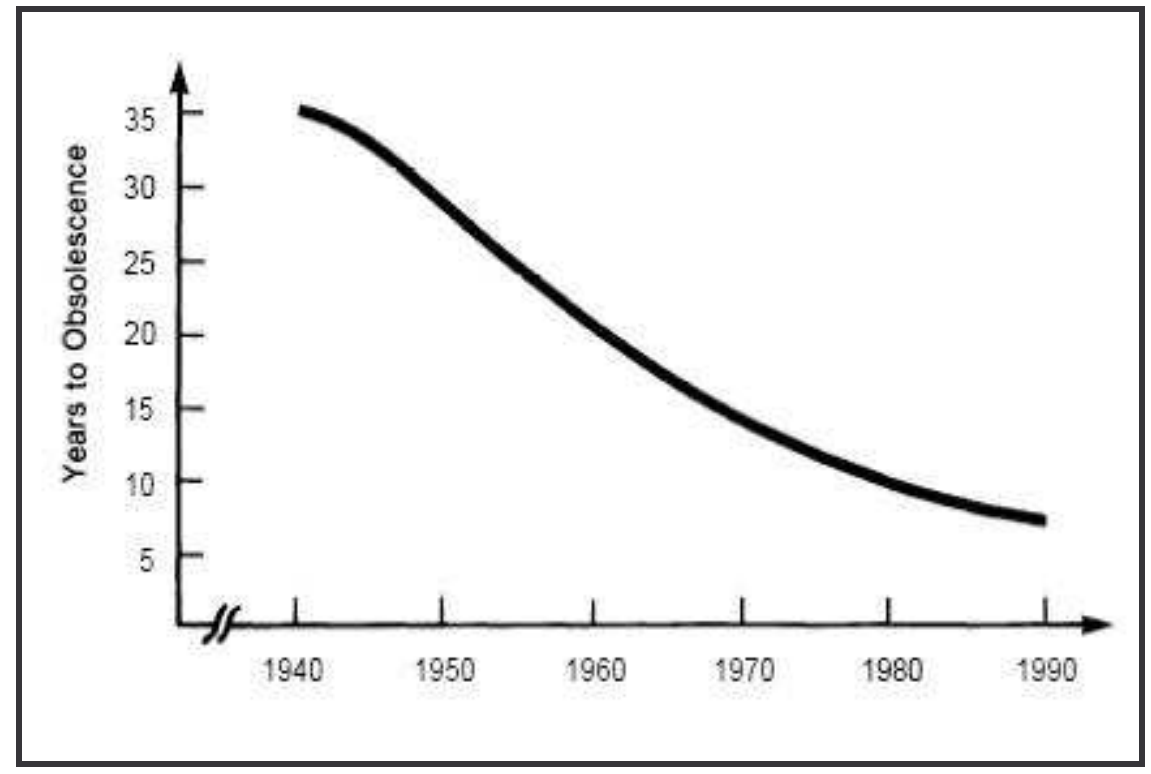

Figura 11 - Expectativa de Vida de Relés de Proteção [6]

O segundo assunto é a pergunta da confiabilidade do software requerida para sistemas de proteção com relés digitais. 
A Figura 12 mostra a mudança de hardware e software nos relés de proteção eletrônicos.

Para os relés digitais de hoje, só $20 \%$ do esforço total envolvido de desenvolvimento são para hardware, comparado a $80 \%$ para o software.

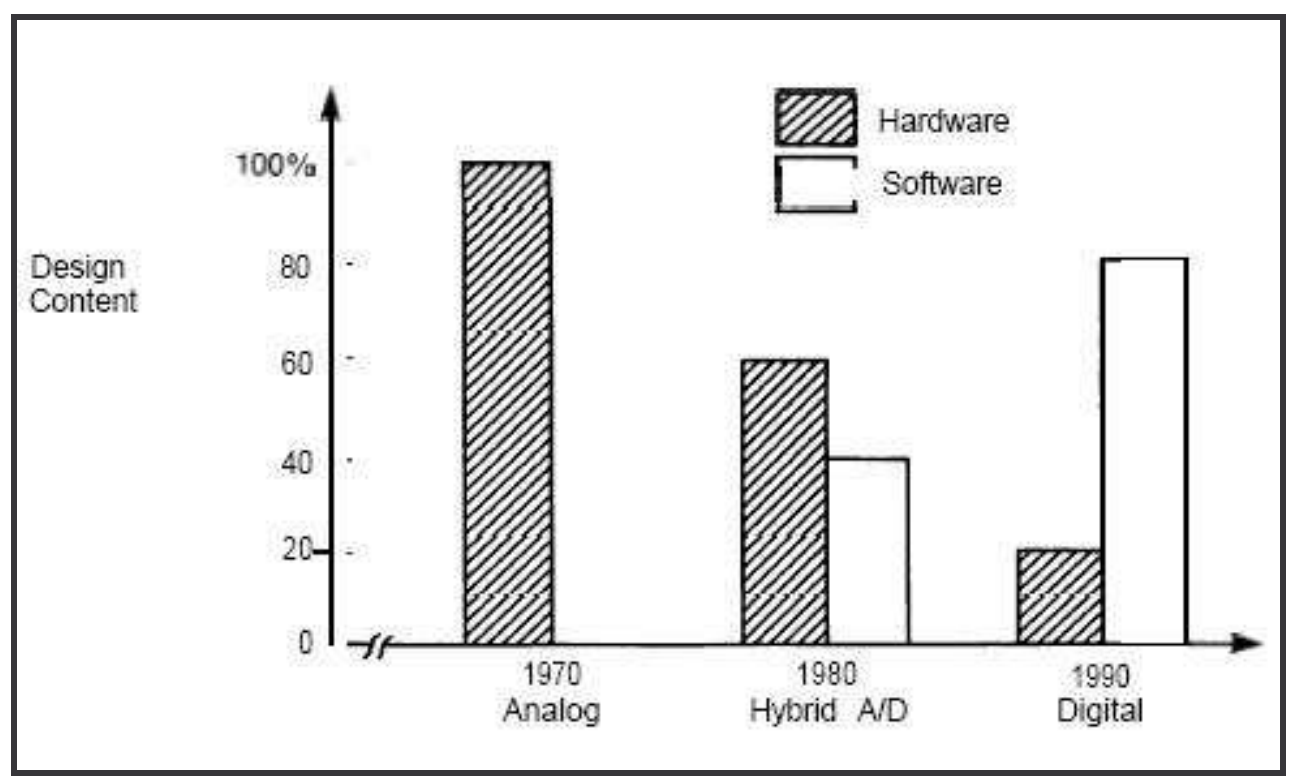

Figura 12 - Evolução do desenvolvimento dos Relés - USA [6] 


\subsection{EXPERIÊNCIA DE CONFIABILIDADE DE SOFTWARE EM OUTRAS INDÚSTRIAS}

Os autores da referência [6] fazem o seguinte questionamento:

Qual tem sido a experiência com problemas de software em indústrias diferente da indústria de energia elétrica?

O que foi feito para provocar melhorias significantes?

Quais são algumas das melhores práticas que foram desenvolvidas para provocar melhorias significantes em confiabilidade de software?

Que lições podem ser aprendidas disto e aplicado ao desenvolvimento de relés de proteção na indústria de energia elétrica?

A referência [6] cita que: a confiabilidade de software foi uma causa principal de falhas em serviço de sistemas comerciais e sistemas militares. Um recente exemplo disto foi à falha de cerca da metade do sistema de telefone de longa distância da AT\&T ao longo da parte Nordeste dos Estados Unidos no dia 15 de janeiro de 1990. Este massivo sistema de falha foi atribuído a um erro de software em um "switch".

O sistema da AT\&T tinha um automonitoramento em todos os "switches"; no caso de uma falha, era suposto que o "switch" se desconectava sozinho, enquanto que o tráfico era redirecionado a outros circuitos. O sistema da AT\&T deveria ter continuado operando depois de uma falha do "switch" por causa de extensiva redundância. Infelizmente, o erro de software resultou o cascateando "desligando" muitos "switches" e derrotou toda a redundância e todo o automonitoramento interno que tinha sido projetado no sistema. Foi necessário o Presidente da AT\&T ir à televisão nacional e se desculpar ao público para o que tinha acontecido e tentando explicar o que foi o problema. Este incidente é um bom exemplo de por que é importante prestar atenção à importância de confiabilidade de software.

A evolução de tecnologia digital em relés de proteção eletrônicos envolve mudanças principais nos fatores que afetam desempenho e confiabilidade, 
como também a probabilidade de vida para desenvolver obsolescência. Métodos tradicionais de avaliar relés através de inspeção de hardware e testes não são muito longos, desde até $80 \%$ do conteúdo de desenvolvimento de engenharia de relés digitais contemporâneos está na área de software. Ficou crescentemente importante então o engenheiro de relés entender as exigências para assegurar uma qualidade ótima de software de relés. 


\subsection{CARACTERÍSTICAS DO HARDWARE DE RELÉS DIGITAIS}

Os relés digitais possuem alguns componentes de hardware de um sistema digital de controle se subestações que estão presentes na maioria dos sistemas devido as suas características que dão razão ao sistema.

Nas figuras Figura 13 e Figura 14 tem-se o exemplo de equipamentos utilizados para proteção de sistemas elétricos de dois fabricantes distintos.

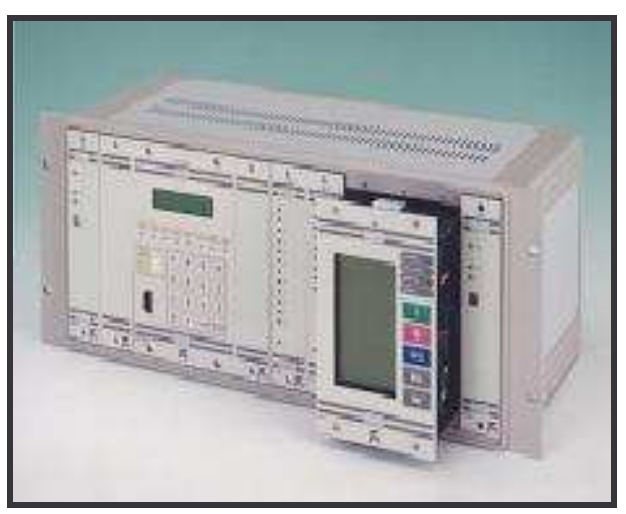

Figura 13 - Relé Multifunção Team-Arteche

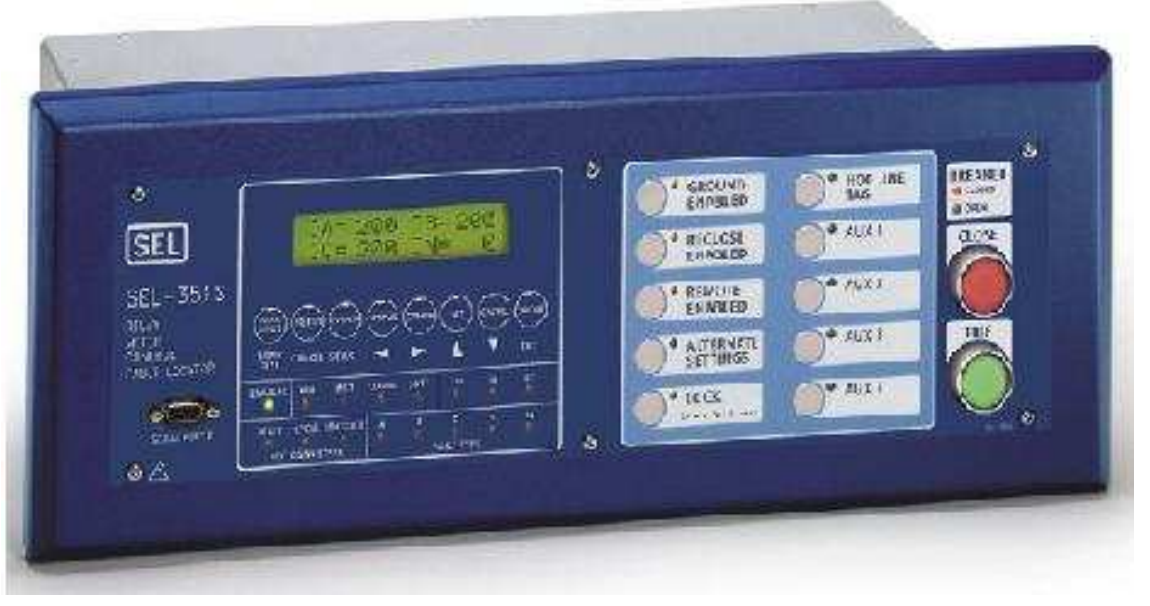

Figura 14 - Relé Digital de Proteção de Alimentador 351 S - SEL 
Os relés digitais normalmente possuem os seguintes componentes, para executar as funções para as quais foram fabricados:

\subsubsection{Fonte de alimentação auxiliar}

A fonte de alimentação auxiliar normalmente possui um conversor CC/CC com isolação galvânica e fornece uma tensão de saída para alimentar os demais componentes de acordo com as características do fabricante para alimentação de seus componentes.

Como é a fonte de alimentação auxiliar quem energiza os demais componentes de hardware do sistema, é fundamental que ela esteja funcionando corretamente. Sendo assim a maioria das fontes de alimentação auxiliar dos equipamentos digitais no mercado, possui um circuito de vigilância que verifica o seu funcionamento o valor de sua tensão de saída.

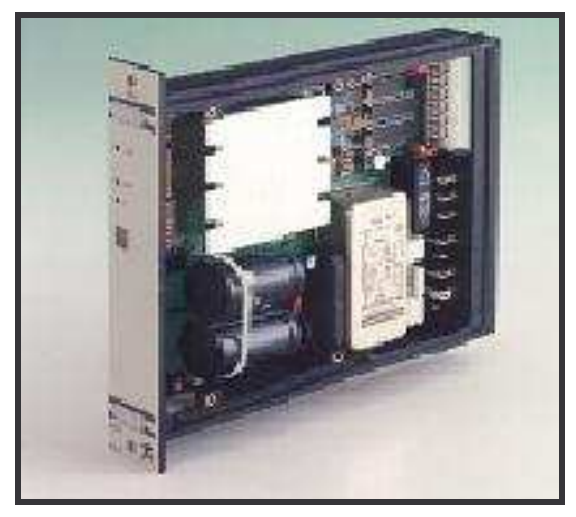

Figura 15 - Exemplo de Fonte de alimentação auxiliar (Team-Arteche) 


\subsubsection{Fonte de alimentação de retaguarda}

A fonte de alimentação de retaguarda possui as mesmas características da fonte de alimentação auxiliar, exceto o fato de ficar em stand-by. Ou seja, esta fonte retaguarda é uma fonte redundante, que somente entrará em funcionamento caso algum problema seja detectado com a fonte auxiliar.

\subsubsection{Entradas digitais}

As entradas digitais ocupam o papel de interface do sistema digital de proteção e controle como os equipamentos em campo.

É através das entradas digitais que se efetuam as aquisições das informações digitais a partir dos contatos externos da instalação, como, por exemplo, estados dos disjuntores e seccionadoras.

Os estados que deverão ser supervisionados para cada subestação, devem ser definidos na fase de projeto e devem estar representadas nos diagramas lógicos, bem como em quais intertravamentos estes irão intervir.

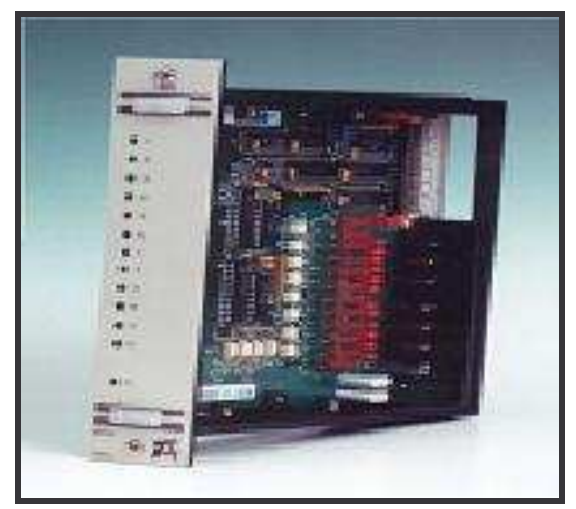

Figura 16 - Exemplo de Cartão de Entradas Digitais (Team-Arteche) 


\subsubsection{Saídas digitais}

As saídas digitais também ocupam o papel de interface do sistema digital de proteção e controle como os equipamentos em campo.

É através das saídas digitais que se efetuam os comandos nos equipamentos da instalação, como por exemplo, nos disjuntores, religadores e comutadores de derivação.

As condições sob as quais os contatos das saídas digitais mudarão de estado devem ser definidas na fase de projeto e devem estar representadas nos diagramas lógicos.

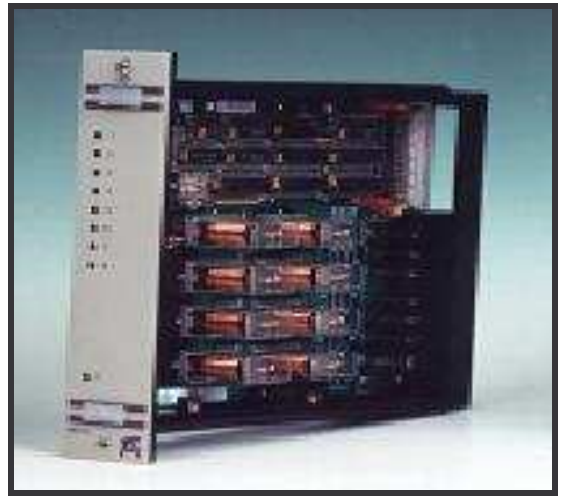

Figura 17 - Exemplo de Cartão de Saídas Digitais (Team-Arteche)

Na Figura 18, conforme referência [52], tem-se a régua de bornes de um relé digital tipo F6 onde são mostradas as saídas digitais, que são possíveis de serem programadas com uma lógica distinta a ser confeccionada pelos Engenheiros de Proteção e Automação quando da execução dos Estudos de Proteção. 


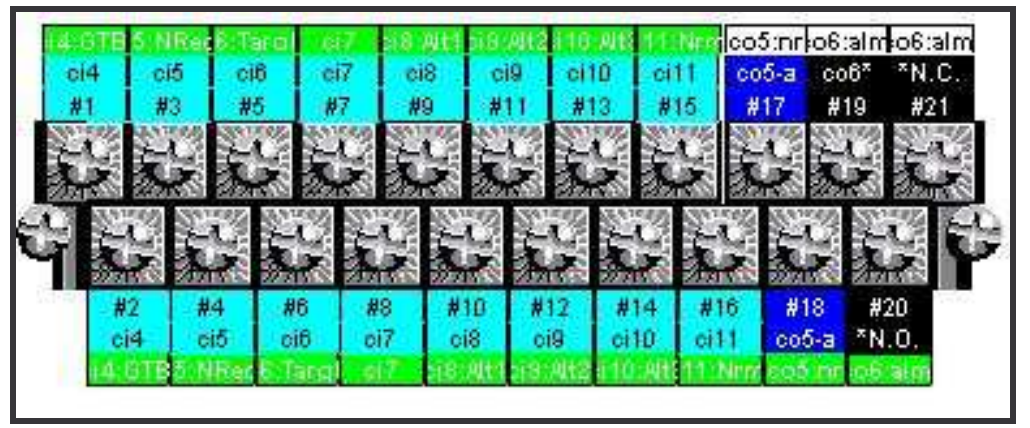

Figura 18 - Saídas Digitais Programáveis do relé F6 - Cooper Power Systems [52]

\subsubsection{Entradas analógicas}

As entradas analógicas servem para a aquisição de informações analógicas a partir de transdutores de corrente ou tensão. Podendo controlar variáveis como temperatura, pressão e detectores de nível de modo a fornecer ao sistema digital a capacidade de realização de automatismo como controle de bancos de capacitores.

Através das entradas analógicas e conversores analógico/digital interno ao equipamento, grandezas analógicas podem ser transmitidas a níveis superiores e gerar alarmes digitais em função de seus valores.

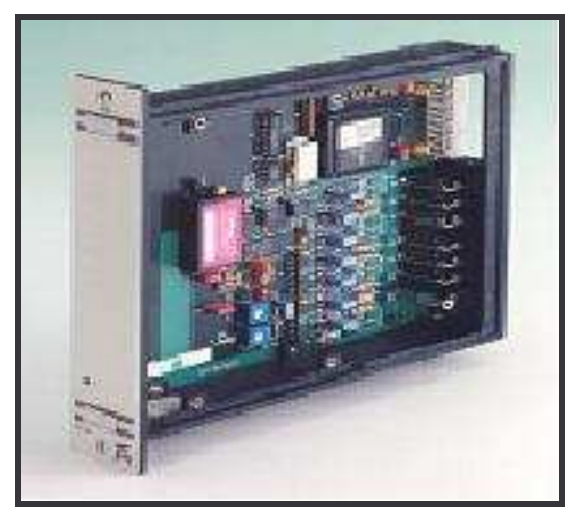

Figura 19 - Exemplo de Cartão de Entradas Analógicas (Team-Arteche) 


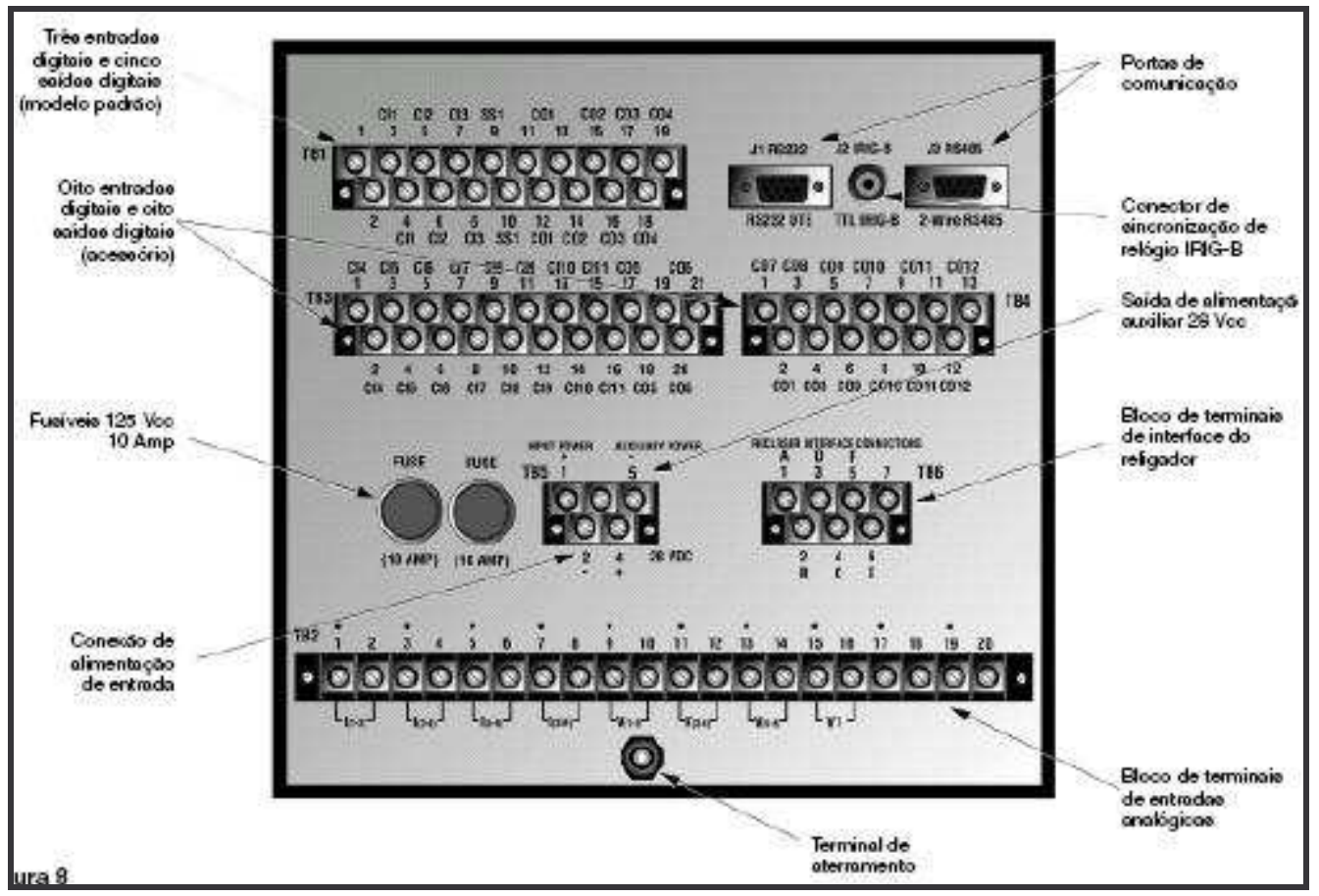

Figura 20 - Painel Traseiro do relé Digital F6 - Cooper Power Systems [referência 52]

Na Figura 20, conforme referência [52], pode-se visualizar o painel traseiro de um relé de proteção multifunção digital, da Cooper Power Systems, onde estão separadas em réguas de bornes distintas as: entradas digitais, saídas digitais, saída de alimentação auxiliar, alimentação de entrada, entradas analógicas, portas de comunicação, porta de sincronização de tempo e conector de aterramento. 


\subsection{COMPARANDO PROTEÇÕES \\ E MICROPROCESSADAS}

\subsubsection{Requisitos quanto ao espaço e ao hardware}

Na referência [5], o autor faz uma comparação, utilizando um típico esquema de proteção de distância com três zonas temporizadas de elementos de trip instantâneos, dois níveis de elementos de disparo temporizados para faltas envolvendo a fase e um elemento de trip instantâneo, e um elemento de sobrecorrente temporizado para faltas a terra. Para esse exemplo, deve-se admitir que a proteção de distância com zonas temporizadas utiliza elementos de distância de fase e de sobrecorrente direcional de terra. Faltas envolvendo a fase são detectadas usando três zonas dos relés de distância de fase. Faltas à terra são detectadas usando um relé de sobrecorrente direcional de terra, que inclui um elemento de sobrecorrente temporizado e um elemento de sobrecorrente instantâneo. O esquema de proteção também inclui um religador que efetue somente uma tentativa de religamento, para restabelecimento automático da linha após a falta ter sido eliminada.[5].

O esquema com relés eletromecânicos utiliza relés de distância trifásicos(21), um relé temporizador (62), relé direcional de sobrecorrente de terra(67), relé de religamento (79), relé de sobrecorrente de fase(51).

O layout do painel de um esquema com relés eletromecânicos é mostrado na Figura 21 .Conforme o autor cita neste trabalho, observar que o esquema eletromecânico requer quase todo o espaço contido no painel de $213,36 \mathrm{~cm}$ por $48,26 \mathrm{~cm}$.[5] 


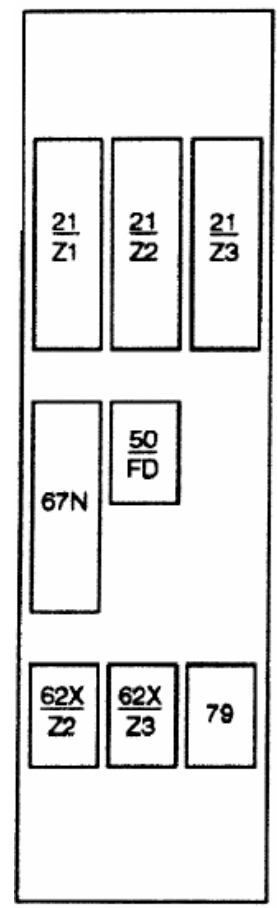

Figura 21 - Layout de Painel com relés Eletromecânicos[5]

FONTE: [5] SEL - Schweitzer Engineering Laboratories, Inc. USA.

Conforme a referência 5, o esquema microprocessado consiste de um relé multifunção que forneça as três zonas de uma proteção de distância com zonas temporizadas, três níveis de proteção de sobrecorrente direcional de terra instantânea ou com tempo definido, uma função de sobrecorrente direcional de terra temporizada, e um religador que efetue três tentativas de religamento. O esquema microprocessado também incluirá um relé microprocessado com uma única zona, para retaguarda no caso de falha do relé de distância principal.

Na Figura 22 pode-se visualizar um painel utilizado para o esquema de proteção com relés microprocessados. O espaço necessário para este esquema é muito menor do que para o esquema com relés eletromecânicos. 


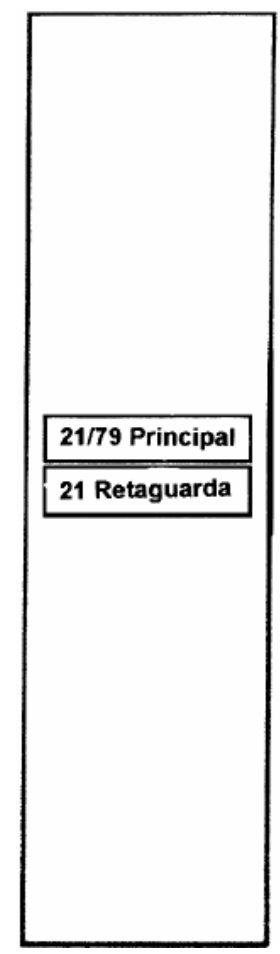

Figura 22 - Layout de Painel utilizando relés microprocessados [5]

FONTE: [5] SEL - Schweitzer Engineering Laboratories, Inc. USA.

A comparação que o autor realiza com os dois lay-outs anteriores é que se supor o custo de todos os relés para o esquema eletromecânico é 1,0 por unidade (p.u.), tem-se que o custo do esquema com relés microprocessados é 0,35 p.u.

A mesma análise é valida para proteção de circuítos alimentadores, onde tería-se a instalação de três relés eletromecânicos de sobrecorrente de fase mais um relé eletromecânico de sobrecorrente de neutro, mais um relé de religamento, mais relés de sobre e sub tensão, um relé de falha de disjuntor, relés de sobrecorrente direcionais de fase e de neutro e relés de sobre e sub freqüência. 
Todos estes equipamentos, instalados de forma individual, são substituídos por um único relé digital, que possue internamente todas estas funções, conforme é mostrado na Figura 23.

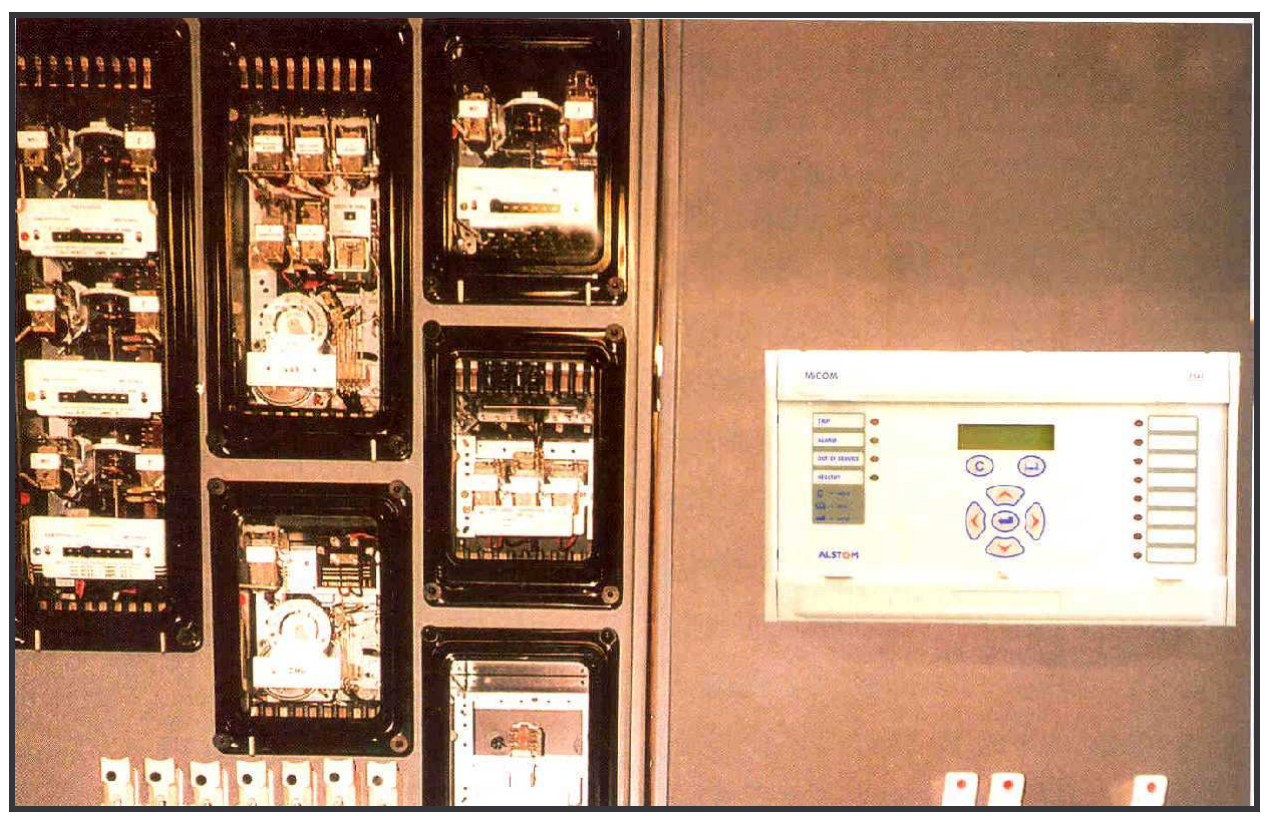

Figura 23 - Comparação entre tecnologia eletromecânica e digital de relés [referência 11]

$\mathrm{Na}$ Figura 23, conforme referência 11, pode-se visualizar a aplicação comparando a tecnologia eletromecânica com a digital, em termos de espaço físico num painel de proteção.

$\mathrm{Na}$ Figura 24, conforme referência 42, pode-se visualizar melhor a diferença de espaço para instalação de um sistema de proteção, que neste exemplo é um sistema de proteção para geradores, mostrando-se o arranjo com relés eletromecânicos, do lado esquerdo da figura, com todos os relés necessários para se realizar todas as funções de proteção para este tipo de máquina girante e no lado direito pode-se visualizar a instalação de dois relés de proteção digital, sendo um principal e outro back-up. 


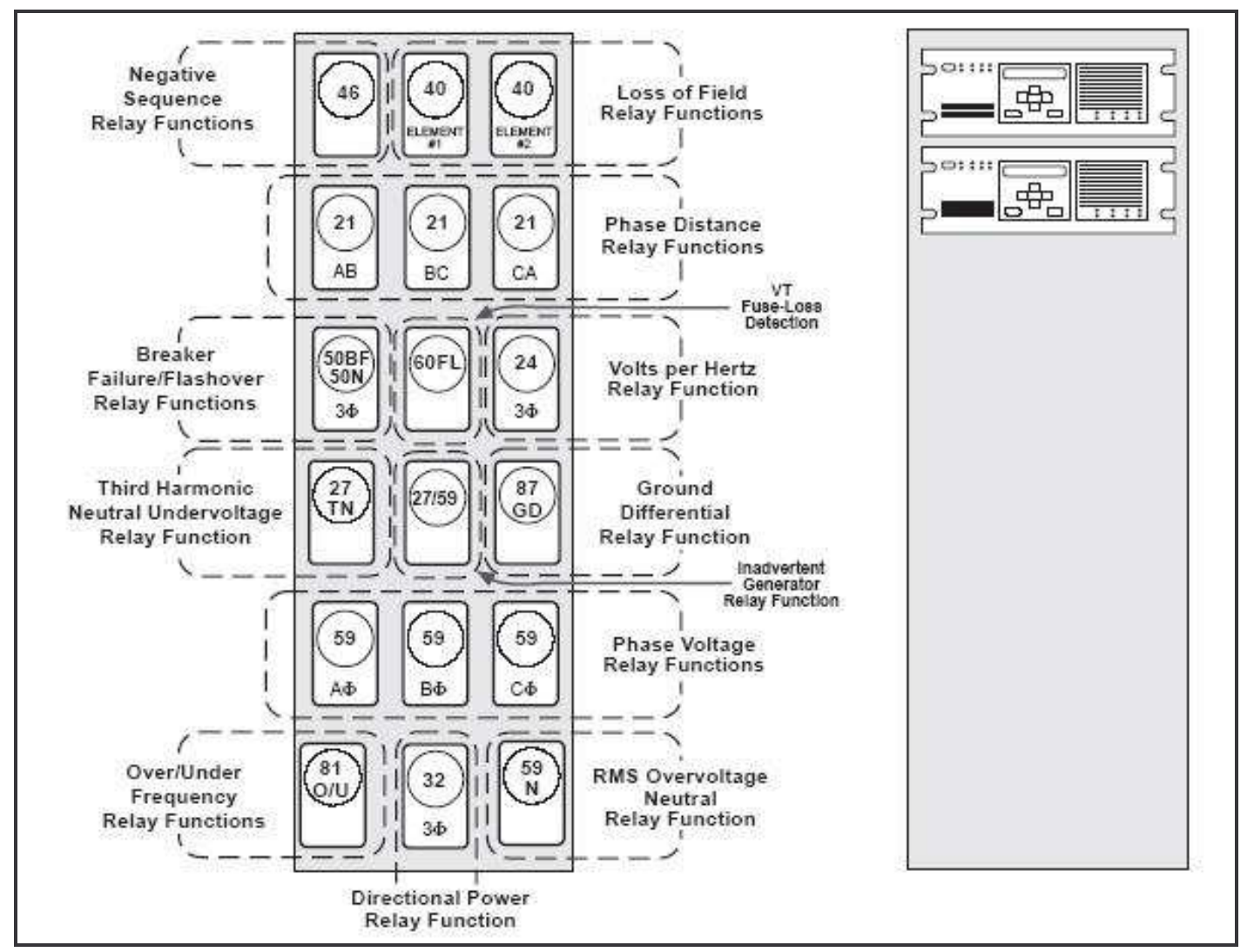

Figura 24 - Painéis de Proteção Eletromecânica e Digital para Geradores [42]

Na referência 42, os autores fazem o seguinte questionamento:

A proteção dual é necessária para os geradores de todo tamanho?

E respondem que não é necessária, pois o tempo MTBF - Mínimo Tempo entre Falhas, para estes tipos de relés, microprocessados, são de 74 anos ou mais, sendo que geradores pequenos podem ser protegidos com apenas um relé digital que contenha todas as funções de proteção necessária para este tipo de máquina.

A proteção dual é justificada quando o custo para o dono do gerador para a perda do mesmo for significante.

Embora a abordagem do trabalho seja referente ao sistema de proteção do da distribuição, o exemplo de proteção de geradores é mostrado a título ilustrativo devido ao fato de que vários coogeradores de energia elétrica estão se conectando aos sistemas de distribuição e os Engenheiros de Proteção devem também realizar os Estudos de Proteção considerando estes tipos de equipamentos. 


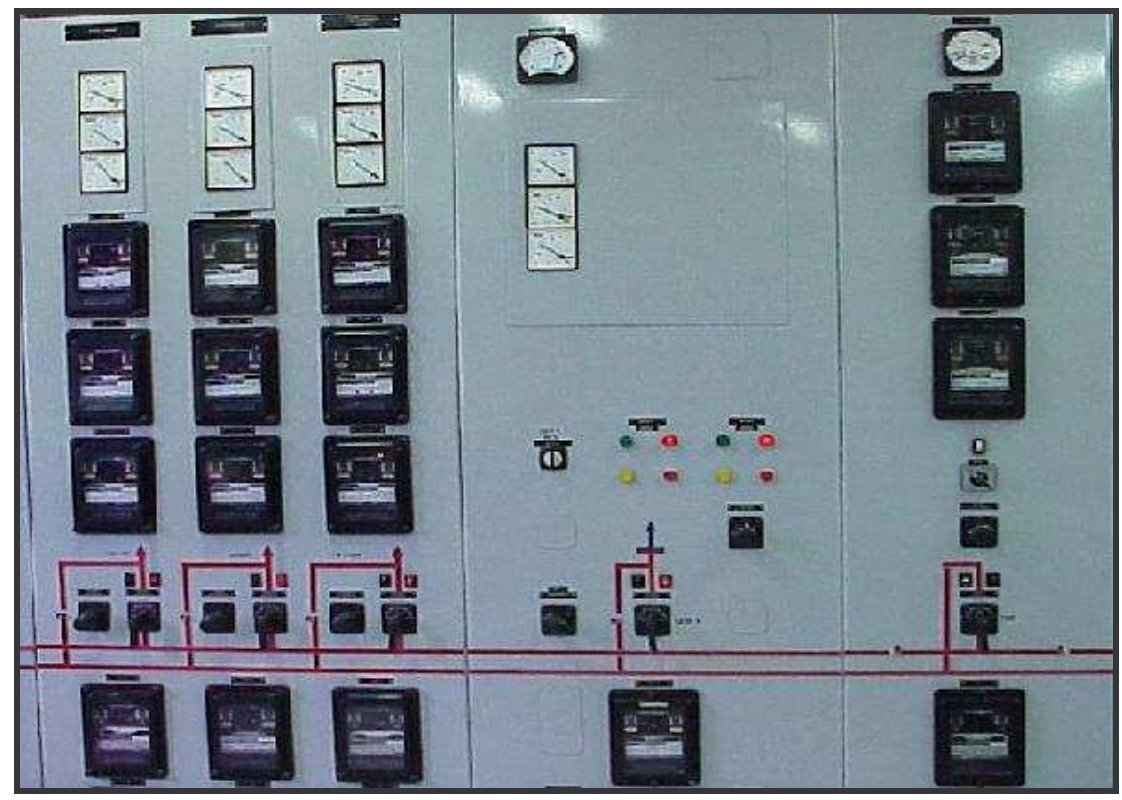

Figura 25 - Painel de Proteção Eletromecânica de Subestação [referência Copel]

Na Figura 25 pode-se visualizar melhor a instalação de relés de proteção eletromecânicos, medidores, chaves de operação, lâmpadas de sinalização e diagrama mímico utilizados para funções específicas de proteção de uma subestação de nível de tensão 138 kV da Copel.

\subsubsection{Requisitos do projeto}

Outra comparação realizada pelo autor na referência [5], diz respeito aos circuitos de alimentação dos relés, com os sinais de corrente, provenientes dos Transformadores de Corrente e de Tensão, provenientes dos Transformadores de Potencial, assim como os esquemas de alimentação em corrente contínua destes dois tipos de relés. Conforme o autor, os circuitos dos esquemas eletromecânicos são mais complexos do que os do esquema com relés microprocessados.

$\mathrm{Na}$ Figura 26 são mostrados os diagramas esquemáticos $A C$ e DC característicos do esquema com relés eletromecânicos. Cada relé deve ser 
ligado aos outros relés para desenvolver o esquema de proteção requerido. Os custos do projeto e da instalação podem ser elevados, devido ao número de pontos de conexão e à relativa complexidade de todo o esquema.

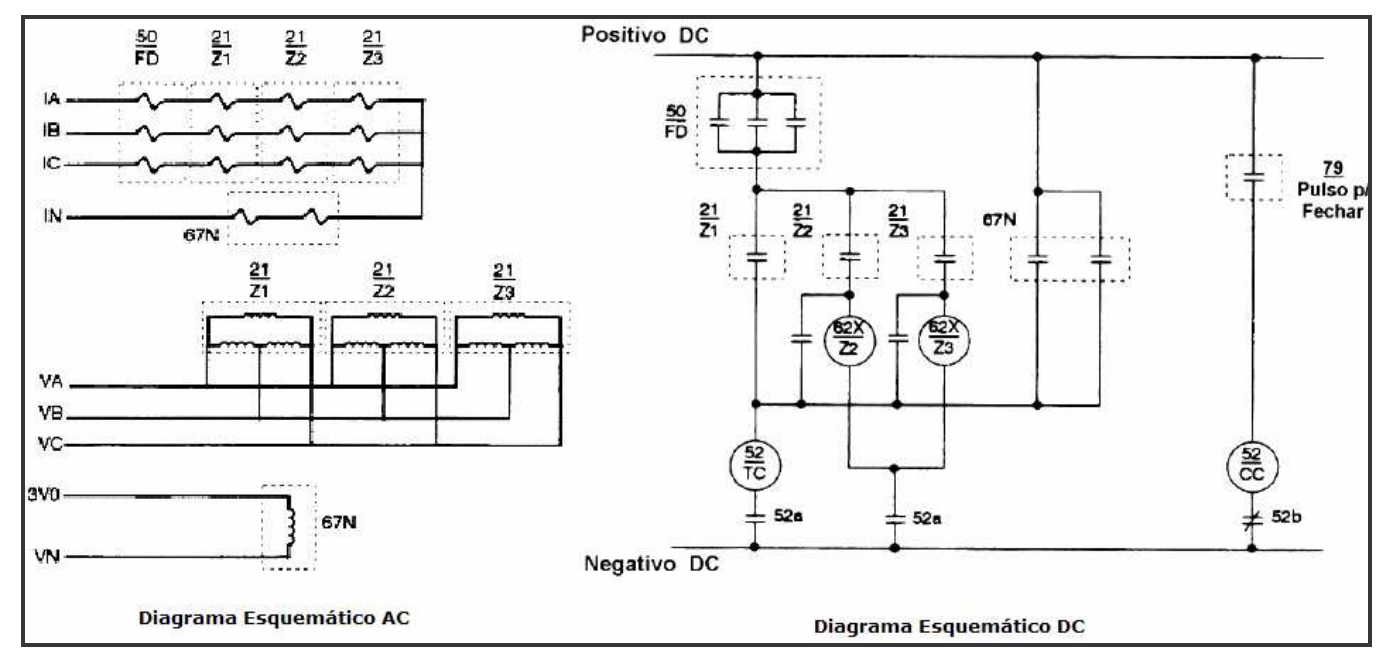

Figura 26 - Diagramas esquemáticos AC e DC de relés eletromecânicos[referência 5\} FONTE: [05] SEL - Schweitzer Engineering Laboratories, Inc. Pullmam. 
A Figura 27 mostra os circuitos AC e DC de um esquema com relés microprocessados. Observa-se que mesmo com a redundância de um relé utilizado para proteção de retaguarda, o número de conexões e a complexidade são muitos pequenos. Em conseqüência, os custos do projeto e da instalação são significantemente reduzidos.

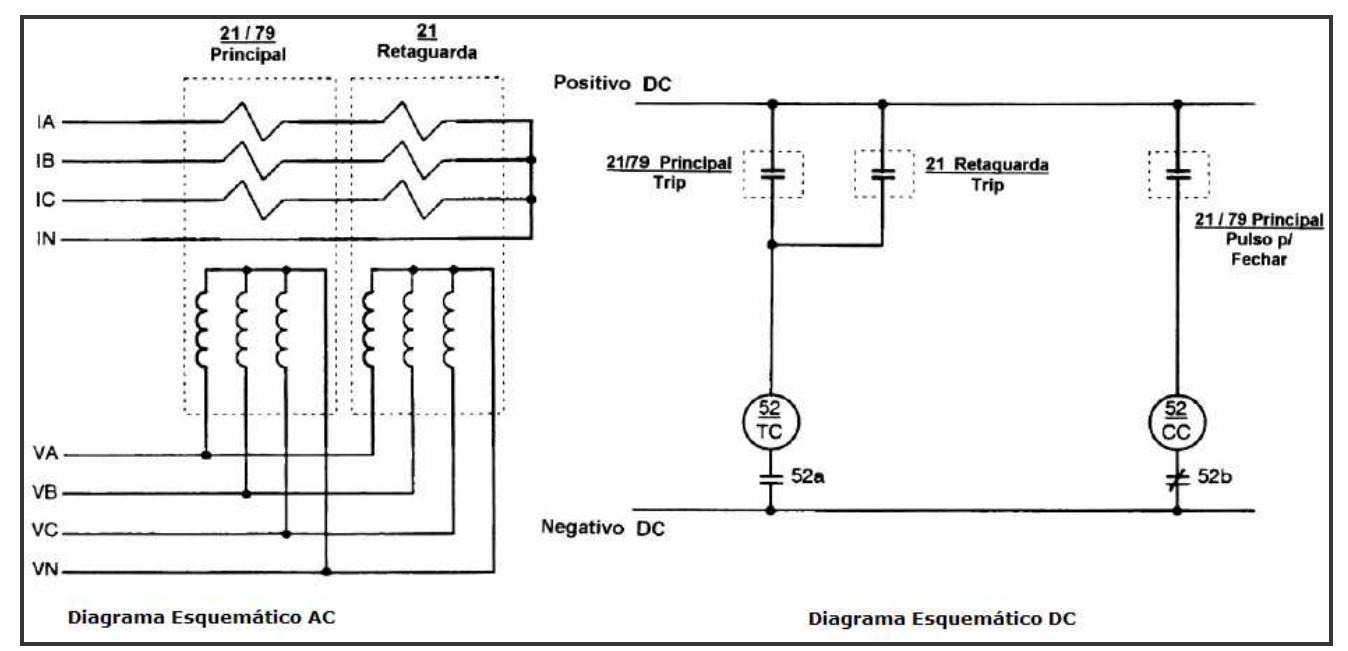

Figura 27 - Diagramas Esquemáticos de AC e DC de relés microprocessados [referência 5] FONTE: [05] SEL - Schweitzer Engineering Laboratories, Inc. Pullmam.

Pela análise do autor da referência [5], se o custo do projeto e instalação do esquema com relés eletromecânicos é 1 p.u., o custo do projeto e instalação do esquema com relés microprocessados é aproximadamente 0,5 p.u.

Dentre as novas características de projeto da proteção digital, podem ser citadas para os sistemas elétricos as seguintes: 
2.8.3 Padronização de curvas de atuação e adaptação a sistemas existentes

A padronização de equipamentos trouxe esta facilidade, sendo que hoje, por exemplo, encontram-se programadas em um relé de sobrecorrente todas as funções dos padrões ANSI/IEEE e IEC e funções de relés eletromecânicos não padronizadas (p.ex., linhas GE-IAC e Westinghouse-CO).

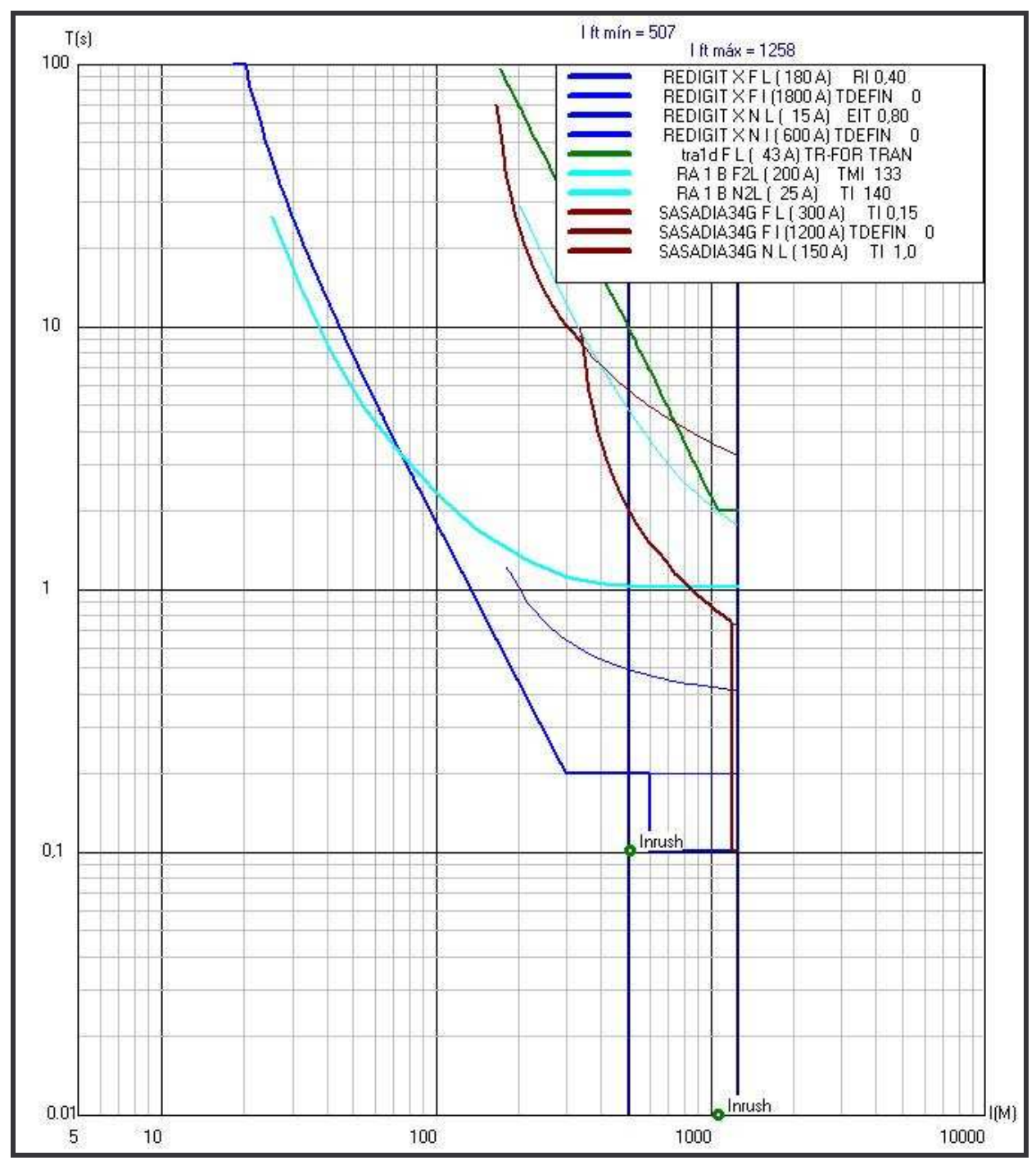

Figura 28 - Curvas de atuação Tempo x Corrente de relés Digitais 
Alguns relés chegam à sofisticação de permitir a programação da curva de atuação ponto a ponto e mais atualmente é possível a inclusão de curvas personalizadas a nível de usuário, isto é o Engenheiro de Proteção pode desenhar a curva tempo x corrente que melhor coordene com os dispositivos de proteção instalados a montante e a jusante do relé que está sendo instalado no sistema elétrico de potência.

\subsubsection{Novos critérios de ajuste}

Com o tratamento mais refinado dos sinais recebidos pelos relés e a utilização de alguns sinais lógicos adicionais permitem, por exemplo, filtrar a corrente de inrush de transformadores e a componente contínua das correntes de curto-circuito e reconhecer a corrente de partida de motores de indução de forma que não são mais necessários as temporizações e aumentos de ajuste comumente utilizados para evitar as atuações indevidas nestes casos.

\subsubsection{Intertravamentos lógicos}

Para composição de esquemas de proteção especiais, as entradas e saídas digitais dos relés digitais permitem a composição quase aleatória de relés de proteção para, por exemplo, montar um esquema de seletividade lógica entre relés de sobrecorrente e conseguir indiretamente a proteção diferencial de barra do painel. Além disso, relés multifunção podem ter suas funções internas combinadas aleatoriamente por meio de programação própria para compor esquemas completos de proteção de equipamentos. 


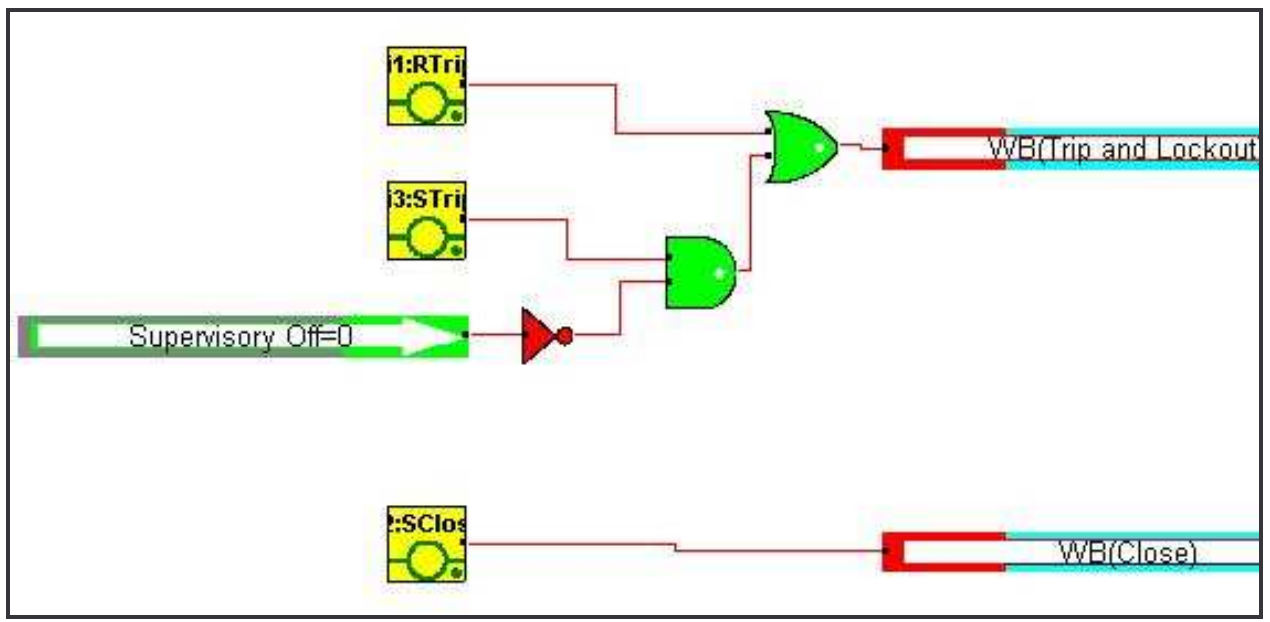

Figura 29 - Exemplo de Esquema Lógico - relé F6 Cooper Power Systems[52]

$\mathrm{Na}$ Figura 29 pode-se visualizar o exemplo de um esquema lógico utilizandos-se variáveis de entrada, diagramas lógicos e sinais de saida.

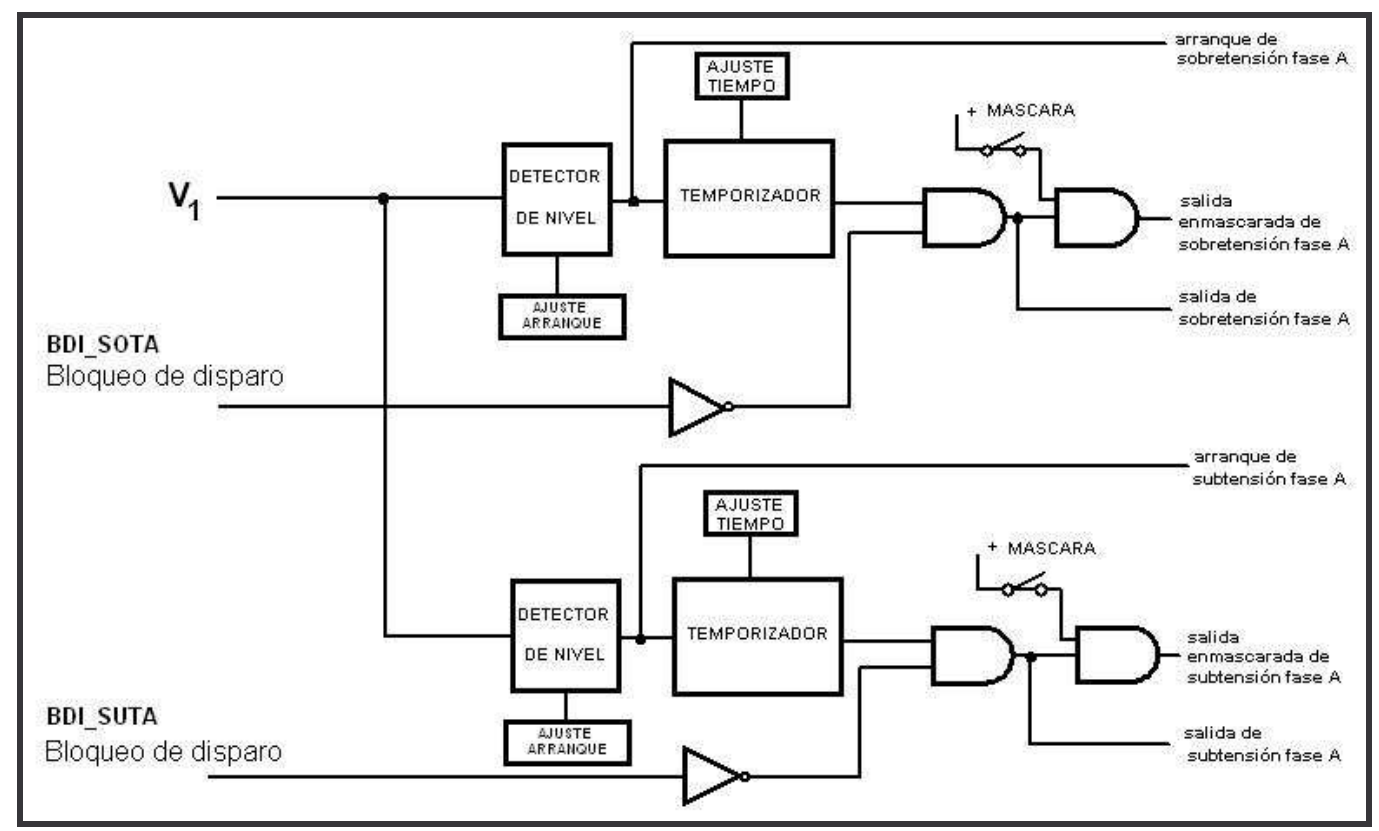

Figura 30 - Lógica Interna de Sub e Sobre Tensão relé IRV [ZIV Espanha]

Na Figura 30, pode-se visualizar uma lógica interna utilizada por um relé digital da ZIV, tipo IRV, onde é mostrada a configuração para execução das funções de sobre e sub tensão utilizadas neste tipo de equipamento. 


\subsubsection{Automonitoramento dos equipamentos e circuitos}

As novas tecnologias de circuitos integrados, circuitos "falha de relé" por exemplo, permitem que se faça o automonitoramento das funções internas do relé e também do circuito de trip do disjuntor. Isto, aliado à facilidade de substituição destes equipamentos, aumenta consideravelmente a confiabilidade e a disponibilidade do sistema de proteção (valor típico de disponibilidade com automonitoramento: 99,97 \%), além de amenizar a necessidade de redundância de sistemas de proteção em aplicações críticas.

Este automonitoramento, conforme pode-se visualizar na Figura 31 e segundo alguns autores, é uma das funções mais importantes que foram implementadas com a tecnologia digital, nos relés de proteção, permitindo com que, através de um sistema de automação, se possa saber se os dispositivos de proteção estão operando adequadamente ou se os mesmos apresentam problemas, permitindo com isto que se acione as equipes de manutenção para prontamente resolver o problema, diminuindo entre outros, o tempo de indisponibilidade da proteção no sistema elétrico.

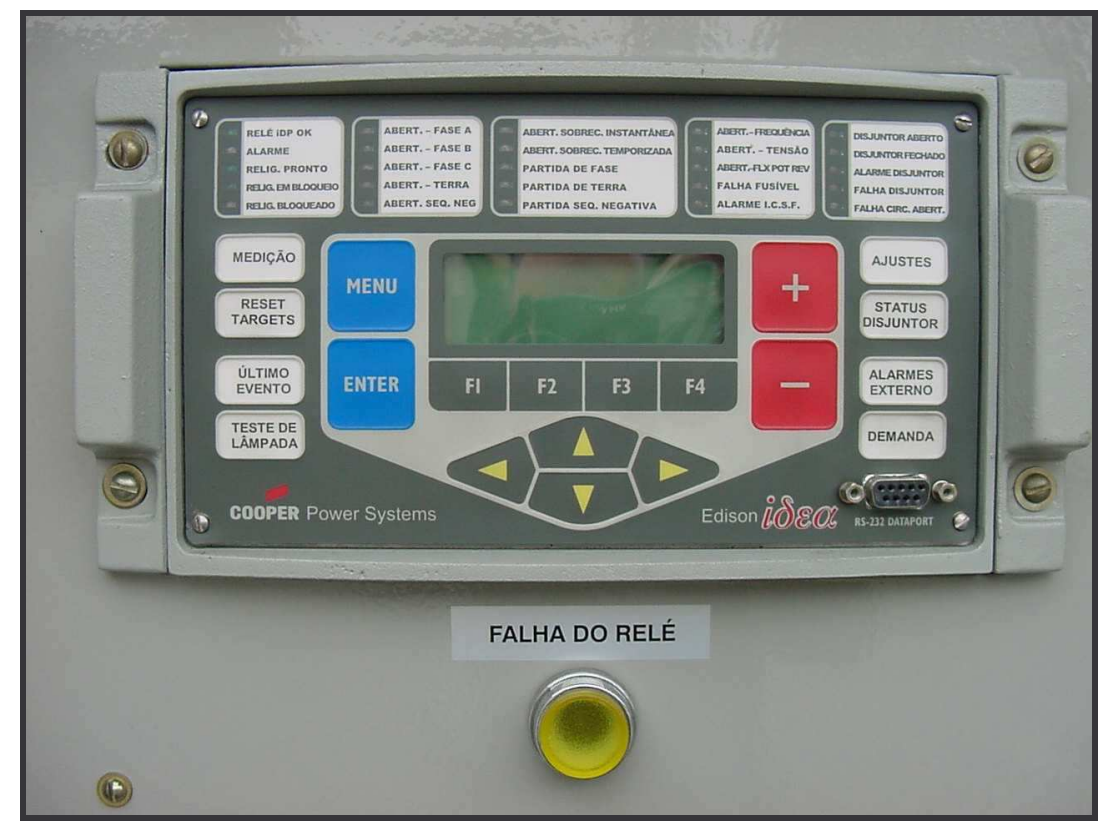

Figura 31 - Automonitoramento de relé IDP-210 [Cooper Power System] 


\subsubsection{Medição, comando e comunicação integrados à proteção}

Os relés hoje são praticamente multi-medidores e mini-CLPs integrados que, aliados à facilidades de comunicação em rede e integração com sistemas supervisores, praticamente eliminam a necessidade de estações remotas e outros equipamentos de medição e comando e permitem realizar funções tais como mudança automática de ajustes (de acordo com a configuração de fontes) e religamento automático de circuitos.

\subsubsection{Requisitos quanto à instalação}

Conforme a referência [1], as instalações de Sistemas Elétricos de Potência também foram bastante beneficiadas, principalmente pela menor dimensão dos equipamentos de proteção e pelo surgimento dos relés multifunção.

Abaixo são citadas as principais mudanças na instalação introduzidas pela proteção digital em sistemas de proteção:

-Compactação e simplificação das instalações - a menor dimensão dos equipamentos e os relés multifunção ocupam menos espaço físico e simplificam o cabeamento do sistema.

-Baixo consumo e menor solicitação de carga de TCs e TPs - pelo baixíssimo consumo de potência do circuito de sinal dos relés digitais, e pela integração entre proteção e medição, os requisitos de carga principalmente sobre os TCs são bastante reduzidos, permitindo assim a utilização de TCs de núcleo reduzido e de baixa corrente nominal mesmo em instalações com nível de curto-circuito elevado

Contudo, a proteção digital possui requisitos de instalação antes inexistentes 
na tecnologia eletromecânica:

-Cabeamento de comunicações - necessário para a interligação entre relés e com o sistema supervisor, possui um grau de dificuldade de instalação maior por utilizar infra-estrutura sofisticada (fibras óticas, interfaces optoeletrônicas) e por se estender em muitos casos por toda a instalação.

-Fonte de alimentação estabilizada e ininterrupta - necessária para a alimentação do sistema de proteção, requer um sistema "no-break" de retificador/ inversor e bancos de baterias dedicados. Existem relés autoalimentados pelos TCs e TPs, porém a prática tem sido prover uma fonte independente do circuito principal para maior confiabilidade.

\begin{abstract}
-Aterramento - os relés digitais, por serem equipamentos sensíveis e por muitas vezes estarem interligados com equipamentos distantes, requerem uma série de cuidados no seu aterramento que devem ser respeitados sob pena de falha de atuação e/ou atuação indevida do equipamento.
\end{abstract}

Em comparação com os benefícios trazidos pelos relés digitais, os novos requisitos não devem ser encarados como empecilho para a sua aplicação.

\title{
2.8.9 Requisitos quanto a testes
}

\subsubsection{Testes de instalação}

Na referência [5], o autor informa que testes de instalação são utilizados para verificar se os relés estão ajustados corretamente, e se o esquema está executado corretamente para a aplicação projetada. Testes de rotina são realizados para assegurar que os relés estejam funcionando dentro das especificações definidas.

O autor esclarece que em um esquema executado com relés eletromecânicos requer um grande número de testes durante a instalação, 
para verificar se todo o esquema está funcionando corretamente. Cada relé deve ser testado e calibrado separadamente.

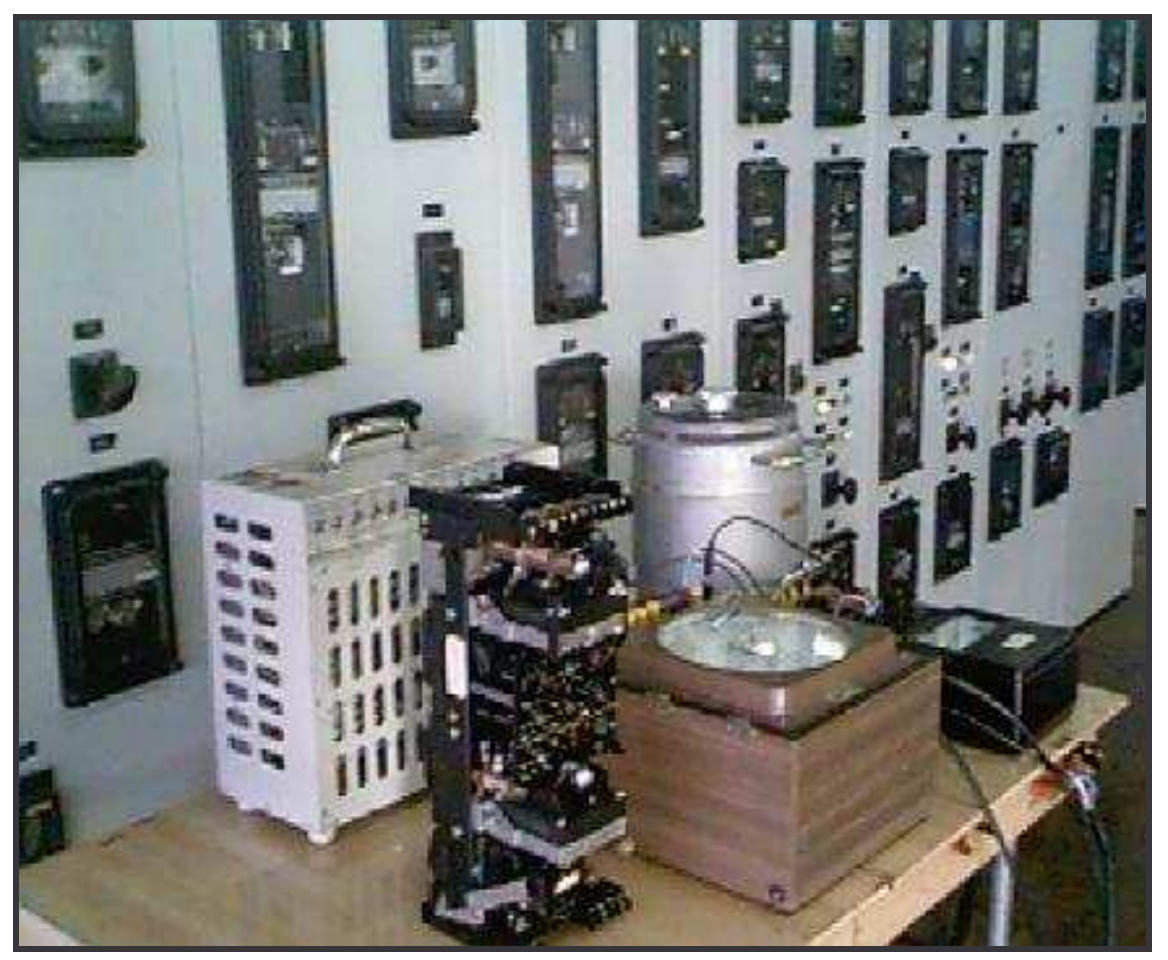

Figura 32 - Testes de Calibração e Recebimento em relés Eletromecânicos [referência Copel]

Na Figura 32 pode-se verificar um esquema para a realização de testes de calibração e recebimento em um painel de Proteção em uma Subestação da Copel, com vários relés eletromecânicos, cada um executando uma função de proteção separada e específica. Pode-se visualizar a quantidade de equipamentos analógicos e fontes, utilizados para a realização destes testes, o que pode acarretar na inclusão de erros de calibração, pela quantidade de variáveis que devem ser controladas por uma pessoa.

O autor da referência [5], mostra um exemplo do esquema de distância com zonas temporizadas onde pelo menos sete relés distintos devem ser testados. O teste de cada relé requer que o mesmo seja conectado a um equipamento de testes, vários ajustes sejam efetuados, e então o relé é testado por uma rotina de testes preestabelecida. Se os resultados dos testes no relé estiverem fora dos padrões estabelecidos, o relé tem que ser 
calibrado. A rotina de calibração pode consumir muito tempo de trabalho.

Um esquema com relés microprocessados é muito simples de testar e verificar. Para realização dos referidos testes, são utilizados um software específico para realização e verificação de suas funções e uma mala de testes digital.

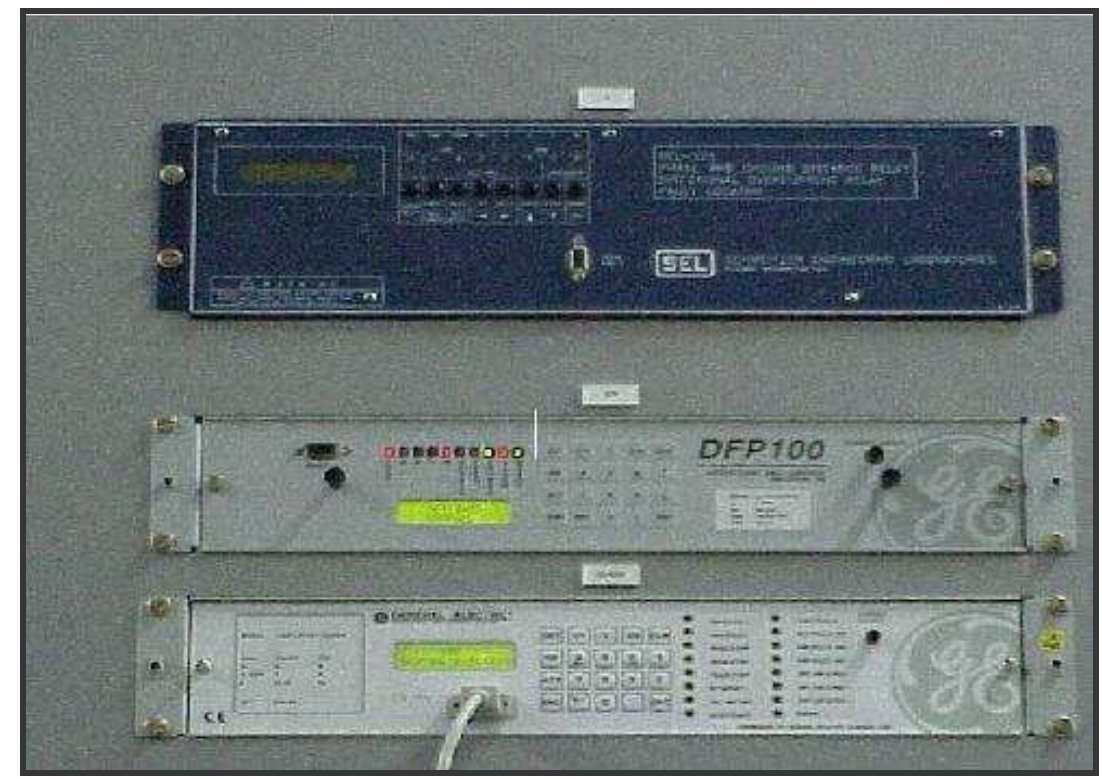

Figura 33 - Realização de Testes em Relés Digitais [referência Copel]

$\mathrm{Na}$ Figura 33 pode-se visualizar a realização de testes de recebimento em um painel de Subestação da Copel onde estão instalados relés de proteção digitais.

A operação das várias funções e lógicas é completamente verificada e testada pelo fabricante do relé durante a fase de fabricação. Em muitos casos, a empresa de energia elétrica também realiza testes nos relés para verificar se o mesmo está de acordo com as especificações apresentadas pelo fabricante e pelas especificações da empresa de energia. 


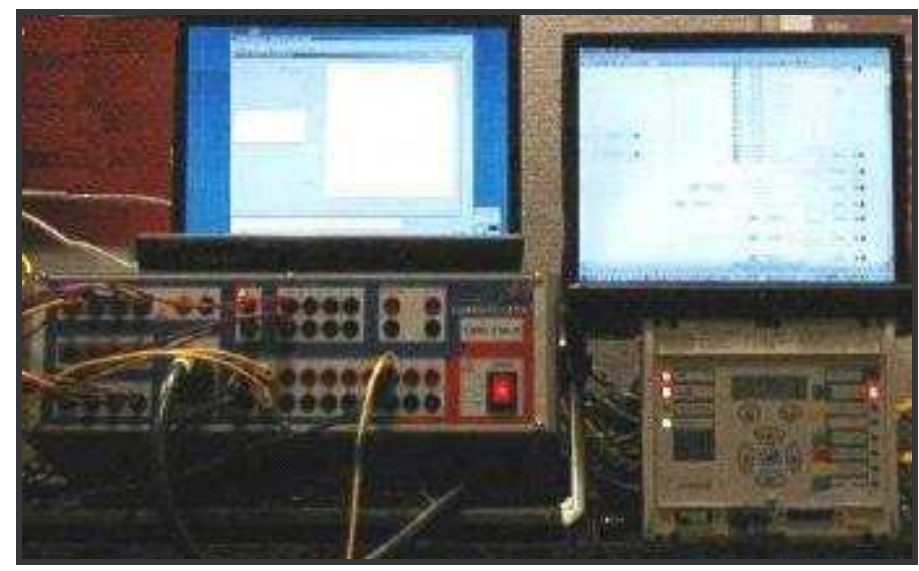

Figura 34 - Testes Automatizados em relés Digitais

Uma vez que o relé foi completamente testado, o software que define as suas características de operação foi verificado. Logo, não é preciso testar completamente cada relé, admitindo-se que os relés são do mesmo tipo e versão de software.[5].

\subsubsection{Testes de rotina}

Outra citação da referência [5] é quanto aos testes de rotina têm que ser executados em relés eletromecânicos para verificar se eles estão operando dentro dos padrões especificados. Esses testes podem ser efetuados em intervalos de um a três anos para relés de distância, baseando-se na prática da empresa em particular. Os testes de rotina executados em um relé eletromecânico são muito similares àqueles efetuados durante o processo de instalação.

Para os relés relés microprocessados, o autor esclarece que os mesmos executam autotestes de rotina ("routine self-checks") para assegurar que os circuitos críticos do relé estejam funcionando corretamente.

Os relés microprocessados executam continuamente as mesmas rotinas do software. Logo, se o relé está funcionando corretamente, os algoritmos do relé irão operar corretamente.

Admitindo-se que o relé microprocessado contenha autotestes suficientes e que um sistema comum de aquisição de dados é usado para a proteção 
assim como para a medição, a manutenção de rotina pode ser significantemente reduzida. Muitas empresas têm prolongado o ciclo de manutenção de rotina de relés microprocessados, de uma e uma e meia para três vezes o ciclo usado nos relés eletromecânicos.[5].

\subsubsection{Redução significativa da manutenção}

$\mathrm{Na}$ referência [48], o autor faz uma descrição sobre os relés microprocessados, também chamados relés digitais que consistem tipicamente de um sistema de aquisição de dados em $A C$, um microprocessador, componentes de memória contendo os algoritmos de relés, contatos de entradas lógicas para controlar o relé e contatos de saída para controle de outros equipamentos. A Figura 35 mostra um diagrama de blocos simples de hardware.

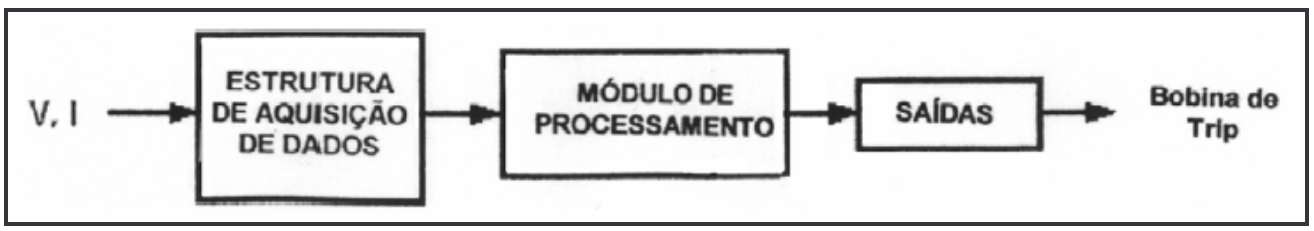

Figura 35 - Diagrama em Blocos de um relé Digital [ referência 48]

FONTE: [46] SEL - Schweitzer Engineering Laboratories

As entradas de tensão e corrente são isoladas, filtradas e amostradas. Então elas são colocadas em escala e convertidas em quantidades digitais para o microprocessador. O programa do microprocessador filtra os dados, cria as características do relé e controla as saídas do relé.

A maioria dos relés digitais tem funções automáticas de autoteste que verificam a correta operação do relé. Virtualmente tudo no relé é submetido ao autoteste exceto as entradas analógicas e os circuitos dos contatos de entrada e saída. Se o autoteste detecta uma condição anormal, ele pode fechar um contato de saída, enviar uma mensagem, ou fornecer alguma 
outra indicação de falha.

Neste parágrafo da referência [48], o autor informa que se pode conectar a saída do alarme do auto-teste ao sistema SCADA RTU (Supervisory Control And Data Acquisition Remote Terminal Unit) ou outro ponto de monitoração para que rapidamente seja enviado um técnico para reparar ou substituir o dispositivo. Logo, quando se testa um relé digital, precisa-se somente testar o que é necessário. Isto usualmente consiste em fazer uma verificação das medições através de uma porta de comunicação, verificando se as saídas estão operando.

O autor esclarece na referência [48], que comparando-se isto a um esquema tradicional pode-se ter:

-Para um alimentador típico com quatro relés de sobrecorrente eletromecânicos, se levar aproximadamente uma hora para testar cada relé, serão necessárias quatro horas para testar os relés do alimentador.

-Para uma subestação com quatro alimentadores, levaria aproximadamente dois dias para testar os relés.

-Um típico relé microprocessado, com simples verificações das medições das tensões e correntes de entrada e verificações das saídas de disparo, leva menos do que uma hora para testar.

-Para uma subestação com quatro alimentadores, um técnico pode testar todos os relés da barra em quatro horas, sobrando tempo para outros testes importantes. 


\subsection{APLICAÇÕES DOS RELÉS MICROPROCESSADOS}

Os relés microprocessados podem ser utilizados em todas as aplicações onde relés eletromecânicos são normalmente utilizados.

2.9.1 Modernização dos esquemas de Proteção com relés mais antigos Conforme a referência [5], quando os relés eletromecânicos estiverem falhando ou necessitando de uma manutenção intensiva, sua substituição pode ser economicamente justificada. Os relés microprocessados são perfeitos para substituir sistemas de proteção existentes. $O$ relé microprocessado utiliza muito menos espaço no painel do que os relés eletromecânicos existentes. Os esquemas e os princípios de operação são quase idênticos. A fiação é simplificada e pode ser facilmente modificada para acomodar o novo relé.

O custo da substituição é também muito baixo com relação à substituição de todos ou, em alguns casos, até de um relé eletromecânico.

\subsubsection{Novas instalações}

O autor da referência [5] esclarece que, quando da construção de novas subestações, é muito fácil a justificativa do uso de relés microprocessados. Eles são muitos atrativos no que se refere ao custo e podem ser integrados em qualquer esquema ou filosofia de proteção. Reduzir a fiação do painel e a necessidade de espaço pode também resultar na economia do custo quando da construção. 


\section{NOVAS FUNÇÕES INCORPORADAS NOS RELÉS DIGITAIS}

\subsubsection{Esquemas com auxílio da comunicação}

Outro benefício ou facilidade mencionada na referência [5] por Mooney é que muitos relés microprocessados incluem um esquema lógico de comunicação. Em muitos casos, os relés incluem toda a lógica requerida para operar um esquema específico com o suporte da comunicação. Isso economiza os custos do projeto e do material, uma vez que relés auxiliares externos não são necessários para a operação do esquema. $O$ relé microprocessado também inclui muito da lógica que estaria aprovisionada no equipamento de comunicação. Utilizar a lógica interna do relé pode reduzir o custo do equipamento de comunicação, uma vez que módulos extras podem não ser necessários.

O relé também oferece uma seleção de diferentes esquemas de abertura usando a comunicação. Isso significa que você pode padronizar um relé para todas as aplicações.

\subsubsection{Múltiplos Grupos de Ajuste}

A maioria dos relés digitais utilizados em esquemas de proteção possuem múltipos grupos de ajustes, normalmente estes ajustes podem ser trocados nas estações de alimentação sem o envio de um técnico.

Este tipo de característica permite ao Engenheiro de Proteção realizar múltiplos ajustes num mesmo relé de proteção, dependo da configuração do sistema. Como por exemplo, nos circuito da Copel, onde se conectam autoprodutores de energia elétrica, umas das características que os relés instalados nos locais de conexão, é de possuir múltiplos ajustes, onde se pode realizar os ajustes dependendo da quantidade de máquinas que o 
autoprodutor estará utilizando quando paralelado ao sistema, quando a sua $\mathrm{PCH}$ ou PCT possuir mais do que um gerador, permitindo com isto que as proteções sejam ajustadas de acordo com as configurações originais do sistema em cada instante.

\begin{tabular}{|c|c|c|c|c|}
\hline Overcurrent Settings & Normal & Alternate 1 & Alternate 2 & Alternate 3 \\
\hline \multicolumn{5}{|l|}{ Phase: } \\
\hline PhsTripBlk & Unblocked & Unblocked & Unblocked & Unblocked \\
\hline FastTripBlock & Unblocked & Unblocked & Unblocked & Unblocked \\
\hline TCCPMinTrip & 100 & 100 & 100 & 100 \\
\hline TCC1PCurve & 104 & 104 & 104 & 104 \\
\hline TCC1PMultEnable & Disable & Disable & Disable & Disable \\
\hline TCC1PMult & 1 & 1 & 1 & 1 \\
\hline TCC1PAddEnable & Disable & Disable & Disable & Disable \\
\hline TCC1PAdd & 0 & 0 & 0 & 0 \\
\hline TCC1PMRTAEnable & Disable & Disable & Disable & Disable \\
\hline TCC1PMRTA & 0.013 & 0.013 & 0.013 & 0.013 \\
\hline TCC1PHCTEnable & Disable & Disable & Disable & Disable \\
\hline TCC1PHCT Mul & 32 & 32 & 32 & 32 \\
\hline TCC1PHCTDly & 0.016 & 0.016 & 0.016 & 0.016 \\
\hline
\end{tabular}

Figura 36 - Tela de Grupos de Ajuste - relé F6 [ referência Cooper Power Systems]

$\mathrm{Na}$ Figura 36 pode-se visualizar um exemplo de relé digital que possui múltiplos grupos de ajuste, referência [52], onde é possível realizar ajustes distintos para todas as funções incorporadas a este tipo de relé.

\subsubsection{Protocolos de Comunicação}

Segundo a referência [10], devido à modernização do sistema elétrico e a digitalização dos centros de geração e distribuição de energia, tornou-se necessário fazer uso se novas tecnologias de comunicação de dados.

Nas subestações convencionais, a operação e controle eram feitos localmente, hoje é possível interagir com o sistema a quilômetros de distância. Com o uso dos protocolos de comunicação tornou-se possível a implementação de subestações totalmente desassistidas, controladas por um ou mais centros de operação, remotamente. 
O uso dos protocolos de comunicação também tornou possível a interligação entre equipamentos de controle, proteção e registros de dados dentro de uma subestação, bem como a interligação entre subestações, usinas geradoras e o operador nacional de sistemas.

Os protocolos de comunicação possibilitam diversas arquiteturas de comunicação: balanceada/não balanceada comunicação ponto a ponto, multiponto, multiponto em estrela, etc. A escolha da arquitetura é geralmente definida pela própria concessionária de energia e leva em consideração a importância da instalação no sistema elétrico, bem como as características dos centros de operação.

Muitos protocolos são usados hoje em dia. Cada um com diferenças que definem a filosofia de aplicação em que será usado e cabe à concessionária definir pelo qual optar, como também definir o perfil que deverá ser implementado.

Os principais protocolos comumente utilizados na área elétrica são o IEC870-5-101, DNP3.0, Modbus, Procome e IEC61850.

Na referência [53], os autores informam que após avaliações realizadas nos protocolos de comunicação existentes, ficou definido o protocolo DNP 3.0 a ser utilizado nos relés digitais do sistema da Copel. 


\subsubsection{Registro de eventos}

A maioria dos relés microprocessados registra as condições do sistema quando os elementos de proteção operam ou quando da ocorrência de condições definidas pelo usuário. São normalmente registrados os valores das correntes e tensões durante uma pré-falta e durante a falta que ocorra no sistema elétrico.

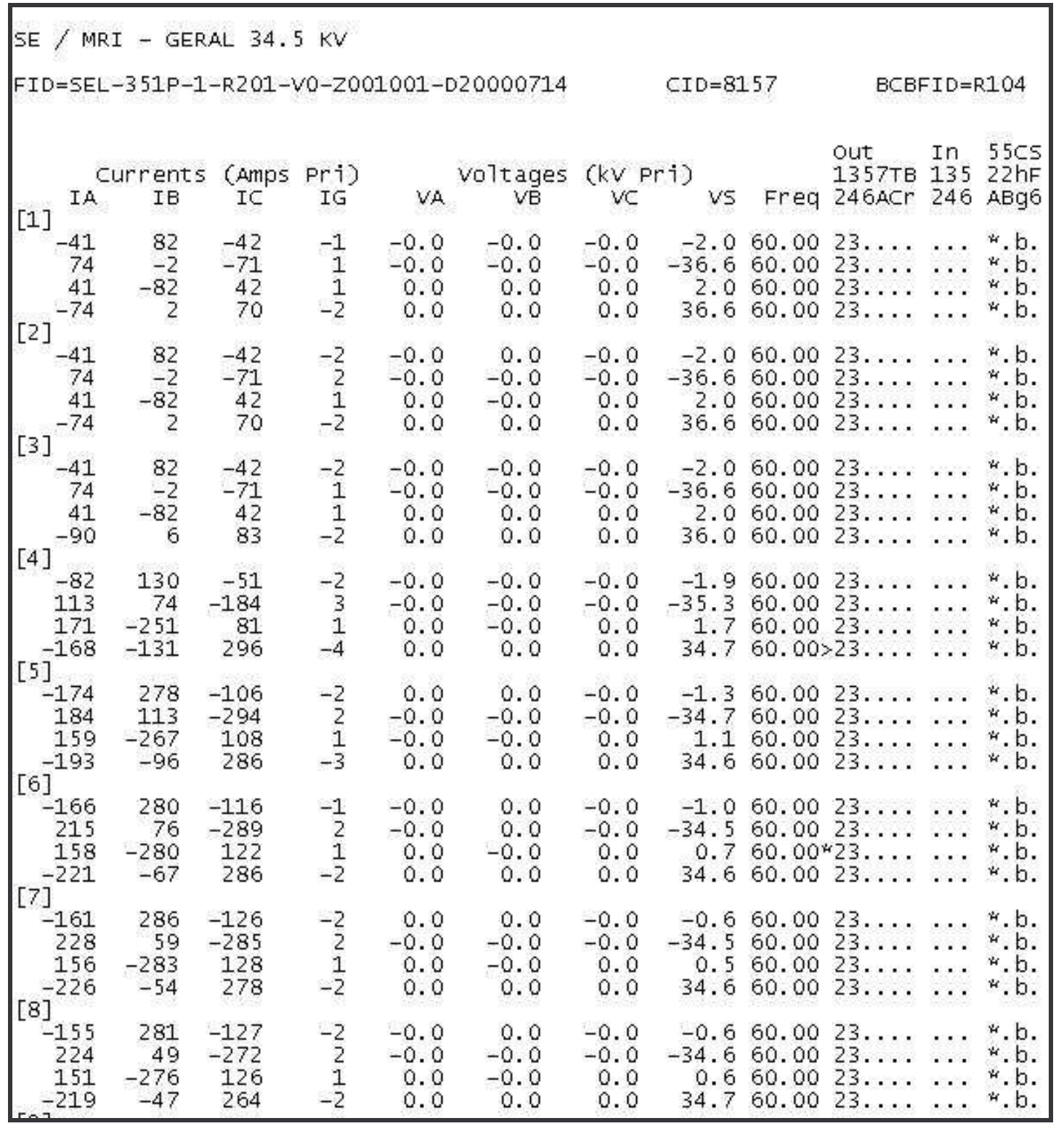

Figura 37 - Relatório de Eventos de um relé digital 351P - Whipp\&Bourne

Na Figura 37 pode-se visualizar um relatório de eventos de um relé digital da 
SEL, modelo 351P, onde se verificam as correntes, tensões, frequência e condições das saídas e entradas do relé. Estes dados são de grande valia para análises das atuações das proteções, quais unidades atuaram, quais contatos fecharam, tempo de atuação das unidades ajustadas no relé, etc.

$\mathrm{O}$ registro de eventos pode também mostrar problemas nas entradas e saídas de controle. Analisar os registros de eventos pode também fornecer valiosas informações na condução de se efetuar melhorias em todo o esquema de proteção.

Na referência [54], os autores informam que os registradores de seqüência de eventos e oscilogramas geralmente são considerados como muito caros para aplicações na distribuição. Um operador experiente deve interpretar a saída do oscilograma. 


\begin{tabular}{|c|c|c|c|}
\hline $\begin{array}{l}308 \\
307 \\
306 \\
305 \\
304 \\
303 \\
302 \\
301 \\
300 \\
299 \\
298 \\
297 \\
296 \\
295 \\
294 \\
293 \\
292 \\
291 \\
290 \\
289 \\
288 \\
287 \\
286 \\
285 \\
284 \\
283 \\
282 \\
281 \\
280 \\
279 \\
278 \\
277 \\
276 \\
275 \\
274 \\
273 \\
272 \\
271 \\
270 \\
269 \\
268 \\
267 \\
266 \\
265 \\
264 \\
263 \\
262 \\
261 \\
260 \\
259 \\
258\end{array}$ & $\begin{array}{l}12 / 17 / 01 \\
12 / 17 / 01 \\
12 / 17 / 01 \\
12 / 17 / 01 \\
12 / 17 / 01 \\
12 / 17 / 01 \\
12 / 17 / 01 \\
12 / 17 / 01 \\
12 / 17 / 01 \\
12 / 17 / 01 \\
12 / 17 / 01 \\
12 / 17 / 01 \\
12 / 17 / 01 \\
12 / 17 / 01 \\
12 / 17 / 01 \\
12 / 17 / 01 \\
12 / 17 / 01 \\
12 / 17 / 01 \\
12 / 17 / 01 \\
12 / 17 / 01 \\
12 / 17 / 01 \\
12 / 17 / 01 \\
12 / 17 / 01 \\
12 / 17 / 01 \\
12 / 17 / 01 \\
12 / 17 / 01 \\
12 / 17 / 01 \\
12 / 17 / 01 \\
12 / 17 / 01 \\
12 / 17 / 01 \\
12 / 17 / 01 \\
12 / 17 / 01 \\
12 / 17 / 01 \\
12 / 17 / 01 \\
12 / 17 / 01 \\
12 / 17 / 01 \\
12 / 17 / 01 \\
12 / 17 / 01 \\
12 / 17 / 01 \\
12 / 17 / 01 \\
12 / 17 / 01 \\
12 / 17 / 01 \\
12 / 17 / 01 \\
12 / 17 / 01 \\
12 / 17 / 01 \\
12 / 17 / 01 \\
12 / 17 / 01 \\
12 / 17 / 01 \\
12 / 17 / 01 \\
12 / 17 / 01 \\
12 / 17 / 01\end{array}$ & $\begin{array}{l}12: 59: 38.840 \\
12: 59: 38.957 \\
12: 59: 38.957 \\
13: 00: 32.788 \\
13: 00: 32.821 \\
13: 00: 32.855 \\
13: 10: 31.847 \\
13: 10: 31.960 \\
13: 10: 31.960 \\
13: 10: 46.253 \\
13: 10: 46.286 \\
13: 10: 46.320 \\
13: 20: 09.991 \\
13: 20: 10.099 \\
13: 20: 10.099 \\
16: 30: 07.633 \\
16: 30: 07.666 \\
16: 30: 07.699 \\
16: 32: 32.283 \\
16: 32: 32.392 \\
16: 32: 32.392 \\
16: 36: 18.285 \\
16: 36: 18.319 \\
16: 36: 18.352 \\
16: 41: 20.246 \\
16: 41: 20.359 \\
16: 41: 20.359 \\
16: 41: 26.805 \\
16: 41: 26.839 \\
16: 41: 26.872 \\
16: 42: 49.607 \\
16: 42: 49.715 \\
16: 42: 49.715 \\
16: 44: 21.305 \\
16: 44: 21.339 \\
16: 44: 21.372 \\
16: 45: 33.335 \\
16: 45: 33.443 \\
16: 45: 33.443 \\
17: 02: 19.867 \\
17: 02: 19.901 \\
17: 02: 19.934 \\
17: 02: 51.183 \\
17: 02: 51.250 \\
17: 02: 59.155 \\
17: 02: 59.222 \\
17: 03: 41.127 \\
17: 03: 41.194 \\
17: 04: 21.457 \\
17: 04: 21.523 \\
17: 05: 18.276\end{array}$ & $\begin{array}{l}\text { CLOSE } \\
\text { CLOSE } \\
52 \mathrm{~A} \\
\text { TRIP } \\
52 \mathrm{~A} \\
\text { TRIP } \\
\text { CLOSE } \\
\text { CLOSE } \\
52 \mathrm{~A} \\
\text { TRIP } \\
52 \mathrm{~A} \\
\text { TRIP } \\
\text { CLOSE } \\
\text { CLOSE } \\
52 \mathrm{~A} \\
\text { TRIP } \\
52 \mathrm{~A} \\
\text { TRIP } \\
\text { CLOSE } \\
\text { CLOSE } \\
52 \mathrm{~A} \\
\text { TRIP } \\
52 \mathrm{~A} \\
\text { TRIP } \\
\text { CLOSE } \\
\text { CLOSE } \\
52 \mathrm{~A} \\
\text { TRIP } \\
52 \mathrm{~A} \\
\text { TRIP } \\
\text { CLOSE } \\
\text { CLOSE } \\
52 \mathrm{~A} \\
\text { TRIP } \\
52 \mathrm{~A} \\
\text { TRIP } \\
\text { CLOSE } \\
\text { CLOSE } \\
52 \mathrm{~A} \\
\text { TRIP } \\
52 \mathrm{~A} \\
\text { TRIP } \\
\text { TRIP } \\
\text { TRIP } \\
\text { TRIP } \\
\text { TRIP } \\
\text { TRIP } \\
\text { TRIP } \\
\text { TRIP } \\
\text { TRIP } \\
\text { CLOSE }\end{array}$ \\
\hline
\end{tabular}

Figura 38 - Registro de Seqüência de Eventos relé 351P Whipp\&Bourne

Na Figura 38 pode-se visualizar uma listagem - sequência de eventos geradas por um relé digital de proteção que se encontra instalado em um circuito de distribuição de 13,8 kV da Copel. Pode-se perceber que são registradas todas as operações realizadas pelo relé ou externas a ele, desde que sejam previamente programadas na lógica do sequenciador de eventos. Este tipo de relatório oferece ao analista de proteção muitas informações importantes para que se descubra que tipo de atuação ocorreu no sistema elétrico e se o relé operou corretamente, assim como também o relé pode mostrar as operações realizadas a nível local ou remotamente, que posteriormente poderão ser analisadas. 
Os engenheiros agora recuperam relatórios de eventos rapidamente de relés de distribuição avançados através de modem telefônico e analisam cada operação. Relatórios de eventos simplificam a análise de eventos, combinando correntes, tensões, elementos de relé e entrada/saída de contato em um relatório.[54]

\subsubsection{Geração e Análise de Oscilografia}

Outra função que merece destaque nos relés digitais de proteção é a oscilografia digital incorporada. Esta oscilografia anteriormente era realizada apenas pelos equipamentos chamados de Oscilo perturbografos, os quais eram instalados em pontos estratégicos do sistema elétrico de potência, funcionavam com fitas magnéticas, onde eram registrados os sinais provenientes dos relés de proteção e de outros dispositivos do sitema elétrico.

Os dados gerados pelas oscilografias dos relés digitais são utilizados nas análises de atuações do sistema de proteção, após a ocorrência dos defeitos. Esta função tem por objetivo o registro de ciclos de grandezas analógicas em caso de falta, armazenando alguns ciclos em condição de pré-falta e outros ciclos em condição de pós-falta.

Nas Figura 39 e Figura 40 pode-se visualizar duas oscilografias geradas por relés de fabicantes distintos, onde são mostrados sinais analógicos ( tensões e correntes) e sinais digitais ( entradas e saídas de relés). 


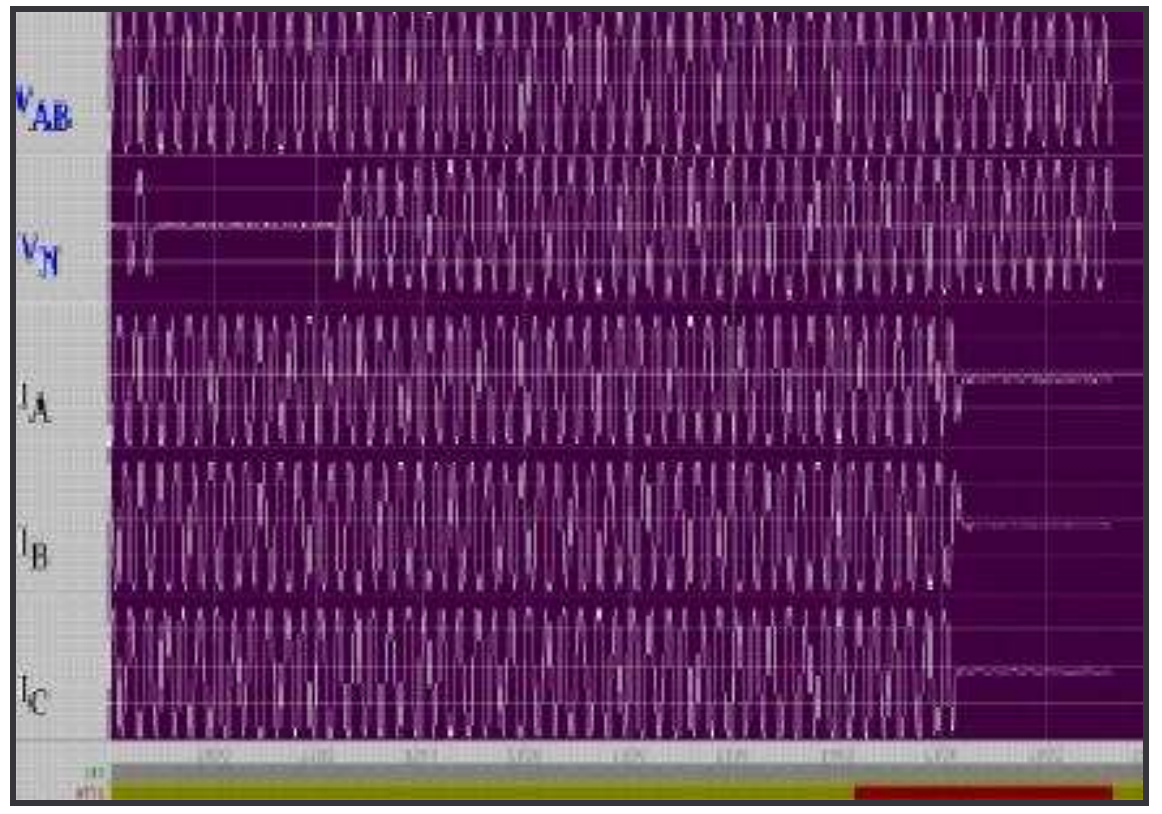

Figura 39 - Oscilografia de um relé digital - falta no neutro - referência[43]

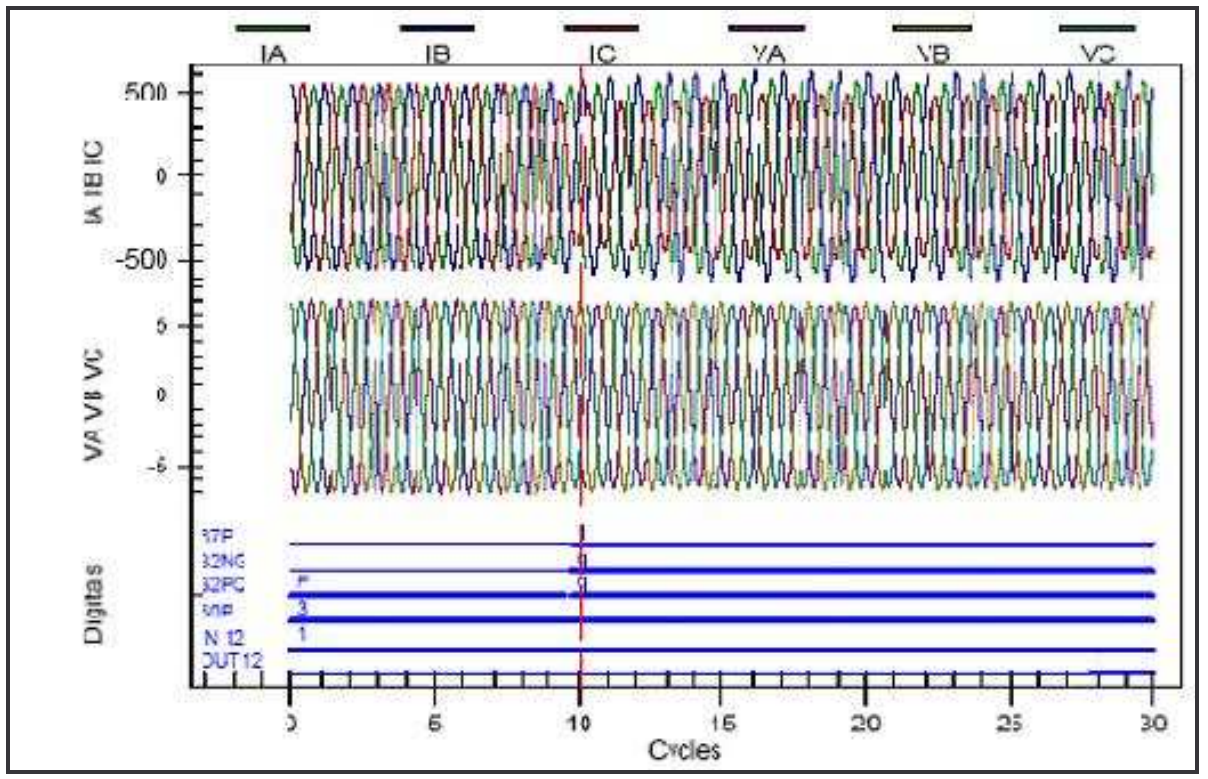

Figura 40 - Oscilografia de Tensões, Correntes e Sinais Digitais - relé SEL 
Conforme referência 43, na Figura 41, pode-se visualizar a oscilografia de um defeito entre fases, onde é possível observar a elevação dos valores das correntes IA, IB, IC e IN. Verifica-se também a elevação do potencial da tensão no neutro VN.

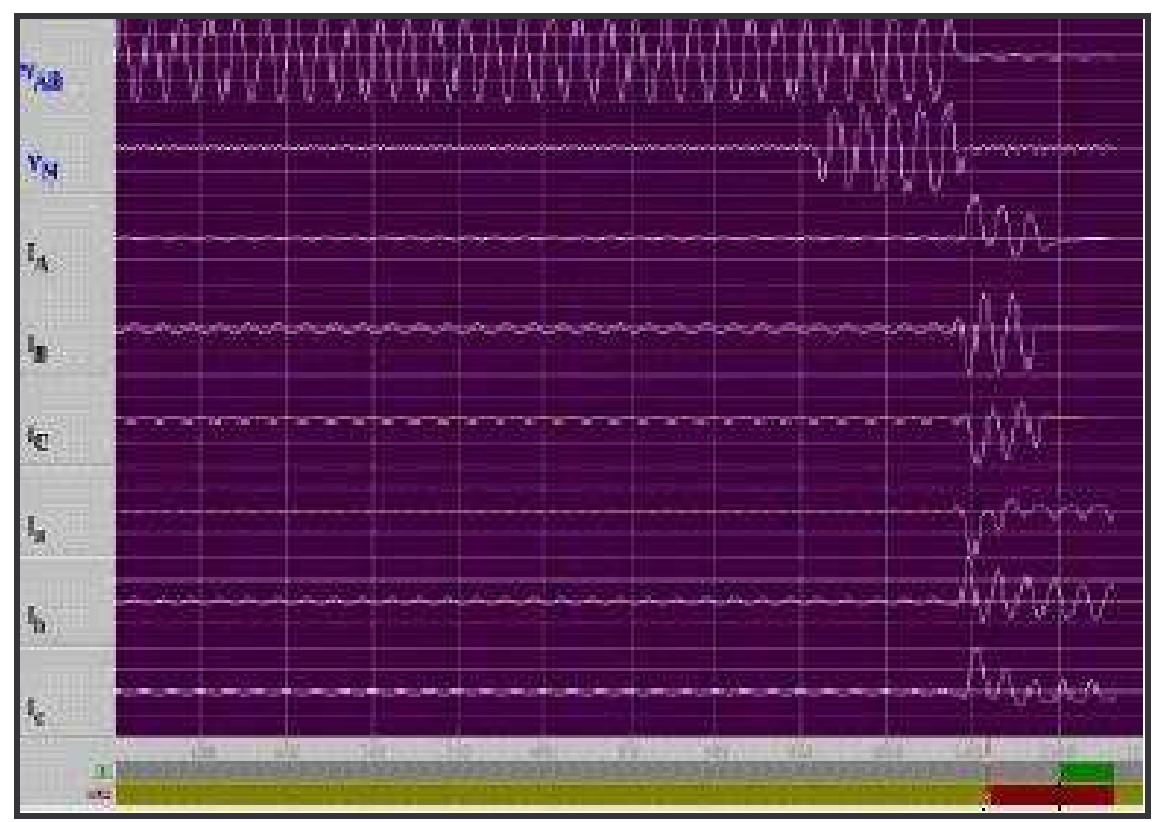

Figura 41 - Oscilografia de uma falta entre fases - referência [43]

\subsubsection{Localização de Faltas}

Na referência [48], o autor cita como outra função importante que pode ser implementada em relés microcessados que é a localização de faltas. Esta função tem a finalidade de quando ocorrer uma falta no circuito alimentador ao qual o relé microprocessado está instalado, como proteção, através de algoritmos próprios ao relé, o mesmo poderá determinar a quantos quilômetros da subestação ou do ponto de instalação do relé, ocorreu a falta, ou a impedância do ponto do defeito.

Cabe aqui lembrar que este é um assunto muito estudado por diversas instituições de pesquisa e por fabricantes de equipamentos de proteção, sendo que esta função oferece uma localização boa para linhas de 
transmissão, já para circuitos de distribuição a sua aplicação não é tão determinística a ponto de dizer em que local dos vários ramais de um circuito de distribuição ocorreu a falta devido as várias variáveis deste tipo do sistema, como por exemplo: impedâncias diferentes de condutores, impedâncias de falta diferentes ao longo dos circuitos, etc.

Mesmo com todas estas restrições, é uma função importante para os Engenheiros de Proteção da distribuição se aliada a outras técnicas de localização de faltas poderão beneficiar os índices de qualidade e continuidade dos sistemas elétricos. 
3.1.7 Alteração dos Parâmetros de Proteção em função do horário do sistema

Uma outra função citada na referência [48], é a alteração das características dos ajustes em função por exemplo do horário do dia. Os relés microprocessados permitem que a empresa de energia ou a indústria altere os ajustes e a lógica da proteção em função da hora do dia e do dia da semana.

Pode-se também implementar uma função em função da curva de carga ou sazonalidade de um determinado circuito de distribuição, alterando as tabelas de ajustes dos relés digitais com a alteração destas variáveis. 


\section{AVALIAÇÃO DE DESEMPENHO E ANÁLISE ECONÔMICA}

\subsection{CONSIDERAÇÕES GERAIS}

Com o objetivo de comprovar-se a real necessidade e os benefícios trazidos pelas novas funções incorporadas aos equipamentos de proteção utilizados nos sistemas de distribuição, realizou-se a instalação destes equipamentos, em substituição aos equipamentos anteriores, eletromecânicos e estáticos, em alimentadores de subestações com características distintas. Nos relés digitais instalados foram ativadas e bloqueadas funções específicas em cada uma destas proteções, nas quais acompanhou-se o desempenho destes equipamentos a fim de poder-se apresentar estes dados de forma que sejam de fácil análise e compreensão.

Estes equipamentos foram instalados nos circuitos alimentadores, em substituição aos relés eletromecânicos e estáticos que realizavam as funções de proteção.

Estes equipamentos foram monitorados pelo período de 12 meses após a sua instalação, com a coleta de dados e índices de interrupções, para que se pudesse realizar uma comparação com os mesmos índices de interrupção e qualidade de energia, com período igual anterior a instalação, onde as proteções eram do tipo eletromecânicas e estáticas. 


\subsection{RELÉS MICROPROCESSADOS TIPO PANACEA, AMAZON E FORM 6}

Foram instalados relés do tipo Panacea e Amazom, juntamente com os religadores do tipo GVR da Whipp\&Bourne, e relés tipo Form 6 juntamente com religadores tipo Nova da Cooper Power System, com o objetivo de realizar-se as análises das novas funções implementadas e utilizadas durantes os Estudos de Proteção com estes relés digitais.

A Copel possui atualmente religadores automáticos tripolares de $13,8 \mathrm{kV}$ e 34,5 kV para instalação externa em subestação ou montagem em poste, compostos de um mecanismo de abertura e fechamento baseado em atuador magnético, de um mecanismo de interrupção a vácuo, com meio isolante a gás $\mathrm{SF}_{6}$ (hexa-fluoreto de enxofre), com um controle eletrônico microprocessado dedicado com cabine, específico para o Religador.

O controle microprocessado possui no mínimo um grupo de ajuste alternativo, além do normal. No caso de mudança de um grupo de ajustes para outro, o controle possibilita a alteração automática de todos os ajustes de proteção (Partida de Fase, Partida de neutro, Sensor de Faltas a Terra SEF e etc...).[55] 
Conforme mostra a Figura 42, os controles microprocessados possuem, tanto para faltas entre fases como para faltas a terra, inúmeras opções de curvas tempo $\mathrm{X}$ corrente de abertura rápidas, lentas, tempo definido, inversa, muito inversa, extremamente inversa e modificadores das curvas, tornando impraticável a elaboração manual de um Estudo de Coordenação de Proteção.

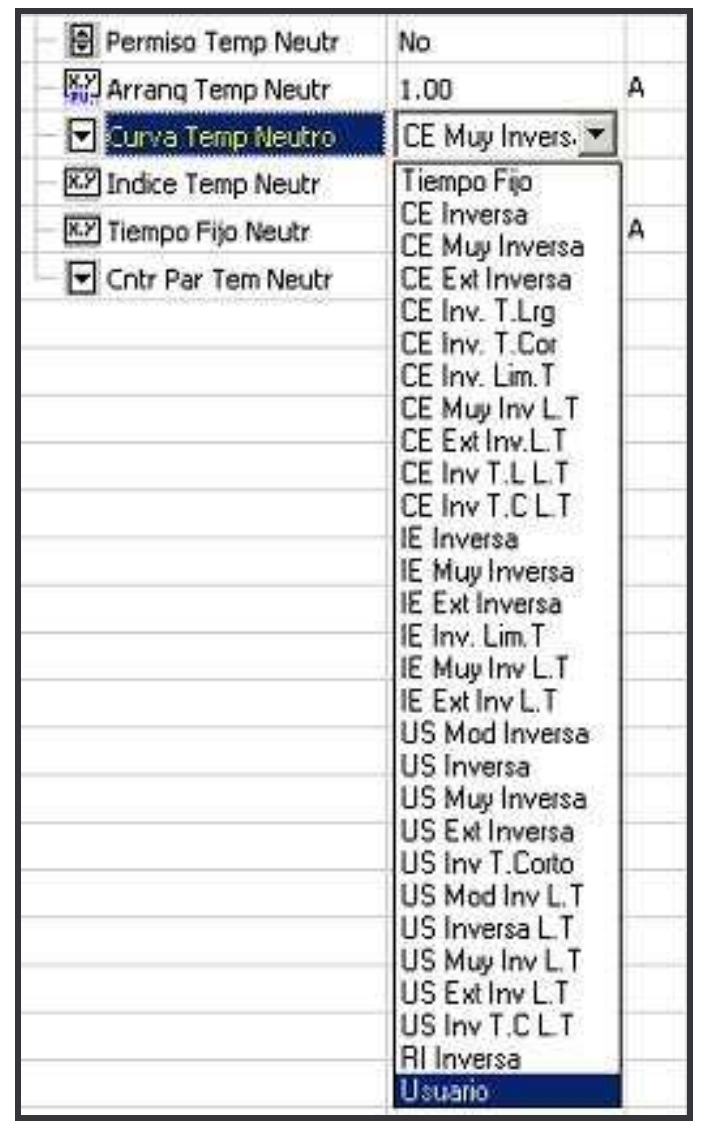

Figura 42 - Curvas características de relés digitais [ZIV - Espanha] 
Os controles microprocessados possuem as funções de modificação de curvas rápidas e lentas, ajustáveis para fase e neutro, conforme são mostrados nos itens a seguir:

\subsubsection{Tempo Mínimo de Resposta}

No gráfico da Figura 43 tem-se a função de tempo mínimo de resposta adicionada a curva temporizada de fase.

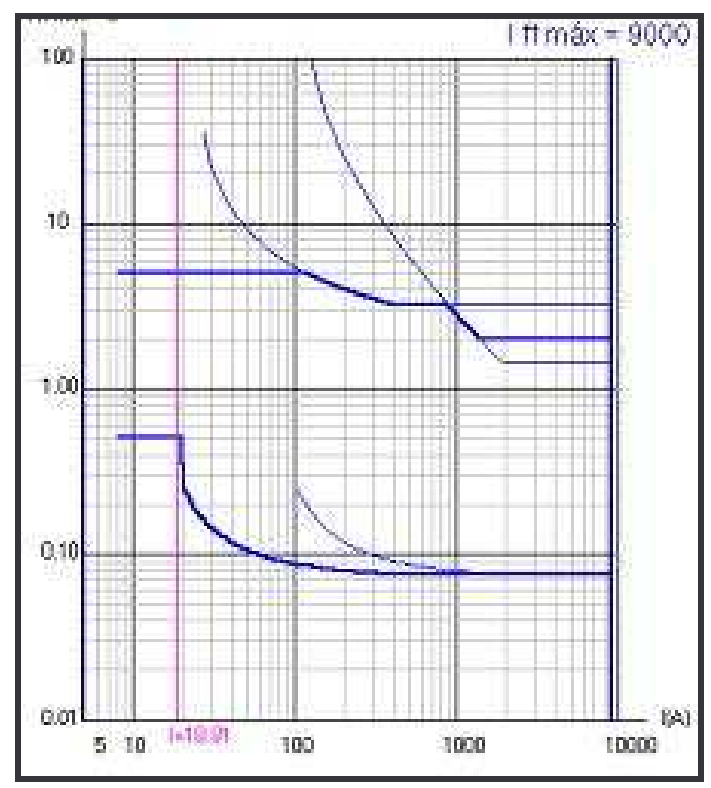

Figura 43 - Tempo Mínimo de Resposta Modificado

\subsubsection{Modificadores de Curvas}

No gráfico da Figura 44 visualiza-se as curvas finais ajustadas, com os modificadores já ajustados, mostrando a situação de como pode ficar o ajuste das curvas de atuação de um relé microprocessado. 


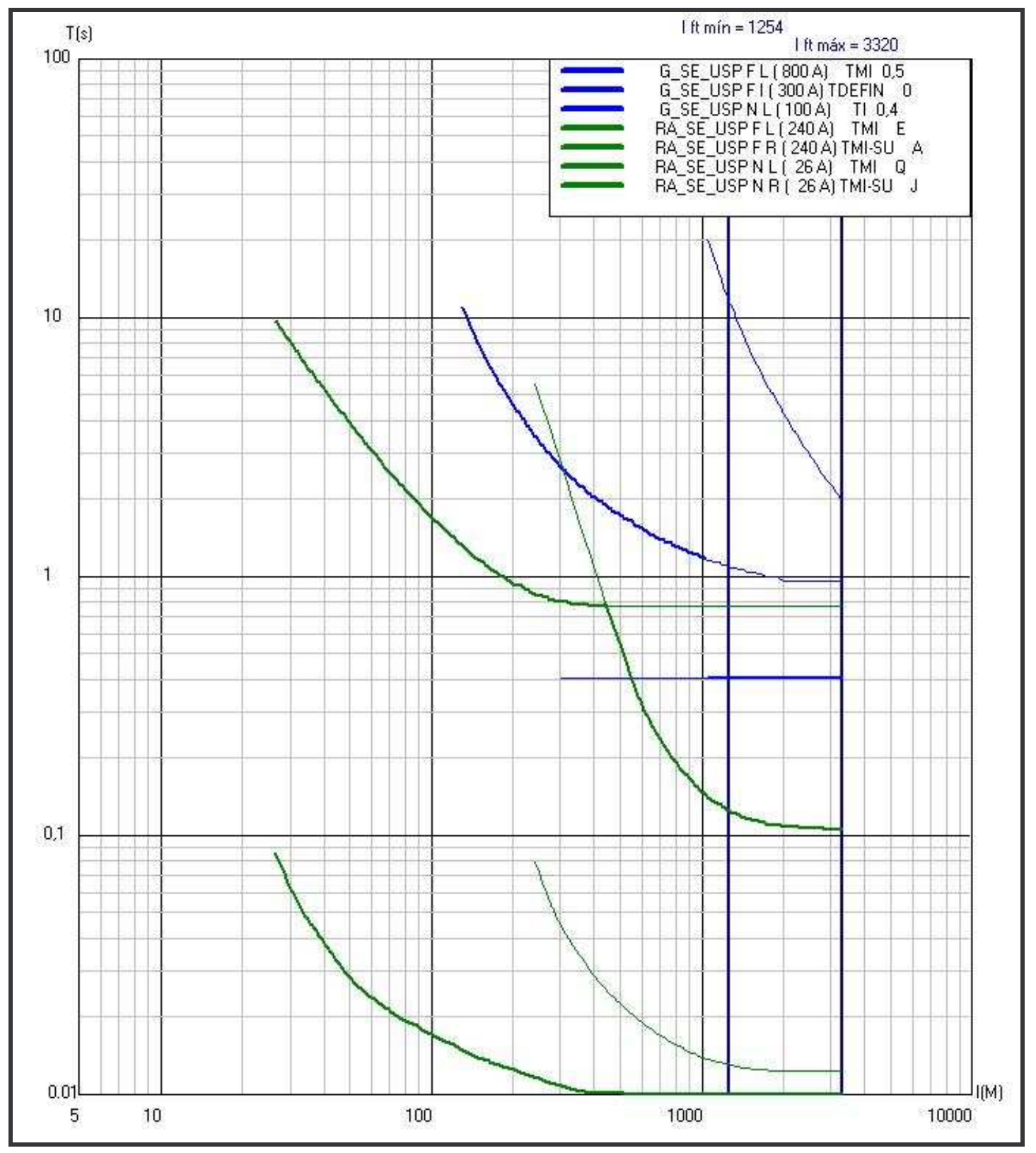

Figura 44 - Curvas Tempo x Corrente Modificada

Pode-se verificar que devido à complexidade das funções de ajustes disponíveis, fica muito difícil de se ajustar um equipamento com estas características, da forma tradicional, isto é, sem o auxílio de um programa de computador.

Nos relés microprocessados tem-se ainda as seguintes funções, que são mais usualmente utilizadas nos Estudos de Proteção: 
- Os tempos de religamentos são ajustáveis, variáveis e independentes entre si. O tempo de rearme também é ajustável.

- O controle microprocessado do religador possui uma função para evitar abertura devido à carga fria.

- O controle microprocessado possui a função de Bloqueio do Religador por Alta Corrente, com ajustes separados de fase e de neutro.

- O controle microprocessado possui a função Abertura Instantânea, com ajustes separado de fase e neutro.

- O controle microprocessado possui a função de Coordenação de Seqüência.

- O controle microprocessado possui um sensor de corrente de neutro tipo alta sensibilidade para faltas a terra "SEF", com ajustes de corrente de partida e curvas de tempo definido.

- O controle microprocessado possui contadores eletrônicos internos, os mesmos são acessíveis através de um teclado e display no painel frontal.

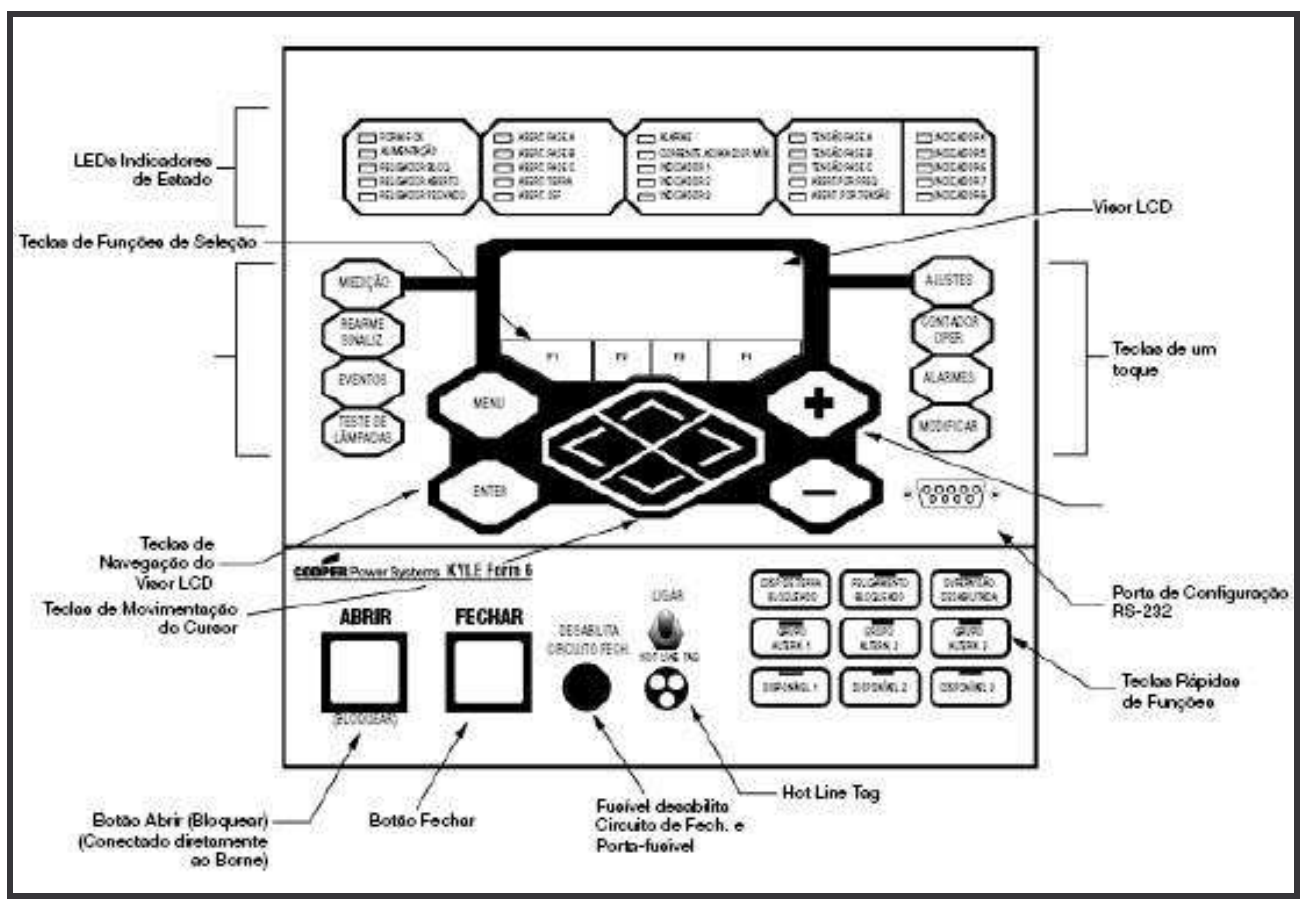

Figura 45 - Painel Frontal do Relé Digital F6 - Cooper Power Systems [52] 


\subsubsection{Análise de Eventos e Oscilografias}

O controle microprocessado registra os últimos eventos e atuações ocorridos, que são armazenados em memória não volátil, que permitem ser acessados pelo operador através do painel frontal e também por dispositivos externos.

O controle microprocessado possui indicação dos valores instantâneos e de demanda, acessíveis via teclado e display no painel frontal, das seguintes grandezas do circuito: corrente, tensão, potência ativa e reativa, etc.[55]

A maioria dos relés microprocessados registra as condições do sistema quando os elementos de proteção operam ou quando da ocorrência de condições definidas pelo usuário. A ferramenta do registro de eventos é valiosa para a análise da performance do relé e do sistema de potência.

Os dados dos eventos devem ser utilizados para avaliar a performance do relé. Rever os dados dos eventos é uma ferramenta valiosa para a manutenção. $O$ registro de eventos mostra os sinais $A C$ e $D C$ que o relé mede durante a perturbação, e também mostra quando o relé fecha 0 contato de disparo do circuito de comando do disjuntor.

Analisar os dados dos eventos é mais proveitoso e preciso do que testes simulados, pois o relé está respondendo a uma falta real no sistema. Logo, a verdadeira performance do relé pode ser melhor avaliada. O registro de eventos pode também mostrar problemas nas entradas e saídas de controle.

Analisar os registros de eventos pode também fornecer valiosas informações na condução de se efetuar melhorias em todo o esquema de proteção. 


\subsection{ANÁLISE DA MELHORIA DE ÍNDICES DE FORNECIMENTO PROPORCIONADOS APÓS A SUBSTITUIÇÃO DOS EQUIPAMENTOS DE PROTEÇÃO}

O acentuado crescimento de cargas não lineares conectadas ao sistema elétrico tem causado preocupação e uma série de estudos e discussões acerca do assunto. Muita atenção tem sido dada a evolução da utilização de cargas eletrônicas: dispositivos, equipamentos, acionamentos estáticos, com vasta aplicação tanto nas áreas industriais, quanto nas áreas comerciais e residenciais.

Apesar disso existem determinados equipamentos elétricos produtores de distorções harmônicas que são utilizados desde o início das aplicações práticas da eletricidade e eletromagnetismo, que são os dispositivos saturáveis. São incluídos nesta categoria, transformadores, motores, geradores, reatores entre outros. As harmônicas são geradas principalmente, devido a característica não linear do aço. Os transformadores normalmente são projetados para trabalhar na faixa linear, abaixo da curva de saturação. A densidade de fluxo necessário para o regime de funcionamento do transformador é definida com base numa complicada otimização, entre o custo do aço, perdas a vazio, ruído e uma série de outros fatores.

Embora a corrente de magnetização de transformadores, possua uma elevada distorção harmônica, esta é tipicamente inferior a $1 \%$ da corrente nominal a plena carga. Empresas de Distribuição de Energia Elétrica que possuam alimentadores com centenas de transformadores, podem ter distorções de harmônicas de tensão significativas, devido a sobreexcitação destes transformadores por variações nos patamares de tensão ou carregamento.

O caso em análise, do referido estudo, apresentou problemas operacionais trazidos pela sobreexcitação de pequenos transformadores monofásicos que alimentam cargas predominantemente rurais. 
A Figura 46 representa o diagrama unifilar da Estação de Chaves Cândido de Abreu com os alimentadores onde foram realizadas as análises propostas neste estudo.

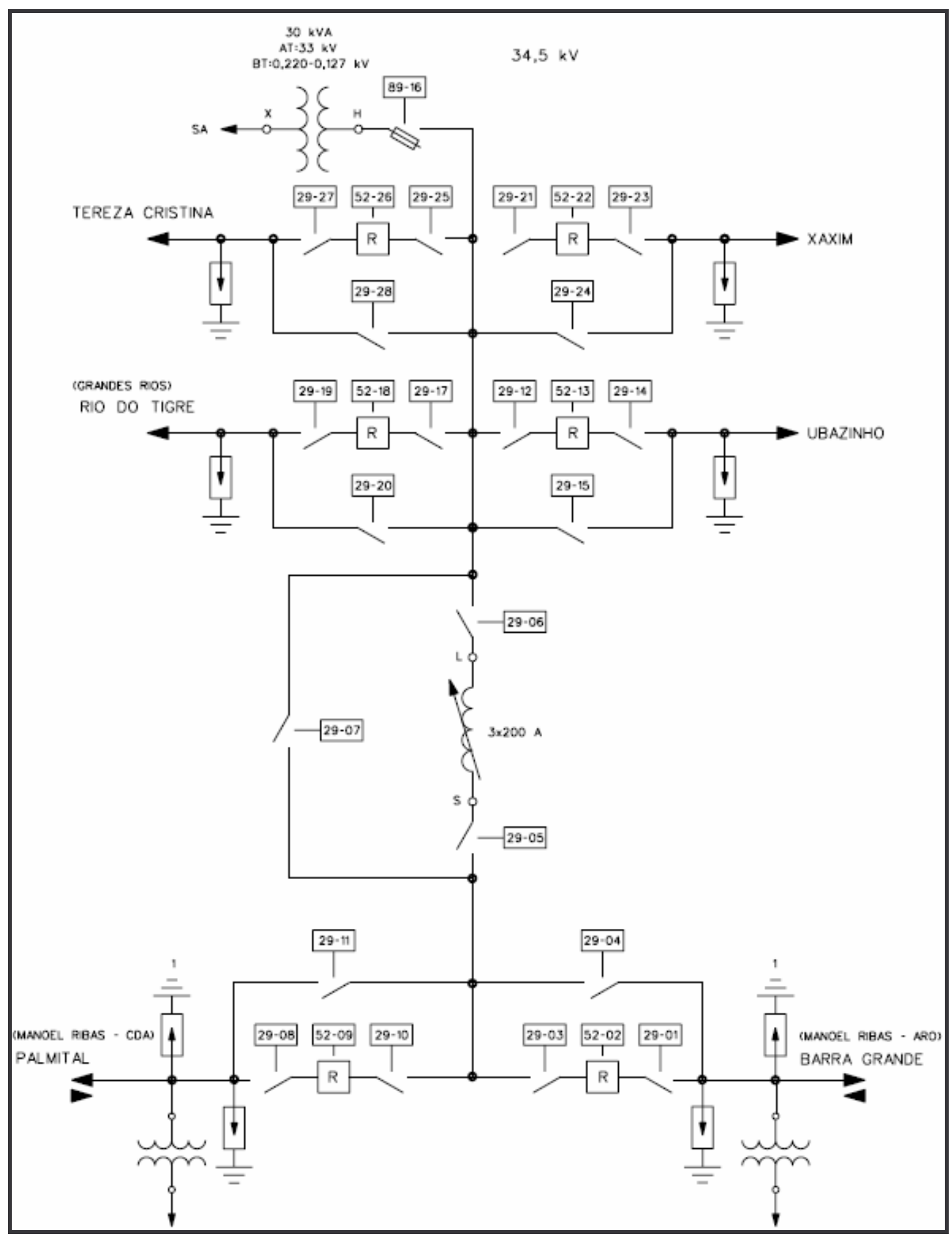

Figura 46 - Diagrama Unifilar da EC Cândido de Abreu - referência Copel 
Com a nova configuração a EC Cândido de Abreu seria alimentada pela SE Pitanga, e a EC Manoel Ribas permaneceria alimentada pela SE Ivaiporã.

Quando o remanejamento de cargas entre os circuitos foi efetivado, começaram a ocorrer problemas de desligamentos sucessivos do Religador que alimentava a EC Cândido de Abreu na EC Manoel Ribas e também na própria EC Cândido de Abreu. Os desligamentos eram sempre por sobrecorrente de neutro, nos religadores da Subestação, sendo que estes religadores possuíam relés do tipo Estático e apenas em determinados períodos do dia como nos finais de noite e madrugada. E quando o sistema retornava a sua configuração antiga, os desligamentos naturalmente paravam.

As equipes de montagem e manutenção, já haviam percorrido e analisado todos os trechos da linha em busca de problemas com isoladores, e provavelmente fuga de corrente para terra.

Houve tentativa de tentar melhorar a distribuição de fases nos ramais monofásicos da EC Cândido de Abreu, com um grande trabalho de remanejamento de cargas. Em paralelo também houve a tentativa de rever os ajustes dos bancos de reguladores de tensão, pois os mesmos na tentativa de melhorar o nível de tensão poderiam trazer, possíveis problemas de desequilíbrio de correntes.

Os valores de ajuste para a corrente de neutro nos relés estáticos foram aumentados de maneira a se tornarem menos sensíveis, comprometendo a detecção para faltas envolvendo a terra.

Todas as tentativas convencionais executadas não trouxeram sucesso, o que motivou a realização de medição mais detalhada dos parâmetros elétricos envolvidos, com medidores utilizados para análise de qualidade de energia.

Para a realização de medições foram utilizados dois registradores digitais de parâmetros de qualidade de energia elétrica, modelo RQE-II ( Registrador de Qualidade de Energia), conforme mostrado na Figura 47. 


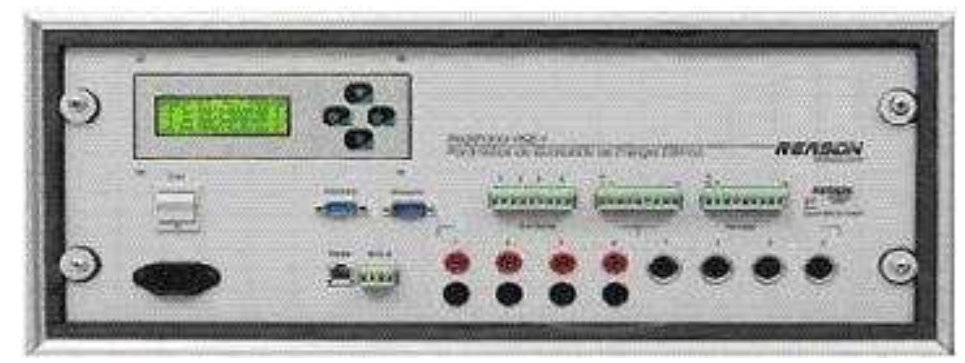

Figura 47 - Analisador de Qualidade de Energia [Reason]

Os registradores foram instalados nos religadores tipo ESV $3810 \mathrm{com}$ controle estático tipo Resco, para serem disparados, a fim de gravarem as oscilografias das grandezas a serem monitoradas, quando ultrapassados os valores nominais das correntes de neutro dos relés estáticos, conforme mostra a Figura 48 . 


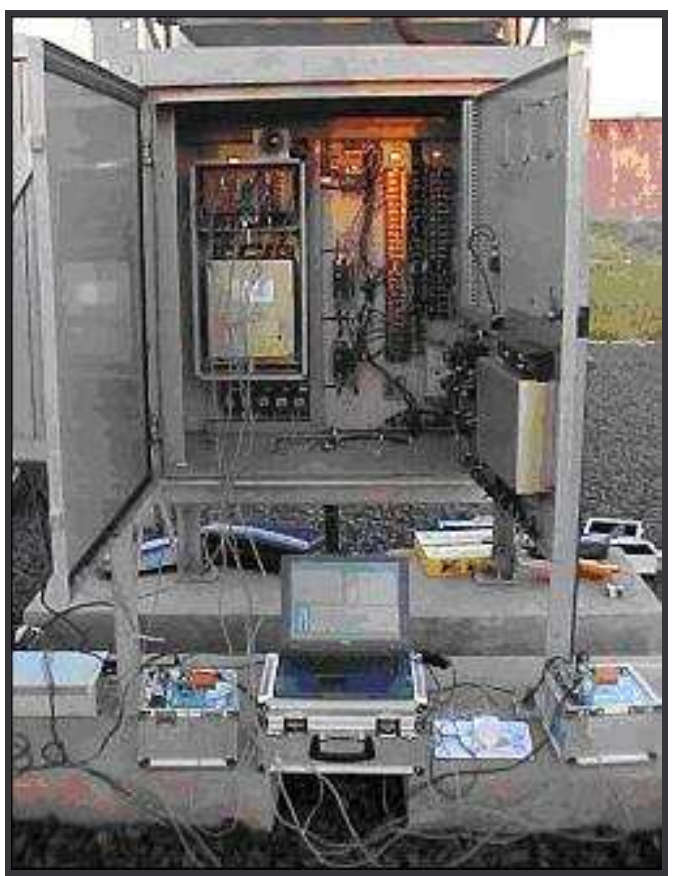

Figura 48 - Religador com Relé Estático - Monitoração das Grandezas

Durante as medições pode-se monitorar e oscilografar o elevado grau de distorção harmônicos das tensões e correntes dos circuitos alimentadores, conforme mostram as Figura 49 e Figura 50.

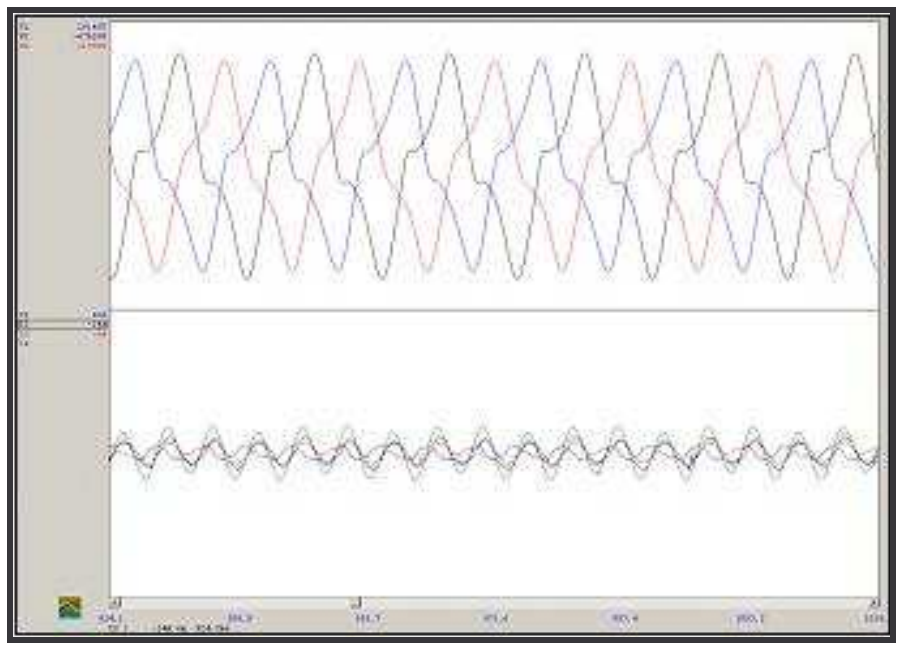

Figura 49 - Oscilografia das correntes distorcidas no relé estático 


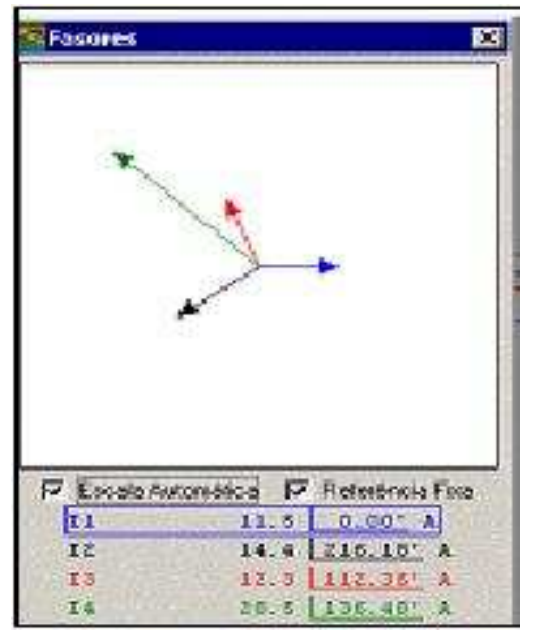

Figura 50 - Fasores de Corrente no relé estático do alimentador monitorado

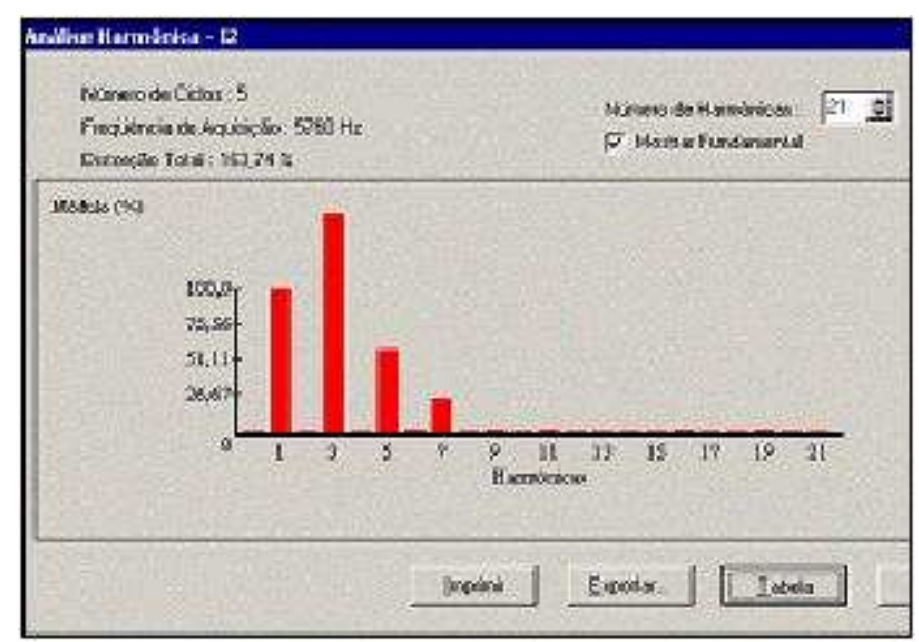

Figura 51 - Espectro de Freqüência da Corrente durante a abertura do religador com relé Estático. 
Analizando-se as oscilografias e o espectro de frequência das correntes, nos religadores com relés estáticos, chegou-se aos seguintes valores máximos:

- THD médio de tensão $=31,3 \%$

- $\quad$ THD médio de corrente $=163,7 \%$

Através da análise dos fasores de corrente da Figura 50, verifica-se que o módulo da corrente que circula pelo sensor de neutro (28,9 Ampéres) é 2,5 vezes maior que a menor corrente que circula pela fase A (11,5 Ampéres). Como os sensores de neutro destes equipamentos estavam ajustados em 15 Ampéres, ocorria a atuação dos relés estáticos devido ao elevado nível de distorção da corrente harmônica, principalmente de terceira ordem.

As atuações dos relés estáticos ocorrem devido ao fato de que os religadores que utilizam estes relés não possuem filtragem adequada dos valores de corrente e tensão, conforme mostrado no apêndice deste trabalho, para realizar a separação dos sinais de correntes e tensões que são utilizados pelos circuitos dos relés para a medição e comparação com os valores das grandezas de correntes e tensões, com os valores pré ajustados. 


\subsubsection{Testes de Filtragem de Componentes Harmônicos em Laboratório}

Após constatados os problemas relatados no ítem anterior, decidiu-se que uma das soluções para a resolução dos problemas, seria a substituição dos relés estáticos, por relés microprocessados, os quais possuem a filtragem dos sinais amostrados.

Uma outra solução a que se chegou, seria a modelagem, projeto e confecção de filtros, analógicos ou digitais, para realizarem a devida filtragem, quando instalados antes das entradas de sinais analógicos, nos relés microprocessados.

Para comprovar-se que a filtragem realizada pelos relés microprocessados, era eficiente, os relés foram submetidos a ensaios de distorções harmônicos de corrente e tensão, em laboratório habilitado para a realização dos mesmos, aplicados em suas entradas de corrente e tensão.

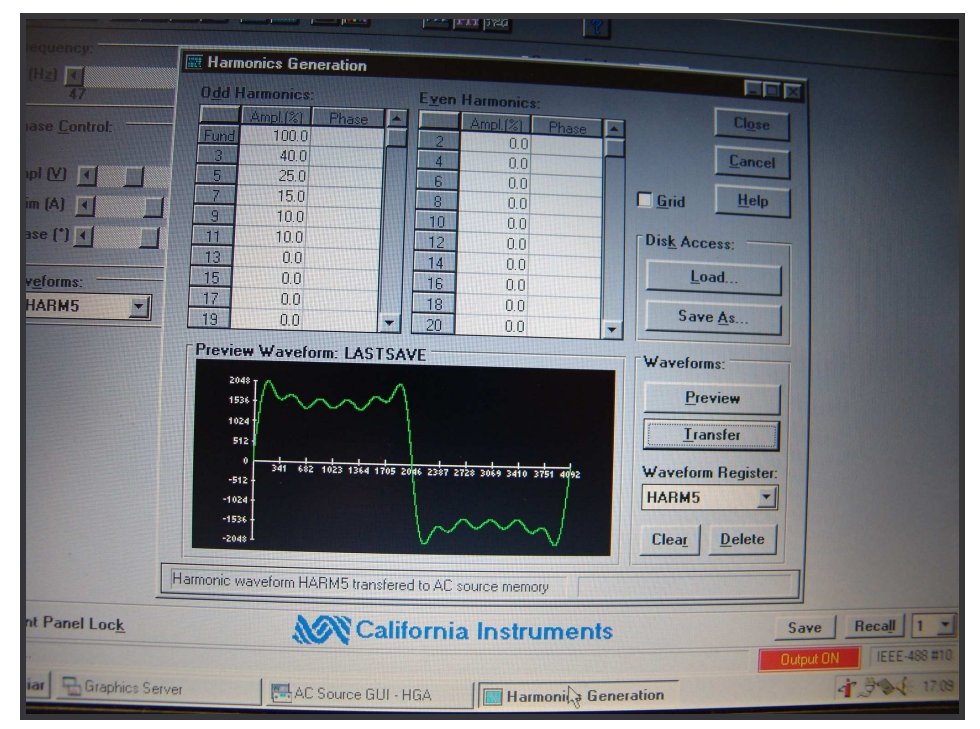

Figura 52 - Teste de distorção harmônica de corrente - distorção combinada de freqüências baixas em relé microprocessado 


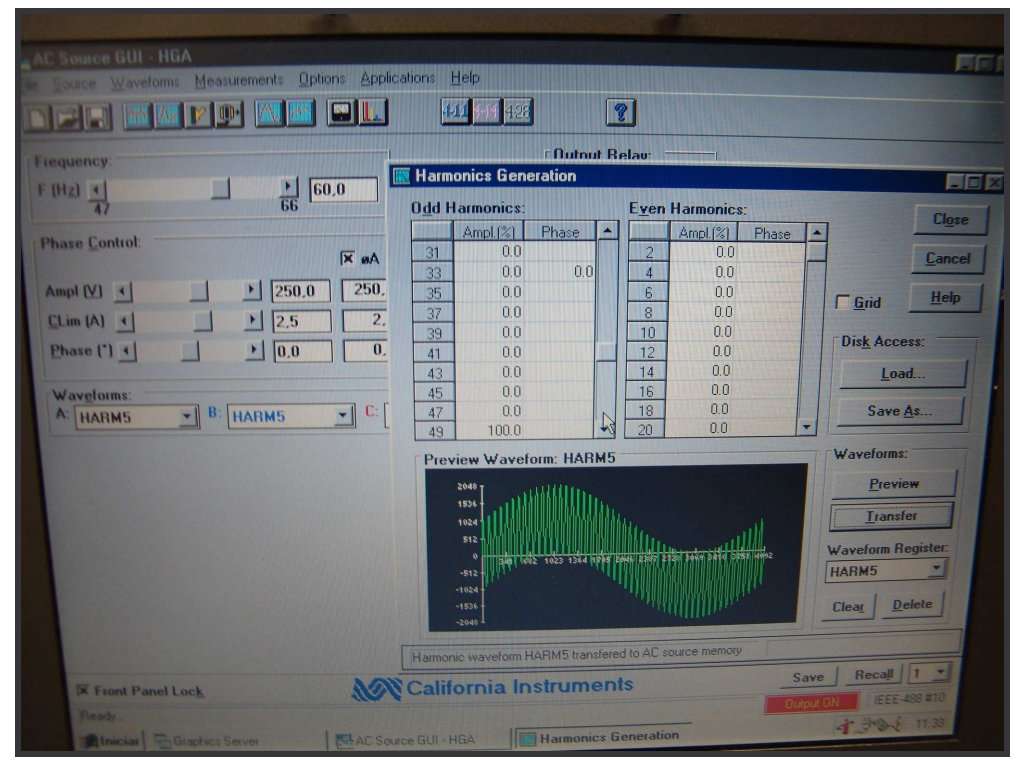

Figura 53- Teste de distorção harmônica de corrente - distorção de freqüências altas em relé microprocessado

Através da análise das Figura 52 e Figura 53, verifica-se que foram aplicadas várias combinações de frequências, com fonte de sinais adequada, de valores baixos de múltiplos da frequência fundamental, $60 \mathrm{Hertz}$, de 3 a ordem e de valores elevados, até a $49^{\mathrm{a}}$ ordem. 
Os relés testados apresentaram comportamento satisfatório, realizando a filtragem dos valores aplicados em suas entradas e utilizando apenas os valores fundamentais de corrente e tensão na realização das funções de proteção, conforme é mostrado na figura Figura 54.

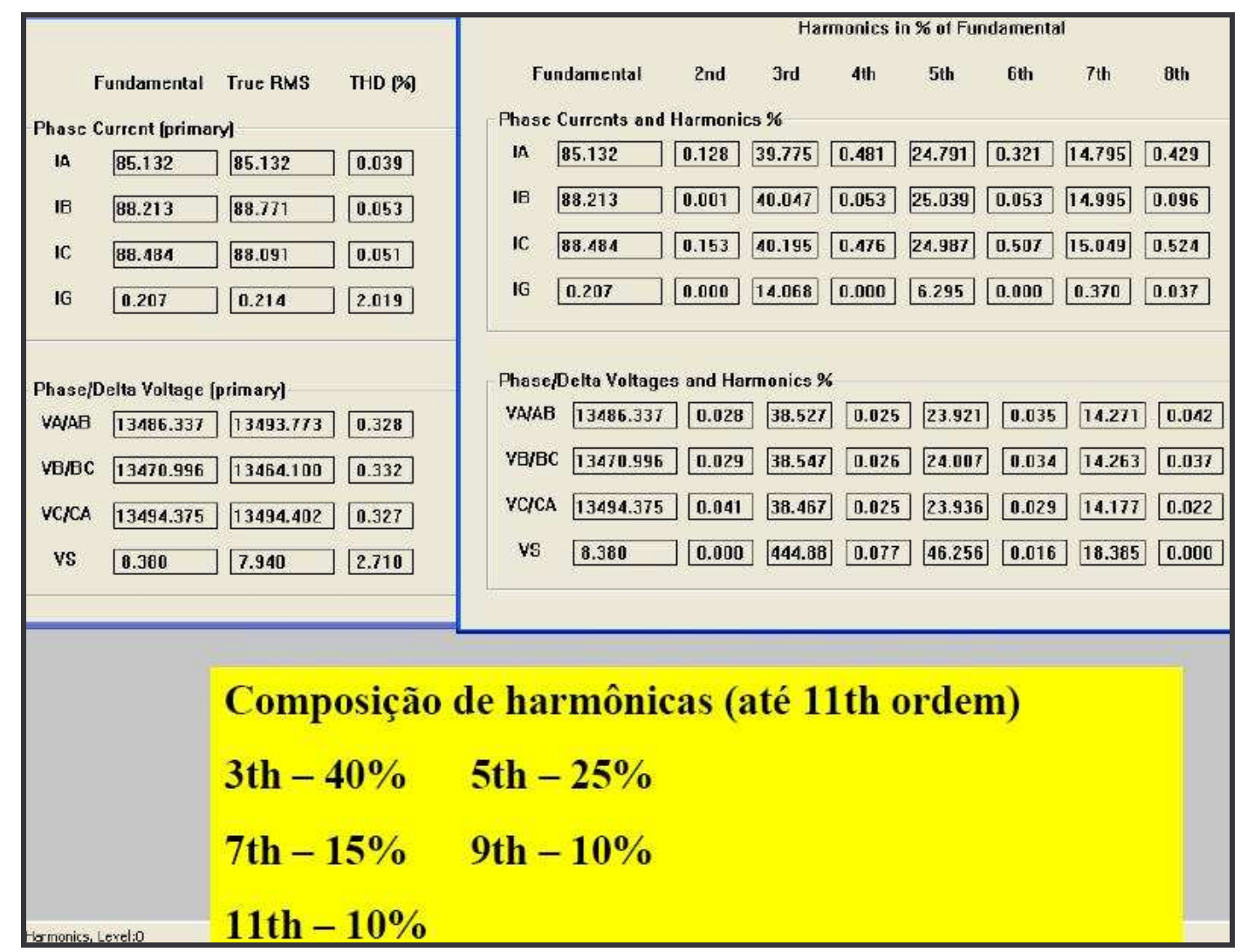

Figura 54 - Valores dos componentes harmônicos de corrente filtrados pelo relé microprocessado testado.

Pode-se visualizar na Figura 54, que os valores filtrados, para $3^{\mathrm{a}}, 5^{\mathrm{a}}$ e $7^{\mathrm{a}}$ ordem, correspondem aos valores aplicados através da fonte geradora de sinais utilizada. 


\subsubsection{Substituição dos Relés Estáticos por Microprocessados}

Devido as atuações freqüentes dos relés de proteção provocados pelos problemas encontrados nas Subestações da Copel de nomes Manoel Ribas e Cândido de Abreu, relatados no capítulo anterior, no final do ano de 2003 foram substituídos quatro religadores da Subestação Cândido de Abreu, os quais possuíam relés estáticos, por quatro religadores do tipo GVR $38 \mathrm{com}$ relés microprocessados tipo Amazon.

Estes novos equipamentos, possuem módulos de filtragem de sinais, conforme mostrados no apêndice deste trabalho, sendo que somente a componente fundamental da corrente e tensão são utilizados pelos algorítmos de proteção internos aos relés, isto é das grandezas "r.m.s." "root mean square" ou, valor eficaz, são extraídos os componentes harmônicos e a componente contínua - "dc" 


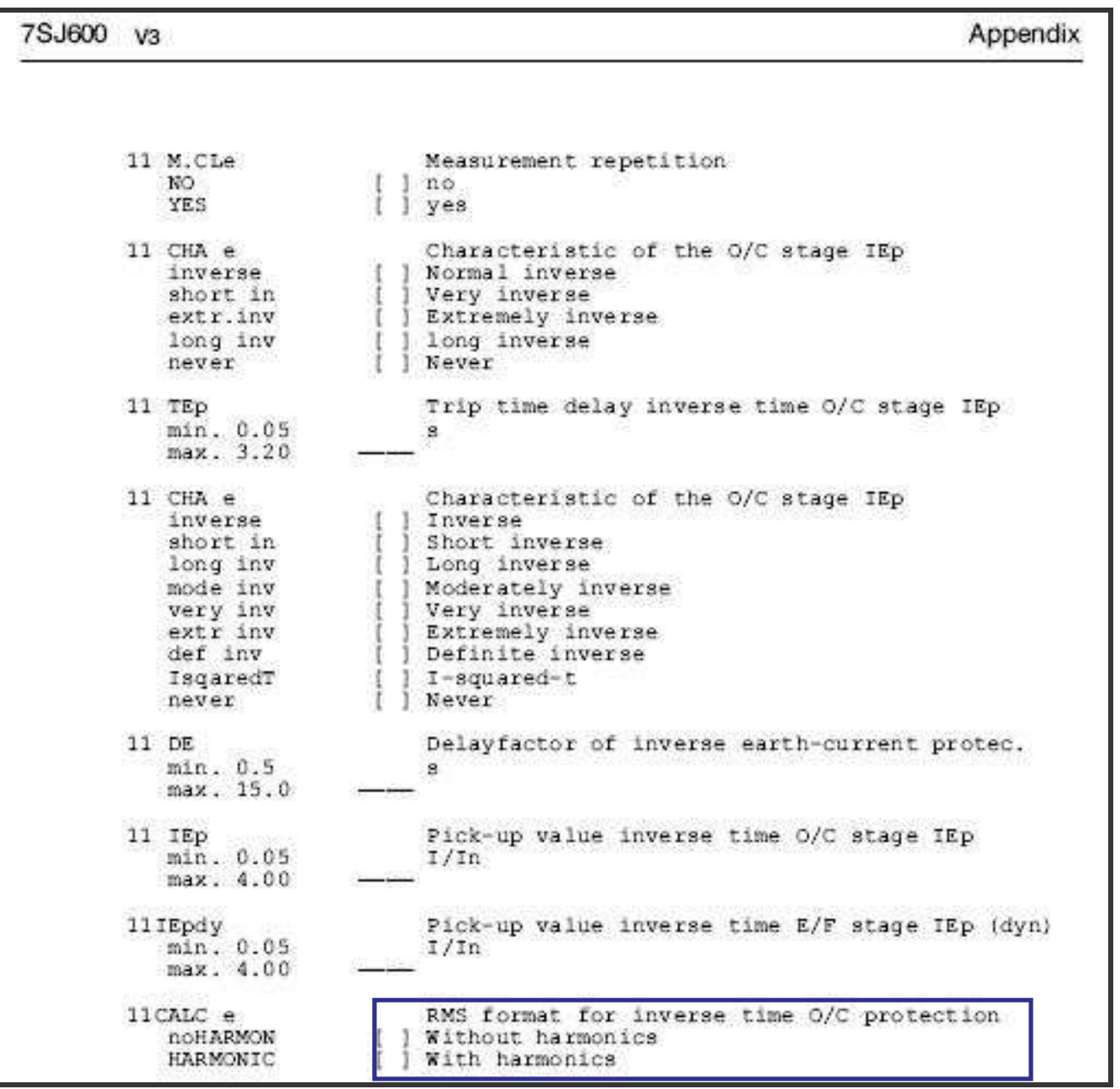

Figura 55 - Tela de Programação relé Siemens 7SJ600 - Valores com Harmônicos ou sem Harmônicos

Em alguns tipos de relés microprocessados é possível realizar uma definição prévia, via software de programação, de quais sinais serão utilizados para realização das tarefas de proteção pelos relés, ou os valores "r.m.s". com os harmônicos ou os valores sem os harmônicos, conforme mostra a Figura 55. 
Após a substituição dos religadores, com relés estáticos por religadores com relés microprocessados na subestação de Cândido de Abreu, foram realizados os Estudos de Proteção e para os quais, para obter um ajuste e coordenação adequados, foram ativadas e devidamente ajustadas as funções de:

- Modificadores de Curvas;

- Tempo adicional nas Curvas de Neutro;

- Disparo por Alta Corrente de Fase;

- Disparo por Alta Corrente de Neutro;

- Disparo Sensitivo de Neutro;

- Tempo Mínimo de Resposta;

- Relés com Filtros de Harmônicos.

Estas funções serão visualizadas nos coordenogramas traçados para cada caso. 


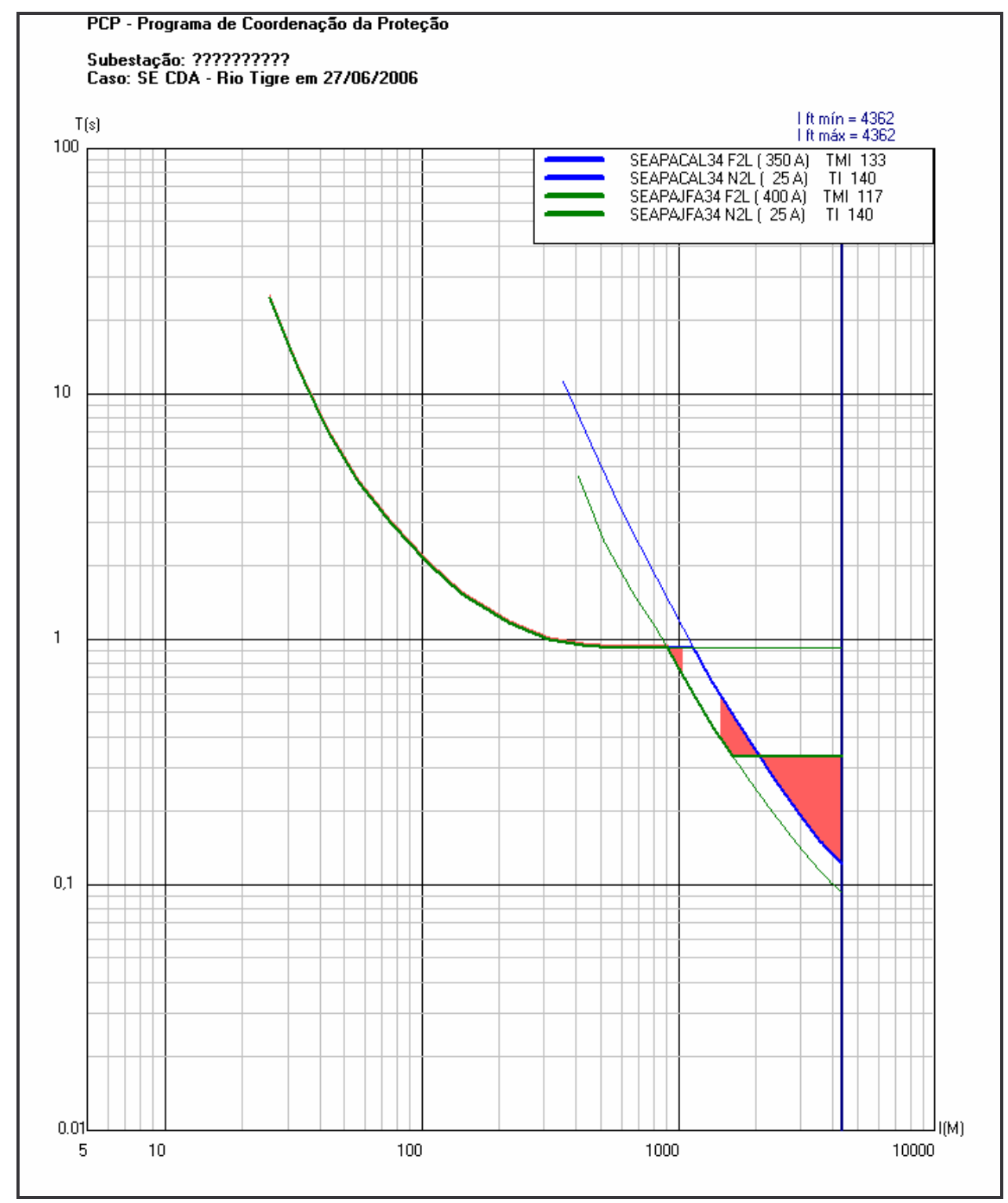

Figura 56 - Coordenograma com curvas sem modificadores - SE Cândido de Abreu Relés Descoordenados

Através de análise da Figura 56, que é o coordenograma de proteção do alimentador Rio do Tigre da SE Cândido de Abreu com o circuito Palmital da SE Manoel Ribas, conforme diagrama unifilar mostrado na Figura 46, podese verificar que com as curvas e funções convencionais e as unidades normais ajustadas nos relés microprocessados, os dois equipamentos instalados em série se encontram descoordenados. 


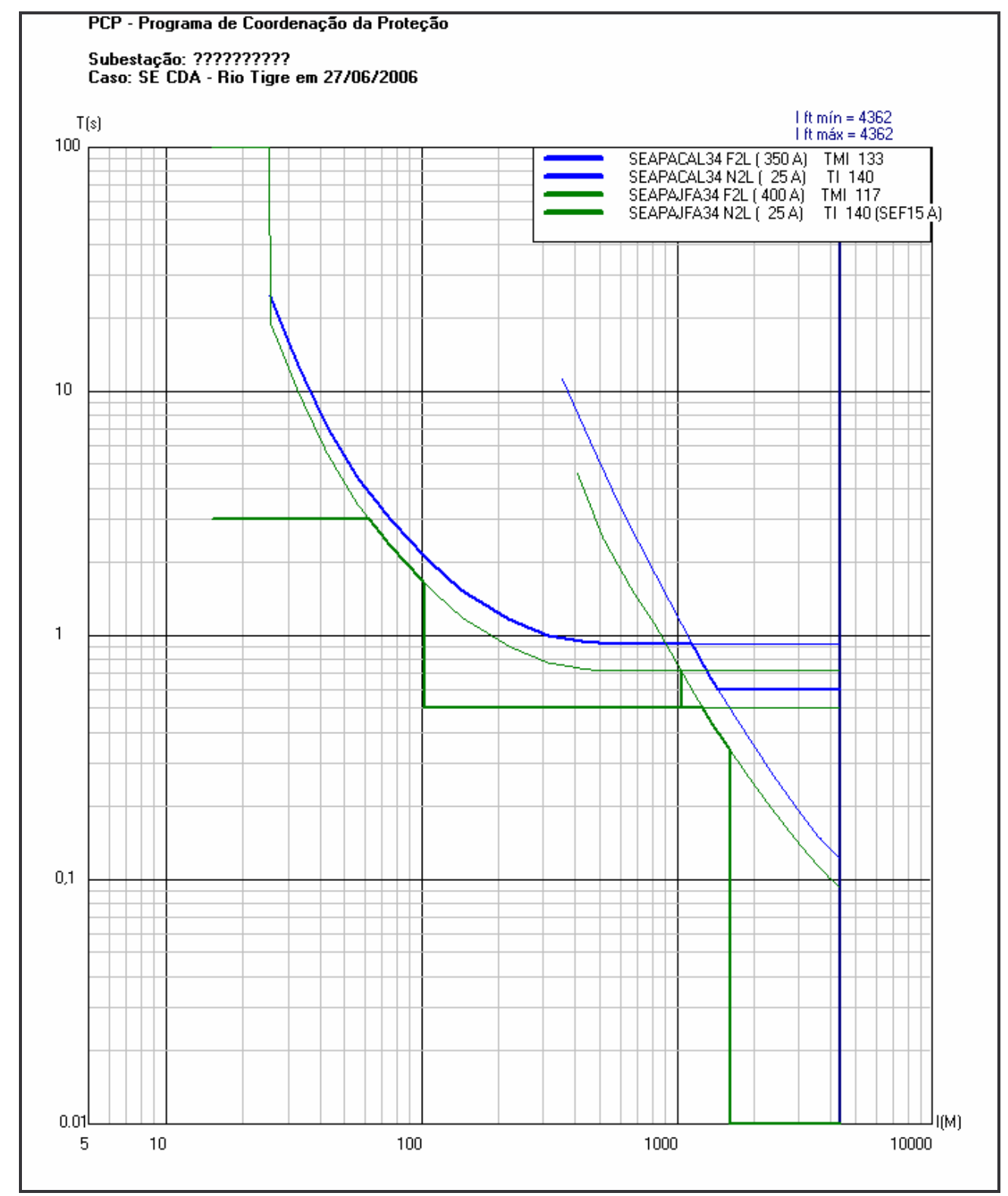

Figura 57 - Coordenograma com os modificadores de curvas e funções Implantados na SE Cândido de Abreu - Relés Coordenados

Com a implantação dos modificadores de curvas e funções enumeradas anteriormente, nos relés microprocessados, pode-se conseguir um ajuste e uma coordenação teórica perfeita, o que se pode visualizar através do coordenograma da Figura 57, para os mesmos circuitos da SE Cândido de Abreu analisados na Figura 56, é que as curvas já modificadas dos dois relés microprocessados instalados em série se encontram agora 
coordenados.

Após realizada a nova programação das funções nos relés microprocessados de quatro circuitos de $34,5 \mathrm{kV}$, os mesmos foram transferidos, testados e instalados nos relés da Subestação de Cândido de Abreu no final do ano de 2003.

\subsubsection{Análise dos Índices de Interrupção dos Alimentadores}

Através do acompanhamento e análise de Interrupções no Sistema de Distribuição, onde são computados todos os problemas ocorridos durante as interrupções acidentais, programadas ou voluntárias, para cada conjunto ANEEL, formados para atender a exigências da ANEEL, contidas nos contratos de concessão de 1999 e na resolução 24/2000, levantou-se os dados de causa, componente e tipo para cada alimentador onde foram instalados os relés microprocessados.

Estes dados foram comparados com período de dois anos anteriores a instalação, para os mesmos alimentadores, onde estavam instalados relés estáticos, os quais foram tabulados e analisados conforme a sua evolução. 
Tabela 3 - Valores de DEC e FEC dos Alimentadores da SE Cândido de Abreu

\begin{tabular}{|c|c|c|c|c|}
\hline \multicolumn{5}{|c|}{ SE CANDIDO DE ABREU - RA ANTIGO ESV 3810 - NOVO AMAZON } \\
\hline & & & & \\
\hline Ano & Alimentador & DEC & FEC & $\begin{array}{l}\text { Média de } \\
\text { Consumidor. }\end{array}$ \\
\hline 2006 & RIO DO TIGRE & 11 & 14 & 862 \\
\hline 2005 & RIO DO TIGRE & 20,9 & 17,37 & 824 \\
\hline 2004 & RIO DO TIGRE & 21 & 19,22 & 793 \\
\hline 2003 & RIO DO TIGRE & 98,73 & 53,54 & 775 \\
\hline 2002 & RIO DO TIGRE & 38,25 & 33,08 & 784 \\
\hline 2006 & $\begin{array}{l}\text { TEREZA } \\
\text { CRISTINA }\end{array}$ & 18,93 & 20,38 & 883 \\
\hline 2005 & $\begin{array}{l}\text { TEREZA } \\
\text { CRISTINA }\end{array}$ & 36,22 & 24,68 & 897 \\
\hline 2004 & $\begin{array}{l}\text { TEREZA } \\
\text { CRISTINA }\end{array}$ & 23,66 & 16,68 & 1.268 \\
\hline 2003 & $\begin{array}{l}\text { TEREZA } \\
\text { CRISTINA }\end{array}$ & 63,45 & 57,91 & 1.113 \\
\hline 2002 & $\begin{array}{l}\text { TEREZA } \\
\text { CRISTINA }\end{array}$ & 82,86 & 58 & 1.002 \\
\hline 2006 & UBAZINHO & 5,66 & 12,52 & 1.454 \\
\hline 2005 & UBAZINHO & 5,4 & 11,07 & 1.497 \\
\hline 2004 & UBAZINHO & 6,01 & 10,93 & 1.299 \\
\hline 2003 & UBAZINHO & 15,55 & 23,54 & 1.259 \\
\hline 2002 & UBAZINHO & 14,52 & 22,47 & 1.213 \\
\hline 2006 & XAXIM & 9,88 & 12,14 & 455 \\
\hline 2005 & XAXIM & 23,83 & 18,38 & 435 \\
\hline 2004 & XAXIM & 22,54 & 15,56 & 430 \\
\hline 2003 & XAXIM & 45,32 & 33,84 & 420 \\
\hline 2002 & XAXIM & 42,25 & 33,25 & 375 \\
\hline
\end{tabular}

Na Tabela 3 são apresentados os índices de DEC e FEC para os quatro circuitos onde foram instalados relés microprocessados. 
A instalação dos relés microprocessados ocorreu no final do ano de 2003.

- Os dados coletados e tabulados entre os anos de 2002 - 2003, referem-se aos relés do tipo estáticos.

- Os dados coletados e tabulados entre os anos de $2004-2006$, referem-se aos relés do tipo microprocessados.

Com os referidos dados da Tabela 3, mostra-se, conforme o gráfico da Figura 58, que houve um decréscimo acentuado no valor do DEC para todos os quatro alimentadores desta subestação. 


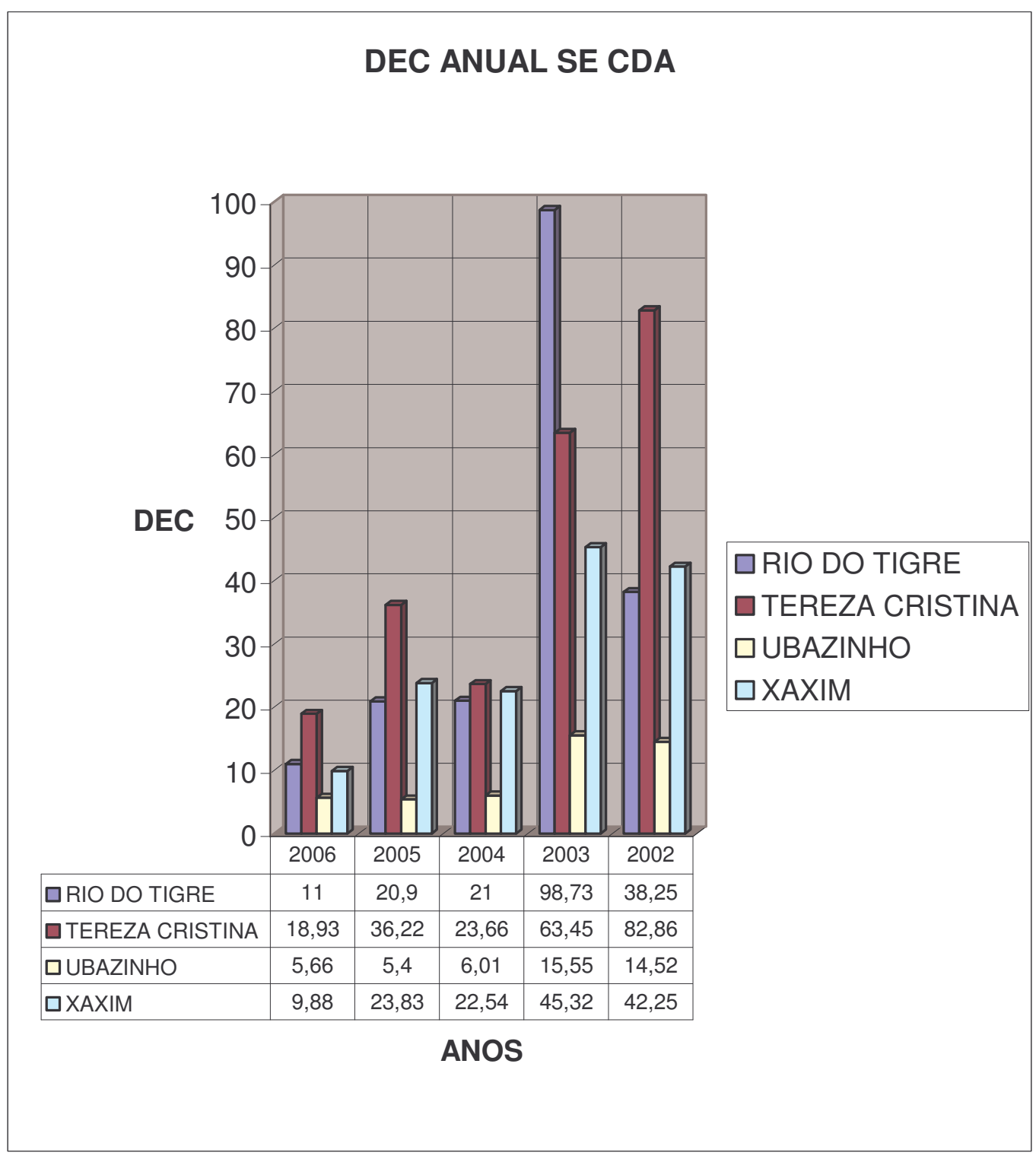

Figura 58 - Perfil de Evolução do DEC anual dos alimentadores da SE CDA

Tomando-se como exemplo o alimentador Tereza Cristina, tem-se que os valores de DEC decresceram de 82,86 horas ano, em 2002 para 23,66 horas ano, em 2004, após a instalação dos novos relés com as novas funções conforme já mostrado anteriormente, isto é, houve uma redução de $250 \%$ neste índice.

O mesmo decréscimo do índice DEC, visualiza-se para os demais alimentadores. 
O mesmo tipo de análise pode-se fazer com respeito ao índice FEC, com base nos dados da Tabela 3, tem-se o perfil de evolução do FEC para os mesmos alimentadores, conforme o gráfico da Figura 59.

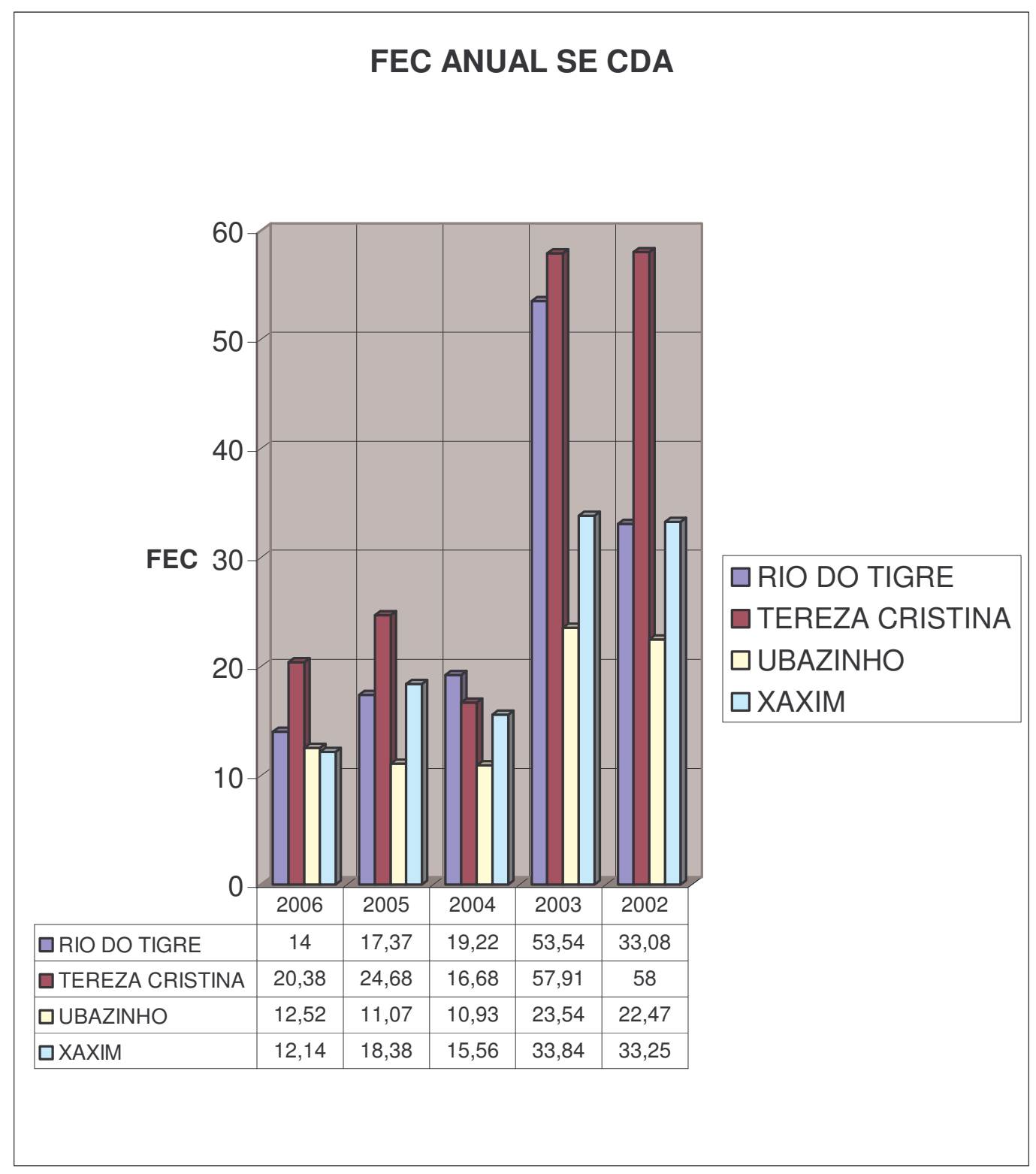

Figura 59 - Perfil de Evolução do FEC anual dos alimentadores da SE CDA

Tomando-se novamente como exemplo o alimentador Tereza Cristina, temse que os valores de FEC decresceram de 58,0 interrupções/ano, em 2002 para 16,68 interrupções/ano, em 2004, após a instalação dos novos relés, com as novas funções conforme mostrado anteriormente, isto é, houve uma 
redução de $247 \%$ neste índice.

O mesmo decréscimo do índice FEC ocorreu com os demais alimentadores.

A fim de se ter certeza de que as atuações dos religadores com relés estáticos ocorreram devido a problemas no próprio equipamento, isto é, atuação do elemento de proteção por descoordenação e por sensibilização dos sensores de neutro, foram levantadas as causas que provocaram as referidas aberturas e que colaboraram para o aumento dos índices de interrupção dos alimentadores conforme mostrados na Tabela 4. 
Tabela 4 - Causas de Interrupções nos Alimentadores da SE CDA

\begin{tabular}{|c|c|c|c|c|c|c|c|c|c|c|}
\hline \multirow[b]{3}{*}{ Causa } & \multicolumn{10}{|c|}{ ANO } \\
\hline & \multicolumn{2}{|c|}{2006} & \multicolumn{2}{|c|}{2005} & \multicolumn{2}{|c|}{2004} & \multicolumn{2}{|c|}{2003} & \multicolumn{2}{|c|}{2002} \\
\hline & DEC & FEC & DEC & FEC & DEC & FEC & DEC & FEC & DEC & FEC \\
\hline $\begin{array}{l}\text { ABALROAMENTO } \\
\text { (VEICULOS, } \\
\text { CAMINHAO) }\end{array}$ & 0,26 & 0,21 & 0 & 0 & 0,52 & 0,98 & 0,75 & 0,65 & 1,45 & 0,25 \\
\hline $\begin{array}{l}\text { ABERT } \\
\text { POSSIBILITA } \\
\text { OPER/SERV RD }\end{array}$ & 0,07 & 0,21 & 0 & 0,01 & 0,32 & 0 & 0,03 & 0,01 & 0 & 0 \\
\hline $\begin{array}{l}\text { ACIDENTE DE } \\
\text { TERCEIROS }\end{array}$ & 0,22 & 0,33 & 0 & 0 & 0,06 & 0,03 & 0 & 0 & 0 & 0 \\
\hline $\begin{array}{l}\text { ANIMAIS/INSETO } \\
\text { S/PASSAROS }\end{array}$ & 0,04 & 0,03 & 0,08 & 0,03 & 0 & 0 & 0,58 & 0,22 & 0,02 & 0,01 \\
\hline $\begin{array}{l}\text { BALANCEAM } \\
\text { CIRC/REMANEJ } \\
\text { TRANSF }\end{array}$ & 0 & 0 & 0 & 0 & 0,65 & 0,37 & 1,24 & 2,42 & 0 & 0 \\
\hline $\begin{array}{l}\text { CASCAS/GALHOS } \\
\text { LANCADOS NA } \\
\text { REDE }\end{array}$ & 1,17 & 0,65 & 1,08 & 0,53 & 0,47 & 0,06 & 0,15 & 0,2 & 0 & 0 \\
\hline $\begin{array}{l}\text { COMPONENTE } \\
\text { AVARIADO/DESRE } \\
\text { GULAD }\end{array}$ & 2,17 & 4,95 & 2,51 & 2,09 & 0 & 0 & 0,05 & 0,03 & 5,28 & 5,58 \\
\hline $\begin{array}{l}\text { CORROSAO/OXID } \\
\text { ACAO/POLUICAO }\end{array}$ & 0,11 & 0,03 & 0,48 & 0,28 & 2,2 & 1,95 & 8,03 & 6,75 & 0,03 & 0,01 \\
\hline $\begin{array}{l}\text { DEFEITO INST. } \\
\text { INTERNA } \\
\text { CONSUMID }\end{array}$ & 0 & 0 & 0,01 & 0 & 0,15 & 0,12 & 0,49 & 1,55 & 0 & 0 \\
\hline $\begin{array}{l}\text { DESCARGA } \\
\text { ATMOSFERICA }\end{array}$ & 2,16 & 1,15 & 5,09 & 5 & 1,47 & 0,88 & 0,09 & 0,03 & 13,6 & 9,42 \\
\hline $\begin{array}{l}\text { FALHA HUMANA } \\
\text { DA EMPRESA }\end{array}$ & 0,26 & 0,33 & 0,09 & 0,76 & 1,5 & 0,08 & 7,02 & 2,13 & 0,12 & 0,03 \\
\hline $\begin{array}{l}\text { GALHOS TOCANDO } \\
\text { A REDE (PODA) }\end{array}$ & 0,23 & 0,02 & 0,89 & 0,31 & 0,45 & 0,93 & 0,38 & 0,35 & 2,49 & 1,99 \\
\hline $\begin{array}{l}\text { GEADA/NEVE/BAI } \\
\text { XA } \\
\text { TEMP./GRANIZO }\end{array}$ & 0 & 0 & 0,76 & 0,56 & 0 & 0 & 0,25 & 0,12 & 0 & 0 \\
\hline $\begin{array}{l}\text { NAO } \\
\text { IDENTIFICADA }\end{array}$ & 3,07 & 3,25 & 4,24 & 2,84 & 4,12 & 2,88 & 19,46 & 21,5 & 11,59 & 13,29 \\
\hline $\begin{array}{l}\text { OBJETOS } \\
\text { ESTRANHOS NA } \\
\text { RD }\end{array}$ & 0,13 & 0,03 & 4,24 & 2,84 & 0,05 & 0,04 & 0,1 & 0,06 & 0.65 & 0.33 \\
\hline $\begin{array}{l}\text { TRANSF } \\
\text { CARGA/RETORN } \\
\text { CONFIG NOR }\end{array}$ & 0,02 & 0,13 & 0,03 & 0,01 & 0,21 & 0,99 & 0,36 & 0,54 & 0,03 & 0,11 \\
\hline $\begin{array}{l}\text { VENTO/VENDAVA } \\
\text { L }\end{array}$ & 3,4 & 3,55 & 2,44 & 2,96 & 4,47 & 5,58 & 18,17 & 6,85 & 6,68 & 5,33 \\
\hline
\end{tabular}

Como não existe no formulário de levantamento de causas um ítem específico para o problema ocorrido, isto é, atuação dos equipamentos de proteção sem que se encontrasse uma causa, as referidas ocorrências são 
lançadas como "Não Identificadas", conforme mostradas na Tabela 4, para o anos de 2002 até 2006. Para os anos de 2004, 2005 e 2006, os valores referem-se aos relés microprocessados e os anos 2002 e 2003 para os relés estáticos. 
Realizando-se uma análise dos valores da causa tipo "Não Identificada" e colocando-se em forma de gráficos para melhor visualização, tem-se na Figura 60 a evolução do índice DEC.

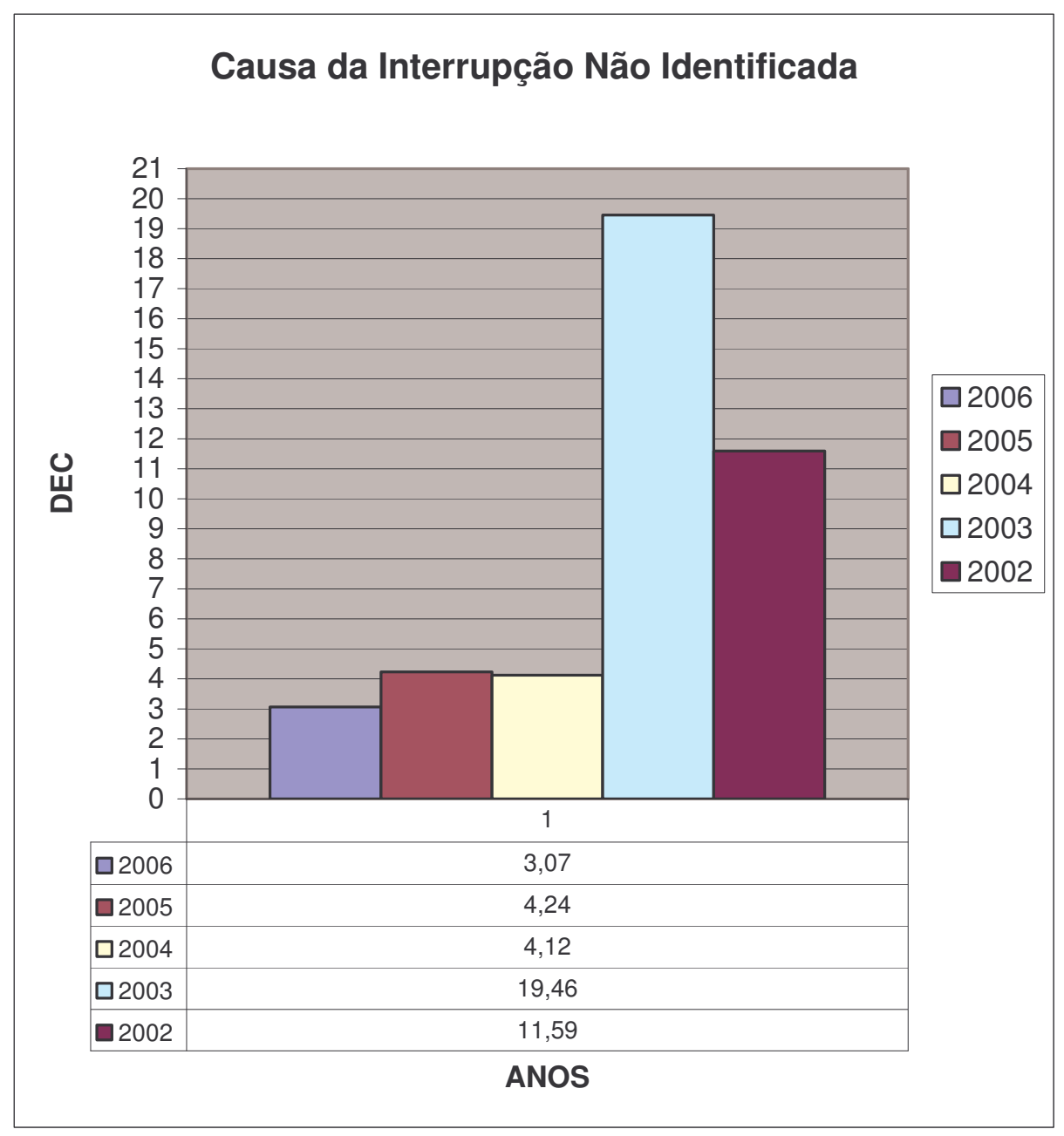

Figura 60 - Evolução do DEC devido a Causa Não Identificada - SE CDA

Através dos valores plotados, verifica-se que ocorreu uma diminuição do DEC, devido a causa "Não Identificada", evidenciando-se um decréscimo acentuado após a instalação dos relés microprocessados no final do ano de 2003 , onde os valores passaram de 19,46 horas/ano para 4,12 horas/ano.

O mesmo tipo de análise pode-se fazer com o índice FEC, verificando-se as 
valores do gráfico da Figura 61.

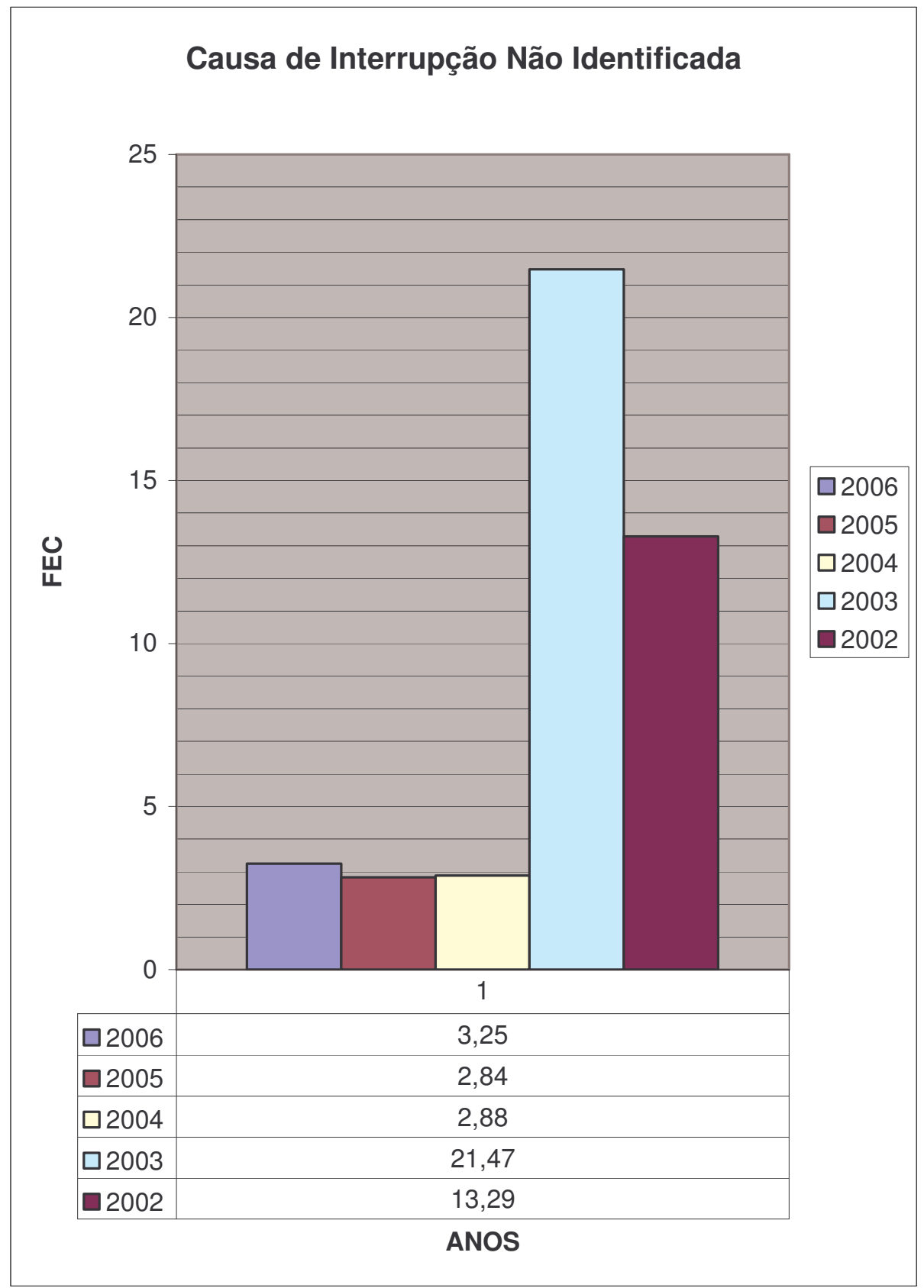

Figura 61 - Evolução do FEC devido a Causa Não Identificada - SE CDA

Através da análise dos valores plotados, ocorreu uma diminuição do FEC, devido a causa "Não Identificada", verificando-se um decréscimo acentuado após a instalação dos relés microprocessados no final do ano de 2003, onde o índice passou de 21,47 interrupções/ano para 2,88 interrupções/ano. 
4.3.4 Análise Econômica pelo método de Priorização de Obras - Payoff

Uma outra análise que pode-se realizar para mostrar as vantagens da substituição dos equipamentos de proteção, com as novas funções a eles agregadas, é o cálculo através do método de priorização de obras - Payoff.

Conforme referência [57], da qual será utilizado o módulo 11 - Instalação de Religadores Automáticos e Pinçamentos.

Onde o benefício esperado é a redução da energia não distribuída proporcionada pela coordenação da proteção que o religador automático instalado proporciona; diminui-se a queima de fusíveis no ramal e também reduz-se o custo de operação com a substituição de fusíveis.

Estes benefícios estão representados pela equação

$$
\Delta \mathrm{C}_{\mathrm{END}}=\left(\sum_{\mathrm{i}=1}^{\mathrm{n}} \mathrm{P}_{\mathrm{INS}} \cdot \mathrm{DPE} \mathrm{E}_{\mathrm{i}}\right) \cdot \mathrm{FU} \cdot \cos \varphi \cdot \mathrm{FC} \cdot \mathrm{f}_{\mathrm{T}} \cdot \mathrm{k}_{\mathrm{CE}} \cdot \mathrm{k}_{\mathrm{m}} \cdot \mathrm{q} \cdot \mathrm{C}_{\mathrm{i}} \quad[\mathrm{US} \$ / \mathrm{ano}]
$$

\section{Equação 1}

onde:

$\mathrm{n}$ : número de chaves fusíveis dos ramais e sub-ramais;

PINSi: potência total instalada a jusante da chave i , em kVA;

$\cos \varphi$ : fator de potência - utilizar 0,92;

DPE $E_{\mathrm{i}}$ d duração das interrupções (próprias) do elo fusível i , em horas/ano;

FU: fator de utilização - utilizar FU = 0,2;

$\mathrm{f}_{\mathrm{T}}$ : índice que exprime a relação defeitos transitórios/defeitos permanentes

- utilizar $\mathbf{f}_{\mathrm{T}}=0,7$;

FC: fator de carga - utilizar FC = 0,3; 
kCE: fator de correção em função de consumidores especiais que serão beneficiados com a obra (valor $=0,95$ para esta obra, conforme o Anexo I do Payoff);

$\mathrm{k}_{\mathrm{m}}$ : fator de correção para considerar o efeito da manutenção preventiva (valor = 0,40 para esta obra, conforme o Anexo II do Payoff);

q: taxa de crescimento da potência instalada - utilizar $q=1,03$;

$C_{j}$ : custo unitário do $\mathrm{kWh}$ não distribuído - utilizar $C_{i}=U S \$ 2.12 / k W h . a n o$.

A Equação 1 considera a substituição de uma chave fusível em um ramal representativo de um alimentador por um religador automático, considerando-se todos os benefícios trazidos por esta substituição.

Como não existe um módulo específico para a substituição de religadores antigos, por novos, microprocessados, a utilização da referida fórmula é válida fazendo-se as correções, de que a potência instalada a ser utilizada será a própria potência do circuito alimentador e a "DPE" que seria a duração das interrupções próprias do elo fusível é substituída pelo DEC total do alimentador no ano considerado antes da substituição do relé estático pelo microprocessado. Desta maneira está se realizando uma aproximação melhor para o caso estudado.

Realizando o cálculo da energia não distribuída para o alimentador Tereza Cristina da Subestação Cândido de Abreu, com os dados obtidos dos relatórios de acompanhamento de índices da Copel e dados fornecidos pelo manual do Payoff, conforme referência [57], para o ano de 2003, antes da substituição dos relés, tem-se:

Cend $=3585 \times 63,45 \times 0,2 \times 0,92 \times 0,3 \times 0,7 \times 0,95 \times 0,40 \times 1,03 \times 2,12$

Cend $=7293,14$ US $\$$ /ano. 
Condiderando-se a taxa de conversão de US $\$ 1,00=\mathrm{R} \$ 2,30$, tem-se:

Cend $=7293,14 \times 2,30$

\section{Cend $=\mathbf{R} \$ 16.774,22$}

O processo adotado para o cálculo do Payoff baseia-se diretamente na função de custo global, o investimento (custo) relativo à execução de uma determinada obra provoca variações (normalmente negativas) em uma ou mais parcelas do custo global:[57]

$$
I N V \Rightarrow\left[\Delta \mathrm{C}_{\mathrm{PER}}+\Delta \mathrm{C}_{\mathrm{OM}}+\Delta \Delta_{\mathrm{LUC}}+\Delta \mathrm{C}_{\mathrm{PEN}}+\Delta \mathrm{C}_{\mathrm{END}}+\Delta \mathrm{C}_{\mathrm{DT}}\right] \quad \text { Equação } 2
$$

Onde:

$\Delta \mathrm{C}_{\mathrm{PER}}=$ Custo das Perdas

$\Delta \mathrm{C}_{\mathrm{OM}}=$ Custo de Operação e Manutenção

$\Delta C_{L U C}=$ Lucro devido à melhoria do nivel de tensão

$\Delta \mathrm{C}_{\mathrm{PEN}}=$ Penalidade devido a violação do indicador de qualidade

$\Delta \mathrm{C}_{\mathrm{END}}=$ Custo da Energia não distribuída

$\Delta \mathrm{C}_{\mathrm{DT}}=$ Custo da Desvio de Tensão

O benefício "B" decorrente da obra é a soma destas variações, com o sinal trocado (representando a diminuição de custos):

$$
\mathrm{B}=-\left(\Delta \mathrm{C}_{\mathrm{PER}}+\Delta \mathrm{C}_{\mathrm{OM}}+\Delta \mathrm{LUC}+\Delta \mathrm{C}_{\mathrm{PEN}}+\Delta \mathrm{C}_{\mathrm{END}}+\Delta \mathrm{C}_{\mathrm{DT}}\right)
$$

As diversas variações são normalmente funções crescentes no tempo, 
acompanhando o aumento normal das cargas. Assim sendo, as variações deveriam ser calculadas ano a ano, durante um período de análise relativamente longo (de dez a vinte anos), e em seguida trazidas para valor presente usando uma taxa de atualização adequada. A divisão dos investimentos pelos respectivos valores presentes representa a relação custo/benefício da obra.

É utilizada uma análise simplificada que consiste na simples divisão do custo da obra pelo benefício provável no primeiro ano: o resultado obtido, expresso em anos, é normalmente designado por payoff e representa, aproximadamente, o tempo necessário para pagar a obra:

$$
\text { PAYOFF }=\frac{\text { INV }}{\text { B }} \quad \text { [anos ] }
$$$$
\text { Equação } 3
$$

A simplificação deve-se ao fato de existir uma relativa compensação entre o crescimento dos benefícios anuais e o processo de cálculo dos respectivos valores presentes. No caso limite de os benefícios aumentarem anualmente a um ritmo igual à taxa de atualização, os seus valores presentes seriam constantes e o cálculo simplificado conduziria a valores exatos.

Neste caso foi considerado para a parcela "B" do Payoff apenas o custo da energia não distribuída.

O valor do investimento considerado é o da substituição do religador com relé estático por um religador com relé microprocessado, para os qual temse os seguintes valores: 
Tabela 5 - Custo Inicial Substituição de 4 religadores com relé microprocessado

\begin{tabular}{||l|lc||}
\hline \multicolumn{3}{||l||}{ AUTOMAÇÃO COM SUBST. RELIGADORES/RELÉS } \\
\hline Investimento Inicial & $\mathbf{R} \$$ & $\mathbf{9 3 . 8 0 6 , 2 4}$ \\
\hline Equipamentos & $\mathrm{R} \$$ & $152.405,99$ \\
\hline (+) Custos de Projeto & $\mathrm{R} \$$ & 828,91 \\
\hline (+) Custos de Instalação & $\mathrm{R} \$$ & $6.859,20$ \\
\hline (-) Aproveitamento de RAs Antigos & $\mathrm{R} \$$ & $66.287,87$ \\
\hline
\end{tabular}

Os valores da Tabela 5 são referenciados para quatro religadores. Como está sendo considerado a análise de apenas o religador do circuito Tereza Cristina, tem-se o Investimento Inicial:

Custo de quatro Religadores Novos $=\mathrm{R} \$ 93.806,24$

Custo para um religador $=\mathrm{R} \$ 93.806,24 / 4$

Custo para um religador $=\mathrm{R} \$ \mathbf{2 3 . 4 5 1 . 5 6}=\mathrm{INV}$

Calculando-se o Payoff, tem - se:

Payoff $=R \$ 23.451,56 / R \$ 16.774,22$

\section{Payoff $=1,4$ anos}

Este é o tempo necessário para que a obra de substituição do religador com relé estático por um religador com relé microprocessado e com os ajustes e funções novas implementadas se pague.

Comparando-se este tempo, com os tempos de outras obras, pode-se concluir que a obra possuí grande oportunidade de ser aprovada para a sua realização quando priorizada com todas as demais obras de uma concessionária de energia. 


\subsection{ANÁLISE ECONÔMICA DA SUBSTITUIÇÃO EQUIPAMENTOS}

4.4.1 Vantagens Econômicas dos Controladores de Subestação Dispositivos Eletrônicos Inteligentes - IEDs

Conforme comparação de valores realizada na dissertação da referência [20], o autor mostra uma tabela comparativa das vantagens econômicas de se utilizar um sistema composto de cinco relés microprocessados, chamados de IEDs - Dispositivos Eletrônicos Inteligentes, integrados através de uma rede padrão Ethernet, dual, através de uma rede de fibras óticas, quando comparada com um sistema onde são utilizados componentes discretos.

Tabela 6 - Comparação entre Scada Tradicional e Controlador de Subestação[20]

\begin{tabular}{|l|l|l|}
\hline \multicolumn{3}{|l|}{ Vantagens Econômicas dos Controladores de Subestação } \\
\hline FUNÇÃO & $\begin{array}{r}\text { CUSTOS INDIVIDUAIS } \\
\text { NO SCADA } \\
\text { TRADICIONAL }\end{array}$ & $\begin{array}{c}\text { SOLUÇÃO DO } \\
\text { CONTROLADOR DE } \\
\text { SUBESTAÇÃO }\end{array}$ \\
\hline CLP & $\mathrm{R} \$ 4.000,00$ & Incorporada \\
\hline UTR & $\mathrm{R} \$ 20.000,00$ & Incorporada \\
\hline Medidores & $\mathrm{R} \$ 6.000,00$ & Incorporada \\
\hline $\begin{array}{l}\text { Monitoramento de } \\
\text { Qualidade de Energia }\end{array}$ & $\mathrm{R} \$ 4.000,00$ & Incorporada \\
\hline $\begin{array}{l}\text { DFR } \\
\text { Interfaces } \\
\text { Comunicação }\end{array}$ & $\mathrm{R} \$ \mathbf{4} 4.000,000,00$ & Incorporada \\
\hline Custos Totais & $\mathbf{R} \mathbf{4} \mathbf{4 8 . 0 0 0 , 0 0}$ & $\mathbf{R} \mathbf{3 0 . 0 0 0 , 0 0}$ \\
\hline
\end{tabular}


Analisando-se os valores da Tabela 6, onde se comparados os Custos Totais de Investimento Inicial para o caso da utilização dos Dispositivos Eletrônicos Inteligentes com o mesmo custo dispendido com os equipamentos necessários para a realização das mesmas funções oferecidas por aqueles equipamentos, isto é, controle, automação, medição, monitoramento da qualidade de energia, gravação das faltas e comunicação:

$$
\left[\frac{R \$ 48.000}{R \$ 30.000}-1\right] x 100=60 \%
$$

Verifica-se uma economia de $60 \%$ ( sessenta por cento) se comparados apenas o custo inicial de implantação, mostrando que a referida substituição é economicamente aceitável. 
4.4.2 Análise Econômica da Substituição de Religadores com relés Estáticos por Religadores com Relés Microprocessados Automatizados

Dispêndios consideráveis de capital são classificados como Investimentos de Longo Prazo, uma vez que comprometem um determinado curso de ação da empresa. Projetos dessa magnitude necessitam de procedimentos para analisar e detalhar adequadamente sua viabilidade.

Neste item realizamos uma análise, no sentido de demonstrar os aspectos técnicos e econômicos que auxiliaram a Copel Distribuição na tomada de decisão em substituir os equipamentos de Proteção.[12]

No passado, utilizava-se um sistema de automação com a topologia constituída de Unidades de Aquisição e Controle - UAC, responsáveis pelo interfaceamento com o processo elétrico, e Unidade Central de Controle UCC, responsável pelo sistema SCADA, UTR e funções automatizadas.

Contudo, com a evolução tecnológica dos equipamentos instalados nas subestações surgiu a opção de automatizar estes equipamentos utilizandose um protocolo de comunicação aberto e acessível no mercado, sem haver a necessidade da instalação de Unidades de Aquisição e Controle (UAC). A opção mais viável por estar presente na maior parte dos equipamentos foi o protocolo DNP3.0.

Contudo, como somente os equipamentos mais modernos, entre eles os relés microprocessados, possuem este tipo de tecnologia embarcada, para que se realize a automação da subestação fez-se necessária a substituição dos referidos relés já instalados.

Com aquisição de relés novos, microprocessados e sem a necessidade da instalação de Unidades de Aquisição e Controle, surgiram como variáveis determinantes do processo os demais benefícios que poderiam ser 
quantificados ao se instalar religadores, com relés microprocessados novos nos circuitos alimentadores:[12]

Substituição de religadores e disjuntores por obsolescência, falta de componentes para manutenção no mercado;

Implementação dos recursos de proteção integrados aos equipamentos (oscilografia, localização de faltas, medições, eventos, etc.);

Substituição de religadores hidráulicos instalados nas subestações (que apresentam poucas opções para a coordenação da proteção, mas bem aproveitados na rede de distribuição); 
4.4.3 Comparação dos Casos por Investimento Inicial e Fluxo de Caixa

Para verificar-se as reais vantagens da substituição dos equipamentos de proteção antigos e comparar-se com um sistema onde se utiliza relés microprocessados e a automação destes diretamente, isto é, sem a utilização das Unidades de Aquisição e Controle, mostra-se a seguir o caso de uma Subestação onde foram substituídos quatro religadores com relés do tipo estático e com automação convencional, por quatro religadores com relés microprocessados, com automação realizada diretamente com a utilização do protocolo de comunicação DNP 3.0 destes relés. 
Tabela 7 - Fluxo de Entrada de Caixa Operacional de Subestação com Relés Microprocessados

\begin{tabular}{|c|c|c|}
\hline \multicolumn{3}{|c|}{$\begin{array}{c}\text { Religadores-Relés Microprocessados - } \\
\text { Automatizados }\end{array}$} \\
\hline Investimento Inicial & $\mathbf{R} \$$ & $93.806,24$ \\
\hline Equipamentos & $\mathrm{R} \$$ & $152.405,99$ \\
\hline (+) Custos de Projeto & $\mathrm{R} \$$ & 828,91 \\
\hline (+) Custos de Instalação & $\mathrm{R} \$$ & $6.859,20$ \\
\hline (-) Aproveitamento de RAs Antigos & $\mathrm{R} \$$ & $66.287,87$ \\
\hline \multicolumn{3}{|l|}{ Fluxos de Entrada de Caixa Operacionais } \\
\hline Receita & $\mathrm{R} \$$ & $141.690,13$ \\
\hline (-) Despesas & $\mathrm{R} \$$ & $16.014,82$ \\
\hline Lucro antes da Depreciação e I. Renda & $\mathrm{R} \$$ & $125.675,31$ \\
\hline (-) Depreciação (5\%) & $\mathrm{R} \$$ & $7.620,30$ \\
\hline Lucro líquido antes do I. Renda & $\mathrm{R} \$$ & $118.055,01$ \\
\hline (-) Imposto de Renda (alíq.30\%) & $\mathrm{R} \$$ & $35.416,50$ \\
\hline Lucro líquido após o I. Renda & $\mathrm{R} \$$ & $82.638,51$ \\
\hline (+) Depreciação (5\%) & $\mathrm{R} \$$ & $7.620,30$ \\
\hline Fluxo de Entrada de Caixa Operacional & $\mathbf{R} \$$ & $90.258,81$ \\
\hline
\end{tabular}


Tabela 8 - Fluxo de Entrada de Caixa Operacional de Subestação com Relés Estáticos e Remota Convencional

\begin{tabular}{|c|c|c|}
\hline \multicolumn{3}{|c|}{$\begin{array}{c}\text { Religadores Estáticos Automatizados com UAC - VIA } \\
\text { REMOTA }\end{array}$} \\
\hline Investimento Inicial & $\mathbf{R} \$$ & $73.499,02$ \\
\hline Equipamentos & $\mathrm{R} \$$ & $62.823,94$ \\
\hline Custos de Instalação & $\mathrm{R} \$$ & $14.675,08$ \\
\hline (-) Aproveitamento de Ativos Velhos & $\mathrm{R} \$$ & $4.000,00$ \\
\hline \multicolumn{3}{|c|}{ Fluxos de Entrada de Caixa Operacionais } \\
\hline Receita & $\mathrm{R} \$$ & $141.690,13$ \\
\hline (-) Despesas & $\mathrm{R} \$$ & $34.180,80$ \\
\hline Lucro antes da Depreciação e I. Renda & $\mathrm{R} \$$ & $107.509,33$ \\
\hline (-) Depreciação (10\%) & $\mathrm{R} \$$ & $6.282,39$ \\
\hline Lucro líquido antes do I. Renda & $\mathrm{R} \$$ & $101.226,93$ \\
\hline (-) Imposto de Renda (alíq.30\%) & $\mathrm{R} \$$ & $30.368,08$ \\
\hline Lucro líquido após o I. Renda & $\mathrm{R} \$$ & $70.858,85$ \\
\hline (+) Depreciação (10\%) & $\mathrm{R} \$$ & $6.282,39$ \\
\hline Fluxo de Entrada de Caixa Operacional & $\mathbf{R} \$$ & $77.141,25$ \\
\hline
\end{tabular}

Na Tabela 7 é apresentado o Fluxo de Caixa para o caso da substituição dos religadores com relés estáticos por religadores com relés microprocessados. Neste caso considerou-se uma depreciação de $5 \%$ para os religadores com relés novos e uma vida útil de 20 anos.

Na Tabela 8 é apresentado o Fluxo de Caixa para o sistema antigo onde os religadores possuíam relés estáticos e a automação é realizada com Unidades de Aquisição e Controle. Para estes equipamentos considerou-se uma taxa de depreciação de 10 \% devido ao fato de que estas unidades de 
aquisição utilizam tecnologia de hardware onde alguns de seus componentes devem ser substituídos a cada 7 anos.

Com base nestas duas tabelas de dados, as quais foram montadas com dados reais, obtidos durante o processo de substituição dos referidos equipamentos, calculou-se o fluxo de caixa incremental anual de :

$\mathrm{R} \$ 90.258,81-\mathrm{R} \$ 77.114,25=\mathrm{R} \$ 13.177,56$

Este valor de $\mathrm{R} \$ 13.177,56$, apresenta uma vantagem favorável para o caso da utilização de religadores com relés microprocessados e automatizados se comparados com a utilização dos religadores com relés estáticos e automatizados com Unidades de Aquisição e Controle distintos. 
4.4.4 Comparação dos Casos pelo método de Valor Presente Líquido (VPL) e Taxa Interna de Retorno (TIR)

Existem vários tipos de técnicas que podem ser utilizadas quando da tomada de decisões para escolha entre um determinado projeto e outro.

Para o caso em questão, onde as vidas dos equipamentos utilizados não são iguais, serão utilizados os métodos recomendados pela bibliografia, conforme os casos a seguir:

Conforme a referência [40], o método do Valor Presente Líquido ( VPL), é a soma dos desembolsos e receitas de um investimento referidos ao instante inicial.

O valor presente de seus fluxos de entrada de caixa é subtraído do investimento inicial, e o resultado é descontado a uma taxa de desconto que chama-se de taxa mínima de atratividade ao investimento, que é a taxa mínima na qual o investidor estaria disposto a aplicar no projeto. Caso o valor do método Valor Presente Líquido a esta taxa seja maior que zero, o projeto é considerado aceitável. [12] [13] [40]. 
Tabela 9 - Análise pelo VPL e TIR para substituição de Quatro Religadores

\begin{tabular}{|c|c|c|c|c|}
\hline \multirow[b]{2}{*}{ Investimento Inicial } & \multicolumn{2}{|c|}{$\begin{array}{c}\text { Religador com } \\
\text { Relé } \\
\text { Microprocessado }\end{array}$} & \multicolumn{2}{|c|}{$\begin{array}{c}\text { Religador com } \\
\text { Relé Estático + } \\
\text { UAC }\end{array}$} \\
\hline & $\mathrm{R} \$$ & $93.806,24$ & $\mathrm{R} \$$ & $73.499,02$ \\
\hline Ano & \multicolumn{4}{|c|}{ Fluxos de Entrada de Caixa Operacionais } \\
\hline 1 & $\mathrm{R} \$$ & $(93.806,24)$ & $\mathrm{R} \$$ & $(73.499,02)$ \\
\hline 2 & $\mathrm{R} \$$ & $90.258,81$ & $\mathrm{R} \$$ & $77.141,25$ \\
\hline 3 & $\mathrm{R} \$$ & $90.258,81$ & $\mathrm{R} \$$ & $77.141,25$ \\
\hline 4 & $\mathrm{R} \$$ & $90.258,81$ & $\mathrm{R} \$$ & $77.141,25$ \\
\hline 5 & $\mathrm{R} \$$ & $90.258,81$ & $\mathrm{R} \$$ & $77.141,25$ \\
\hline 6 & $\mathrm{R} \$$ & $90.258,81$ & $\mathrm{R} \$$ & $77.141,25$ \\
\hline 7 & $\mathrm{R} \$$ & $90.258,81$ & $\mathrm{R} \$$ & $77.141,25$ \\
\hline 8 & $\mathrm{R} \$$ & $90.258,81$ & $\mathrm{R} \$$ & $77.141,25$ \\
\hline 9 & $\mathrm{R} \$$ & $90.258,81$ & & \\
\hline 10 & $\mathrm{R} \$$ & $90.258,81$ & & \\
\hline 11 & $\mathrm{R} \$$ & $90.258,81$ & & \\
\hline 12 & $\mathrm{R} \$$ & $90.258,81$ & & \\
\hline 13 & $\mathrm{R} \$$ & $90.258,81$ & & \\
\hline 14 & $\mathrm{R} \$$ & $90.258,81$ & & \\
\hline 15 & $\mathrm{R} \$$ & $90.258,81$ & & \\
\hline 16 & $\mathrm{R} \$$ & $90.258,81$ & & \\
\hline 17 & $\mathrm{R} \$$ & $90.258,81$ & & \\
\hline 18 & $\mathrm{R} \$$ & $90.258,81$ & & \\
\hline 19 & $\mathrm{R} \$$ & $90.258,81$ & & \\
\hline 20 & $\mathrm{R} \$$ & $90.258,81$ & & \\
\hline Período de Pay Back Time & & 0 meses & 0 anc & e 11 meses \\
\hline Taxa Mínima de Atratividade & & $5 \%$ & & $15 \%$ \\
\hline Valor Presente Líquido - VPL & & $.903,22$ & $\mathbf{R} \mathbf{\$}$ & $215.166,04$ \\
\hline Taxa Interna de Retorno - TIR & & $6 \%$ & & $104 \%$ \\
\hline
\end{tabular}


Pela análise dos dados obtidos na Tabela 9, onde é utilizada uma taxa mínima de atratividade de $15 \%$, verifica-se que para o método do Valor Presente Líquido, a substituição de religadores com relés microprocessados e automatizados é mais atraente que a utilização de religadores com relés estáticos e automatizados com Unidades de Aquisição e Controle.

Conforme a referência [13], o método da Taxa Interna de Retorno (TIR) é uma técnica de orçamento de grande aceitação. A TIR é a taxa de desconto que iguala a VLP de um projeto em estudo a zero. Caso a TIR seja maior que a taxa mínima de atratividade o projeto poderá ser aceito.

A TIR é também chamada de taxa de retorno.[40]

No caso em estudo, verificou-se que a TIR para o projeto utilizando-se relés microprocessados foi de $96 \%$ e para o projeto com relés estáticos foi de 104 $\%$ ambos maiores do que a taxa mínima de atratividade que é de $15 \%$, logo os dois casos são aceitáveis.

Comparando-se o método do VPL e da TIR, neste caso, verifica-se que há um conflito entre os dois métodos.

Para dirrimir melhor os resultados foram traçados os perfis de Valor Presente Líquido, que descrevem valores presentes líquidos a diversas taxas de desconto, uma das quais a própria TIR.[12] 
Conforme a referência [56], plotou-se o gráfico da Figura 62, do Valor Presente das duas alternativas em função da Taxa de Desconto em percentual, onde os vários valores de Taxa de Desconto representam as várias posições possíveis que a Taxa Mínima de Atratividade pode ocupar.

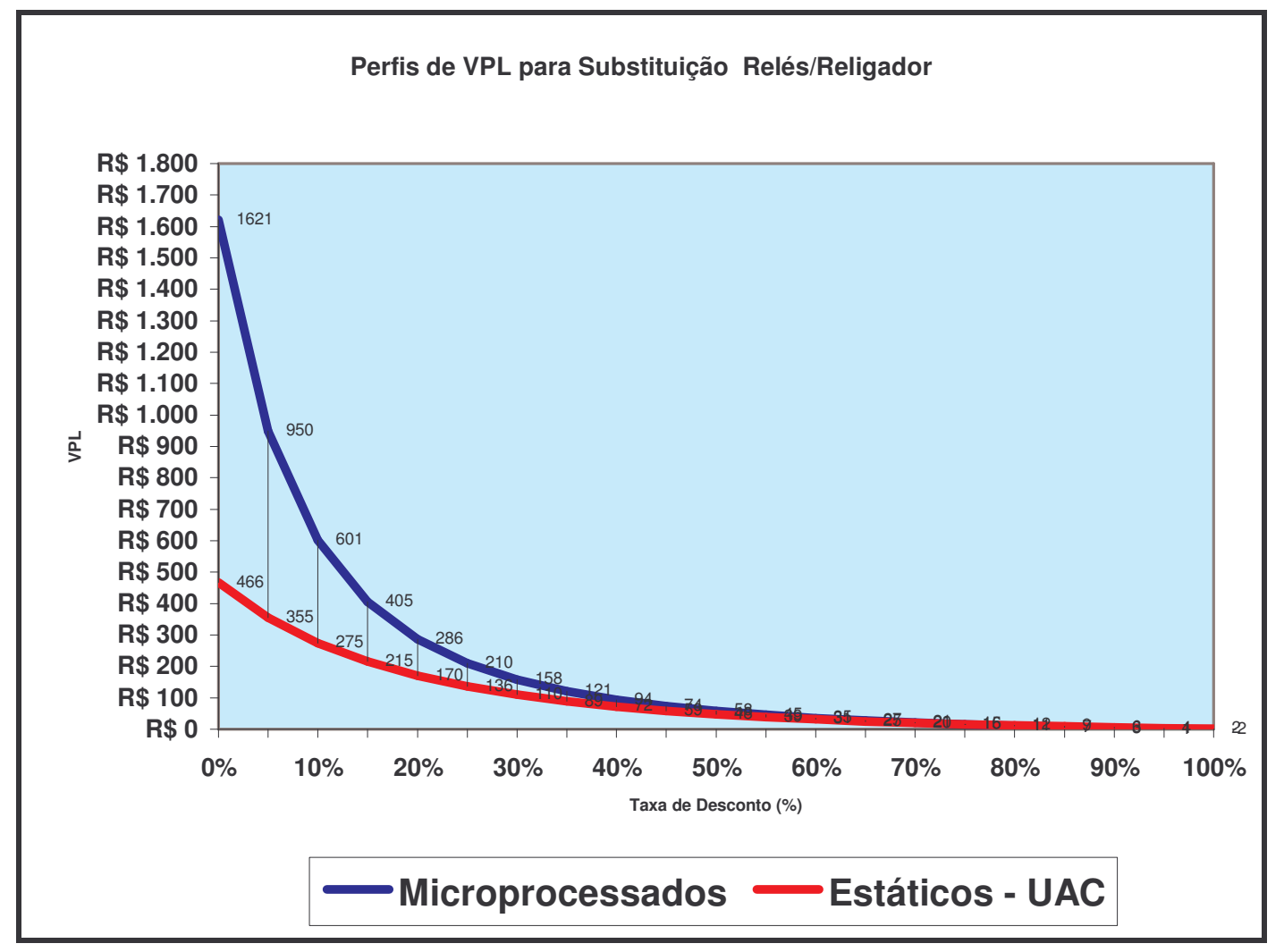

Figura 62 - Perfil de Valor Presente Líquido para substituição de relés estáticos por microprocessados.

Em virtude da existência do Ponto de Equilíbrio (intersecção das duas curvas representativas do fluxo de caixa - Relés Microprocessados e Relés Estáticos), a seleção de melhor alternativa dependerá da localização da Taxa Mínima de Atratividade em função à taxa correspondente ao ponto de intersecção das duas alternativas.

Assim, pela análise dos dados plotados no gráfico da Figura 62, o ponto de Equílibrio se encontra em $70 \%$, logo podería-se dizer que, se a Taxa 
Mínima de Atratividade fosse igual a:

- $15 \%$ - a melhor alternativa seria a de substituir or relés estáticos por relés microprocessados automatizados, por possuir, a esta percentagem, um Valor Presente ( $\mathrm{R} \$ 404.903,22)$ mais alto do que o Valor Presente da alternativa com relés estáticos ( $R \$ 215.166,04$ ), apesar de ambas as propostas serem aceitáveis como investimentos produzindo retornos não negativos de rentabilidade, uma vez que, isoladamente, apresentam Taxas de Retorno não inferiores à Taxa Mínima de Atratividade ( $96 \%$ e 104\% respectivamente).[56]

- $70 \%$ - as duas alternativas são iguais, podendo qualquer uma, indistintamente, ser selecionada, visto que ambas são aceitáveis como investimentos produzindo retornos não negativos de rentabilidade, uma vez que, isoladamente, apresentam Taxas de Retorno não inferiores à Taxa Mínima de Atratividade.

- $90 \%$ - a melhor alternativa já passa a ser a de permanecer com os relés estáticos automatizados, por possuir, a esta percentagem, um Valor Presente $(R \$ 6.000,00)$ mais alto do que a alternativa de substituição dos relés por microprocessados ( $R \$ 3.000,00$ ), apesar de ambas as propostas serem aceitáveis como investimentos produzindo retornos não negativos de rentabilidade, uma vez que, isoladamente, apresentam Taxas de Retorno não inferiores à Taxa Mínima de Atratatividade.

Através da análise do gráfico da Figura 62 tem-se que para taxas de desconto da VPL menores que $70 \%$, a utilização de religadores com relés microprocessados apresenta um valor presente líquido maior do que a com a utilização de relés estáticos automatizados apesar de que a Taxa Interna de Retorno que zera o Valor Presente Líquido deste projeto ser menor ( 96\% e 104\% respectivamente) conforme mostra a Tabela 9. Como a taxa de atratividade utilizada nos dois casos foi de $15 \%$, o projeto com a substituição dos religadores com relés estáticos por religadores com relés 
microprocessados e ambos automatizados, mostra-se mais vantajoso, financeiramente. 


\section{CONCLUSÕES}

Os relés microprocessados oferecem muitas vantagens e benefícios sobre os relés eletromecânicos, como custos de instalação e manutenção reduzidos, flexibilidade de aplicação e funções de controle e monitoração cada vez mais desenvolvidas.

A utilização dos relés eletromecânicos não foi abandonado por não atenderem aos requisitos de proteção dos sistemas elétricos de potência, mas devido a sofisticação cada vez maior e ao número de funções e facilidades que os relés digitais tem oferecido aos Engenheiros de Proteção e de análises de ocorrências das empresas de energia e da indústria.

Os relés digitais além de fazerem a função principal para o qual os relés eletromecânicos e estáticos foram desenhados e construídos, também realizam as funções de medição, controle, oscilografia, comunicação, automação e integração com os demais componentes do sistema elétrico de potência.

Atualmente com o avanço dos sistemas da Internet e Ethernet também já é possível poder se realizar a monitoração, interrogação e alteração dos ajustes dos relés digitais de proteção desde um microcomputador instalado em um escritório de uma companhia de energia ou mesmo também através de um Palmtop remotamente através de um sistema de comunicação, como por exemplo o sistema Wirelles.

Uma outra vantagem de relés possíveis de serem automatizados frente à automação convencional (lógica à relés) é a diminuição da quantidade de relés auxiliares, que podem ser substituídos por linhas de programação com a mesma confiabilidade, conseqüentemente diminuindo o tamanho dos painéis, casa de comando como também diminuindo a quantidade de fiação.

A complexidade dos estudos de proteção onde são empregados dispositivos de proteção de sobrecorrente pode ser avaliada com base na quantidade de tipos diferentes de dispositivos, principalmente com o advento dos controles 
microprocessados, que possibilitam inúmeros modificadores de curvas para atender a imensa variedade de parâmetros reais que ocorrem em cada segmento do Sistema de Distribuição de energia elétrica. Sabe-se que erros na elaboração de um estudo de proteção, ocasionam interrupções indevidas e prejudicam financeiramente tanto às concessionárias (multas) como aos consumidores, logo não é mais admissível a ocorrências destas interrupções.

Neste trabalho, mostrou-se através de alguns casos reais ilustrados no capítulo 4, como a utilização de relés microprocessados permitem solucionar problemas que até então não poderiam ser resolvidos com a utilização dos relés convencionais.

No caso das Subestações de Manoel Ribas e Cândido de Abreu, onde existiam os problemas de atuação das proteções por problemas de harmônicos existentes nas redes de distribuição, sendo que estas atuações foram resolvidas com a utilização de relés microprocessados com filtros incorporados em seu hardware. Também nestas subestações foi resolvido o problema da não coordenação entre as proteções de sobrecorrente, quando da utilização de relés estáticos, pela falta de opção de ajustes e funções mais flexíveis oferecidas pelos relés microprocessados.

A proteção de sobrecorrente aplicada corretamente otimiza e direciona o pessoal de operação quanto à inspeção do sistema de distribuição. O custo da elaboração e implantação de estudos de proteção é insignificante comparado aos benefícios alcançados.

Neste trabalho, também no capítulo 4, mostrou-se a viabilidade econômica da utilização dos relés microprocessados em substituição à proteções com relés estáticos e eletromecânicos, onde se comparou através de exemplos reais de substituição, através do emprego de métodos de comparação, da Engenharia Econômica, como por exemplo os métodos de Fluxo de Caixa, Investimento Inicial, Valor Presente Líquido e Taxa Interna de Retorno, que as substituições são viáveis economicamente.

Realizou-se também uma análise quanto aos índices de interrupção 
provocados no sistema de distribuição e a sua diminuição quando da substituição das proteções estáticas por microprocessadas, comprovando-se também que tais substituições são viáveis se analisadas pelo método de Priorização de Obras, onde o exemplo real utilizado apresentou um valor de Payoff de 1,4 anos.

Em conclusão o trabalho mostrou a viabilidade e benefícios técnicos e econômicos da utilização dos relés microprocessados.

Como parte do estudo cabe a indicação de possíveis desenvolvimentos futuros. Este trabalho abre perspectivas para novos desafios de estudos, análises e utilização de equipamentos para proteção do sistema de distribuição, como por exemplo:

- Desenvolvimento de filtros analógicos e digitais para os equipamentos de proteção antigos;

- Redução adicional de custos no desenvolvimento de novos hardwares para utilização em relés de proteção e para integração com mecanismos de interrupção, como disjuntores e religadores de diversas tecnologias;

- Softwares inteligentes para a realização automática dos ajustes e coordenações das funções de relés microprocessados;

- Utilização de novos tipos de sistemas de proteção que empregam sistemas inteligentes de reconfiguração do sistema elétrico e reconfiguração automática dos parâmetros de proteção sem a intervenção de operadores externos. 


\section{REFERÊNCIAS BIBLIOGRÁFICAS}

[01] VASCONCELLOS, A. S; JÚNIOR, José Carlos M. V. Sistemas de Proteção Digitais: Mudanças no Projeto, Instalação e Operação de Sistemas Elétricos. São Paulo, 2003.

[02] SENDI - Seminário Nacional de Distribuição de Energia Elétrica. Disponível em: http://www.sendibrasilia.com.br

[03] RUFATO, Eloi Jr, OLIVEIRA, Carlos C. B., OMORI, Júlio et alli. Análise da Influência de Componentes Harmônicos de Corrente em relés de Proteção nos Sistemas Monofásicos com Retorno pela Terra. VIII Simposio Iberoamericano sobre Protección de Sistemas Electricos de Potencia - SIPSEP. Monterrey. México, 05/2006.

[04] GE P\&C PUBLICATION. GEK - 105548A - DLP - Digital Transmission Line Relaying System with Three Phase Tripping, General Electric. USA, 2005.

[05] MOONEY, JOE. Microprocessor-Based Transmission Line Relay Applications. Schweitzer Engineering Laboratories, Inc, Pullman, WA, USA.

[06] HEISING, CHARLES R., PATTERSON, RONALD C, WEINTRAUB, ELAINE Y.. Digital Relay Software Quality. General Electric Protection \& Control. Malvern. PA. USA, 1997.

[07] ABB Relays AB. Relay circuits in high voltage power plants and substations. 1981.

[08] GE PUBLICATION. GET- 6450. Distribution System Feeder Overcurrent Protection. General Electric, USA 
[09] BURKE, J. J., KOCK, R. F., POWELL, L. J. A. Comparison of Static ad Electromechanical Time Overcurrent Relay Characteristics, Application and Testing. Presented at Pennsylvania Electric Association. USA, 1975

[10] TEAM ARTECHE - Disponível em: http://www.teamarteche.com

[11] ALSTOM T\&D ENERGY. Network Protection - Automation Guide. First Edition. Levallois-Perret. France, July 2002.

[12] PORTELA, Juliano C.,PINTO, José M., PEREIRA, Joel G.. Automação de Subestações através de Substituição de Religadores - Técnicas de Decisão. XV SEMINÁRIO NACIONAL DE DISTRIBUIÇÃO DE ENERGIA ELÉTRICA - SENDI 2002. Foz do Iguaçú, 2002.

[13] GITMAN, Lawrence J.. Princípios de Administração Financeira Essencial. Bookman. Porto Alegre, 2001.

[14] BORENSTEIN C. R., CAMARGO C. C. B.. O Setor Elétrico Brasileiro. 1997.

[15] STEVESON, Willian. Elementos de Análise de Sistemas de Potência. Mc Graw Hill, 1986.

[16] COURY, D. V. Introdução aos Sistemas Elétricos de Potência. Universidade de São Paulo. Escola de Engenharia de São Carlos. São Carlos.

[17] RUFATO, ELOI JR. Filosofia Geral de Proteção. Apostila do Curso de Proteção de Sistemas. CEFET-PR. Curitiba, 2002.

[18] KINDERMANN, GERALDO. Curto Circuito. editora Sagra-DC Luzzato, 1 edição. Porto Alegre,1992. 
[19] RUFATO, ELOI JR.. Relatórios de Ensaios de Curto Circuito na SE de Francisco Beltrão e Marmeleiro. Copel - CNDS - Relatório 01/98, Curitiba, 02/2002.

[20] OMORI, J. S., ORTEGA M. R., RUFATO, E., et alli. Análise de Componentes Harmônicos de Corrente em Sistema com Preponderância de Carga Conectada a Sistemas Monofásicos com Retorno pela Terra. XVI SEMINÁRIO NACIONAL DE DISTRIBUIÇÃO DE ENERGIA ELÉTRICA - SENDI 2004, Brasília,2004.

[21] COPEL - COMPANHIA PARANAENSE DE ENERGIA. Manuais de Instruções Técnicas de Proteção de Redes de Distribuição contra Sobrecorrentes - MIT's 162501, 162502 e 162503. Curitiba, 2004.

[22] CAMINHA, A.C. Introdução à Proteção dos Sistemas Elétricos. editora Blucher, 8 edição. São Paulo, 2000.

[23] RUFATO, ELOI JR; KOEHLER, MARCOS. Avanços Tecnológicos sob o Aspecto de Funções da Proteção de Sobrecorrente do Sistema de Distribuição. Universidade de São Paulo. São Paulo, 2002.

[24] BLACKBURN, J. L. Applied Protective Relaying. 2 edição. Editora: Westinghouse Electric Corporation. Coral Springs.Flórida, 1979.

[25] WESTINGHOUSE ELECTRIC CORPORATION. Electrical Transmission and Distribuition Reference Book. 4 edition. Westinghouse Electric Corporation. East Pittsburgh, PA, 1964.

[26] RAO, T. S. Madhava. Power System Protection Static Relays: New Delhi. Editora: McGraw-Hill. 1979. Páginas 1-9.

[27] SENGER, EDUARDO C.. Proteção Digital. Escola Politécnica - USP Universidade de São Paulo. São Paulo, 06/2001. 
[28] KUMM, JOHN J., SCHWEITZER, EDMUND O. III, HOU, DAQING. Assessing the Effectiveness of Self-Tests and Other Monitoring Means in Protective Relays. Presnted to the PEA Relay Committee Spring Meeting. Pennsylvania. USA, 1995.

[29] MOZINA, CHARLES J. Mejoramiento de La Proteccion de Generadores usando Tecnologia Digital. Canadian Electrical Association. Vancouver, B.C.1995.

[30] HOROWITZ, S. H. and PHADKE ARUN G. Power System Relaying. Jonh Wiley and Sons. USA, 1993.

[31] MASON, C. RUSSELL. The Art and Science of Protective Relaying. John Wiley and Sons, Inc. New York, 1956.

[32] E. O. SCHWEITZER III, DAQING HOU. Filtering for Protective Relays. V Seminário Técnico de Proteção e Controle, Curitiba, 1995.

[34] PENDER, NORBERT. Curso de Proteção em Sistemas Elétricos com Microprocessadores. Curso de especialização em tecnologia digital. CEFET. Curitiba, 1998.

[35] KIDO, MITSUYASU, CHIBA, TOMIO ET ALLI. Digital Input Filters for Measurement, Control and Protection of Electric Power Systems. Electrical Engineering in Japan, Vol. 112, n. 5, 1992.

[36] MANN e MORRISON. Digital Calculation of Impedance for Transmission Line Protection. IEEE Transactions on PAS, 1971.

[37] ADAMIAK, M. G.,ALEXANDER, G. E.,PREMERLANI, W. Advancements in Adaptive Algorithms for Secure High Speed Distance Protection. GE Power. Malvem, PA, USA.

[38] ANSI/IEEE STANDARD. ANSI/IEEE Standard C37-2 - Standard Electrical Power System Device Function Numbers ANSI number. IEEE Sevice Center, 1979. 
[39] ALSTOM T\&D Protection and Control. Protective Relays Application Guide. $3^{\text {rd }}$ edition, 1987.

[40] CAMARGO, IVAN. Noções Básicas de Engenharia Econômica Aplicações ao Setor Elétrico. Finatec. Brasília, 1998.

[41] KInDERmamm, G. Proteção de Sistemas Elétricos de Potência. Volume.1, UFSC - EEL - LabPlan. Florianópolis, 1999.

[42] MOZINA, CHARLES J. And MURTY V.V.S.,YALLA. Fundamental Reliability Considerations in the Design, Manufacturing and Application of Multifunction Digital Relays for Generator Protection. Canadian Electrical Association. Montreal, Canada, April 1996.

[43] MOZINA, CHARLES J. Power Plant "Horror Stories. Beckwith Electric Co., Inc., Largo. Flórida, USA.

[44] PINHO, ANTONIO C.. Apostila de Compatibilidade Eletromagnética CEFET-Pr/SIEMENS. Curitiba,.julho/02.

[45] OMODEI, ALEXANDRE, FUJITA, CLAUDIO et ALLI Automação dos Sistemas de Distribuição - Proteção e Operação. Trabalho Graduação CEFET-PR. Curitiba, 2001

[46] JARDINI, JOSÉ ANTONIO. Sistemas Elétricos de Potência Automação. EPUSP, São Paulo.

[47] SENGER, E. C. Proteção Digital de Sobrecorrente. Tese de Doutorado. Escola Politécnica da USP. São Paulo, 1991.

[48] ZIMMERMAN, KARL..Microprocessor - Based Distribution Relay Applications. Schweitzer Engineering Laboratories, Inc. Belleville, IL, USA. 
[49] HIRSCHFELD, HENRIQUE. Engenharia Econômica. 2 Edição, Editora Atlas S. A.. São Paulo, 1982.

[50] CASTILHO, ADRIANO L., RAMOS, RAMOS F. Análise Técnico Econômica das Funções Incorporadas aos relés de proteção. Trabalho CEFET-PR. Curitiba, 2004.

[51] SENGER, E. CÉSAR, REIS, FRANCISCO A. F., MANASSERO, GIOVANNI JR, NAKAGOMI, RENATO M.. Desenvolvimento de Um Relé Digital de Distância. VII STPC. Rio de Janeiro, Julho 2003.

[52] COOPER POWER SYSTEM. Controle de Religador Microprocessado Form 6. São Paulo, 2002.

[53] MARQUEZ, DIOGENES C., KRAUSS, CARLOS C. et ALLI. A Experiência da Copel na Integração de Proteções Digitais ao Sistema de Automação de Subestações. XVII SNPTEE. Uberlândia, Minas Gerais, 2003.

[54] E. O. SCHWEITZER III, SCHEER, GARY W., FELTIS, MARK W. A Fresh Look at Distribution Protection. Second International Symposium on Distribution Automation and Demand side Management. Florida, 1992.

[55] WHIPP\&BOURNE. GVR recloser and Panacea control Instruction Manual. Castleton. England, 1997.

[56] HIRSCHFELD, HENRIQUE. Engenharia Econômica. $2{ }^{a}$ edição. Atlas. São Paulo, 1982.

[57] COPEL DISTRIBUIÇÃO S/A..Priorização de Obras da Distribuição Método do Payoff. Curitiba, 2002. 


\section{APÊNDICE A - RELÉS DE PROTEÇÃO}

\section{Função Principal da Proteção com Relés}

Embora a função principal da proteção com relés é diminuir os efeitos de curtos circuitos, outras condições operacionais anormais também surgem isso requer a atuação da proteção com relés. Isto é particularmente verdade de geradores e motores.

\section{Função Secundária da Proteção com Relés}

A função secundária dos relés de proteção é prover indicação do local e tipo de defeito. Tais dados não só ajudam o reparo, mas também, por comparação com observação humana e registros oscilográficos, eles provêem meios para analisar a efetividade da prevenção de faltas.

\section{Finalidade do Relés}

São funções dos relés de proteção:

-medir as grandezas atuantes;

-comparar os valores medidos com os valores dos ajustes aplicados;

-operar (ou não) em função do resultado dessa comparação;

-acionar a operação de disjuntores ou relés auxiliares;

-sinalizar sua atuação via indicador de operação visual e / ou sonoro.

-localizar faltas no sistema elétrico

-emitir relatório de eventos

-automatizar os sistemas elétricos 


\section{Estrutura Física}

O relé consiste basicamente de um elemento de operação (bobina) e um jogo de contatos. O elemento de operação capta a informação de corrente e ou tensão através de transformadores (TP's / TC's), analisa a grandeza medida e transforma o resultado num movimento dos contatos se necessário. No caso de um equipamento em situação de defeito, os contatos do relé serão fechados, energizando os circuitos de alarme e abertura de um disjuntor, que será responsável pela isolação do elemento em curto, interrompendo o fluxo de corrente para aquele elemento. Normalmente o relé possui uma forma visual de indicar que operou. 


\section{APÊNDICE B - CARACTERÍSTICAS FUNCIONAIS DOS RELÉS}

Para um melhor entendimento do sistema de proteção, é necessário que se conheçam as características e o princípio de funcionamento dos relés.

O relé é a parte lógica do sistema de proteção. É um dispositivo, eletromecânico, estático, analógico ou digital, que conectado ao sistema elétrico é responsável pela detecção de condições intoleráveis ou indesejáveis ao sistema elétrico e pela tomada de decisão de abertura ou não dos disjuntores adequados a ele associados, a fim de iniciar o processo de retirada de operação da parte faltosa da linha, mantendo com isso a continuidade do fornecimento de energia elétrica e limitando os danos aos equipamentos.

Tecnicamente, o sistema de proteção é composto por um conjunto de relés de diferentes tipos ou não. Porém, para efeito de estudo, entende-se como sistema de proteção o conjunto formado por disjuntores, transdutores e relés, como mostrado na Figura 63.[15]

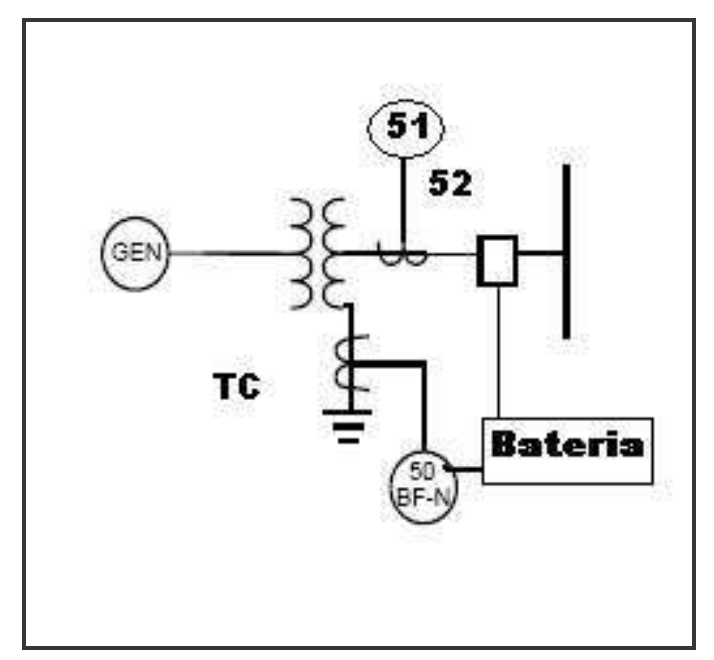

Figura 63 - Composição de um sistema de proteção. [17]

Transdutores: ou TPs e TCs, responsáveis por reduzir a magnitude da tensão e corrente, dentro de certos limites, reproduzindo fielmente seus 
valores no secundário;

Relés: são os elementos lógicos do sistema de proteção. Normalmente respondem a tensões e correntes e provem a abertura ou não dos disjuntores a ele associado;

Bateria: supre o sistema de proteção na falta de fornecimento de energia.

O sistema de proteção não deve ser requisitado para operar durante o funcionamento normal do sistema elétrico, mas deve estar disponível para operar imediatamente após a detecção de condições anormais.

Assim, o relé deve ser capaz de estabelecer uma lógica entre os parâmetros de entrada do sistema de potência, sinais de tensão e corrente provenientes dos transdutores, e tomar a decisão correta de abertura, sendo sua decisão de trip baseada diretamente na comparação ou combinação destes parâmetros com um valor predeterminado.

\section{Zonas de Proteção}

Existem algumas características básicas para a aplicação da proteção. Quando uma falta é detectada pelo relé, o sistema de proteção envia um sinal de trip para os disjuntores, os quais irá isolar a menor porção possível do sistema sob falta. Para isto, os relés possuem uma área de operação abrangendo uma parte do sistema definida como zona de proteção do relé. A lógica de operação do sistema de proteção divide o sistema de potência em várias zonas de proteção, cada uma requerendo seu próprio grupo de relés.

Em nenhum caso o sistema de proteção deve atuar se não existir defeito na sua zona de proteção. $O$ acionamento de disjuntores que não estão associados à área sob falta pode causar mais danos ao sistema que a não atuação da proteção quando necessária. 

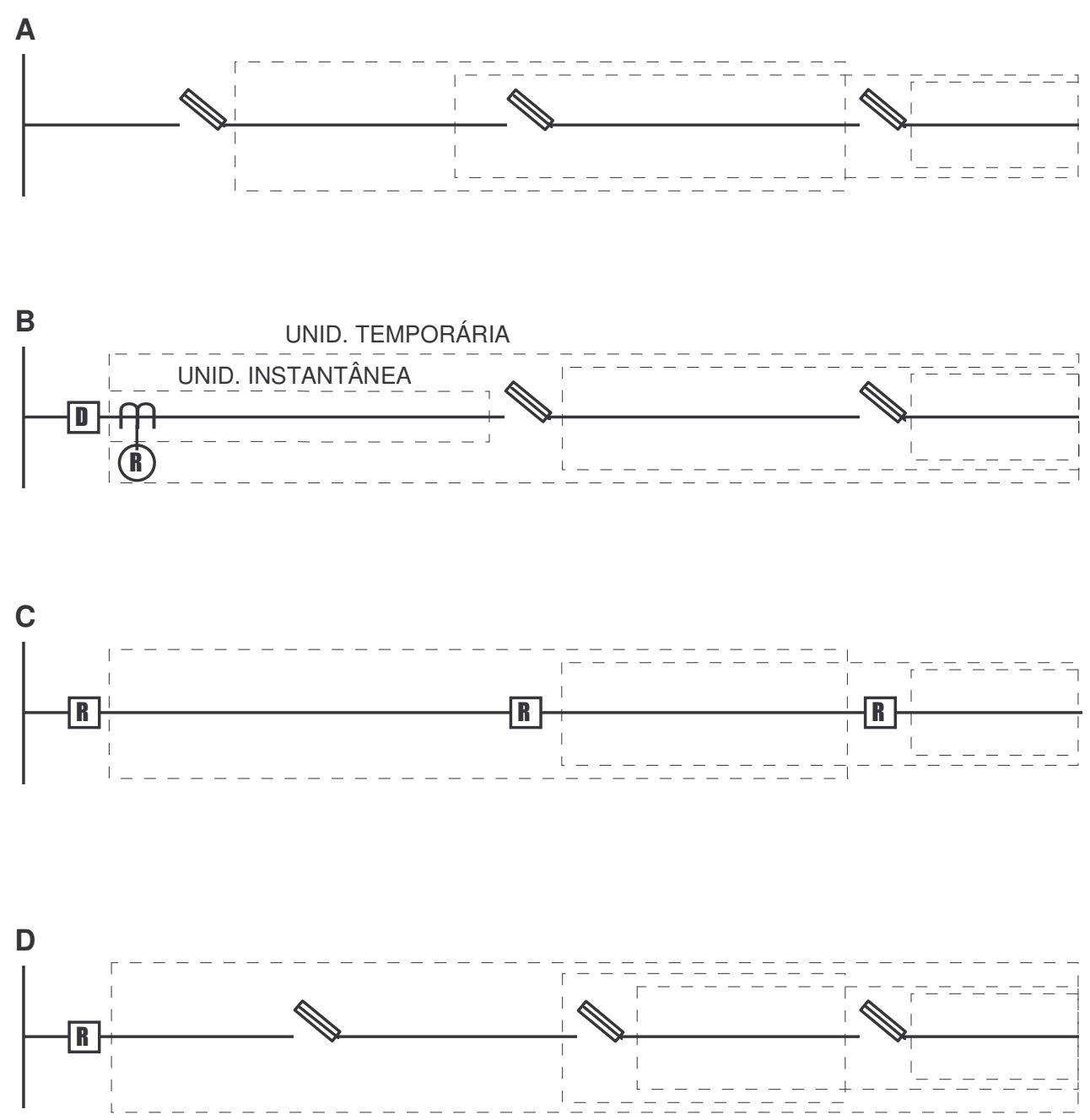

Figura 64 - Zonas de Proteção do Sistema Elétrico

Na Figura 64, barra da Subestação designada por $A$, tem-se o caso de proteção utilizando elos fusíveis. Neste caso sempre deverá existir um elo fusível como proteção de retaguarda.[23]

Na Figura 64, barra da Subestação designada por B, tem-se o caso de proteção utilizando relés e elos fusíveis. A unidade temporizada do relé deve ser ajustada de tal maneira que seja sensível para todos os valores de curto circuito em todo o alimentador. 
A unidade instantânea do relé deve ser ajustada para atuar antes do primeiro elo fusível instalado a jusante do relé.

$\mathrm{Na}$ Figura 64, barra da Subestação designada por C, tem-se o caso de proteção utilizando religadores.

O religador de montante deverá oferecer proteção de retaguarda para o religador de jusante.

Na Figura 64, barra da Subestação designada por D, tem-se o caso de proteção utilizando religadores e elos fusíveis.

A zona de proteção do religador deverá abranger todo o circuito alimentador e no caso de fusíveis ver considerações da barra A.

\section{Características Básicas da Proteção com Relés}

É desejável que a proteção tenha um comportamento de acordo com algumas características básicas. Confiabilidade, seletividade, velocidade, simplicidade, sensibilidade e econômia, são termos empregados para descrever estas características funcionais dos relés de proteção.

Confiabilidade e Segurança

Confiabilidade é o grau de certeza que o relé irá operar corretamente. Segurança é o grau de certeza de que o relé não irá operar em condições normais de operação. Então, confiabilidade indica a habilidade do relé de executar corretamente sua função quando requerido e evitar operação desnecessária durante a operação normal do sistema ou na presença de faltas fora de sua zona de proteção. 
Seletividade:

A proteção é seletiva quando é dimensionada de tal forma que para qualquer tipo de falta o dispositivo de proteção mais próximo da falta antecipe sua atuação, independente da natureza da falta, isolando o trecho defeituoso, conforme exemplos na Figura 65.

a)
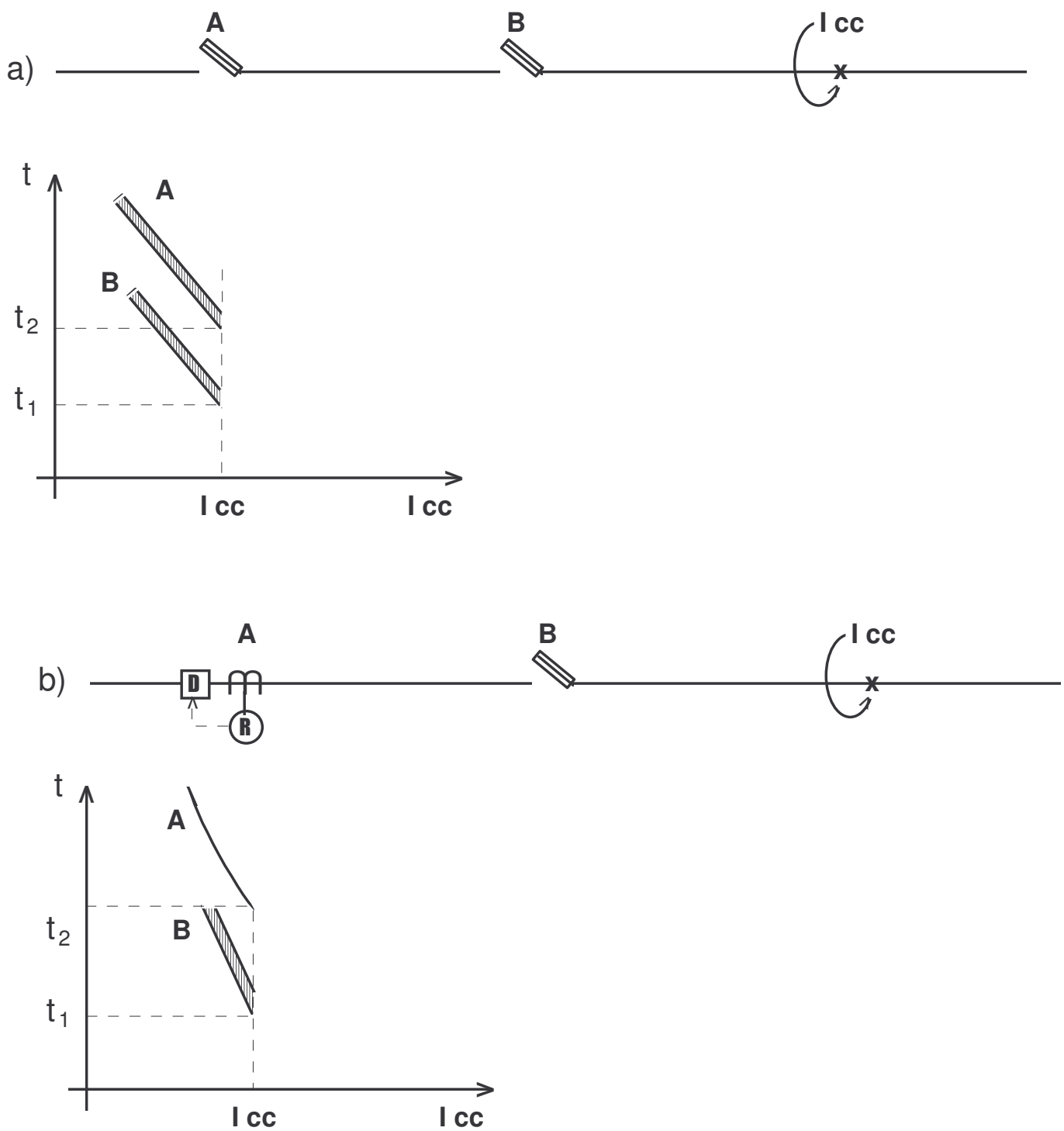

Figura 65 - Exemplos de Seletividade

Na Figura 65 - item "a" - No caso de ocorrer um curto circuito "Icc", no ponto " $x$ ", 0 elo fusível protetor B deverá atuar antes que o elo fusível protegido $\mathrm{A}$, de forma seletiva. 
Na Figura 65 - item "b" No caso de ocorrer um curto circuito "Icc", no ponto " $x$ ", o elo fusível protetor $B$ deverá atuar antes que a curva temporizada do relé $A$.

Velocidade:

O tempo entre a incidência da falta e o comando de abertura do disjuntor dado pelo relé é determinado pela configuração do sistema e no caso da proteção digital, é tipicamente alguns ciclos de freqüência do sistema. Assim, é desejado que o relé tenha uma velocidade de atuação necessária para assegurar um rápido isolamento da zona de proteção em que se encontra a falta, principalmente quando a necessidade de seletividade é envolvida.

A velocidade de operação também depende do tipo de mecanismo do disjuntor que irá interromper a falta, disjuntores mais antigos possuem mecanismos tipo motor $x$ mola que são mais lentos para atuarem $\mathrm{e}$ requerem tempos longos para carregamento das molas após a primeira operação. Os mecanismos mais recentes constituídos de atuadores magnéticos possuem um tempo de atuação mais rápido se comparados com os de motor x mola, podendo chegar até a $20 \mathrm{~ms}$.

É importante ressaltar que não adianta combinar relés digitais, com tempos de operação muito rápidos, com disjuntores que possuem mecanismos de operação demorados, pois o ganho em velocidade de operação será desprezível. Já mecanismos rápidos com relés digitais nos proporcionam um tempo de atuação rápida.[17] 
Sensibilidade

É a capacidade que um equipamento de proteção tem de abrir o circuito em resposta aos valores mínimos de curto-circuito fase e fase e fase e terra mínimos calculados a partir da resistência de falta no final do trecho considerado, conforme a Figura 66.

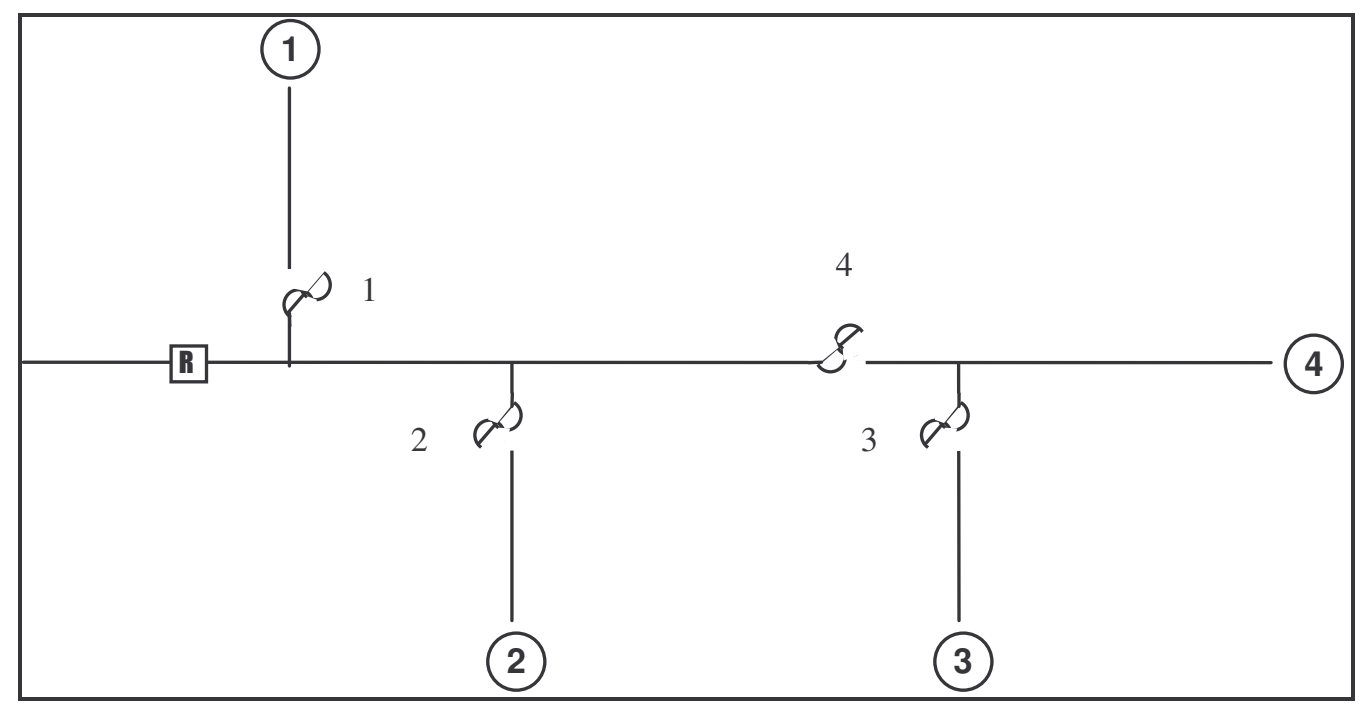

Figura 66 - Exemplos de Sensibilidade de dispositivos de proteção

a - O elo fusível 1 deve ser sensível para o mínimo curto circuito no ponto 1 b - O elo fusível 2 deve ser sensível para o mínimo curto circuito no ponto 2 c - O elo fusível 3 deve ser sensível para o mínimo curto circuito no ponto 3 d - O elo fusível 4 deve ser sensível para o mínimo curto circuito verificado entre os pontos 3 e 4 . 
Simplicidade e Economia

O sistema de proteção com relés deve ser o mais simples possível, desde que inclua todos o parâmetros de ajustes requisitados pelo pessoal de Proteção e ajustes, pois serão estas pessoas que estarão ajustando e testando estes equipamentos na prática, além disto devem ser simples de operar e instalar. Aliado a simplicidade os relés de proteção devem ser econômicos para não tornar o sistema de proteção impraticável e dispendioso.[17]. 
Classificação geral dos Relés

\section{Quanto à natureza da grandeza atuante}

- Elétrico;

- Térmico;

- Mecânico.

Designação das Principais Funções Utilizadas

Conforme a referência [38], as funções de proteção mais utilizadas são:

Número

12

21

24

25

27

32

37

38

39

40

46

Seqüência Negativa)

47

Seqüência Negativa)

Descrição da Função

Elemento de Sobrevelocidade

Elemento de Distância

Elemento Volts/Hertz

Elemento de Verificação de Sincronismo

Subtensão

Elemento Direcional de Potência

Subcorrente

Elemento de Sobretemperatura nos Mancais

Elemento de Vibração nos Mancais

Perda de Excitação

Desbalanço de Corrente (ou sobrecorrente de

Desbalanço de Tensão (ou sobretensão de 48

Rotor Bloqueado

49

Elemento de Sobretemperatura no Estator

50 
51

$51 \mathrm{~V}$

$50 \mathrm{G} / 50 \mathrm{~N}$

$51 \mathrm{G} / 51 \mathrm{~N}$

50BF

59

$59 \mathrm{~N}$

60

64

64R

67

$67 \mathrm{G} / 67 \mathrm{~N}$

74

68

79

$81 \mathrm{U}$

810

86

87

94
Sobrecorrente Temporizado de Fase

Sobrecorrente de Fase com Restrição por Tensão

Sobrecorrente Instantâneo de Terra / Neutro

Sobrecorrente Temporizado de Terra / Neutro

Elemento de Falha do Disjuntor

Sobretensão

Sobretensão de Neutro

Falha do Fusível do TP

Falta a Terra no Estator

Falta a Terra no Rotor

Sobrecorrente Direcional de Fase

Sobrecorrente Direcional de Terra / Neutro

Elemento de Alarme

Out-of-step (proteção de falta de sincronismo)

Religamento

Subfrequência

Sobrefrequência

Bloqueio

Diferencial

Elemento de Trip 
Termos Técnicos mais Utilizados em Relés de Proteção

-Pick-up: ponto em que a corrente ou tensão injetada no relé sensibiliza as suas unidades de proteção, causando o início da operação em relés eletrônicos ou digitais e/ou o movimento do disco de indução em relés eletromecânicos;

-Trip: ponto em que o relé de proteção fecha os contatos de saída. Isso ocorre quando o valor da corrente ou tensão de pick-up permanecem no sistema por um período de tempo especificado pelo usuário ou por um tempo definido por uma curva de atuação, também pré-determinada pelo usuário;

-Dropout: retorno dos contatos dos relés de proteção a sua posição de repouso ou reset da unidade de proteção após ter executado com sucesso sua operação. 


\section{Classificação quanto ao princípio de funcionamento dos relés}

Os relés são classificados de acordo com seu princípio de funcionamento como:

relés de magnitude: responde as mudanças em magnitude como pro exemplo os relés de sobrecorrente;

relés direcionais: respondem ao ângulo de fase entre duas entradas $A C ; V$ e I ou $I_{1}$ e $I_{2}$,

relés de distância: respondem a razão de dois fasores de entrada - número complexo; ex: relé de impedância;

relés diferenciais: respondem a soma algébrica de correntes entrando em uma zona de proteção;

relés com fio piloto: utiliza comunicação de informação de localização remota como sinal de entrada.

E de acordo com sua tecnologia construtiva, levando em conta os três principais termos utilizados, podem ser classificados em:

Relés Eletromecânicos: funcionam através de propriedades eletromagnéticas, apresentado ,em geral, apenas uma função;

Relés Estáticos Analógicos: utilizam componentes eletrônicos de silício (estáticos) para simular as funções dos eletromecânicos;

. Relés Estáticos Digitais: transformam as entrada analógicas em sinais digitais, para serem processados por microprocessadores. São capazes de fornecer múltiplas funções. 


\section{APÊNDICE C - RELÉS ELETROMECÂNICOS}

São classificados em quatro tipos, quanto ao princípio de atuação:

- atração magnética;

- indução magnética;

- D'Arsonval;

- Térmicos.

Cada um deles será visto a seguir.

Atração Magnética

Três tipos construtivos de atração magnética são comumente usados:

- bobina móvel (solenóide);

- armadura em charneira;

- ferro móvel (polarizado).

Mecanismo tipo Armadura em charneira

Este modelo construtivo mostrado na Figura 67 possui uma peça magnética na forma de $\mathrm{U}$ com uma armadura móvel através da unidade aberta. A armadura é articulada de um lado e contida por mola do outro. Quando a bobina elétrica associada é energizada, a armadura se move para o núcleo magnético, abrindo ou fechando um jogo de contatos com um torque proporcional ao quadrado da corrente na bobina. Os valores de pick-up e drop-out destas unidades são menos apurados que no modelo construtivo do tipo Bobina Móvel, por isso este modelo é normalmente aplicado como auxiliar.[24] 


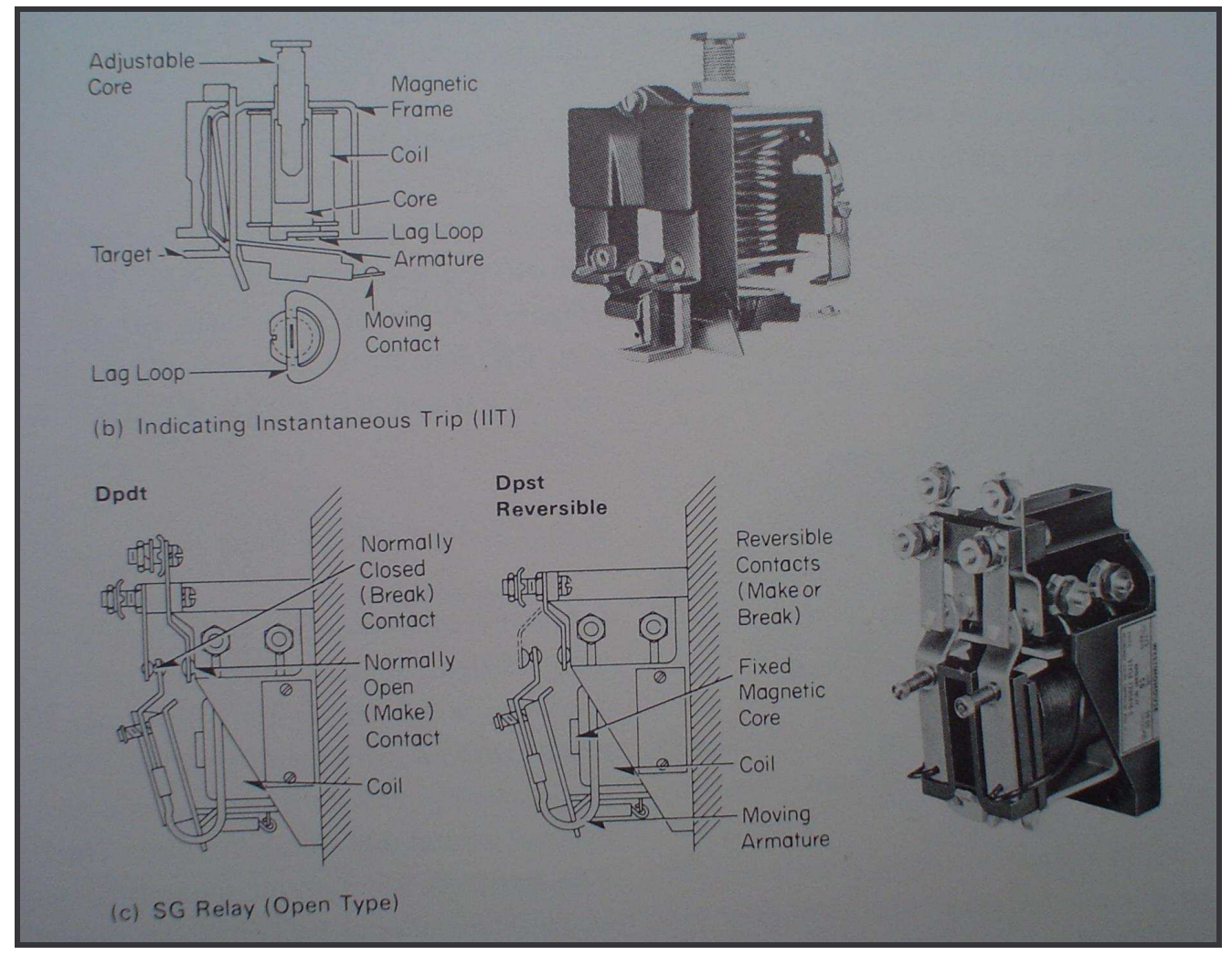

Figura 67 - Mecanismo de Armadura em Charneira [ referência 24]

\section{Mecanismo tipo Ferro Móvel}

Este tipo de mecanismo mostrado na Figura 68, atua diretamente em função da corrente aplicada à bobina ao redor da armadura articulada no centro da estrutura magnética. Um ímã permanente através da estrutura polariza os pólos abertos da armadura. Dois espaçadores não magnéticos, localizados na parte traseira do quadro magnético, são conectados por duas derivações magnéticas ajustáveis. Este arranjo permite que os caminhos do fluxo magnético sejam ajustados para o pick-up e para a ação de contato. Com os espaços de ar equilibrados a armadura irá flutuar no centro com a bobina desenergizada. Com os espaços desequilibrados, um pouco do fluxo será desviado através da armadura. A polarização resultante mantém a armadura contra um pólo, com a bobina desenergizada. A bobina é arranjada de modo 
que sua linha central magnética esteja em linha com a armadura, e no ângulo certo do eixo do ímã permanente. A corrente na bobina magnetiza a armadura tanto norte como sul, aumentando ou diminuindo qualquer polarização prévia da armadura.[24]

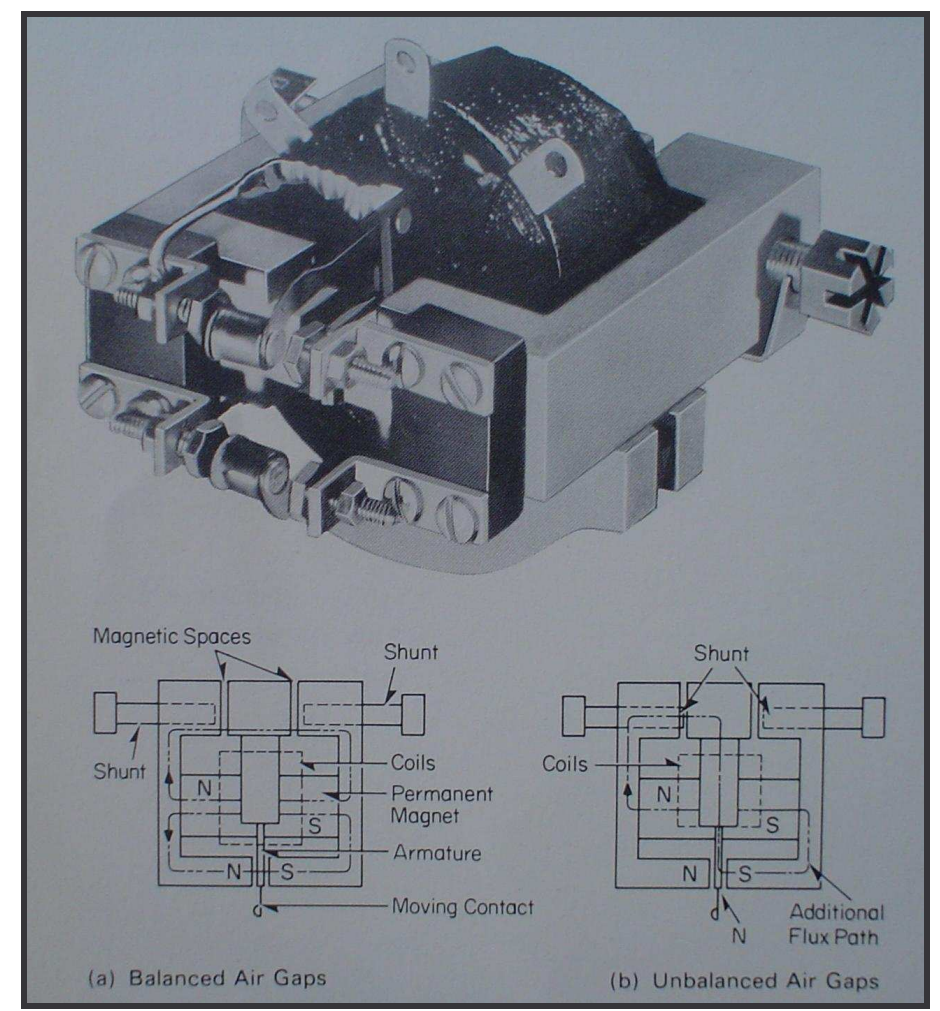

Figura 68 - Mecanismo tipo Ferro Móvel [ referência 24 ]

Indução Magnética

Existem dois tipos gerais de mecanismos de indução magnética, que são:

- disco de indução;

- cilindro de indução. 
Mecanismo tipo Cilindro de Indução

A operação do mecanismo do tipo cilindro de indução é similar a de um motor de indução com pólos salientes. O modelo básico mostrado na Figura 69, utilizado para relés tem um núcleo de aço interno ao centro do quadrado eletromagnético, com um cilindro de alumínio de parede fina rodando na abertura central. O curso do cilindro é limitado a uns poucos graus pelo contato; uma mola espiral fornece o torque de reinicio. O torque operacional é uma função do produto de duas grandezas operacionais e do co-seno do ângulo entre elas.

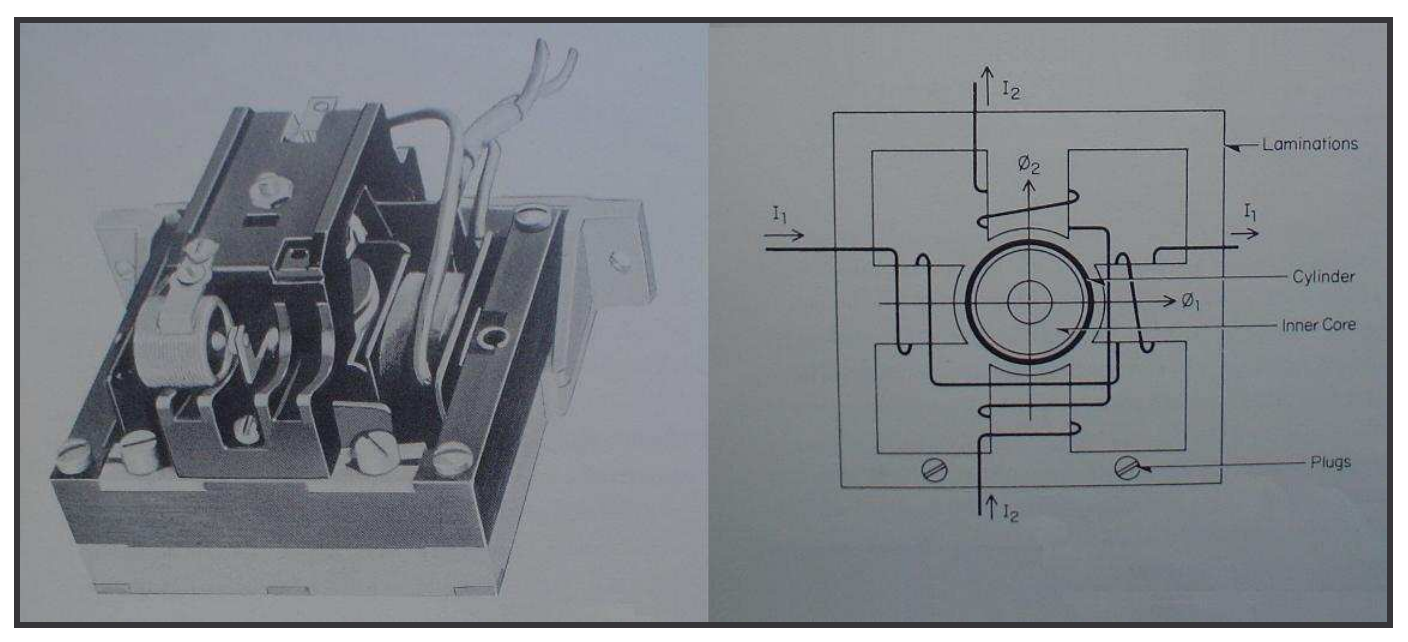

Figura 69 - Mecanismo do Tipo Cilindro de Indução [referência 24]

\section{Mecanismo Tipo D’Arsonval}

No modelo D’Arsonval da Figura 70, uma estrutura magnética e um ímã permanente interno formam um núcleo cilíndrico de dois pólos. Uma mola móvel enlaçada na lacuna é energizada por corrente direta, que reage com o fluxo da lacuna para criar o torque rotacional. O modelo D'Arsonval opera com energia de entrada bastante baixa, tal como aquela disponível em shunts CC, pontes retificadoras, etc. 


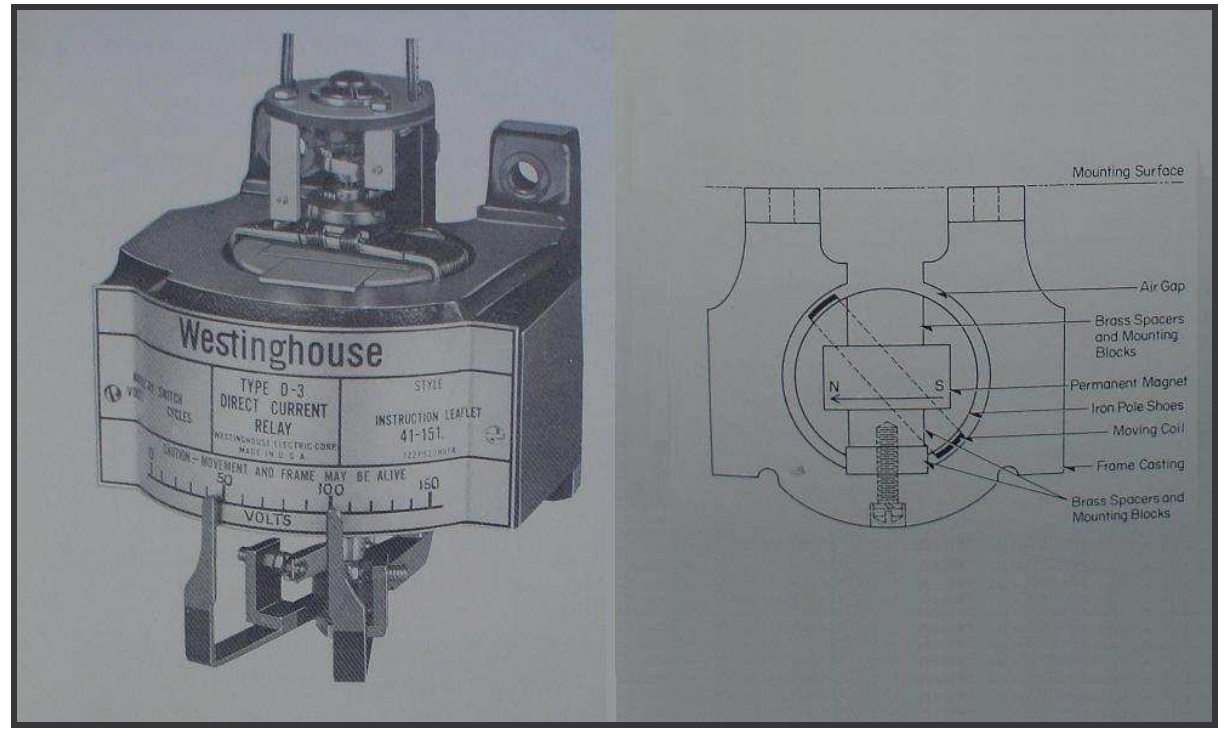

Figura 70 - Mecanismo do Tipo D'Arsoval [referência 24] 


\section{APÊNDICE D - RELÉS ESTÁTICOS}

Relé Estático de sobrecorrente de tempo definido

Conforme a referência 46, na Figura 71, estão representados os blocos esquemáticos do relé de sobrecorrente de tempo definido, função (50).

A corrente do secundário do TC passa por um filtro e por um resistor sobre o qual aparecerá uma tensão (VR) proporcional à corrente. Esta tensão VR passa por um retificador de onda completa e depois por outro filtro resultando a tensão (Vf). Este valor de tensão (Vf) é comparado com a tensão de referência (er). Quando Vf for maior que (er), na saída do amplificador operacional aparecerá um pulso que a seguir passa por um circuito de atraso.

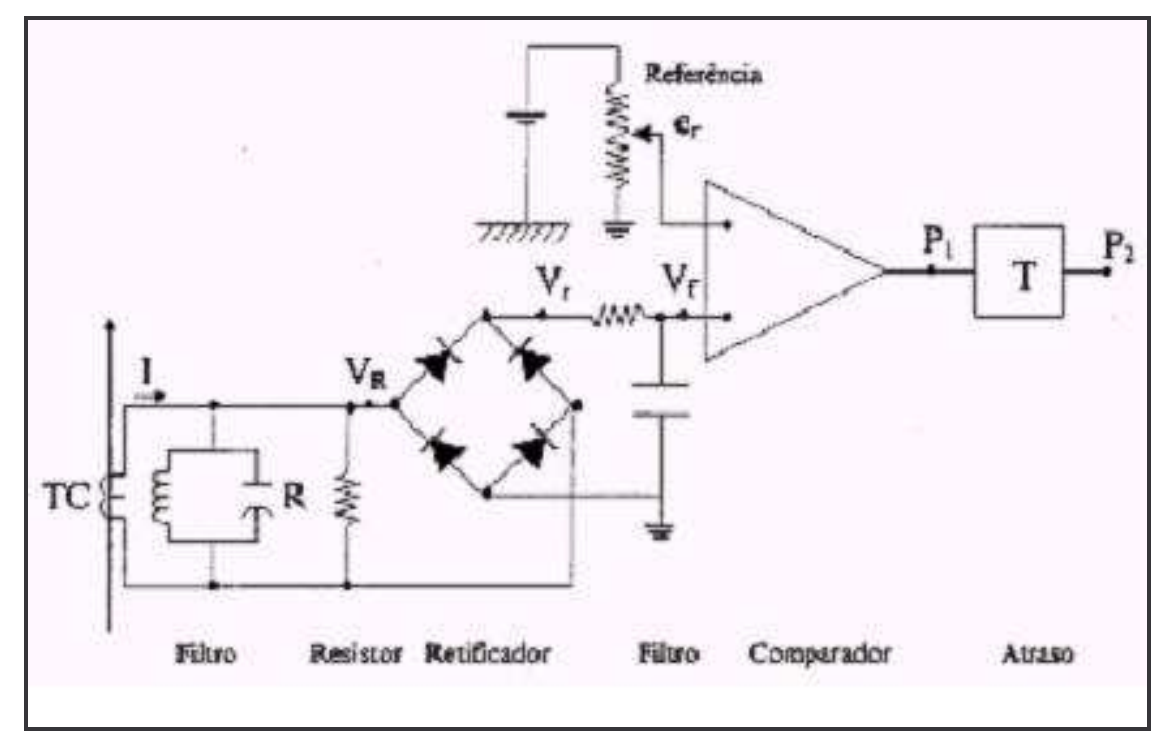

Figura 71 - Diagrama de um Relé Estático de Sobrecorrente. [referência 46]

Na Figura 72 estão apresentadas as formas de onda nos vários pontos do circuito do relé estático de sobrecorrente. 


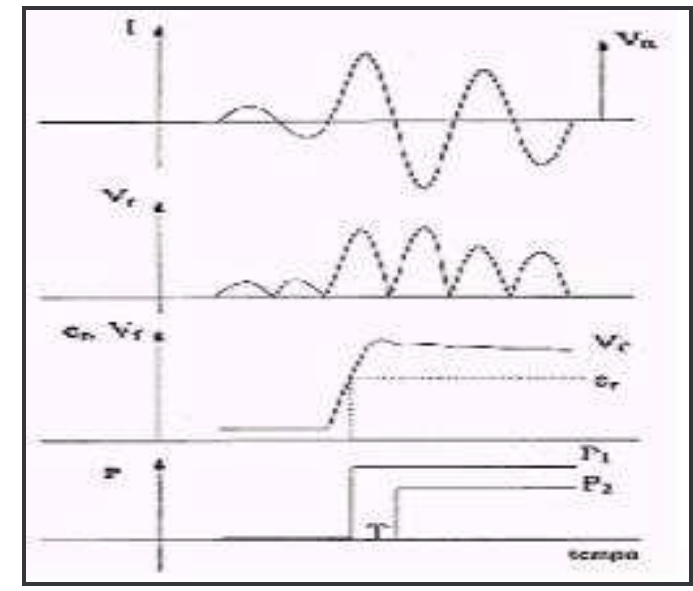

Figura 72 - Formas de Onda do relé estático [ referência 46] 


\section{APÊNDICE E - RELÉS DIGITAIS}

\section{Componentes Básicos de um Relé Digital}

\section{Subsistema de Condicionamento de Sinais}

\section{Transdutores}

Como os relés operam com os sinais de tensão e corrente relativamente altos, estes devem ser atenuados a um nível compatível com os exigidos pelos processadores através de transformadores denominados por transdutores, ou simplesmente, transformadores de potencial ou TP's, e transformadores de corrente ou TC's.

Os transdutores provêm isolação entre a linha de transmissão e o relé e devem sempre possuir alta qualidade a fim de reduzir o erro nesta etapa, visto que o desempenho do relé depende da exatidão da reprodução da corrente de falta.

\section{Módulo de interface}

Depois que os sinais de tensão e corrente do secundário dos TP's e TC's forem atenuados, eles entram em um módulo de interface, constituído basicamente por capacitores e transformadores de isolação, onde serão novamente atenuados até atingirem níveis de discretização. Esse módulo é composto por transformadores e filtros passa-baixa. Uma alternativa para se atingir níveis discretos de sinais é a utilização de TC's auxiliares. Contudo qualquer erro no TC auxiliar irá contribuir para o erro total no processo de conversão analógica/digital, que deve ser o menor possível.

Conforme a referência [27] o condicionamento dos sinais é determinado por: 
-Relação dos transformadores auxiliares;

-Shunts de correntes e divisores resistivos;

-Amplificador de ganho programável.

Os transformadores reduzem ainda mais os níveis de tensão da entrada e os filtros eliminam os componentes transitórios de alta freqüência dos sinais de entrada, evitando assim um fenômeno conhecido como aliasing, que é a sobreposição de espectros. O fenômeno aliasing acarretará outra fonte de erro na conversão analógica/digital.

Nesta etapa é realizada ainda a conversão dos sinais da corrente para sinais de tensão, pois os computadores trabalham somente com estes sinais.

\section{Filtragem dos dados}

Após os dados atenuados, o passo seguinte é a filtragem analógica dos sinais amostrados, com a finalidade de reduzir os componentes de alta freqüência presentes quando uma falta ocorre, evitando-se assim o fenômeno aliasing como descrito anteriormente. As características dinâmicas dos filtros passa-baixa assim como suas características em regime são de fundamental importância [16]. Entre elas destacam-se:

-tempo de subida: característica que indica quanto tempo a saída de um filtro passa-baixa demora a atingir o seu valor final;

-overshoot: característica que indica o quanto a saída do filtro irá ultrapassar o seu valor em regime;

-tempo de acomodação: que indica quanto tempo o filtro demora até acomodar-se no seu valor em regime. 


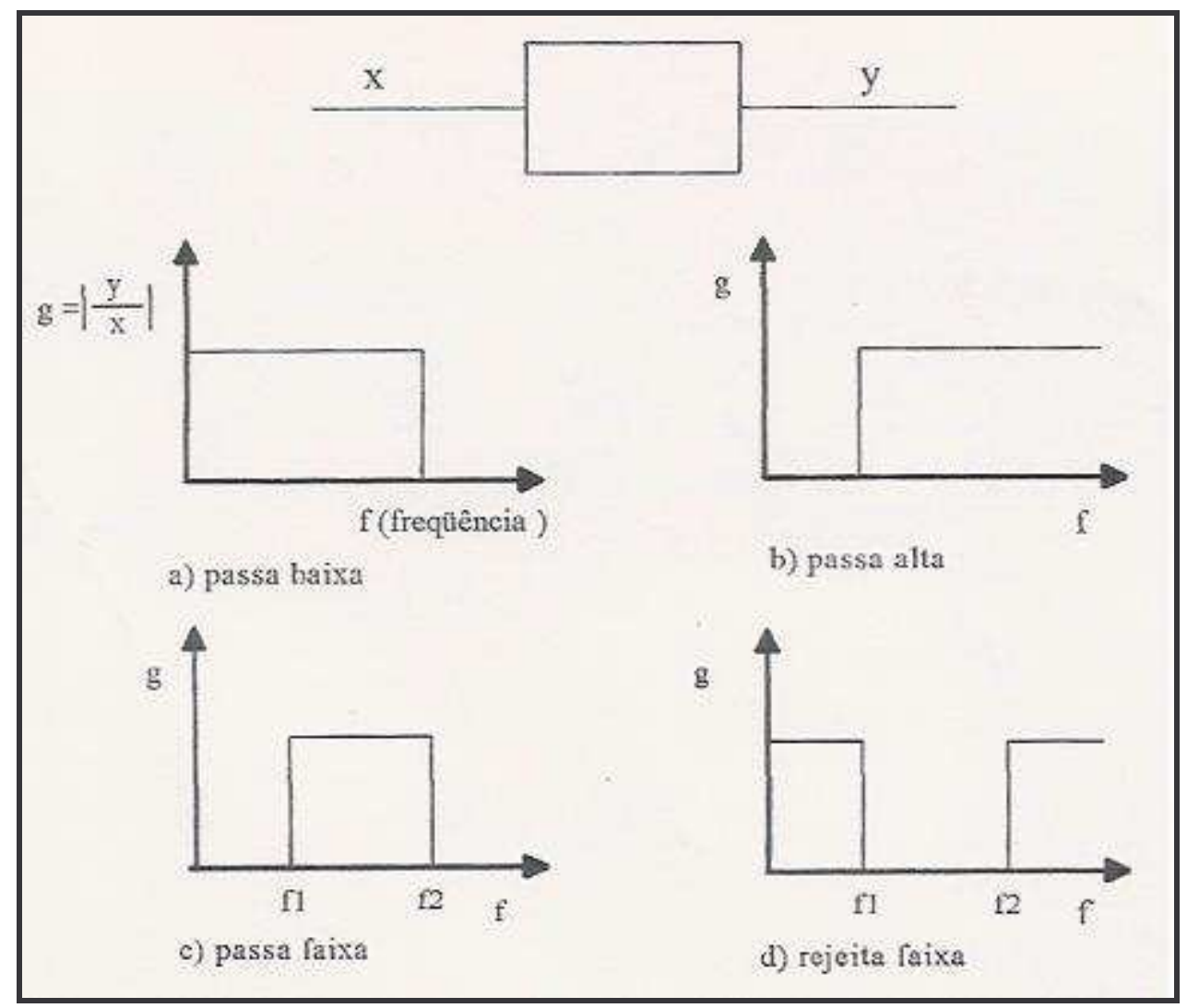

Figura 73 - Características de Filtros [referência 46]

Conforme a referência [27], esta filtragem é realizada por um filtro passabaixa Butterworth, no qual simula-se um filtro passa-baixa analógico real. Este filtro fornece uma significativa atenuação para as freqüências acima da metade da freqüência de amostragem (freqüência de Nyquist)

\section{Subsistema de Conversão}

\section{Sample and Hold}

Conforme a referência [16], o relé digital é um dispositivo que trabalha com múltiplas entradas dos sinais de tensão e corrente amostrados, para que ele possa fazer uma correta análise do sinal, é desejável que todos os sinais 
sejam amostrados simultaneamente. Uma possível solução para esse problema seria o emprego de vários conversores $A / D$ operando simultaneamente, disponibilizando assim os vários sinais digitais para a CPU do relé.

Uma solução alternativa para o problema é o emprego de vários circuitos conhecidos como Sample and Hold dispostos em conjunto com um circuito multiplexador.

Neste esquema, o circuito Sample and Hold é responsável pela amostragem e armazenamento do sinal de entrada para que o conversor A/D possa realizar as várias conversões existentes para cada instante de amostragem. Esses vários circuitos em conjunto com um circuito multiplexador possibilitam uma solução economicamente viável ao processo de amostragem do sinal.

Conforme a referência [27], a função de digitalização consiste em transformar o sinal analógico em uma série de números binários de "n" bits, os quais poderão ser manipulados pelo microprocessador.

A digitalização consiste dos seguintes processos:

-Amostragem - transforma o sinal de tempo contínuo em sinal de tempo discreto;

-Quantização - transforma o sinal de tempo discreto em amplitude contínua em sinal digital;

-Codificação - 


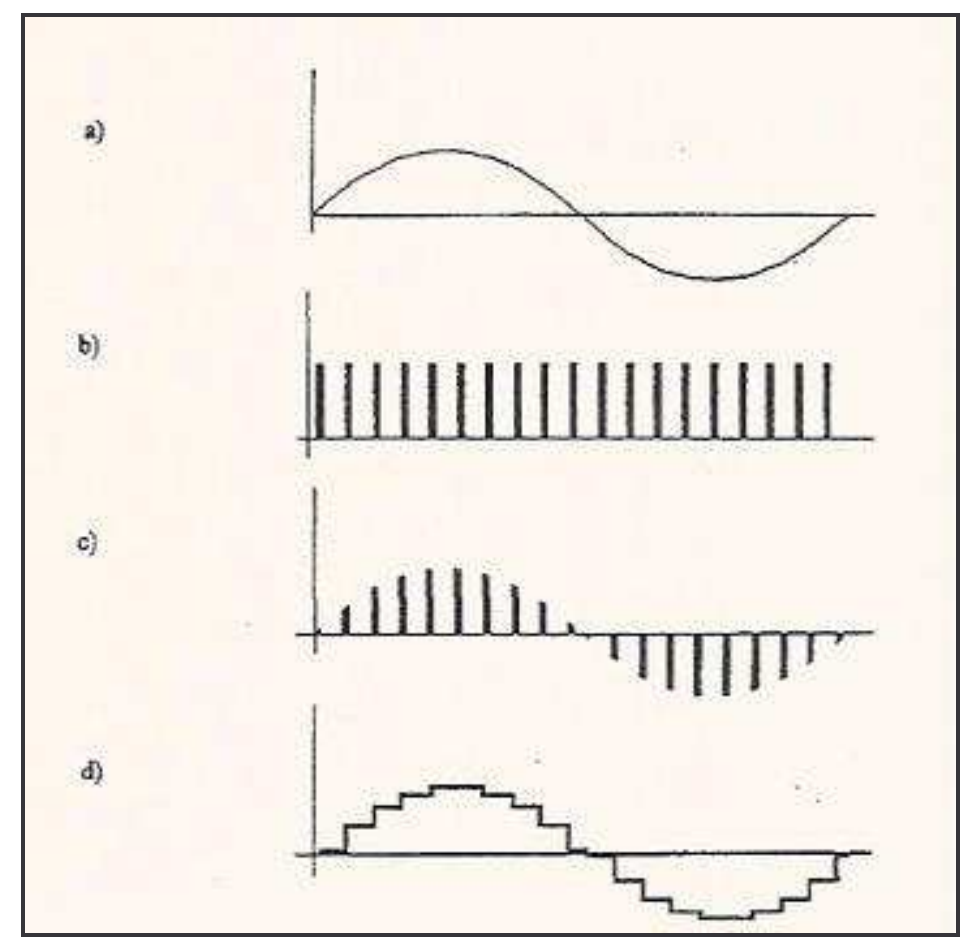

Figura 74 - Amostragem do Sinal [referência 46]

Conforme referência 46, analisando-se a Figura 74 , item "a", está indicado o sinal analógico a ser convertido. O trem de pulso em "b" representa uma chave que conecta o sistema de aquisição de dados ao sinal analógico por um tempo bastante rápido. Em 'c', aparece o sinal de entrada modulado pela chave. Se agora após a chave, o sinal for aplicado em um capacitor, este manterá o valor do sinal até o próximo acionamento da chave, resultando que o sinal na entrada do conversor A/D será aquele mostrado em "d“. Desta forma como a chave é rápida os sinais nas diferentes fases estarão sincronizados, ou seja, durante o intervalo eles serão lidos, porem todos se referem ao valor no instante de fechamento da chave, mantido durante o intervalo.[45]

Em cada degrau haverá conversão $A / D$ do sinal, sinal este que foi portanto amostrado com a freqüência da chave (20 amostras por ciclo do sinal analógico de entrada na Figura 74).

É importante mencionar que a velocidade do conversor A/D deve ser compatível com a duração do pulso de cada amostra. Também importante é 
determinar qual a freqüência que o sinal deverá ser amostrado. Quanto maior a freqüência de amostragem melhor será a reprodução do sinal, porém mais rápidos e caros deverão ser os componentes eletrônicos.

Amostrar um sinal de $60 \mathrm{~Hz}$ algumas poucas vezes por segundo não leva a resultado significativo. Se uma amostra é coletada a cada $1 \mathrm{~ms}$ então a freqüência de amostragem é $1000 \mathrm{~Hz}$ ou $1 \mathrm{kHz}$ (1 / tempo de amostragem).

A freqüência de amostragem deve ser a maior possível de tal forma que, porém, reproduza as freqüências de interesse.

O teorema de amostragem de sinais de Nyquist estabelece que: "se um sinal limitado em freqüência, não contém freqüências maiores que $f c$, então ele pode ser recuperado e reproduzido sem distorção se a sua amostragem for maior ou igual a $2 \times f c$.

Se um sinal $60 \mathrm{~Hz}$, com harmônicos, for coletado a uma freqüência de 18 vezes por ciclo (0,9 ms por amostra) então pode-se afirmar que o sinal está bem reproduzido até a 9 a harmônica. Utilizando este critério evita-se 0 fenômeno conhecido com "alias" conforme mostra a Figura 75.

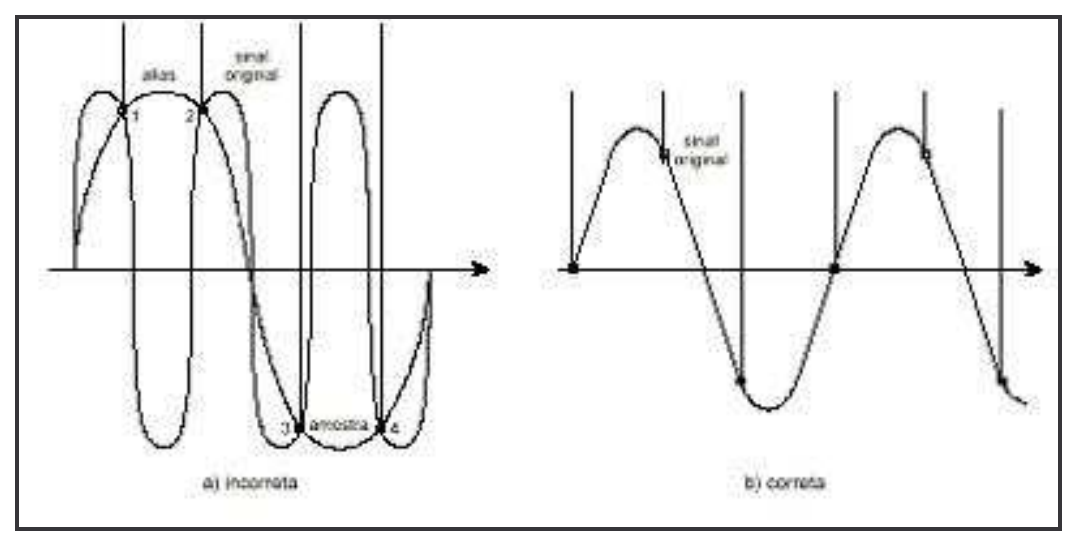

Figura 75 - Amostragem de Sinais Incorreta e Correta [referência 46]

Na Figura 75 item "a" o sinal original foi conectado com a freqüência indicada (amostra 1 a 4), não atendendo ao critério de Nyquist. Olhando os pontos 1 a 4, que é o que resta após a amostragem, observa-se o aparecimento de uma freqüência ("alias") que não existia no sinal original. No item "b" é mostrado o caso com a freqüência de amostragem correta.[46] 


\section{Multiplexador}

$\mathrm{Na}$ operação de releamento digital é usualmente utilizado um multiplexador analógico que é um dispositivo que seleciona um sinal de um número de canais de entrada e o transfere para o canal de saída, permitindo a transmissão de vários sinais simultaneamente.

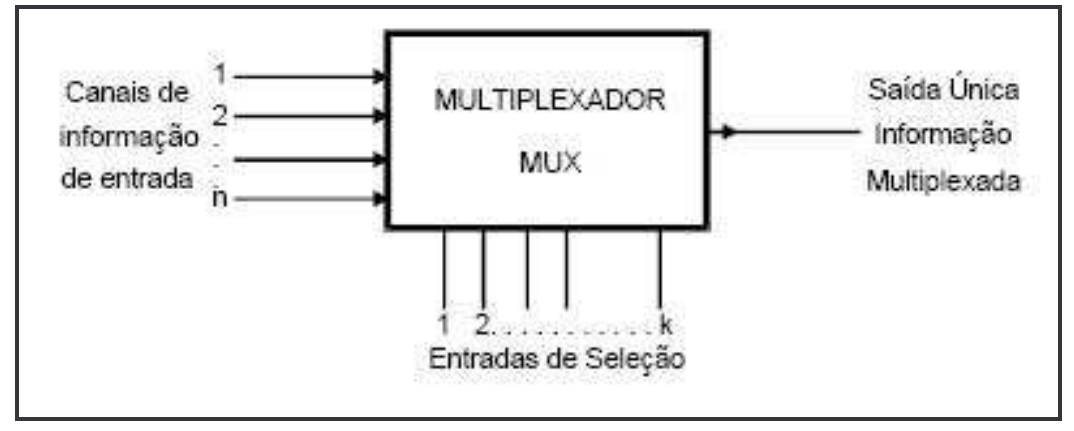

Figura 76 - Multiplexador - [referência 46]

\section{Conversão analógico/digital}

Conforme a referência [16], para cada instante definido pelo clock, é executada uma conversão dos sinais analógicos de entrada para a forma digital através do conversor analógico/digital.

Na Figura 77 é mostrado o processo de conversão de uma variável analógica para digital. 


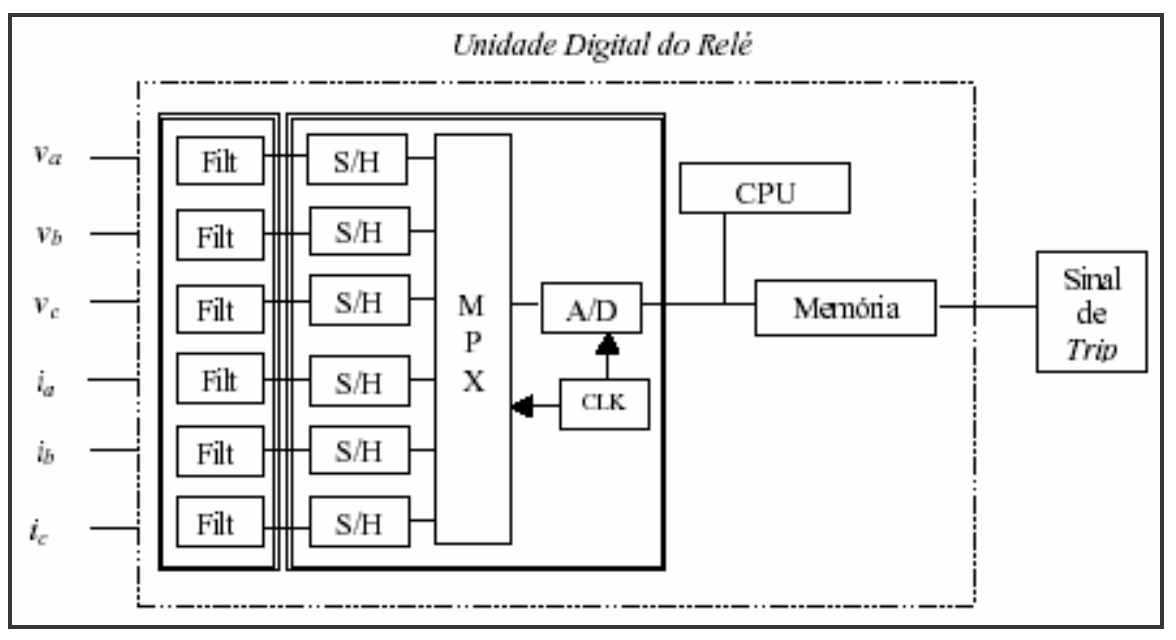

Figura 77 - Sistema de Entrada de Dados Analógicos e conversão digital [16]

\section{Subsistema de Processamento Digital do Sinal}

Conforme a referência [16], o subsistema de processamento digital do sinal compreende o hardware e o software do relé. O hardware consiste em uma central de processamento, memórias e dispositivos de entrada e saída. $\mathrm{O}$ software compreende a parte lógica do relé e o princípio de operação acrescido de algumas rotinas que possibilitam o seu correto funcionamento, tais como: rotinas para a manipulação de dados de entrada e saída, rotinas para a autochecagem do hardware, etc. O software é implementado através de alguma linguagem de programação e compilado para o modelo de CPU presente em seu hardware.

O algoritmo usado varia de acordo com a aplicação do relé.

Conforme referência 11, na Figura 78 é mostrada a arquitetura típica de um relé digital de proteção, que basicamente consiste de um ou mais microprocessadores DSP ( Processador de Sinal Digital), elementos de memória, entradas digitais e analógicas de sinais e fonte de tensão. Segundo os autores, a comunicação interna ao relé, entre os barramentos e o hardware são componentes críticos no desenho do equipamento 


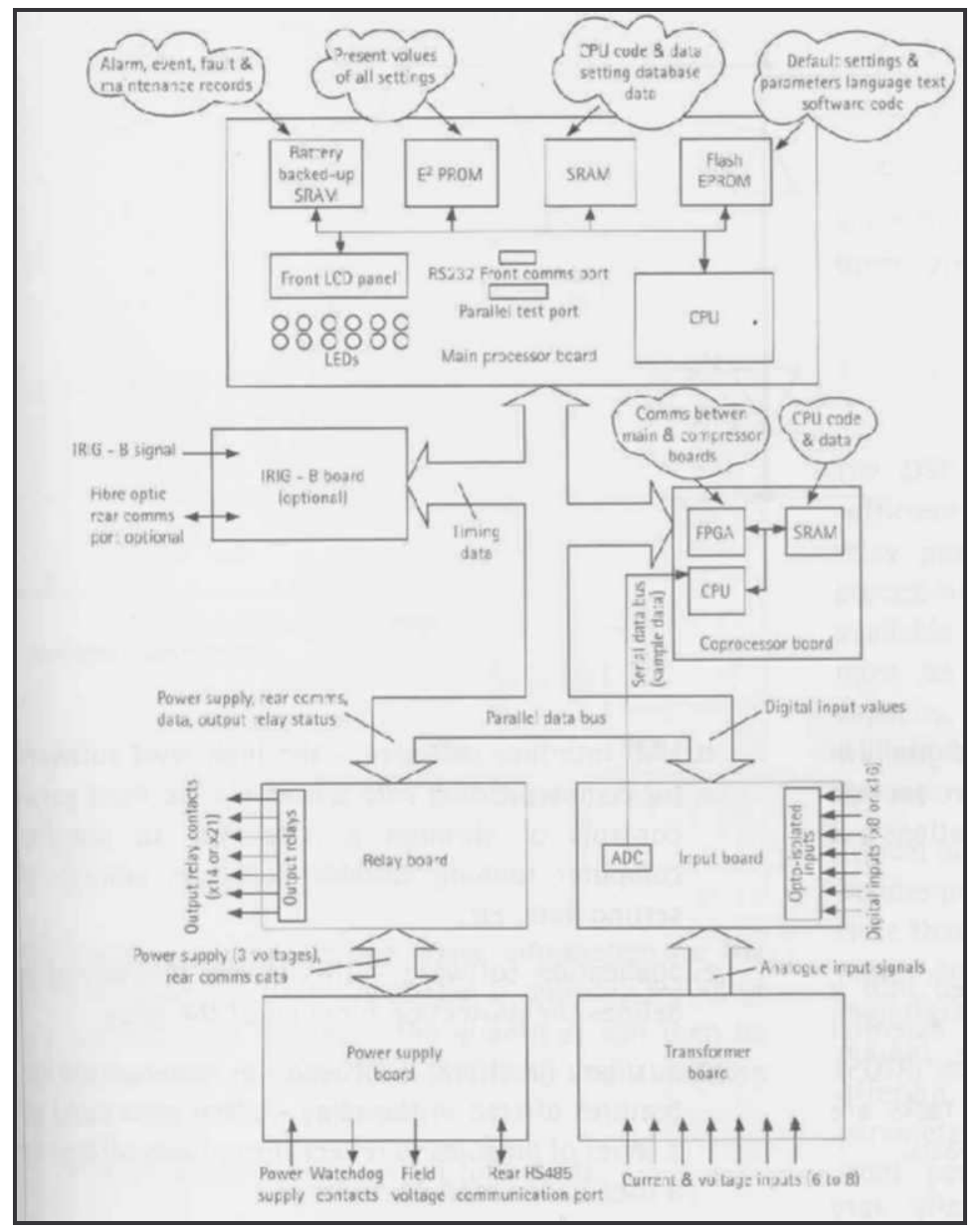

Figura 78 - Diagrama em Blocos de um relé Digital [ referência 11]

Deve-se ter um especial cuidado relevante na blindagem de todo 0 equipamento, pois eles trabalham com altas velocidades de processamento e com baixos níveis de tensão, que devem ser imunes a interferências eletromagnéticas radiadas e conduzidas.

\section{Algoritmos Utilizados em Relés de Proteção Digitais}

Conforme a referência [27], o Algoritmo com Amostragem Síncrona foi um dos primeiros algorítmos propostos e tentava amostrar o valor de pico de um sinal de corrente, de forma a obter uma quantidade proporcional ao valor eficaz da onda.

Após vieram os algoritmos assíncronos para Proteção de Distância. 
O primeiro proposto por MANN e MORRISON [36], chamado de algoritmo baseado no cálculo da amostra e derivada.

Outros algoritmos são os de Filtragem Digital os quais também são aplicados em proteção de transformadores, geradores e linhas de transmissão. Dentre estes algoritmos, existem:[34] [35] [36]

-Algoritmos baseados na análise de Fourier;

-Algoritmo de Fourier obtido a partir da TDF ( Transformada Discreta de Fourier;

-Algoritmo de Fourier com janela de $1 / 2$ ciclo;

-Filtro SENO;

-Filtro COSSENO;

-Algoritmos baseados no Método dos Mínimos Quadrados;

-Algoritmo baseado na Equação Diferencial;

-Algoritmos baseados nos Transitórios de Faltas;

-Algoritmo Recursivo de Fourier;

-Algoritmo de Walsh;

-Filtro de Kalman.

$\mathrm{Na}$ referência [51], os autores citam também alguns outros tipos de algoritmos baseados na técnica da equação diferencial, os quais foram utilizados para o desenvolvimento de um relé digital de distância, que são:

- Algoritmo Mclnnes;

- Algoritmo Mclnnes - filtragem;

- Algoritmo CHO;

- Algoritmo Bonard-Bastide.

Segundo os autores, em suas expêriencias, o algoritmo Mclnnes se mostrou extremamente sensível aos transitórios de alta frequência, desaconselhando a utilização deste algoritmo, em sua forma original. O algoritmo de $\mathrm{CHO}$ também apresenta uma forma sofrível neste aspecto, conforme os autores. Os algoritmos de McInnes- filtragem e Bonard alcançaram um bom desempenho, e segundo os autores da referência [51], 
o algoritmo Bonard foi o selecionado para ser utilizado neste relé de distância digital.

\section{Técnicas Adaptativas}

Conforme a referência [37], a utilização de técnicas numéricas para relés de proteção permitiu aos algoritmos de proteção ficarem adaptáveis para condições no sistema de potência. A utilização destes algoritmos adaptativos pode aumentar a segurança e a confiabilidade do sistema protetor comparadas com semelhantes sistemas de relés eletrônicos e eletromecânico. 


\section{APÊNDICE F - NORMAS TÉCNICAS E ENSAIOS APLICADOS EM RELÉS}

Os materiais e equipamentos elétricos, entre eles incluem-se os relés de proteção, a serem utilizados devem ser projetados, fabricados, montados e testados de acordo com as normas mencionadas e em especial, de acordo com as normas e especificações técnicas que abaixo estão relacionadas:

IEC-255-5 Class C (Insulation Tests for Electrical Relays);

IEC-255-21-1 Class I (Vibration Tests);

IEC-255-22-1 Class III (Electrical Disturbance Tests for Measuring Relays and Protection Equipment - $1 \mathrm{MHz}$ Burst Disturbance Tests);

IEC-255-22-2 Class III (Electrical Disturbance Tests for Measuring Relays and Protection Equipment - Electrostatic Discharge Tests);

IEC-255-22-3 Class III (Electrostatic Disturbance Test for Measuring Relays and Protection Equipment - Radiated Field Disturbance Tests);

IEC-255-22-4 Class IV (Electrostatic Disturbance Test for Measuring Relays and Protection Equipment - Fast Transient Disturbance Tests);

IEC-256-6- Class III Impulse Test and Interference;

IEC-255-11 Teste de Imunidade a interrupções e chaveamentos rápidos na alimentação DC e AC;

DIN-40046 Teste de Resistência Mecânica em Operação;

IEC-57(C022) Teste de Temperatura;

IEC-68-2-3 Teste de Umidade;

IEC-255-4 Class II e III-Teste de Interferência e Impulso;

IEC-255-6 (Teste de Alta freqüência);

IEC-C15-PR11(Radio Disturbance). 


\section{Ensaios de Compatibilidade Eletromagnética}

Conforme a referência 44, os ensaios de compatibilidade eletromagnética (EMC), realizados por alguns laboratórios no Brasil, contribuem diretamente para melhorar a qualidade de equipamentos a sistemas produzidos no parque industrial, à medida que tornam acessíveis, aos diversos agentes, facilidades de ensaio a investigação necessárias ao desenvolvimento de novos projetos e tecnologias.

O que também contribui para a competitividade dos produtos a sistemas. Cabe ressaltar, igualmente, a crescente pressão no sentido de qualificar produtos, sistemas e processos de acordo tom normas nacionais a internacionais (ISO, IEC, ABNT a outras), o que constitui um procedimento essencial para garantir a sua aceitabilidade no mercado. Desse modo, investimentos nas áreas de calibração de instrumentos de medida a de ensaios têm grande poder multiplicador, e a toda atividade industrial que os utiliza.

\section{Normas de EMC da União Européia}

A União Européia é constituída por 15 países membros, que envolvem uma população de 370 milhões de pessoas. Desde janeiro de 1996, o fabricante de equipamentos eletrônicos tem se submetido.nova diretiva 89/336/EEC par, compatibilidade eletromagnética Essa diretiva requer a adoção das normas genéricas EN50081, que cobre ensaios de emissão eletromagnética residencial a comercial (EN50081-1) a equipamentos industriais (EN50081-2); a EN50082, que cobre os ensaios de imunidade, subdividindo-se em imunidade residencial a comercial (EN50082-1) e equipamentos industriais (EN50082-2). Essas normas recaem naquelas genéricas da Internacional Electrotechnical Commission (IEC).

A IEC é composta, no campo da eletricidade a eletrônica, pelas normas de emissão IEC 61000-3 a de imunidade IEC 61000-4. A comunidade européia 
adota, respectivamente, as designações EN61000-3 e EN61000-4. As normas de imunidade, com relação às normas genéricas EN50082-1 a EN50082-2, são relacionadas na Tabela 10.

Tabela 10 - Normas de Imunidade

\begin{tabular}{|l|l|l|}
\hline Relacionada a EN & Relacionada a IEC & Função \\
\hline EN61000-4-2 & IEC 1000-4-2 & $\begin{array}{l}\text { Descarga } \\
\text { Atmosférica }\end{array}$ \\
\hline EN61000-4-3 & IEC 1000-4-3 & Cargas Irradiadas \\
\hline EN61000-4-4 & IEC 1000-4-4 & Transientes Burst \\
\hline EN61000-4-5 & IEC 1000-4-5 & Transientes Rápidos \\
\hline EN61000-4-6 & IEC 1000-4-6 & Radio Freqüência \\
\hline EN61000-4-7 & IEC 1000-4-7 & Cargas Magnéticas \\
\hline EN61000-4-8 & IEC 1000-4-8 & Campos Magnéticos \\
\hline EN61000-4-9 & IEC 1000-4-9 & Pulsos Magnéticos \\
\hline EN61000-4-11 & IEC 1000-4-11 & Interrupção de \\
& & Tensão \\
\hline
\end{tabular}

Algumas características das normas.

\section{Descargas eletrostáticas: EN61000-4-2 ou IEC1000-4-2}

A eletricidade eletrostática é gerada pelo contato e subseqüente separação de diferentes materiais existentes no meio ambiente. Em alguns casos podem ocasionar a destruição do dispositivo eu equipamento. Conforme mostrado na Tabela 11. 
Tabela 11 - Nível de Severidade de Descarga Eletrostática

\begin{tabular}{|l|l|l|l|}
\hline \multicolumn{2}{|l|}{ Descarga por Contato } & \multicolumn{2}{l|}{ Descarga pelo ar } \\
\hline Nível & Tensão de Teste & Nível & Tensão de Teste \\
\hline 1 & $2 \mathrm{kV}$ & 1 & $2 \mathrm{kV}$ \\
\hline 2 & $4 \mathrm{kV}$ & 2 & $3 \mathrm{kV}$ \\
\hline 3 & $6 \mathrm{kV}$ & 3 & $8 \mathrm{kV}$ \\
\hline 4 & $8 \mathrm{kV}$ & 4 & $15 \mathrm{kV}$ \\
\hline
\end{tabular}

Susceptibilidade irradiada: EN61000-4-3 ou IEC1000-4-3

Os distúrbios irradiados são provenientes de fontes geradoras de radio freqüência, como estações de amplitude a freqüência modulada, celulares a quaisquer outros dispositivos que gerem radio freqüência. Esses sinais são acoplados aos equipamentos, tendo como meio o ar. Seu nível de severidade é relacionado na Tabela 12.

Tabela 12 - Nível de Severidade

\begin{tabular}{|l|l|}
\hline Nível & Intensidade de Campo V/m \\
\hline 1 & 1 \\
\hline 2 & 3 \\
\hline 3 & 10 \\
\hline 4 & 30 \\
\hline
\end{tabular}




\section{Transientes rápidos burst: EN61000-4-4 - IEC 61000-4-4}

O pulso de burst, também chamado de transiente elétrico rápido (EFT), é gerado na linha de energia das concessionárias pela formação de arco oriundo da abertura de contatos, durante a manobra de chaves elétricas. As cargas conectadas nas linhas de energia causam o aparecimento de pulsos de burst, que podem gerar interferência em equipamentos eletrônicos conectados a ela. No caso dos ensaios de burst, os pulsos são aplicados com um nível de tensão de pico de 500 V a 4000 V. Seu nível de severidade é relacionado na Tabela 13.

Tabela 13 - Nível de Severidade de Pulso Burst

\begin{tabular}{|l|l|l|l|l|}
\hline Nível & \multicolumn{2}{l|}{ Linha de Alimentação } & \multicolumn{2}{l|}{ Linha de Dados (I/O) } \\
\hline & Tensão Pico & Razão de rep. & $\begin{array}{l}\text { Tensão } \\
\text { Pico }\end{array}$ & $\begin{array}{l}\text { Razão de } \\
\text { rep. }\end{array}$ \\
\hline 1 & 0.5 & 5 & 0.25 & 5 \\
\hline 2 & 1 & 5 & 0.5 & 5 \\
\hline 3 & 2 & 5 & 1 & 5 \\
\hline 4 & 4 & 2.5 & 2 & 5 \\
\hline
\end{tabular}


Transientes rápidos surge: EN 61000-4-5 ou IEC 61000-4-5

O ensaio simula os efeitos causados por descargas atmosféricas, e também tensões geradas pelos distúrbios de chaveamento de subestações, de energia. A simulação de tensão de pico pode variar do $500 \mathrm{~V}$ a $4000 \mathrm{~V}$ e as correntes, de pico, de 250 A a 2000 A. Ao contrário dos pulsos de burst, o pulso de surge pode ser altamente destrutivo se o equipamento vítima não tiver as adequadas proteções. Seu nível de severidade é apresentado na Tabela 14.

Tabela 14 - Nível de Severidade de Pulso Surge

\begin{tabular}{|l|l|l|}
\hline Nível & \multicolumn{2}{|l|}{ Linha de Alimentação } \\
\hline & $\begin{array}{l}\text { Tensão entre } \\
\text { linha linha kV }\end{array}$ & $\begin{array}{l}\text { Tensão entre } \\
\text { linha terra kV }\end{array}$ \\
\hline 1 & - & 0.5 \\
\hline 2 & 0.5 & 1 \\
\hline 3 & 1 & 2 \\
\hline 4 & 2 & 4 \\
\hline
\end{tabular}

Rádio Freqüência current injection (BCI): EN61000-4-6 ou IEC 61000-4-6

A injeção de corrente de radiofreqüência $(\mathrm{BCl})$ envolve distúrbios conduzidos a acoplados por esse meio, diretamente na linha de alimentação. Os distúrbios são gerados por sinais eletromagnéticos de alta freqüência, conduzidos nas linhas de energia elétrica a demais cabos de sinais de dados de comunicação ou de sinais analógicos. Seu nível de severidade é mostrado na Tabela 15. 
Tabela 15 - Nível de Severidade de Injeção de Corrente e Rádio Freqüência

\begin{tabular}{|l|l|l|}
\hline Nível & \multicolumn{2}{|l|}{ Nível de Tensão em $\mathrm{f}$} \\
\hline & V (dBuV) & V $(\mathrm{V})$ \\
\hline 1 & 120 & 1 \\
\hline 2 & 130 & 3 \\
\hline 3 & 140 & 10 \\
\hline
\end{tabular}

Faixa de Freqüência de $150 \mathrm{kHz}$ a $80 \mathrm{MHz}$

Imunidade a campos magnéticos: EN61000-4-8 ou IECI000-4-8

Essa norma simula o efeito de campos magnéticos gerados por correntes em condutores de energia, por transformadores a outras correntes oriundas de quaisquer condutores. Seu nível de severidade é mostrado na Tabela 16.

Tabela 16 - Nível de Severidade para Campos Magnéticos

\begin{tabular}{|l|l|}
\hline Nível & $\begin{array}{l}\text { Intensidade de Campo } \\
\text { Magnético }(\mathrm{A} / \mathrm{m})\end{array}$ \\
\hline 1 & 1 \\
\hline 2 & 3 \\
\hline 3 & 10 \\
\hline 4 & 30 \\
\hline 5 & 100 \\
\hline
\end{tabular}




\section{Pulsos magnéticos: EN61000-4-9 ou IEC 1000-4-9}

Essa norma simula o efeito de pulsos magnéticos gerados por descargas atmosféricas em prédios e estruturas metálicas próximas a equipamentos eletrônicos. Seu nível de severidade é apresentado na Tabela 17.

Tabela 17 - Nível de Severidade para Pulsos Magnéticos

\begin{tabular}{|l|l|}
\hline Nível & $\begin{array}{l}\text { Intensidade de Campo } \\
\text { Magnético Pulsado } \\
(\mathrm{A} / \mathrm{m})-\text { Pico }\end{array}$ \\
\hline 1 & $\mathrm{~N} / \mathrm{A} 2$ \\
\hline 2 & $\mathrm{~N} / \mathrm{A} 2$ \\
\hline 3 & 100 \\
\hline 4 & 300 \\
\hline 5 & 1000 \\
\hline
\end{tabular}

Dips ou interrupção de tensão: EN61000-4-11 ou IEC 1000-4-11

Os dips, ou interrupções de tensão, são variações ou interrupções de energia elétrica da rede de alimentação de tensão, alternada ou continua. 
Essas variações têm como causa a variação das cargas conectadas à rede de energia. Durante sua ocorrência, há uma gradual variação da tensão na linha de energia. Seu nível de severidade é relacionado na Tabela 18.

Tabela 18 - Nível de Severidade para Variação de Tensão

\begin{tabular}{|lr|l|lr|lr|}
\hline Nível & de & Tempo para & Tempo para & Tempo para \\
Tensão & de & Redução da & Redução & da & Aumento & da \\
Teste & Tensão & Tensão & Tensão & \\
\hline $40 \%$ Ut & $2 s+-20 \%$ & $1 s+-20 \%$ & $2 s+-20 \%$ & \\
\hline $0 \%$ Ut & $2 s+-20 \%$ & $2 s+-20 \%$ & $2 s+-20 \%$ & \\
\hline
\end{tabular}

Conforme as normas mostradas anteriormente, conclui-se que é da mais alta importância o conhecimento, por parte dos engenheiros de desenvolvimento e aplicação de relés de proteção, da função de cada uma das normas citadas, uma vez que isso será de importância vital para o perfeito desenho e funcionamento destes equipamentos nas instalações do sistema elétrico de potência. 